\title{
DAMAGE TO COMMERCIAL AND INDUSTRIAL BUILDINGS EXPOSED TO NUCLEAR EFFECTS
}

By

Bruce G. Johnston

Approved by: BENJAMIN C. TAYLOR

Director

Program 31
Approved by: ROBERT L. CORSBIE

Director

Civil Effects Test Group

Federal Civil Defense Administration

Battle Creek, Michigan

Engineering Research Institute

University of Michigan

Ann Arbor, Michigan

February 1956 


\section{DISCLAIMER}

This report was prepared as an account of work sponsored by an agency of the United States Government. Neither the United States Government nor any agency Thereof, nor any of their employees, makes any warranty, express or implied, or assumes any legal liability or responsibility for the accuracy, completeness, or usefulness of any information, apparatus, product, or process disclosed, or represents that its use would not infringe privately owned rights. Reference herein to any specific commercial product, process, or service by trade name, trademark, manufacturer, or otherwise does not necessarily constitute or imply its endorsement, recommendation, or favoring by the United States Government or any agency thereof. The views and opinions of authors expressed herein do not necessarily state or reflect those of the United States Government or any agency thereof. 


\section{DISCLAIMER}

Portions of this document may be illegible in electronic image products. Images are produced from the best available original document. 



\begin{abstract}
One equipment control building designed to be blast resistant and two each of three standardized types of metal warehouse or utility buildings were exposed to the effects of a nuclear device detonation. One of the utility buildings was frameless, with deeply corrugated wall and roof sections; a second was very largely frameless, utilizing interlocking channel sections; and in the third the aluminum-panel wall and roof covering was supported by girts and purlins, which in turn were supported by steel frames. Because of atmospheric conditions at the time of an earlier detonation in the test series, one of each of the three types of utility buildings was exposed to approximately 0.7 psi overpressure before the planned test. In the planned test, held during the open shot (Apple II), one of each of the three types was exposed to approximately 3.0 psi overpressure and one to 1.3 psi, with the intention of bracketing their overpressure survival range and obtaining data for possible economic redesign for improved blast resistance. The equipment control building utilized continuous-welded steel frames and reinforced-gypsum curtain-wall construction. The control building was exposed to approximately $4.1 \mathrm{psi}$, in the anticipated fringe zone of major structural damage, to determine its protective capabilities.

The blast-resistant equipment control building was not structurally damaged by the blast, thus exceeding the expectations of the design. Each of the three utility buildings received severe damage at the near range, one being completely destroyed, whereas at the far range the damage in every case was repairable.

The test results are discussed, and recommendations for improved designs are made. Damage records during the unexpected test and at the far range in the planned test are correlated by means of dynamic analyses with pressure-time data and studies of structural resistance. Pressure-time information is provided in Appendix C.
\end{abstract}


$\hat{C}^{*}$

$+$

$-$

$-$

4

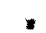

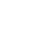

.

9

. 


\section{ACKNOWLEDGMENTS}

Credit is given to the following persons for their parts in making the necessary arrangements for the tests, for supervision during construction, and for constructive criticism and assistance on the report:

Robert L. Corsbie, Director, Civil Effects Test Group

Harold L. Goodwin, Director, Atomic Test Operations, Federal Civil Defense Administration

J. Slaten Jenner, Federal Civil Defense Administration

Leonard H. Lieberman, Federal Civil Defense Administration

Charles L. Berry, Public Buildings Service

Benjamin C. Taylor, Federal Civil Defense Administration

Marie S. Zeigner, Federal Civil Defense Administration

Assisting the writer very materially in all phases of the work as industrial participants were:

Walter D. Behlen, Behlen Mfg. Co., Assistant Project Officer

Robert Blickensderfer, Armco Drainage \& Metal Products, Inc., Assistant Project Officer

Paul E. Brandt, Reynolds Metals Co., Inc., Assistant Project Officer

Kenath A. Kettle, Union Carbide \& Carbon Corp., Assistant Project Officer

Orris L. Adkins, Union Carbide \& Carbon Corp., Project Consultant

Robert S. Dalrymple, Reynolds Metals Co., Inc., Project Consultant

Howard L. Reichart, Union Carbide \& Carbon Corp., Project Consultant

Herbert F. Reinhard, Union Carbide \& Carbon Corp., Project Consultant

Marvin K. Snyder, Butler Mfg. Co., Project Consultant

Ralph F. Thompson, Jr., Reynolds Metals Co., Inc., Project Consultant

The services of the author, Bruce G. Johnston, as Project Officer, were made available by the University of Michigan through its Civil Engineering Department under a contract between the Federal Civil Defense Administration and the Engineering Research Institute of the University of Michigan, Ann Arbor, Mich.

Pressure vs time instrumentation was by Sandia Corporation, Albuquerque, N. Mex. Total thermal-energy instrumentation was by Edgerton, Germeshausen \& Grier, Boston, Mass., and Las Vegas, Nev.

The furnishing of radiation dosimeters and the analyses of results were under the supervision of the Division of Biology and Medicine, U. S. Atomic Energy Commission, Washington, D. C.

Documentary still photography was by the Graphic Arts Group of the Los Alamos Scientific Laboratory, Los Alamos, N. Mex.

Automatic motion-picture photography during the period of thermal and blast effects was by Edgerton, Germeshausen \& Grier, Boston, Mass,, and Las Vegas, Nev.

General and aerial postshot still and motion-picture photography was by Byron, Inc., Washington, D. C., under contract with the Federal Civil Defense Administration. 
.

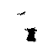

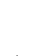

$+$

$-$

- 


\title{
CONTENTS
}

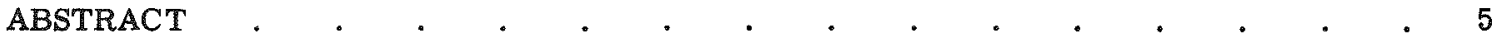

ACKNOWLEDGMENTS . . . . . . . . . . . . . . . . . 7
\end{abstract}

CHAPTER 1 INTRODUCTION.

1.1 Objectives. . . . . . . . . . . . . . . 15

1.2 Background and Theory . . . . . . . . . . . . . . 15

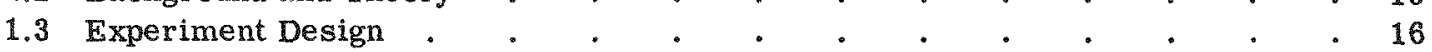

1.3.1 Blast-resistant Control-room Building . . . . . . . 17

1.3.2 Steel-frame Buildings with Aluminum Siding . . . . . . 17

1.3.3 Frameless Steel Buildings with Deep Corrugations in Side
and Roof .

1.3.4 Frameless Steel Buildings with Channel Side Walls . . . . 37

1.4 Instrumentation. . . . . . . . . . . . . 37

CHAPTER 2 TEST RESULTS.$\quad$.

2.1 Damage Caused by Unexpected Test . . . . . . . . . . . 38

2.1.1 General . . . . . . . . . . . . . 38

2.1.2 Damage from Unexpected Test at Locations 5500 and 6800
Ft from Planned Test Shot . . . . . . . 38

2.1 .3 Damage from Unexpected Test to Buildings at 15,000 Ft
from Planned Test. . . . . . 45

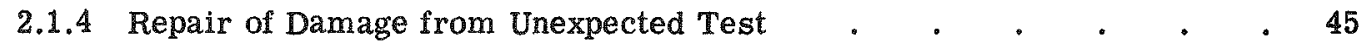

2.2 Results of Planned Test .

2.2 .1 General . . . . . . . . . . . . . 45

2.2.2 Damage to Union Carbide Building 31.2-e1 . $\quad . \quad$. $\quad . \quad$. $\quad$. 45

2.2.3 Damage to Reynolds Metals Co.-Butler Building 31.2-a1 . . $\quad$ - 51

2.2.4 Damage to Behlen Building 31.2-b1. . . . . . . . . . 59

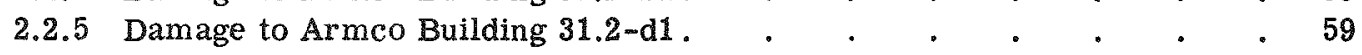

2.2.6 Damage to Reynolds-Butler Building 31.2-a2 . . . . . . . . $\quad$. 62

2.2.7 Damage to Behlen Building 31.2-b2 . $. \quad . \quad . \quad . \quad . \quad . \quad .74$

2.2.8 Damage to Armco Building 31.2-d2 . $\quad . \quad . \quad . \quad . \quad . \quad . \quad . \quad 74$

2.2.9 Gamma Radiation Measurements Within Buildings . . . . . . . 74

CHAPTER 3 DYNAMIC ANALYSES.$\quad$. . . . . . . . . . . 75

3.1 General • . . . . . . . . . . . . . . . 75

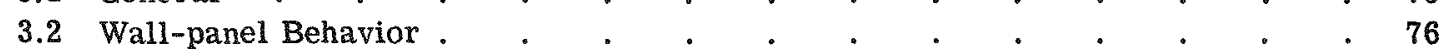

3.2 .1 General . . . . . . . . . . . . . . 76

3.2.2 Comparison of Dynamic Analyses and Test Results for
Wall Panels 


\section{CONTENTS (Continued)}

CHAPTER 4 DISCUSSION

4.1 General . . . . . . . . . . . . 79

4.1.1 Union Carbide Building 31.2-e1 . . . . . . . . . . . . 80

4.1.2 Reynolds-Butler Buildings 31.2-a1 and 31.2-a2 . . . . . . 80

4.1.3 Behlen Buildings 31.2-b1 and 31.2-b2 . . . . . . . . . 81

4.1.4 Armco Buildings 31.2-d1 and 31.2-d2 . . . . . . . . . 82

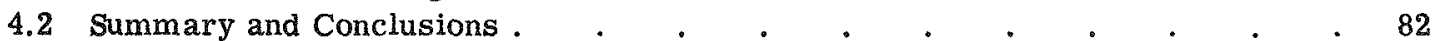

4.3 Recommendations . . . . . . . . . . . . . . . . 83

APPENDIX A ANALYSIS OF WALL BEHAVIOR: REYNOLDS-BUTLER

BUILDINGS • . . . . . . . . . . . 84

APPENDIX B ANALYSIS OF WALL BEHAVIOR: ARMCO BUILDINGS . $\quad$ • $\quad 100$

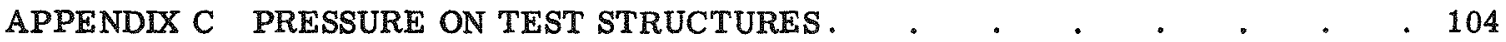

C.1 General . . . . . . . • . . . . . . 104

C.2 Overpressure Data near Test Site 1 . $\quad . \quad$. $\quad . \quad$. . . . . . . 104

C.3 Pressure Data at $5500 \mathrm{Ft}$ from GZ, Apple II Shot . . . . . . 104

\section{ILLUSTRATIONS}

\section{CHAPTER 1 INTRODUCTION}

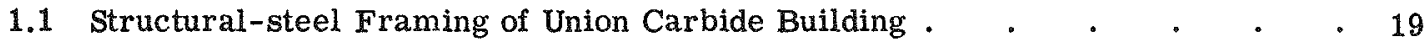

1.2 Architectural Plan and Details of Union Carbide Building . . . . . $\quad 20$

1.3 Front Elevation of Union Carbide Building. ..$\quad$. $\quad . \quad$. $\quad . \quad 21$

1.4 South Elevation of Union Carbide Building . . . . . . . . . 21

1.5 East Elevation of Union Carbide Building . . . . . . . . . 22

1.6 West Elevation of Union Carbide Building . . . . . . . . . . 22

1.7 North and East Walls of Union Carbide Building Prior to Planned

Test . . . . . . . . . . . . . . . 23

1.8 West Wall of Union Carbide Building Prior to Planned Test . . . . 23

1.9 Interior View of West Wall and Frame of Union Carbide Building . . . $\quad 24$

1.10 General Views of Reynolds-Butler Buildings . . . . . . . . $\quad 25$

1.11 Cross-sectional Elevation and Typical Details of Reynolds-Butler Buildings . . . . . . . . . . . . . . 26

1.12 North Wall and East End of Reynolds-Butier Building 31.2-a2 . . . . 27

1.13 Interior View Looking East in Reynolds-Butler Building . . . . . 27

1.14 Interior View of Frame Base and Wall Details in Reynolds-Butler

Buildings . . . . . . . . . . . . . . 28

1.15 Perspective and Plan Views of Behlen Building . . . . . . . $\quad 29$

1.16 End, Side, and Cross-sectional Elevations of Behlen Building . . . . 30

1.17 North Wall and East End of Behlen Building 31.2-b2 . . . . . . $\quad 31$

1.18 View Looking Along South Wall of Behlen Building 31.2-b2 $\quad . \quad$. $\quad$ - 31

1.19 Interior View of Behlen Building . . . . . . . . . . . . 32

1.20 Elevations and Plan Cross Section of Armco Buildings . . . . . . 33

1.21 Typical Wind Bracing and Other Details of Armco Buildings . . . . . 34

1.22 Armco Building 31.2-d1 Repaired After Unexpected Test . . . . . . $\quad 35$

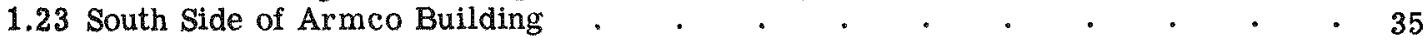

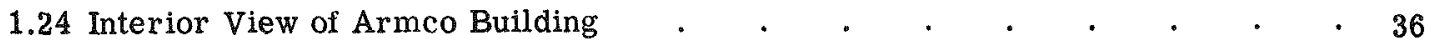




\section{ILLUSTRATIONS (Continued)}

\section{CHAPTER 2 TEST RESULTS}

2.1 General View of North and West End Walls, Showing Damage from Unexpected Test to Reynolds-Butler Building 31.2-a1

2.2 Offset Measurements of Permanent Wall and Roof Deflections in Inches in Reynolds-Butler Buildings in Which Sheeting Remained in Place

2.3 Damage to Roof of Reynolds-Butler Building 31.2-a1 from Unexpected Test

2.4 Interior View of Damage to North Wall in Reynolds-Butler Building 31.2-a1 from Unexpected Test

2.5 North and South Sides of Reynolds-Butler Building 31.2-a1 During Repair of Damage from Unexpected Test

2.6 Damage to North Walls of Armco Building 31.2-d1 from Unexpected Test .

2.7 Offset Measurements of Permanent Wall and Roof Deflections in Inches in Armco Buildings That Remained Intact

2.8 Interior View of Damage to North Wall of Armco Building 31.2-d1 from Unexpected Test

2.9 Interior View of Wall Damage in Reynolds-Butler Building 31.2-a2 from Unexpected Test

2.10 North Wall of Union Carbide Building After Planned Test

211 South Wall of Union Carbide Building After Planned Test .

2.12 Interior View Looking Out Doorway of Union Carbide Building After Planned Test

2.13 Interior View of Southeast Corner of Union Carbide Building After Planned Test

2.14 Deflections of Roof and North Wall in Union Carbide Building During Planned Test .

2.15 Southeast Corner Frame Connection of Union Carbide Building

2.16 Shear Crack at Top of West Wall North of Union Carbide Building

2.17 North Side of Reynolds-Butler Building 31.2-a1 After Planned Test .

2.18 Interior Detail of Northeast Column in Reynolds-Butler Building 31.2-a1 After Planned Test

2.19 Interior Detail of Northwest Column in Reynolds-Butler Building 31.2-a1 After Planned Test

2.20 View Looking Down on Sill Angle in Reynolds-Butler Building 31.2-a1 After Planned Test

2.21 Interior Detail of Torn Girt Connector North of Reynolds-Butler Building 31.2-a1 After Planned Test

2.22 Interior View of Reynolds-Butler Building 31.2-a1 After Planned Test .

2.23 Roof Purlins at Northeast Corner of Reynolds-Butler Building 31.2-a1 After Planned Test

2.24 End Crippling of Purlins at Northeast Corner of Reynolds-Butler Building 31.2-a1 After Planned Test .

2.25 Underside of Roof at Northwest Corner of Reynolds-Butler Building 31.2-a1 After Planned Test .

2.26 South Side and East End of Reynolds-Butler Building 31.2-a1 After Planned Test

2.27 North Girts and Siding Blown Through South Wall of Reynolds-Butler Building 31.2-a1 After Planned Test .

2.28 Underside of Southeast Roof Section of Reynolds-Butler Building 31.2-a1 After Planned Test

2.29 West End of Reynolds-Butler Building 31.2-a1 After Planned Test 


\section{ILLUSTRATIONS (Continued)}

2.30 East End of Reynolds-Butler Building 31.2-a1 After Planned Test . . . 58

2.31 North Side of Behlen Building 31.2-b1 After Planned Test . . . . . . $\quad 60$

2.32 View Looking Along North Roof of Behlen Building 31.2-b1 After Planned Test

2.33 Permanent Deflection of Behlen Building 31.2-b1 at $6800 \mathrm{Ft}$ After Planned Test

2.34 West End of Behlen Building 31.2-b1 After Planned Test

2.35 Northeast Corner of Behlen Buidang 63

2.36 Interior Planned Test

2.37 North Side of Armco Building 31.2-d1 After Planned Test . . . . . . 64

2.38 West End of Armco Building 31.2-d1 After Planned Test . . . . . 65

2.39 Northeast Corner of Armco Building 31.2-d1 After Planned Test . . $\quad 65$

2.40 West End and South Side of Armco Building 31.2-d1 After Planned Test .

2.41 East End and South Side of Armco Building 31.2-d1 After Planned Test

2.42 Sill Along North Wall of Armco Building 31.2-d1 After Planned Test .

2.43 Interior Detail of Sill at Southwest Corner of Armco Building 31.2-d1 After Planned Test

2.44 Interior View Toward Northeast Door Frame of Armco Building

$31.2-\mathrm{d} 1$ After Planned Test
2.45 Interior View of Armco Building $31.2-\mathrm{d} 1$, Showing Front Paneling Draped Around Machinery After Planned Test

2.46 North Side and West End of Reynolds-Butler Building 31.2-22 After Planned Test

2.47 South Side of East Interior Column Footing of Reynolds-Butler Building 31.2-a2 After Planned Test .

2.48 West End of Reynolds-Butler Building 31.2-22 After Planned Test

2.49 East End of Reynolds-Butler Building 31.2-a2 After planned Test . . . 70

2.50 East End and North Side of Behlen Building 31.2-b2 After Planned Test

2.51 North Side of Armco Building 31.2-d2 After Planned Test.

2.52 East End and North Side of Armco Building 31.2-d2 After Planned Test

2.53 View Looking South into Interior of Armco Building 31.2-d2 After Planned Test

2.54 Gamma Radiation Measurements in Union Carbide Building

\section{CHAPTER 3 DYNAMIC ANALYSES}

3.1 Estimated Pressure on Exterior of North Wall for Cases Analyzed in Appendixes A and B

\section{APPENDIX A ANALYSIS OF WALL BEHAVIOR: REYNOLDS-BUTLER BUILDINGS}

A.1 Wall Cross Section at Center Line of Girt, Showing Forces Acting at Large Deflection

A.2 Estimated Load-displacement Diagram for Girt in Tension

A.3 Approximate Plastic Resistance of Girts vs Vertical Displacement . . . $\quad$. 89

A.4 Approximate Plastic Resistance of Eave Member vs Vertical Displacement

A.5 Resistance Function for Side Walls of Reynolds-Butler Buildings 


\section{ILLUSTRATIONS (Continued)}

A.6 Calculated Acceleration, Velocity, and Displacement at Center of Girt in Center Wall Panel of Reynolds-Butler Building 31.2-a2 in Planned Test at $15,000 \mathrm{Ft}$.

APPENDIX B ANALYSIS OF WALL BEHAVIOR: ARMCO BUILDINGS

B.1 Resistance Functions for Side Walls of Armco Buildings . . . . . 102 APPENDIX C PRESSURE ON TEST STRUCTURES

C.1 Overpressure-time Curves for the Unexpected Test . . . . . . 105

C.2 Comparison of Design and Estimated Front Face Average Pressures on Union Carbide Building for Apple II Shot

TABLES

\section{CHAPTER 3 DYNAMIC ANALYSES}

3.1 Comparison of Test Results with Dynamic Analyses . • . . . . 78 CHAPTER 4 DISCUSSION

4.1 Building Damage Related to Approximate Peak Overpressures . . . . . 82 APPENDIX A ANALYSIS OF WALL BEHAVIOR: REYNOLDS-BUTLER BUILDINGS

A.1 Computation for Determining the Load Carried by Catenary

Action

A.2 Computation of Load Carried by Girt Bending, Girt Catenary, and Panel Catenary .

A.3 Calculation of Load After Girt Connection Fallure

A.4 Typical Calculation of the Dynamic Behavior of Wall Paneling in Pound-Inch-Second Units. 


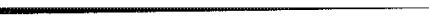




\section{Chapter 1}

\section{INTRODUCTION}

\subsection{OBJECTIVES}

The objective of Project 31.2 was to expose conventional and special designs of industrial buildings to the detonation of a nuclear device at the Nevada Test Site of the U. S. Atomic Energy Commission for the purposes of determining, in so far as possible, the survival range of the test structures. Redesign for greater resistance to lateral blast loadings within economic limitations is to be expected as a result of these tests.

The project was made possible as a result of the invitation of the Federal Civil Defense Administration to industry to voluntarily participate in a nuclear effects test operation. Since previous effects testing of buildings in this category was for military purposes, many of the results were classified and not available to industry.

\subsection{BACKGROUND AND THEORY}

The behavior of a structure or one of its component parts under a sudden or shock load can be predicted by a dynamic analysis. Dynamic behavior (motion resulting from force) results whenever all the forces acting on a structure, or on any part of it, are not in a state of equilibrium. According to Newton's law, each elemental part will be accelerated in direct proportion to the resultant force acting upon it and in inverse proportion to its mass. In the case of a structure under blast load, the unbalanced force is (in a general sense) the difference between the pressure load and the resistance that the structure or component offers as a result of its deflection. By the use of Newton's law, the acceleration of a point in a structure can be computed at successive intervals of time, and the velocity and displacement of the structure can be predicted. An estimate of acceleration, velocity, and displacement, each as a function of time, constitutes a principal result of the dynamic analysis.

To make the analysis of the wall panels, the differential pressure between the outer and inner surfaces must be known as a function of time. In the analysis of the frame as a whole, if the panels do not fail, the frame is subjected to an over-all translational force as a result of the differential pressures between the outer surfaces of the front and rear walls and between the front and rear outer sloping faces of the roof. If the panels fail, the subsequent lateral force on the frame is the cumulative transient drag force summed over the various individual members of the frame after exposure.

Drag force is the component in the direction of blast propagation of all the pressure acting on the total exterior surface of an individual member that is completely enveloped in a moving mass of air. It is primarily a function of air velocity, density, and the shape of the member. Regardless of whether of not the wall panels fail, the over-all resultant of force tending to push the building sideways can be evaluated as a function of time if the pertinent blast-wave information is available.

Structural resistance can be approximated by static test or by theoretical analysis in both the elastic and inelastic ranges of behavior. In introducing the inelastic range of material behavior, the static strength properties are usually multiplied by a "dynamic increase factor" to compensate for the increase of strength properties with strain rate. 
Although the results of most of the previous nuclear effects structural tests remain classified, there have been numerous unclassified analytical studies made relating to the behavior of various types of industrial buildings. These studies have been made principally by the University of Illinois, Armour Research Foundation, Massachusetts Institute of Technology, Stanford University, Lehigh University, and the University of Michigan, as well as by a number of engineering firms. Unclassified studies have usually been based on pressure-time information available in "The Effects of Atomic Weapons." Studies of industrial buildings were reported at a conference ${ }^{2}$ in 1952.

A concise paper by Newmark ${ }^{3}$ provides a convenient means of estimating the permanent set of a simple structure under an idealized simplification of blast type load, a single diagram providing a direct reading of elastic and/or permanent deformation, if the peak value and the duration of the transient load, of blast type, and the plastic resistance level of the structure are known. A recent paper by the author ${ }^{4}$ presents specific suggestions for good design practice in improving the blast resistance of conventional industrial buildings.

\subsection{EXPERIMENT DESIGN}

The test program afforded an evaluation of three typical utility building types suitable as small warehouses or shops. The buildings are not intended to be blast resistant; they are de signed for conventional loads. The buildings are particularly useful during an emergency since the parts are standardized and can be stored in a small space, and the buildings can be assembled or disassembled rapidly by the use of bolts. Of the three types of utility buildings under test, two are "frameless," in that the exterior paneling in itself provides the strength of the structure, both as a result of the shape of the individual panel units and of the over-all boxlike nature of the buildings as a whole. The third type of building utilizes heavy-steel welded and bolted building bents with an exterior cover of light-weight aluminum siding and roofing.

In addition to the tests of utility type buildings designed for conventional loads, the industrial building program included one proof test of a blast-resistant structure, incorporating heavy-steel frames and intermediate-steel verticals integral with poured reinforced-gypsum curtain walls.

When the three utility buildings at 6800 ft from Ground Zero $(G Z)$ were substantially completed, they received unexpected overpressure of about 0.7 psi because of atmospheric conditions during the detonation of a nuclear device at a greater distance than that of the planned test. This resulted in a very low level of damage, which was repaired in order to bring the buildings substantially back to their original state prior to the planned test.

In the planned test the blast-resistant building was located at $5500 \mathrm{ft}$ from $\mathrm{GZ}$, with a short side embodying windows facing the blast source. One of each of the three types of utility buildings was located at $6800 \mathrm{ft}$ from $\mathrm{GZ}$ in a region where the se conventionally designed buildings were expected to experience severe damage. The long (north) side of these buildings faced the blast source. A second set of utility buildings was located at $15,000 \mathrm{ft}$ from $\mathrm{GZ}$, where light damage might be expected.

The buildings will be referred to in this report either by shortened names or by code numbers as follows:

\begin{tabular}{rrl}
$\begin{array}{c}\text { Building } \\
\text { code No. }\end{array}$ & $\begin{array}{c}\text { Distance } \\
\text { from GZ, ft }\end{array}$ & \multicolumn{1}{c}{ Building designation } \\
& & \\
$31.2-\mathrm{e} 1$ & 5,500 & Union Carbide \\
$31.2-\mathrm{a} 1$ & 6,800 & Reynolds Metals Co.-Butler \\
$31.2-\mathrm{b} 1$ & 6,800 & Behlen \\
$31.2-\mathrm{d} 1$ & 6,800 & Armco \\
$31.2-\mathrm{a} 2$ & 15,000 & Reynolds Metals Co.-Butler \\
$31.2-\mathrm{b} 2$ & 15,000 & Behlen \\
$31.2-\mathrm{d} 2$ & 15,000 & Armco
\end{tabular}




\subsubsection{Blast-resistant Control-room Building}

The blast-resistant control-room building (31.2-e1) was at $5500 \mathrm{ft}$ from GZ.

Union Carbide \& Carbon Corp., which contributed this structure, is interested in maximum personnel and control instrument safety, both from the standpoint of localized explosive forces and civil defense in case of an enemy attack. Since it is impractical to accomplish this purpose by protective measures for entire operating units, it is considered that protection of the central control buildings will give maximum protection for a minimum investment. Accordingly, a control-room prototype was constructed with reinforced-gypsum walls and roof poured integral with a welded steel frame.

All the usual materials and types of construction were considered for this structure. Appearance is an important consideration, but it was waived in order that safety could be the controlling factor. Previous experience with gypsum has shown that, although it is usually badly shattered after a severe blast, it can be expected to remain in place and to offer protection. Accordingly, the use of specially reinforced gypsum was considered for the walls and roof, and a fully continuous-welded steel frame was provided. Previous test data for this type of construction were not available.

The foundation for this building consisted of a reinforced-concrete 2 -ft-deep perimeter beam supported at the four corners on reinforced-concrete footings. The four corner columns of the continuous-welded steel frame were centered over the footings and anchored to, and supported by, thickened areas of the perimeter beam. The walls of the building were anchored to, and supported by, the perimeter beam, independent of the steel frame. The steel frame supported the roof. General design drawings of this structure are shown in Figs. 1.1 and 1.2. Figures 1.3 to 1.6 , inclusive, show elevations of each wall with the crack damage pattern resulting from the planned test. Figures 1.7 and 1.8 show different views of the exterior; in Fig. 1.9, a view of the interior, the continuous-welded steel-frame construction can be noted.

The walls and roof were of double-reinforced gypsum. In the east and west walls the reinforced gypsum was discontinuous, having been poured as panels between the 4-in.-wideflange steel studs to the full wall thickness of $4 \mathrm{in}$. In the north and south walls and the roof, the reinforced gypsum was semicontinuous, the steel having been carried across the rail sections, which served as wall studs and secondary roof beams, from one panel to the next.

The floor was an unreinforced-concrete slab resting on both the tamped soil fill and a 1-in. seat all around the inner face of the perimeter beam.

A continuous corrugated glass-fiber-reinforced plastic window was provided across the north and south walls from a level approximately $7 \mathrm{ft}$ above the floor nearly to the roof. One standard industrial type steel door, located near the center of the west wall, provided the only access to the building.

All elements of the building, except the plastic windows and steel industrial door, were designed to resist a 4 psi blast pressure with some permanent plastic deformations.

\subsubsection{Steel-frame Buildings with Aluminum Siding}

Buildings $31.2-\mathrm{a} 1$ at $6800 \mathrm{ft}$ and $31.2-\mathrm{a} 2$ at $15,000 \mathrm{ft}$ were furnished by the Reynolds Metals Co., Inc., and were designed and fabricated by the Butler Mfg. Co.

General drawings of the framing details of these buildings are presented in Figs. 1.10 and 1.11. An exterior view is given in Fig. 1.12, and two interior views in Figs. 1.13 and 1.14 show, respectively, the general arrangement of the steel framing and the frame base and wall details.

These Butler buildings, measuring $24 \mathrm{ft}$ wide and $36 \mathrm{ft}$ long, have gable roofs, and they are rigid frame type buildings of the standard construction for commercial buildings. The rigid frames are welded tapered columns and roof beams. Column flanges are approximately $1 / 4$ in. thick, and the web is approximately $3 / 16$ in. thick. Roof beams and column-haunch assemblies are bolted in the field, eliminating the need for any field welding. The rigid frames are $12 \mathrm{ft}$ on centers.

Purlins and girts are cold-formed $\mathrm{Z}$ sections fabricated from light-gauge steel and factory punched for field bolting to the primary framing and for attachment of the roof and wall covering. Purlins are of 14-gauge material, and the girts and eave struts are of 12-gauge material. 
Roofs and walls are covered with 0.026 -in. aluminum panels having high rib corrugations $12 \mathrm{in}$. on centers and approximately $1 \mathrm{in}$. deep. Panels are bolted to the roof and wall framing members with $1 / 4$ - by $3 / 4$-in. galvanized bolts.

This type of construction is standard for most Butler buildings, which are available in widths from 20 to $80 \mathrm{ft}$.

\subsubsection{Frameless Steel Buildings with Deep Corrugations in Side and Roof}

Buildings $31.2-\mathrm{b} 1$ at $6800 \mathrm{ft}$ and $31.2-\mathrm{b} 2$ at $15,000 \mathrm{ft}$ are standardized utility structures designed, developed, and furnished for the test program by the Behlen Mfg. Co. The walls and roofs are constructed of 43 -in. - wide panels singly corrugated to $7 \frac{1}{2} \mathrm{in}$. in depth by cold-rolling 16-gauge steel sheet. These panels are bolted together at the sides and at the eaves and roof ridge, and the wall panels are bolted to the concrete foundation. These entire structures are monolithically self-supporting without frames, girts, or purlins, which are used in more conventional construction.

General drawings of the Behlen buildings are shown in Figs. 1.15 and 1.16, and Figs. 1.17 and 1.18 show different exterior views of the structures. The lack of conventional girts, purlins, and bracing within the interior is indicated in Fig. 1.19.

\section{GENERAL NOTES FOR FIG. 1.1 (SEE FACING PAGE)}

Poured Gypsum Side Walls and Roof Slab

Gypsum shall be Class 2 structural gypsum as called for in Table 24 of the Pacific Coast Building officials Conference Uniform Building Code 1952 edition, Vol. 1, having a minimum ultimate compressive strength of 1000 psi when tested according to Uniform Building Code Standard 24-20: "Basic specification for Class 2 structural gypsum: Gypsum stucco $97 \%$ minimum and process shavings not to exceed $3 \%$.

Stucco in this formula is special axidized stucco whose rock purity is from 85 to $95 \%$. Consistency is 70 to $74 \mathrm{cc}$. Grind is through $100 \mathrm{mesh}, 85$ to $90 \%$. Structural gypsum is to be mixed with approximately $6 \frac{1}{2} \mathrm{gal}$. of water per $80-1 \mathrm{~b} \mathrm{bag,} \mathrm{giving} \mathrm{an} \mathrm{equivalent} \mathrm{consistency} \mathrm{of} 68 \mathrm{cc}$. Gypsum is to be mixed in a continuous mixer and pumped through a hose into place."

Water used in mixing shall be potable, clean, and free from deleterious amounts of acids, alkalis, or organic materials. All containers and apparatus used for mixing shall be kept clean and free from foreign substances which would prevent the gypsum from developing its ultimate required strength.

All gypsum form boards in side walls and roof shall be fitted neatly on all four edges. Gypsum form boards in side walls shall be in single pieces the full height of the wall and shall be braced during the pouring of the gypsum to prevent bulging from the pressure of the wet gypsum. All removable forms shall be built to conform to the dimensions called for on the drawings and shall be sufficiently tight to prevent leakage of the gypsum during the pour. They shall be properly braced and tied together so as to maintain the required position and shape.

Roof shall be poured to the thickness shown on the drawings and shall be screeded to a smooth even surface. Side walls shall be poured in place solidly, without voids, honeycombs, or other defects which would adversely affect its required strength.

Accessories such as rails, reinforcing mesh, and gypsum form board shall be as noted on the drawings.

Roof Covering, One Building Only

Roofing shall be 4-ply built-up gravel-topped roofing installed according to the manufacturer's 20year bond specification (bond not required).

Translucent Plastic Side Wall

Corrugated translucent plastic sheets shall be of thermosetting plastic material, smooth on both sides, and reinforced with glass fiber. The sheets shall average approximately $1 / 16$ in. in thickness and shall weigh $7 \frac{1}{2}$ to $8 \mathrm{oz}$ per square foot with an average of $2 \mathrm{oz}$ of glass fibers in each square foot evenly distributed throughout the sheet. Corrugations shall have a 4.2 in. pitch. The sheets shall develop a minimum loadcarrying capacity of $100 \mathrm{lb} / \mathrm{sq} \mathrm{ft}$ on a $4-\mathrm{ft}$ span.

Panels shall be free of resin-starved areas, large air pits, and foreign matter. Any standard color may be used.

Panels shall be installed according to details on the drawing. Side laps shall be sealed with clear thermosetting mastic. [Reference drawings: concrete foundation, SK 60975; structural steel, SK 60976 (Fig. 1.2).] 


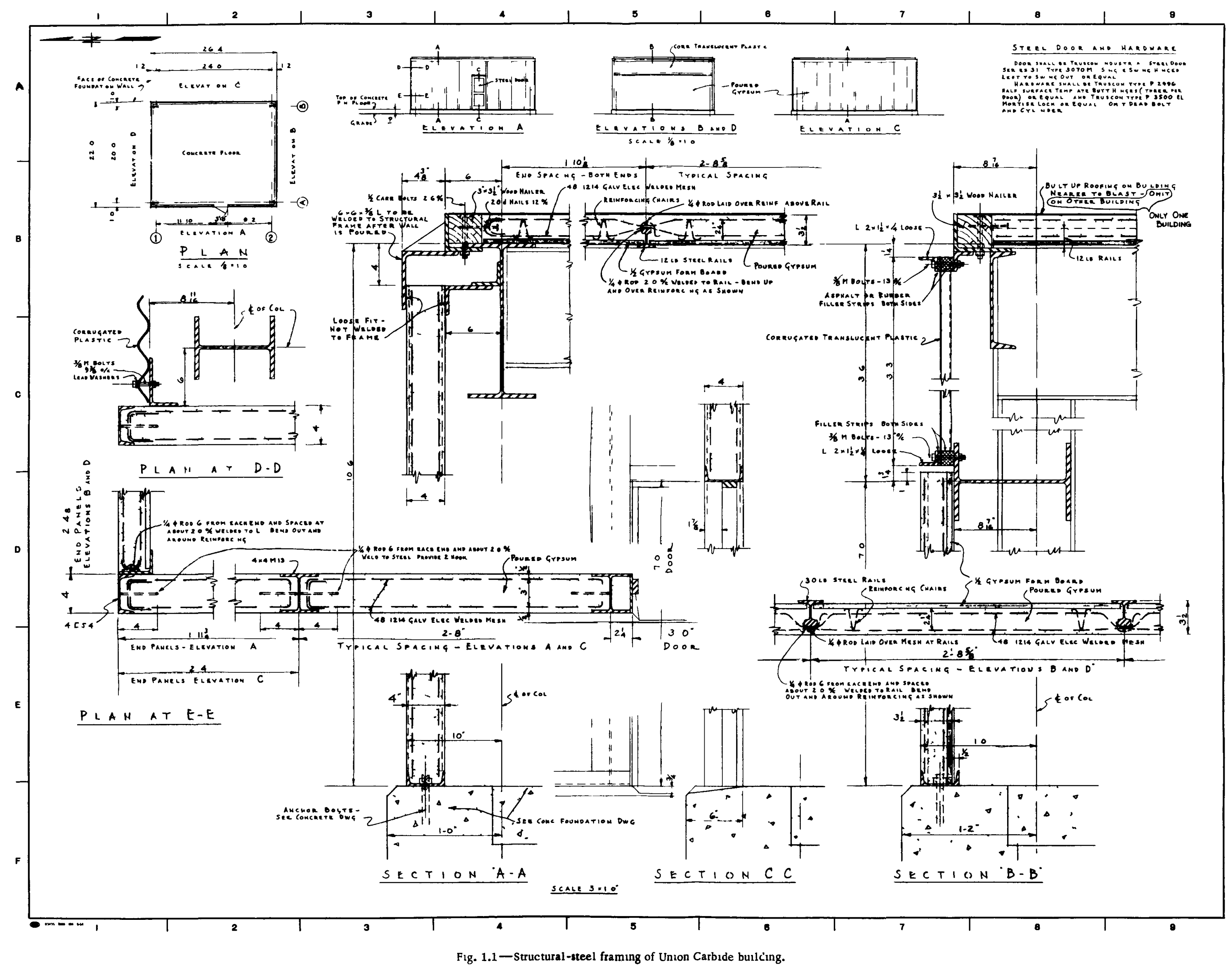




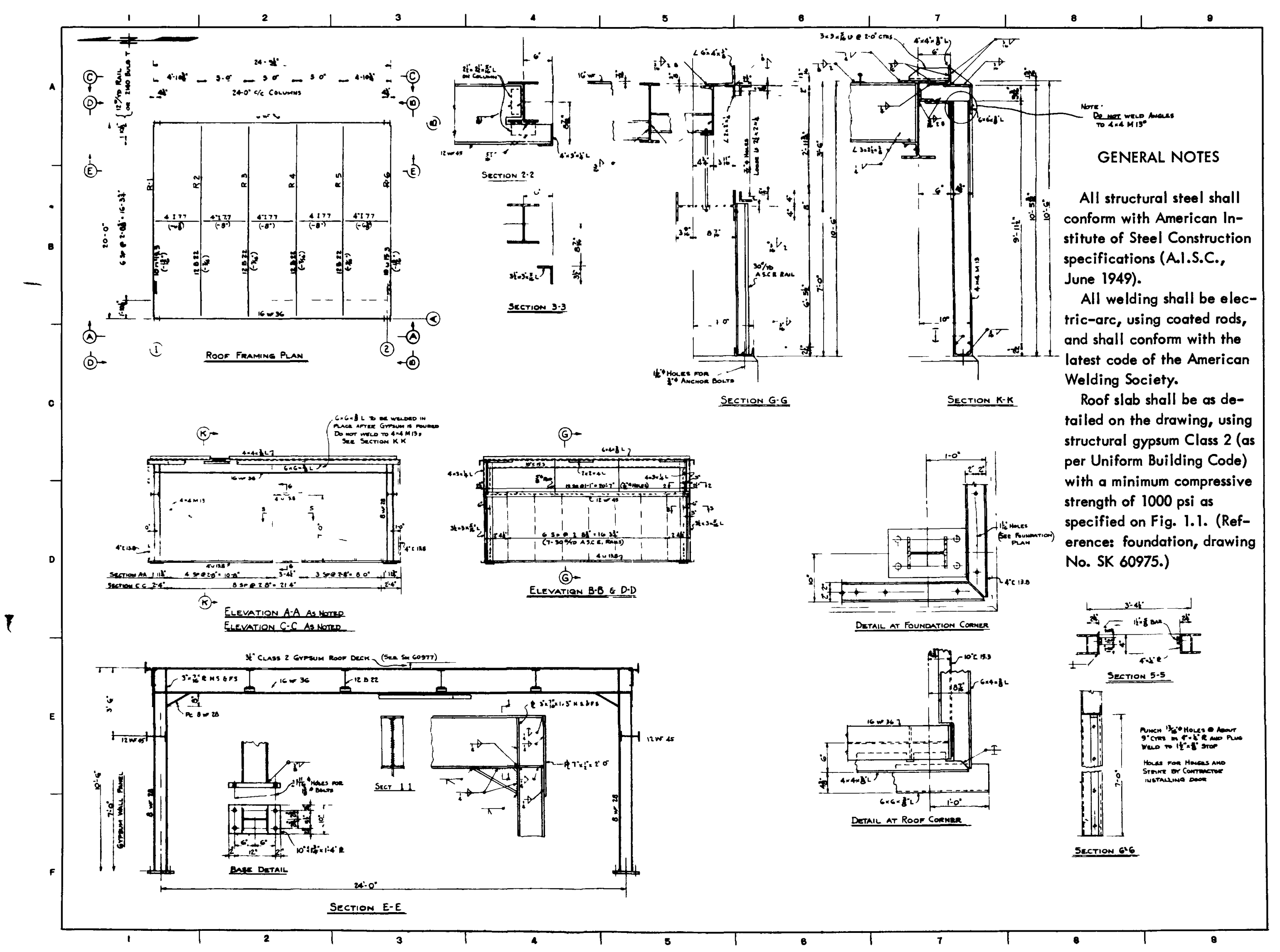

Fig. 1.2-Architectural plan and details of Union Carbide buldıng. 


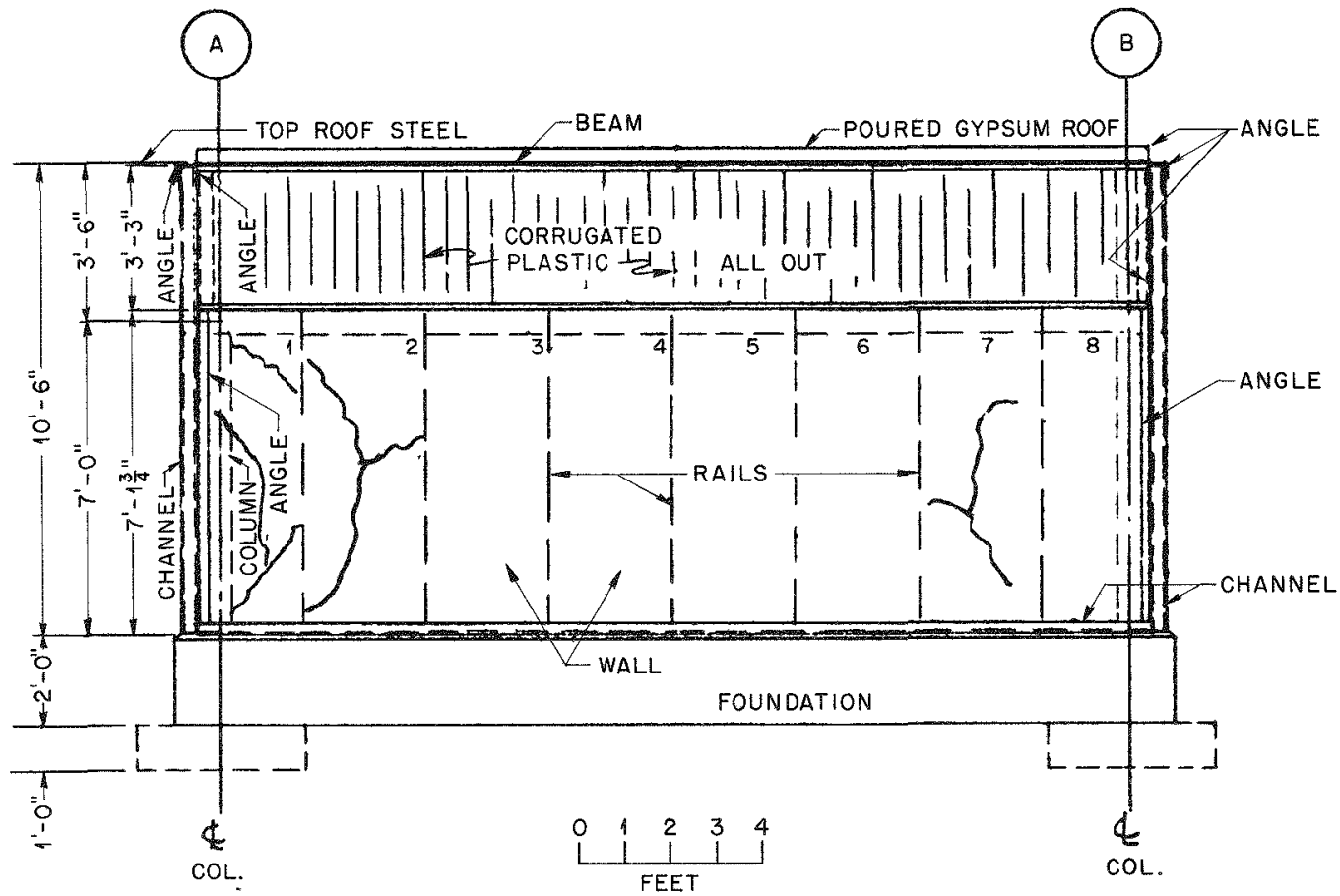

Fig. 1.3 - Front elevation of Union Carbide building.

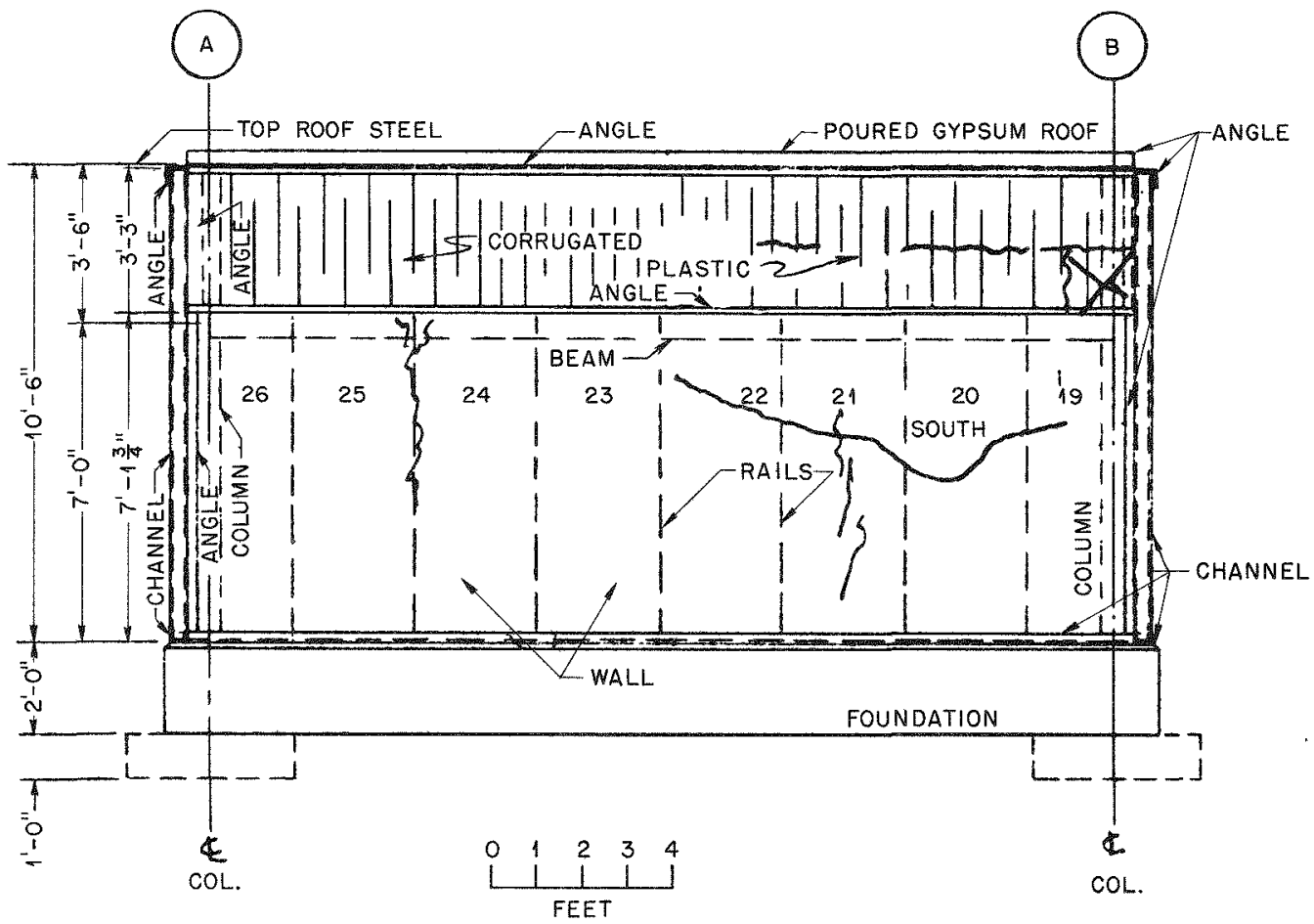

Fig. 1.4-South elevation of Union Carbide building. 


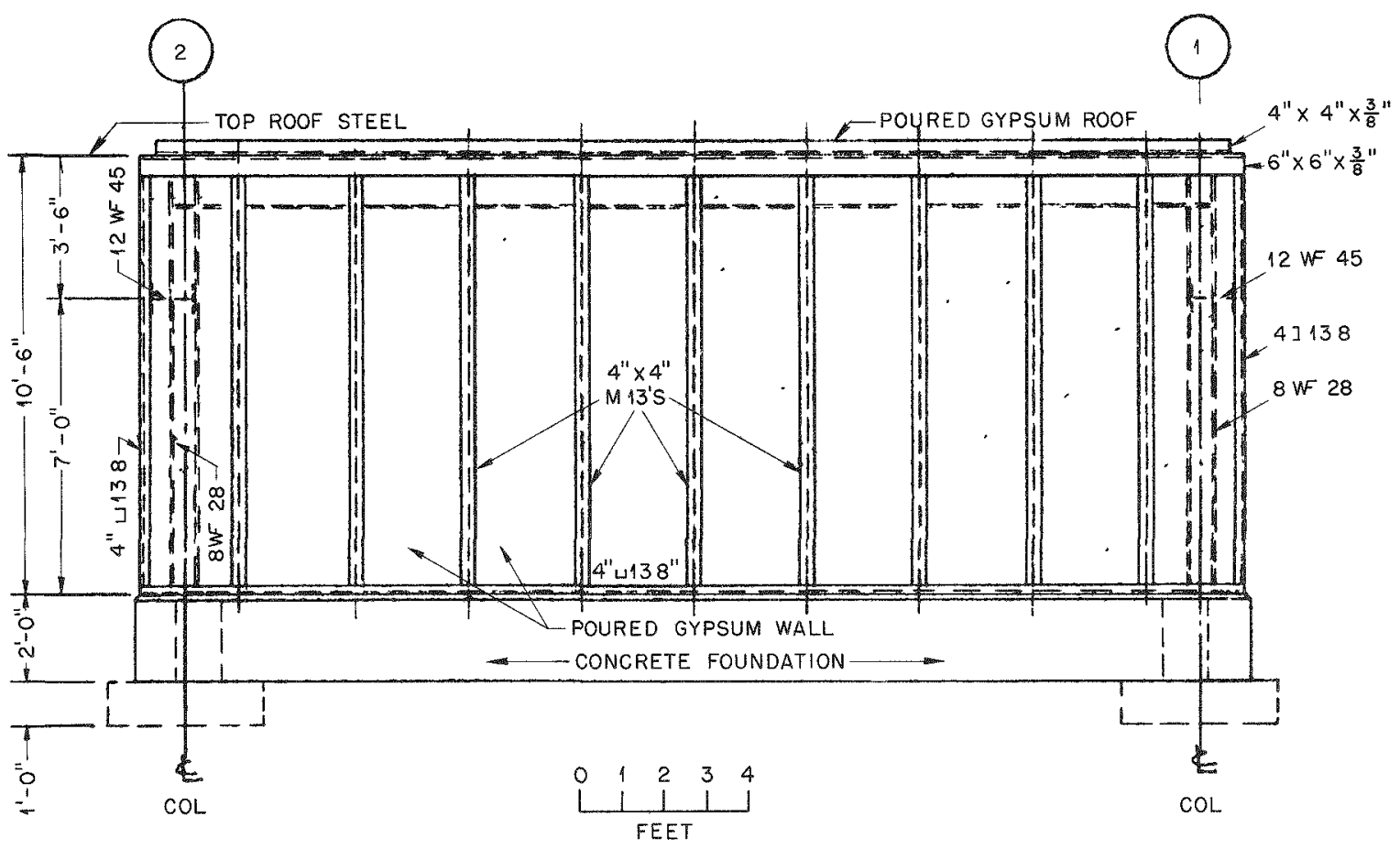

Fig. 1.5-East elevation of Union Carbide building.

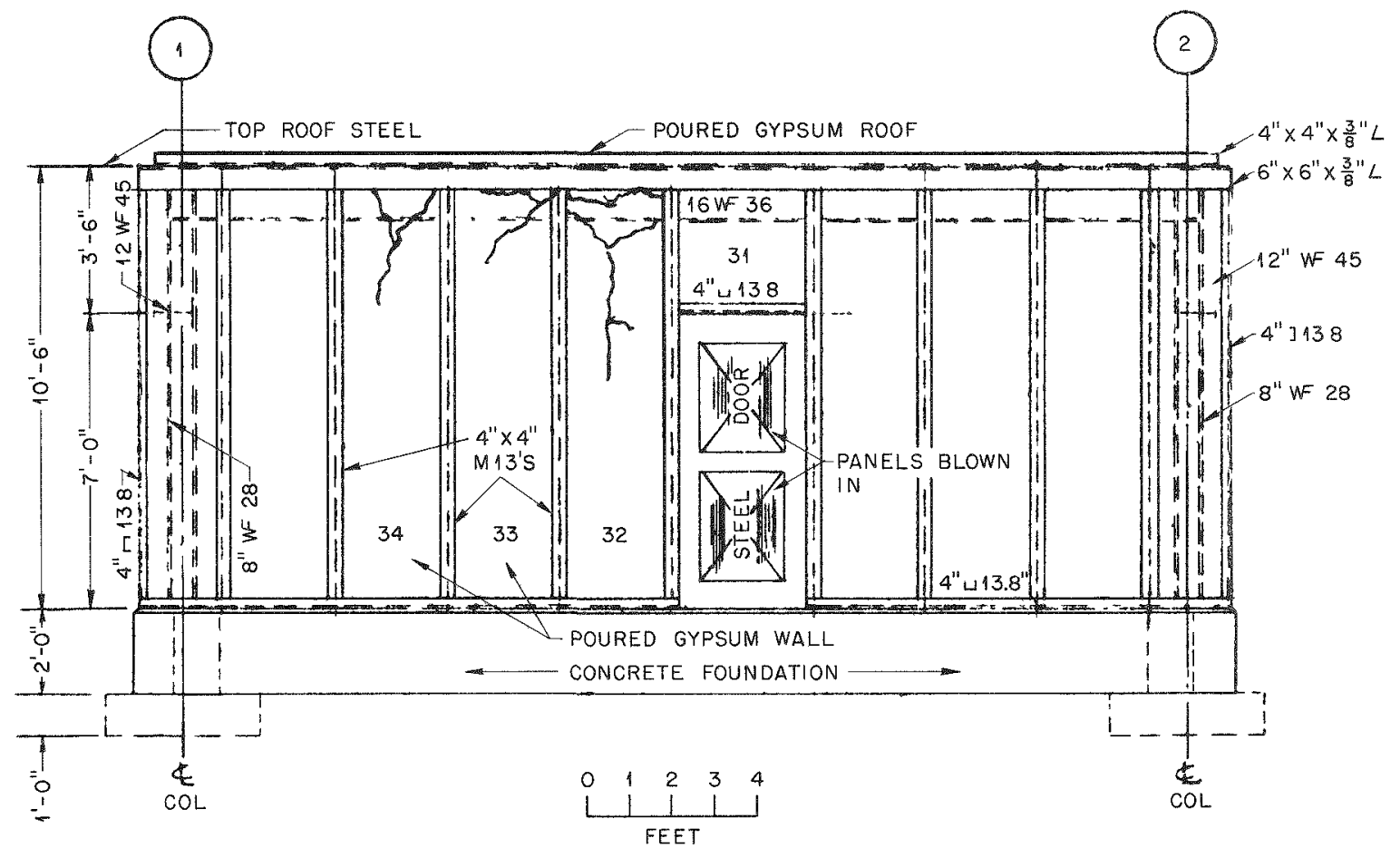

Fig. 1.6-West elevation of Union Carbide building. 


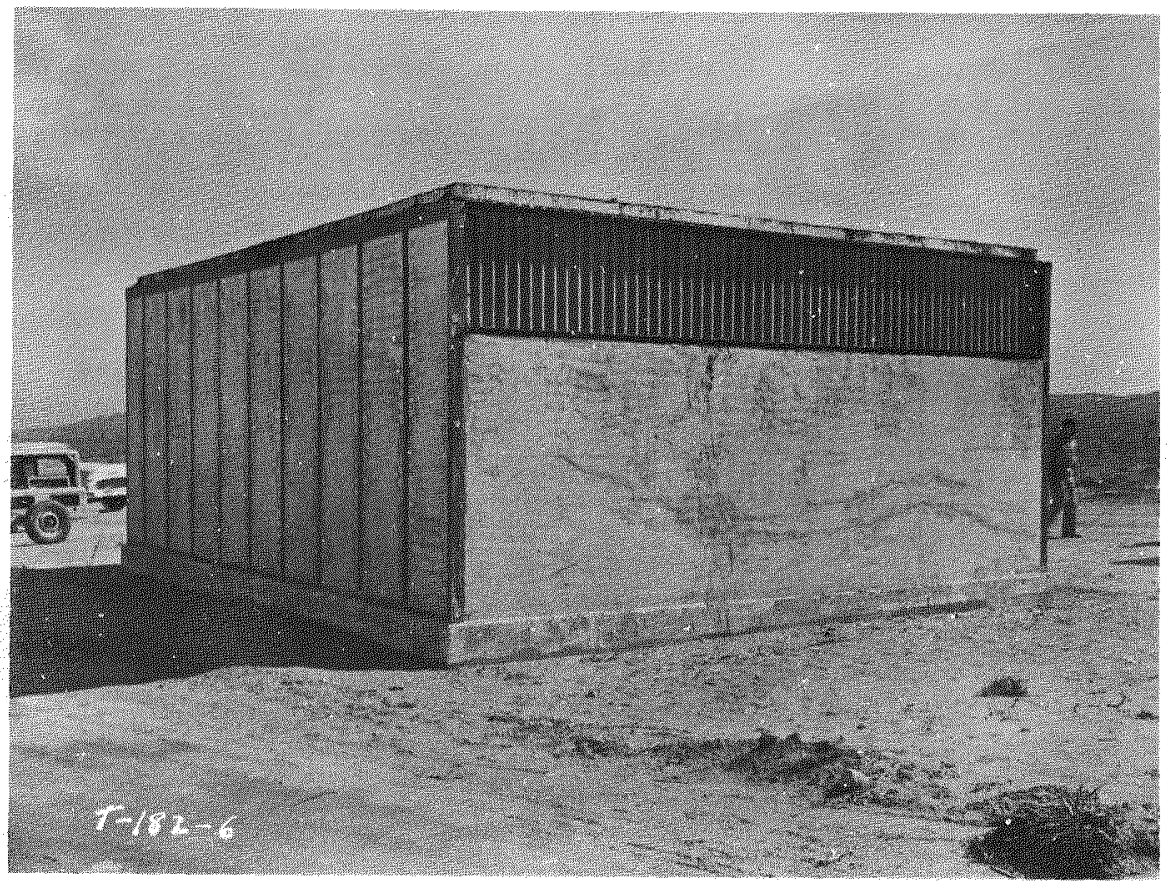

Fig. 1.7-North and east walls of Union Carbide building prior to planned test.

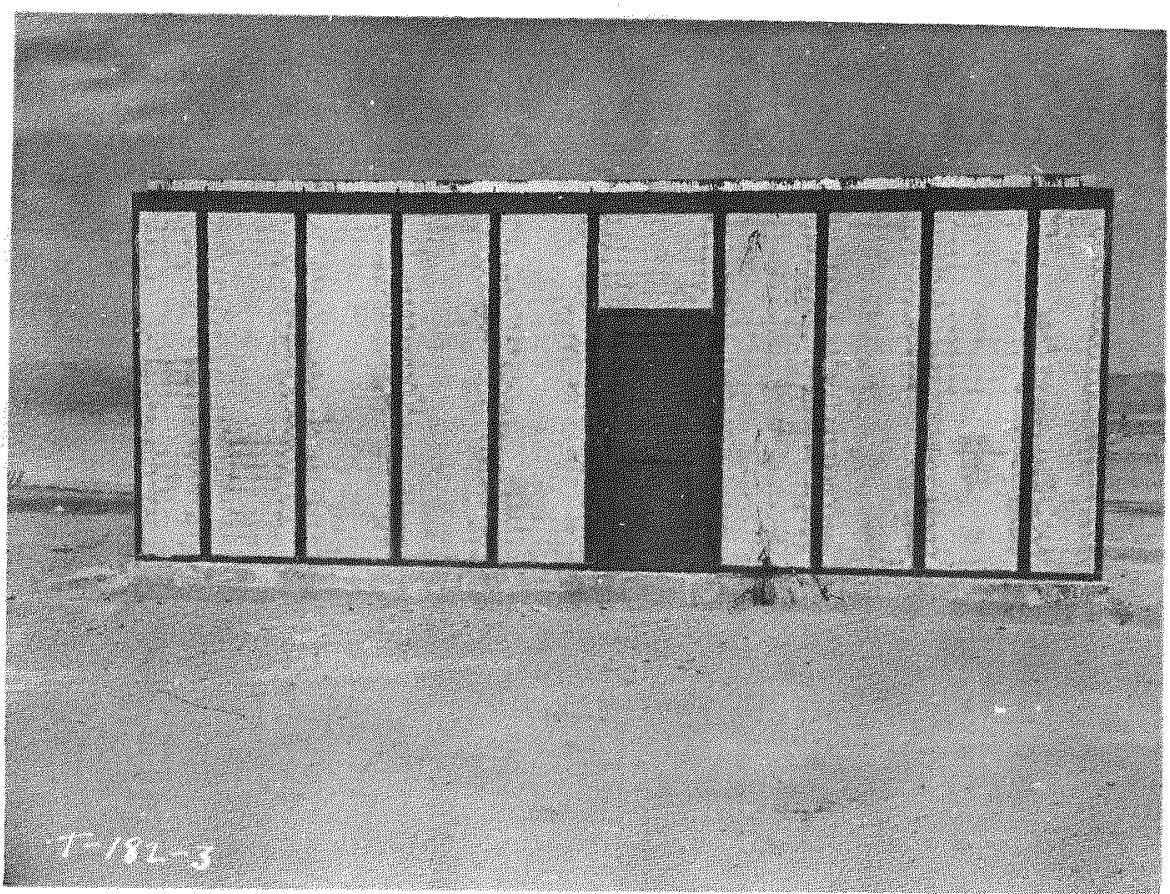

Fig. 1.8- West wall of Union Carbide building prior to planned test. 


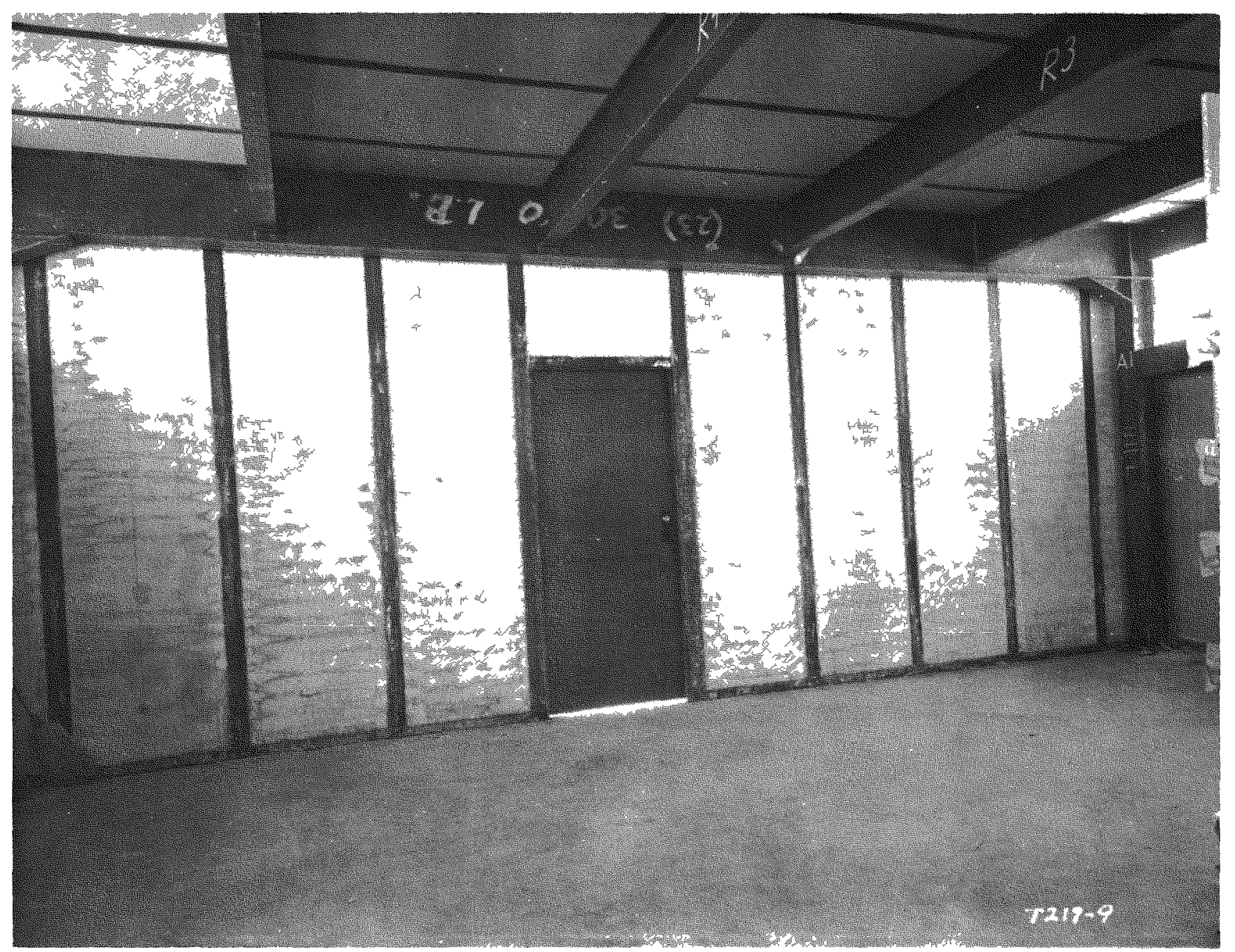

F1g. 1.9 - Interior view of west wall and frame of Union Carbide building. 

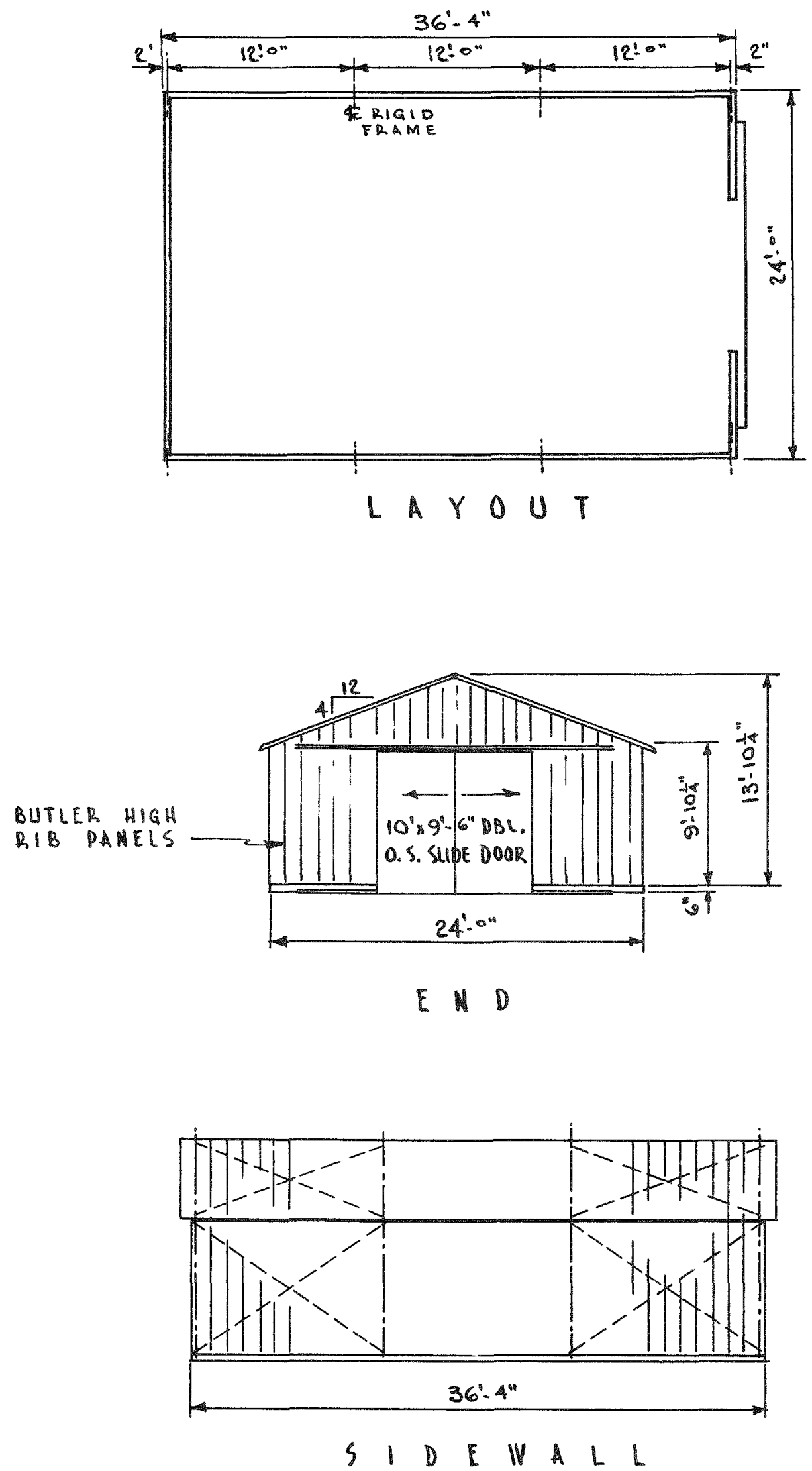

Fig. 1.10-General views of Reynolds-Butler buildings $(31.2-\mathrm{a} 1$ at $6800 \mathrm{ft}$ and $31.2-\mathrm{a} 2$ at $15,000 \mathrm{ft})$. 


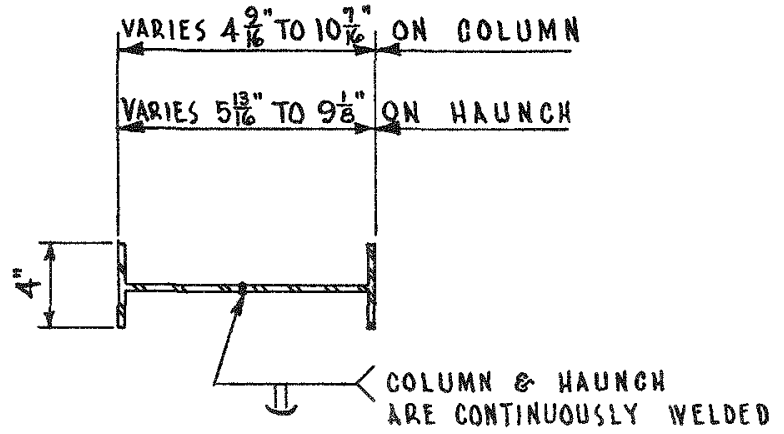

SECTION THROUGH GOLUMN AND HAUNCH

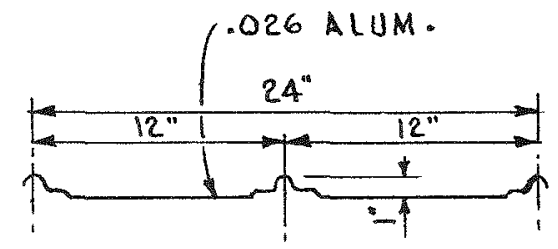

SECTION THROUGH BUTLER HIGH RIB DANEL

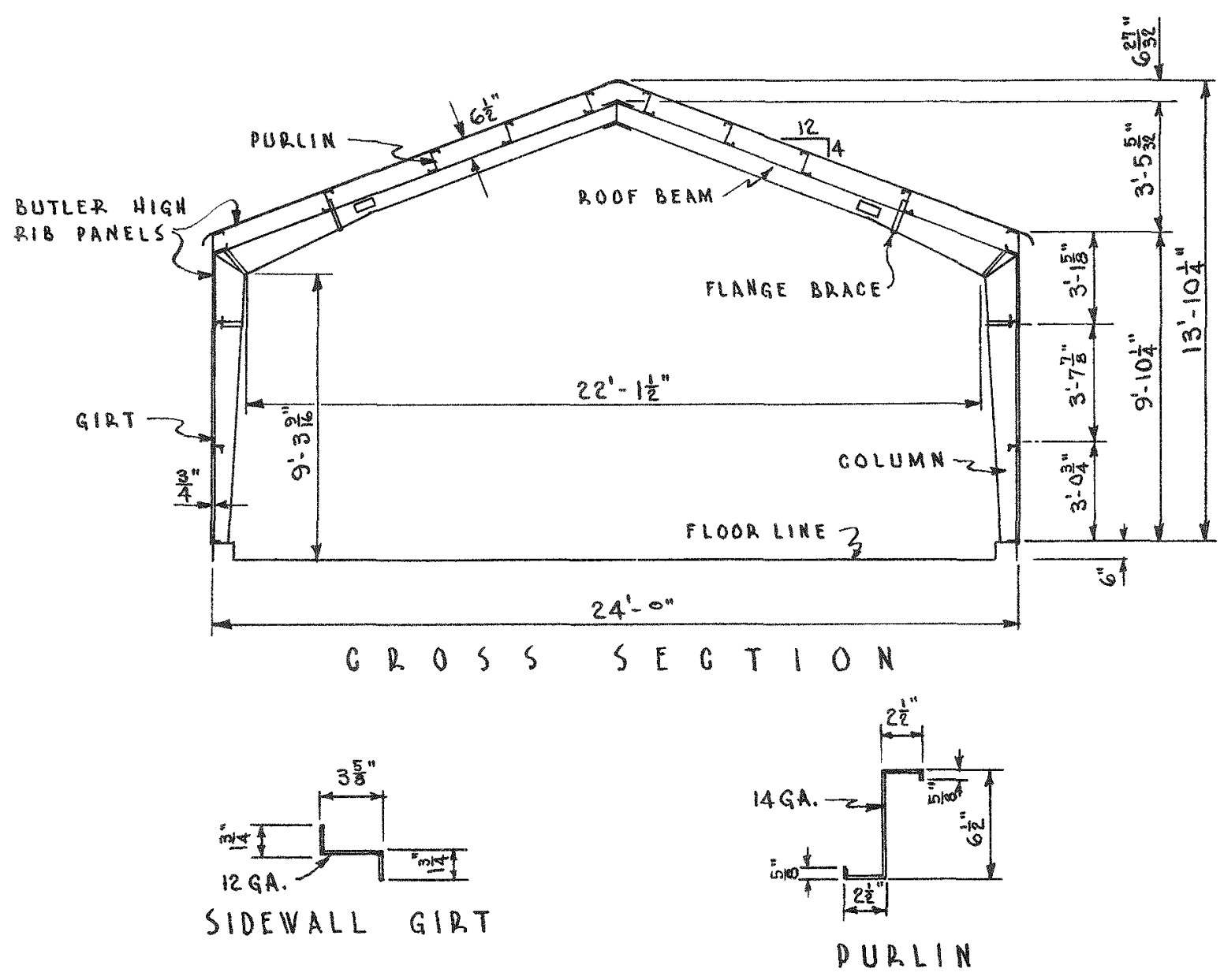

Fig. 1.11-Cross-sectional elevation and typical details of Reynolds-Butler buildings. 


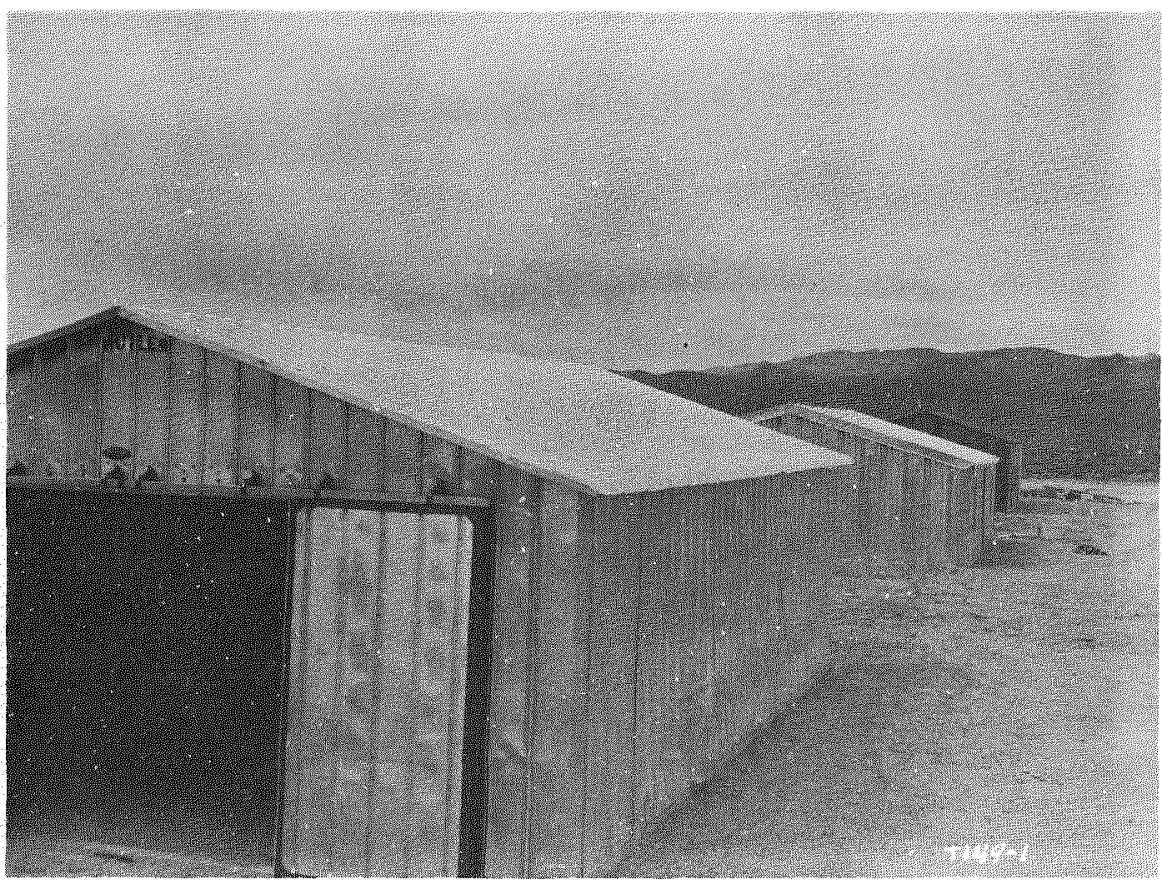

Fig. 1.12-North wall and east end of Reynolds-Butler Building 31.2-a2.

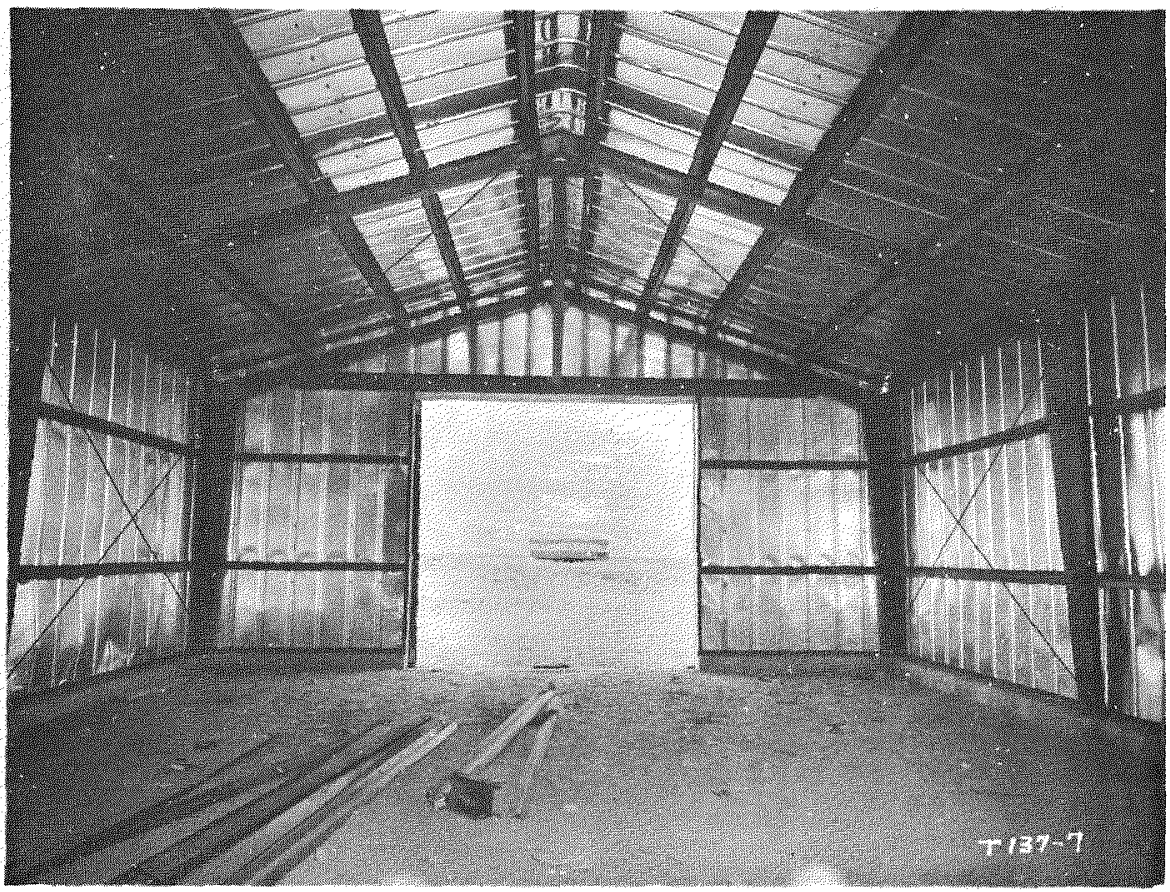

Fig. 1.13 - Interior view looking east in Reynolds-Butler building. 


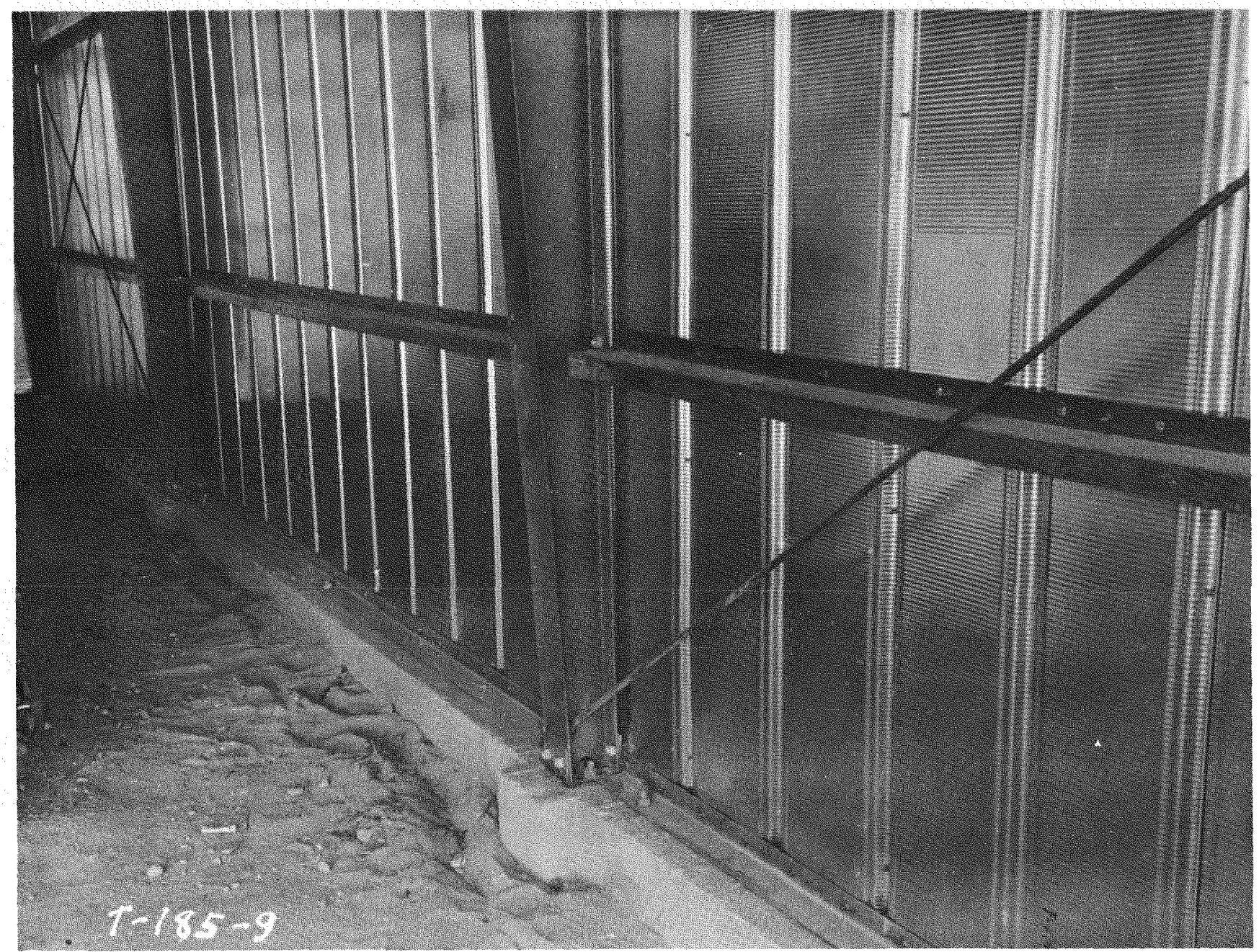

Fig. 1.14-Interior view of frame base and wall details in Reynolds-Butler buildings. 

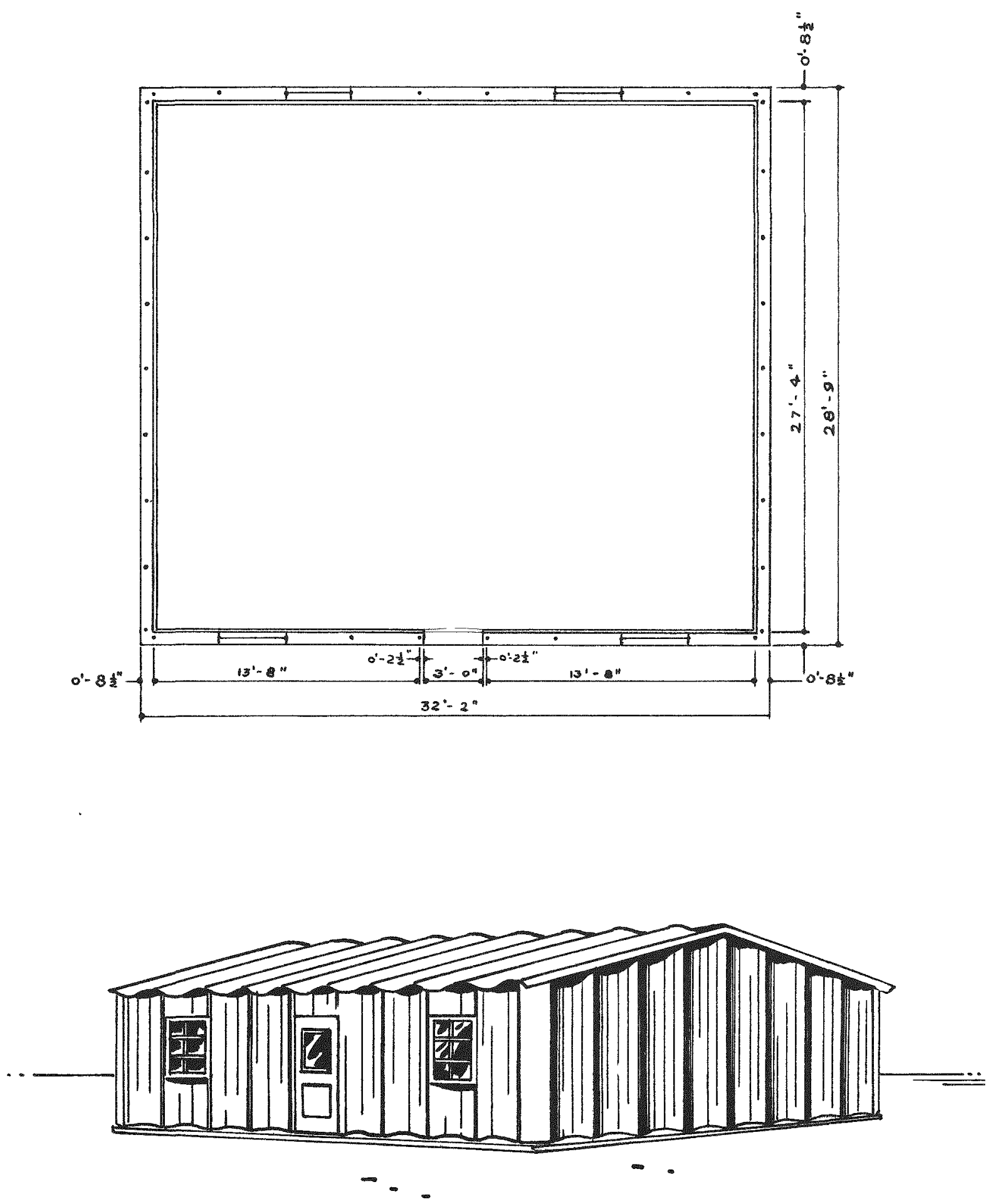

Fig. 1.15-Perspective and plan views of Behlen building. 
Dor

$-3^{i}-0^{11} \times 7^{i}-0^{\prime \prime}$

Windows $-3=0 \times 4-.0$
Building -16 Go. Galv. Stee

Conc. Ftgs. $-8^{\prime \prime}$ ide $\times 24^{\prime \prime}$ deep

(2)

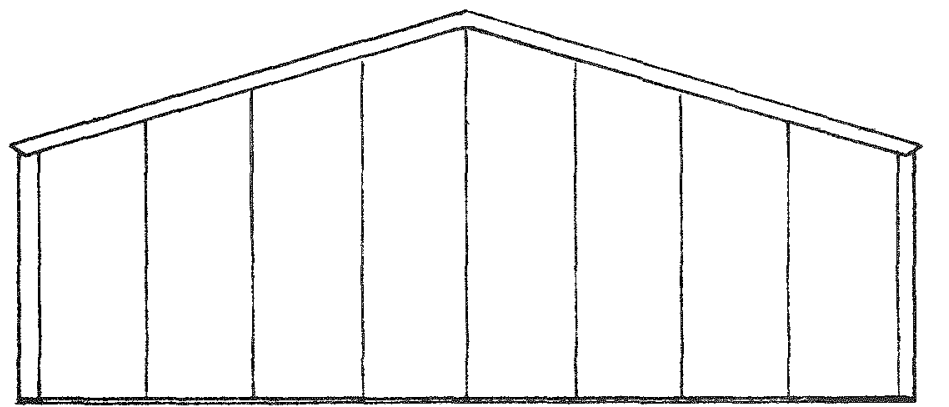

END ELEVATION

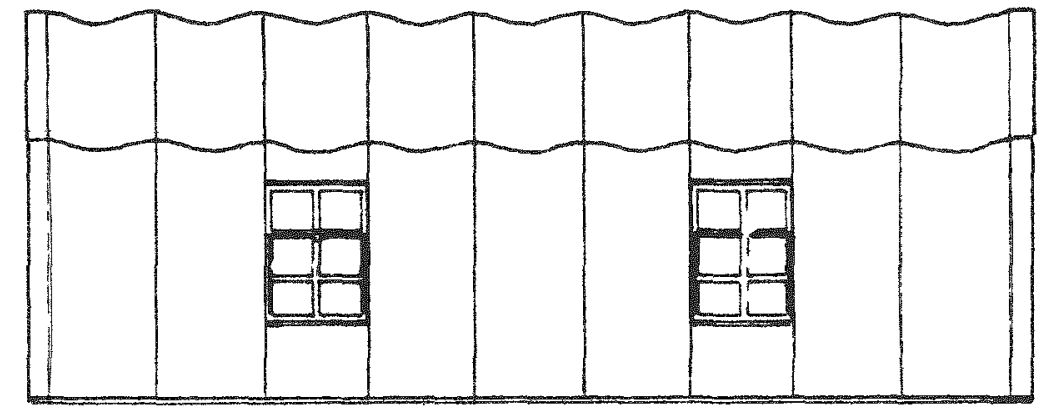

SIDE
ELEVATION

옹
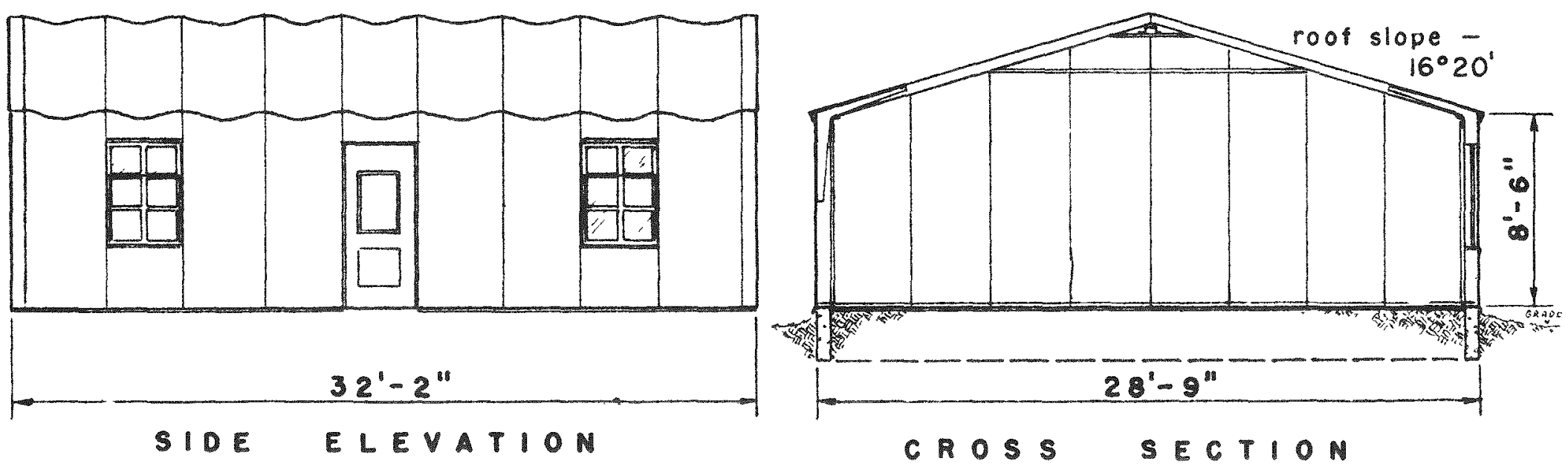

Fig, 1.16-End, side, and cross-sectional elevations of Behlen building. 


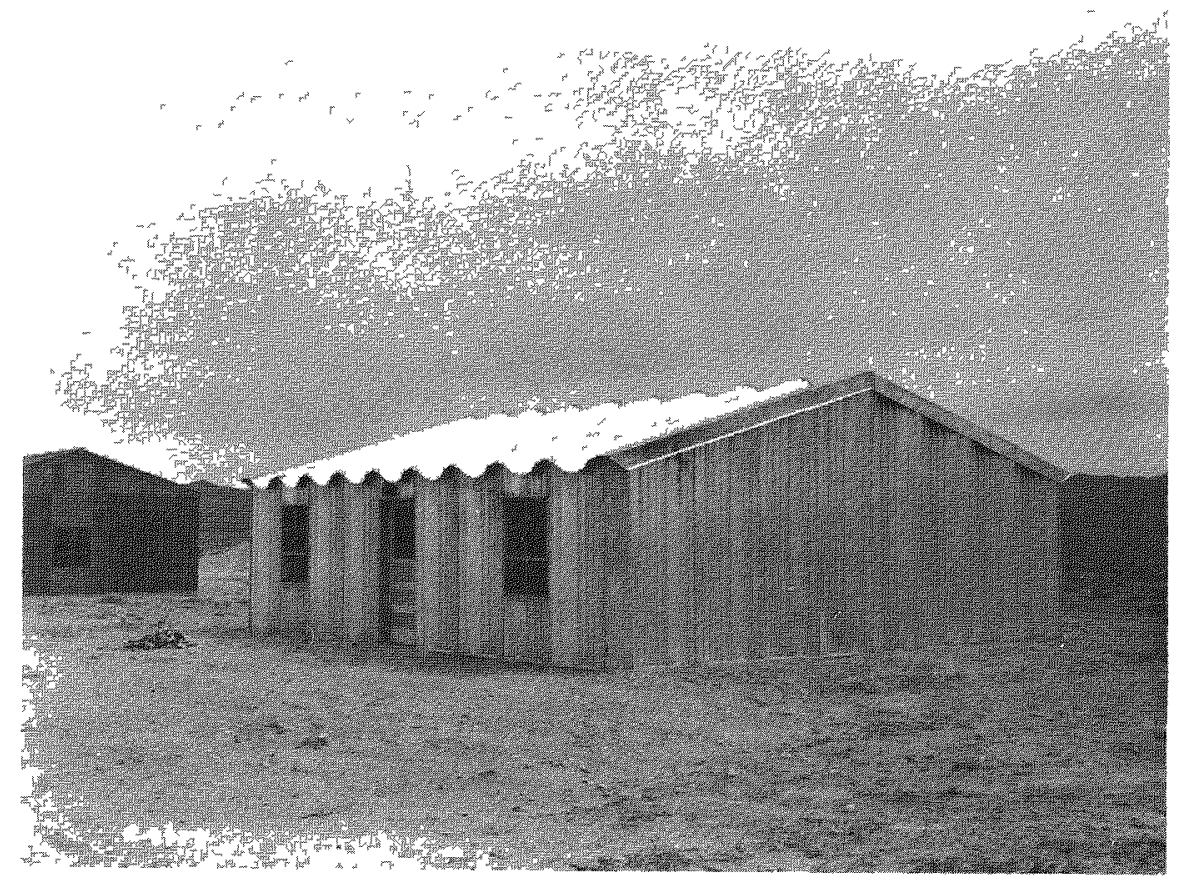

Fig. 1.17-North wall and east end of Behlen Building 31.2-b2.

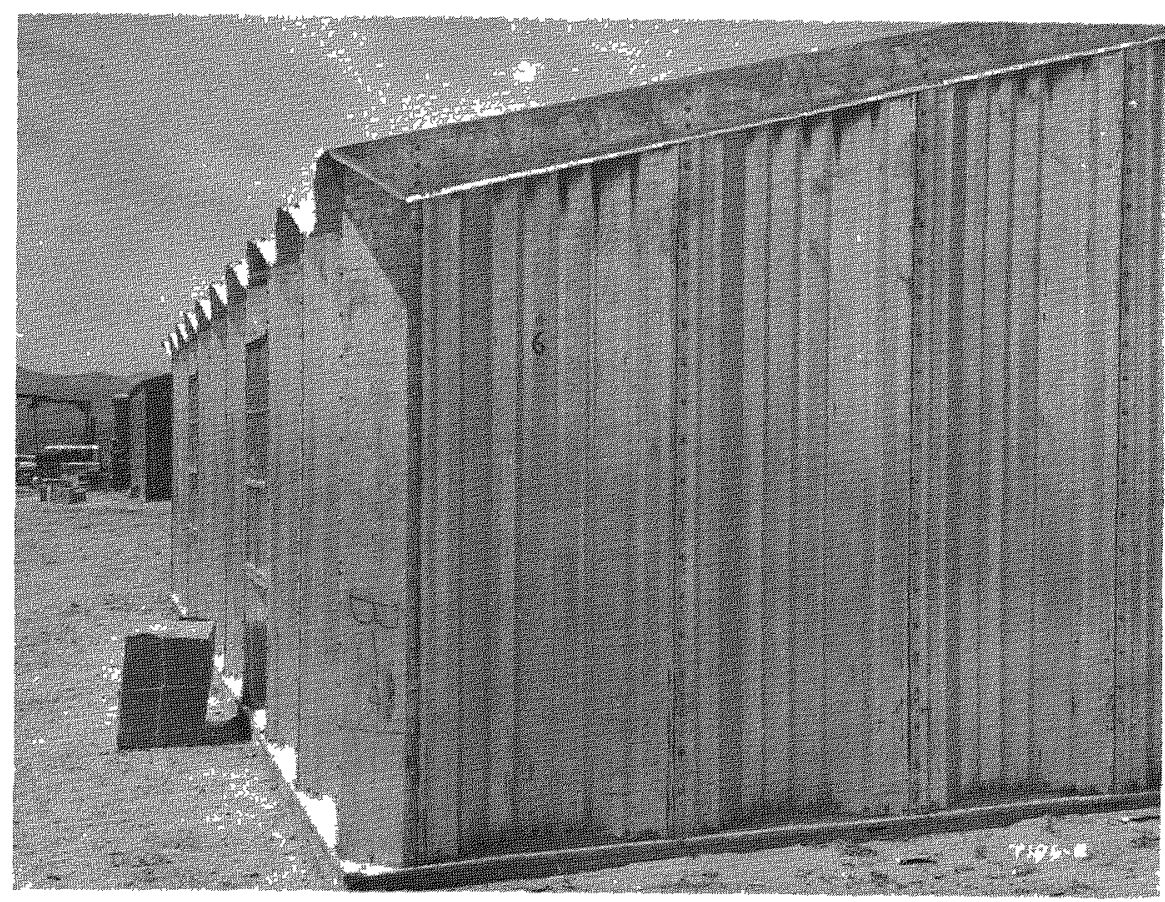

Fig. 1.18 - View looking along south wall of Behlen Building 31.2-b2. 


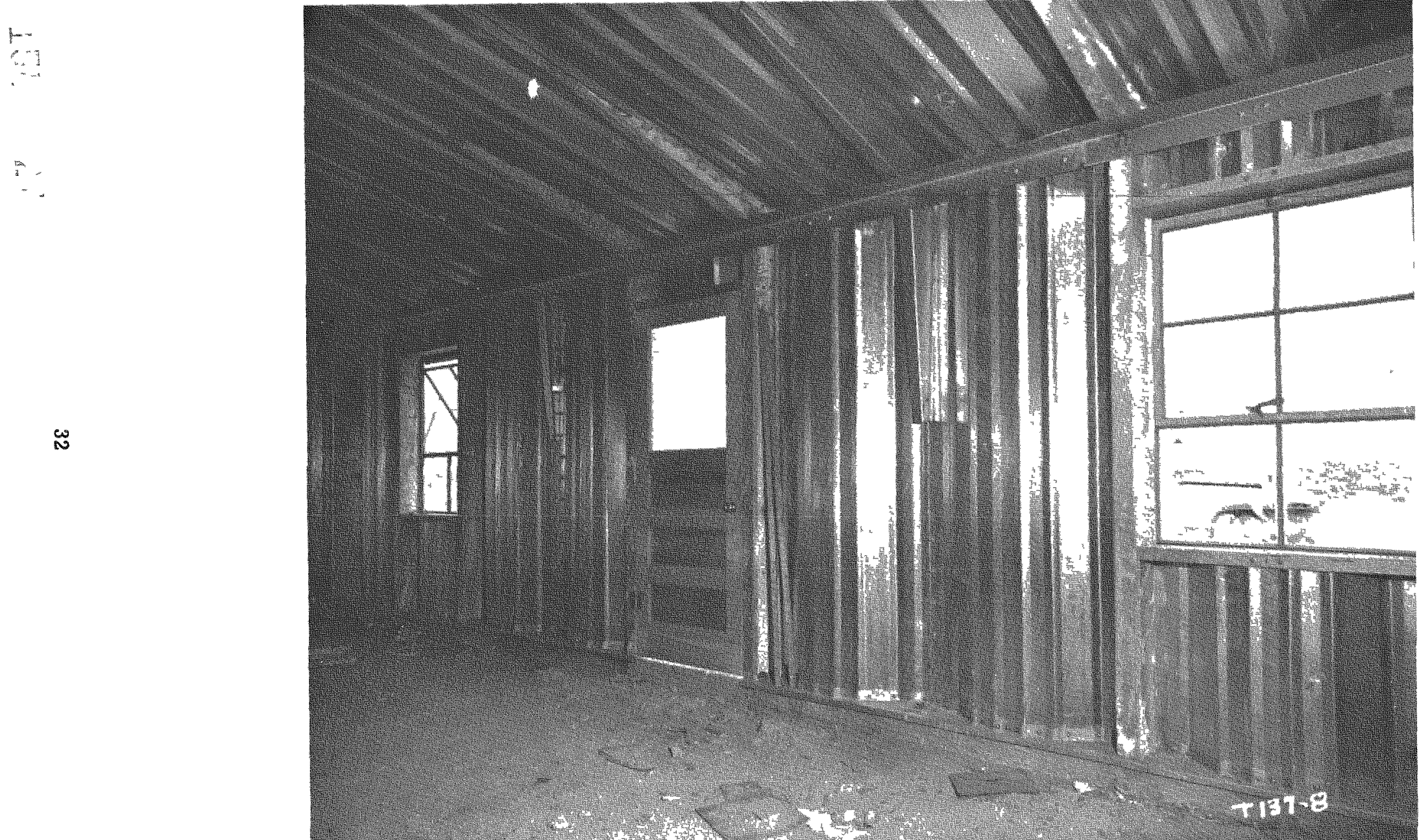

Fig. 1.19-Interior view of Behlen building. 


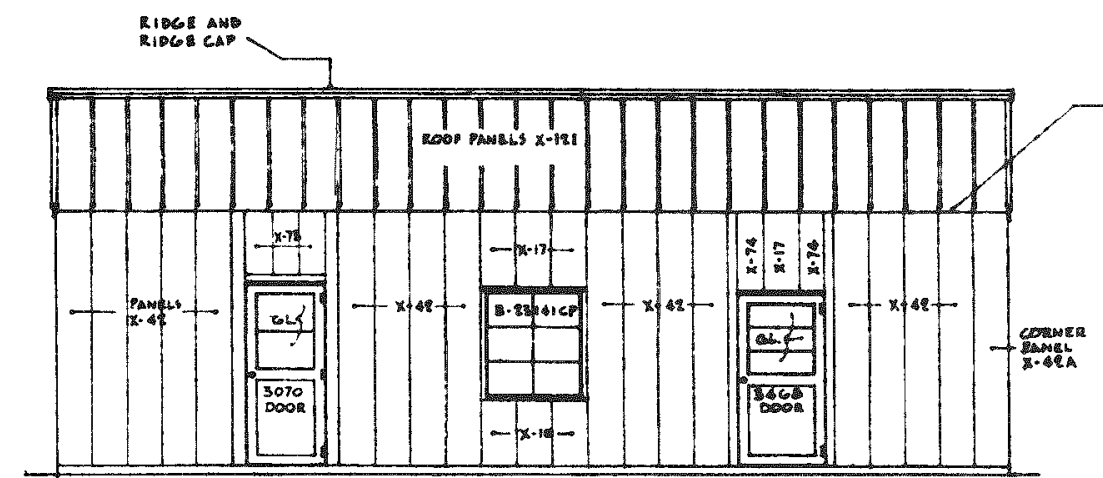

SIDE WALLELEVATION

$\omega$

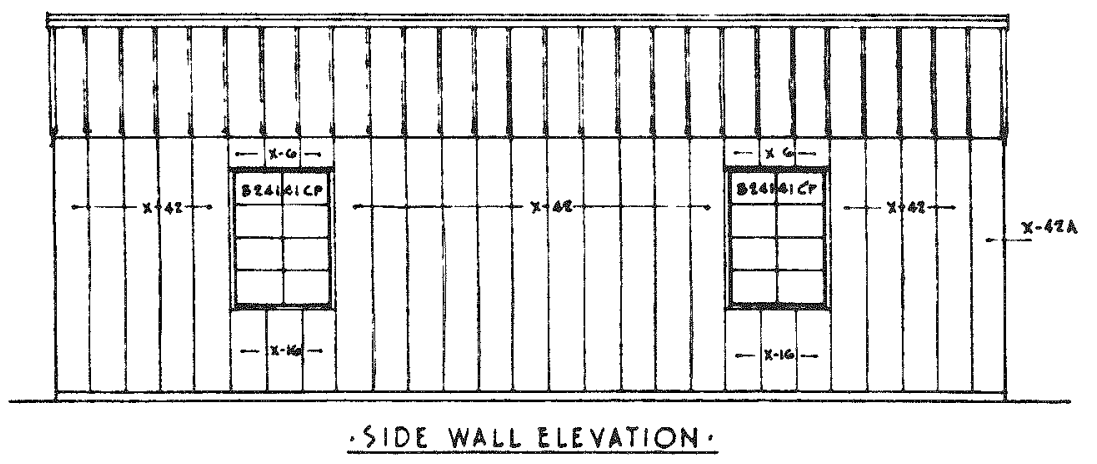

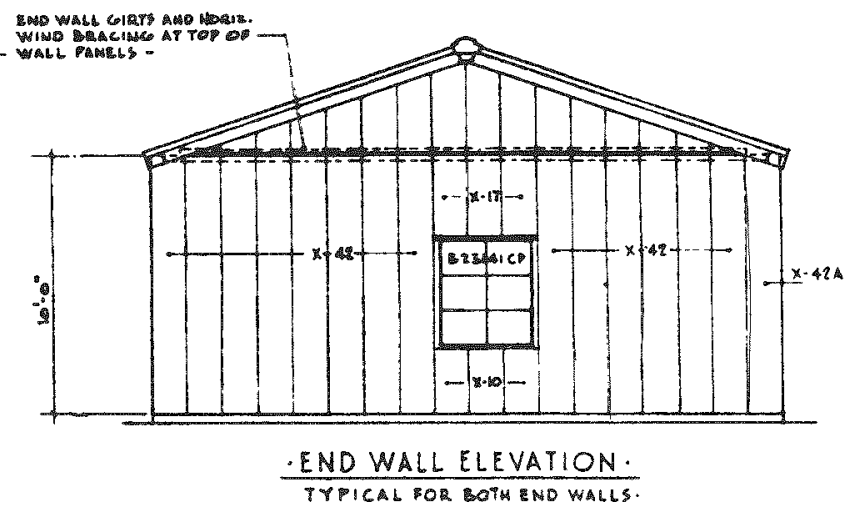

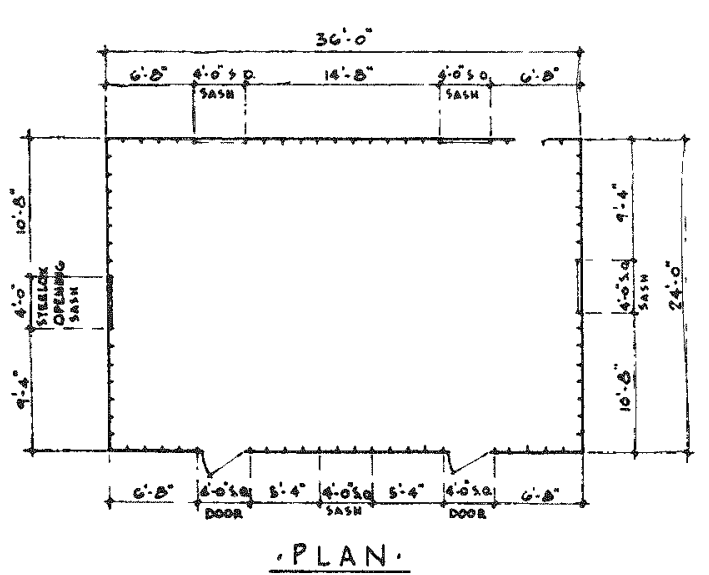

Fig. 1.20-Elevations and plan cross section of Armco buildings. 

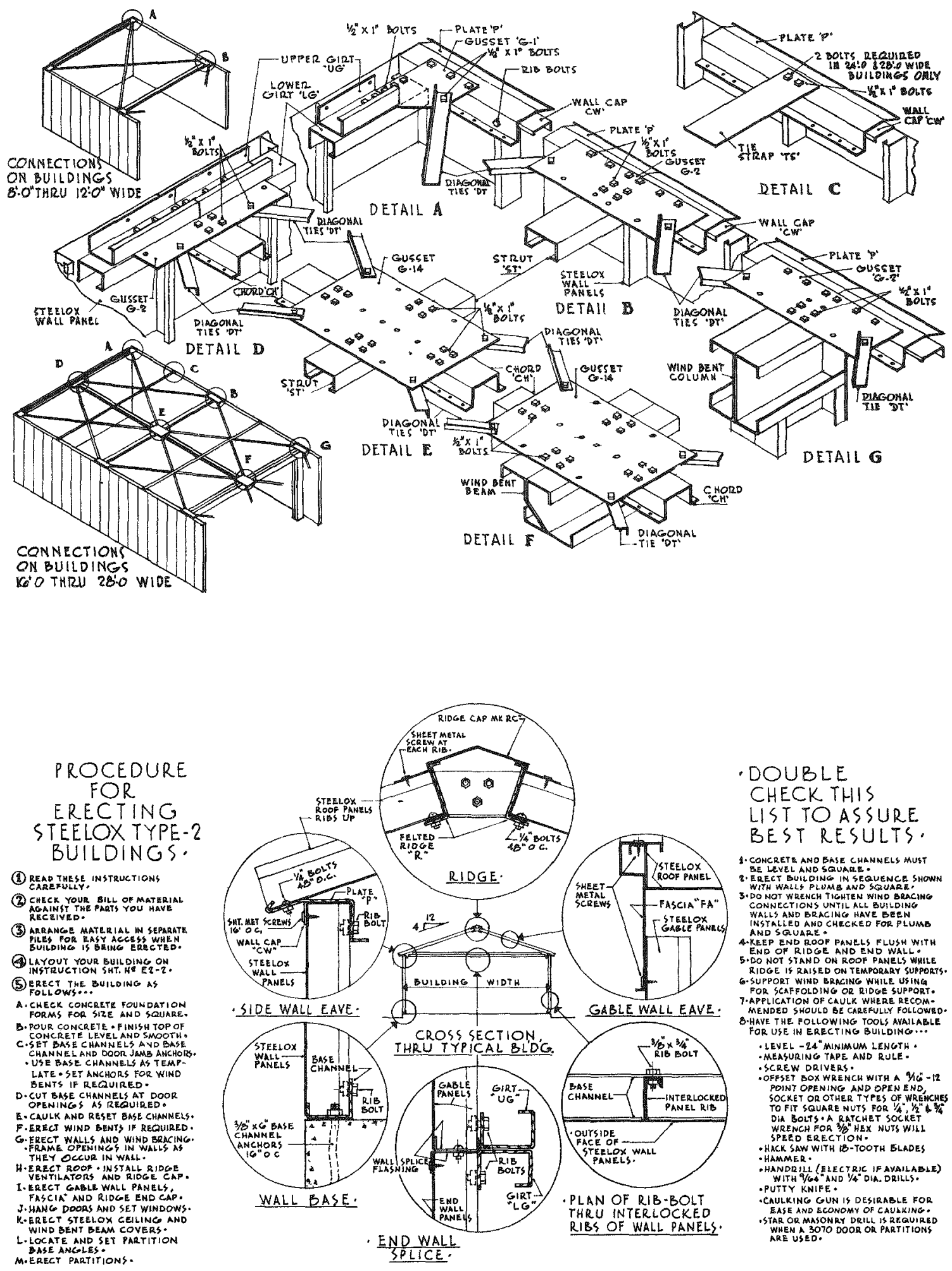

Fig. 1.21 - Typical wind bracing and other details of Armco butldings. 


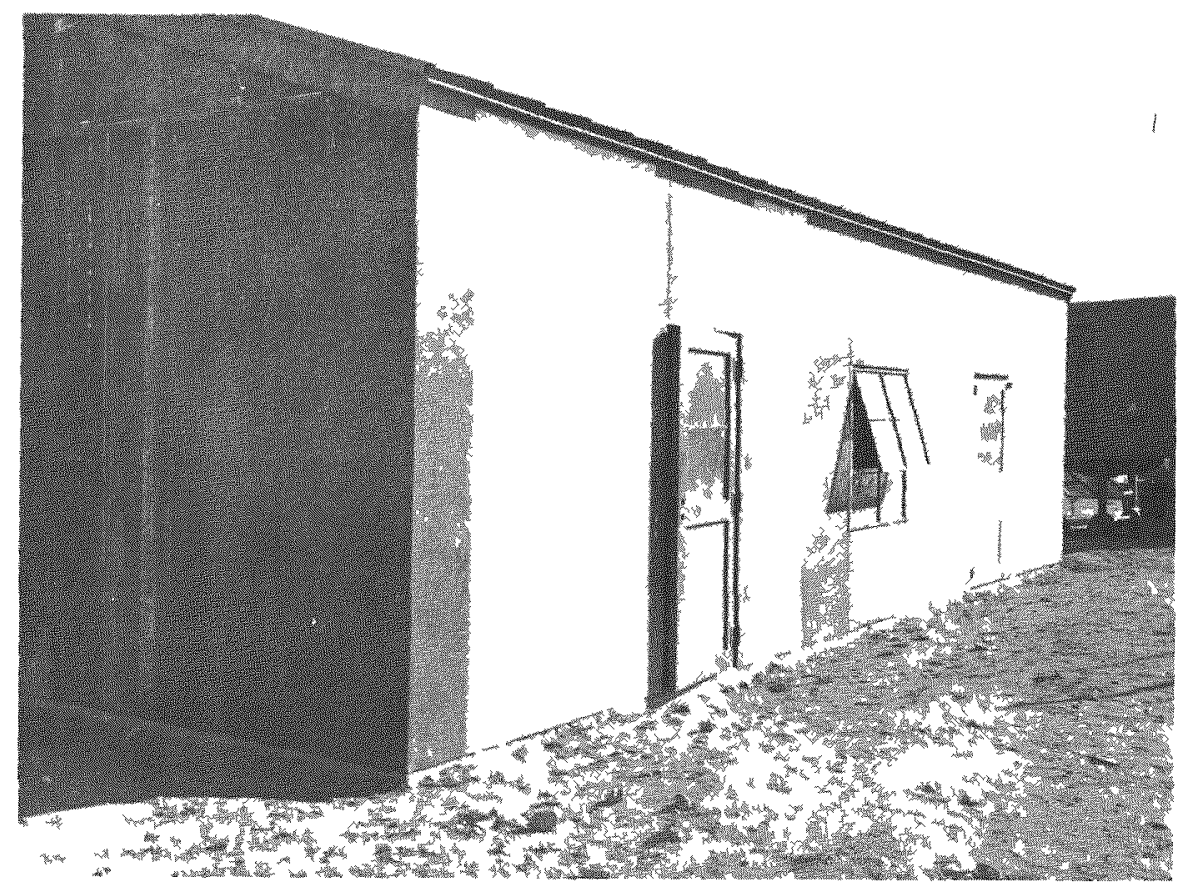

Fig. 1.22-Armco Bullding 31.2-d1 repaired after unexpected test.

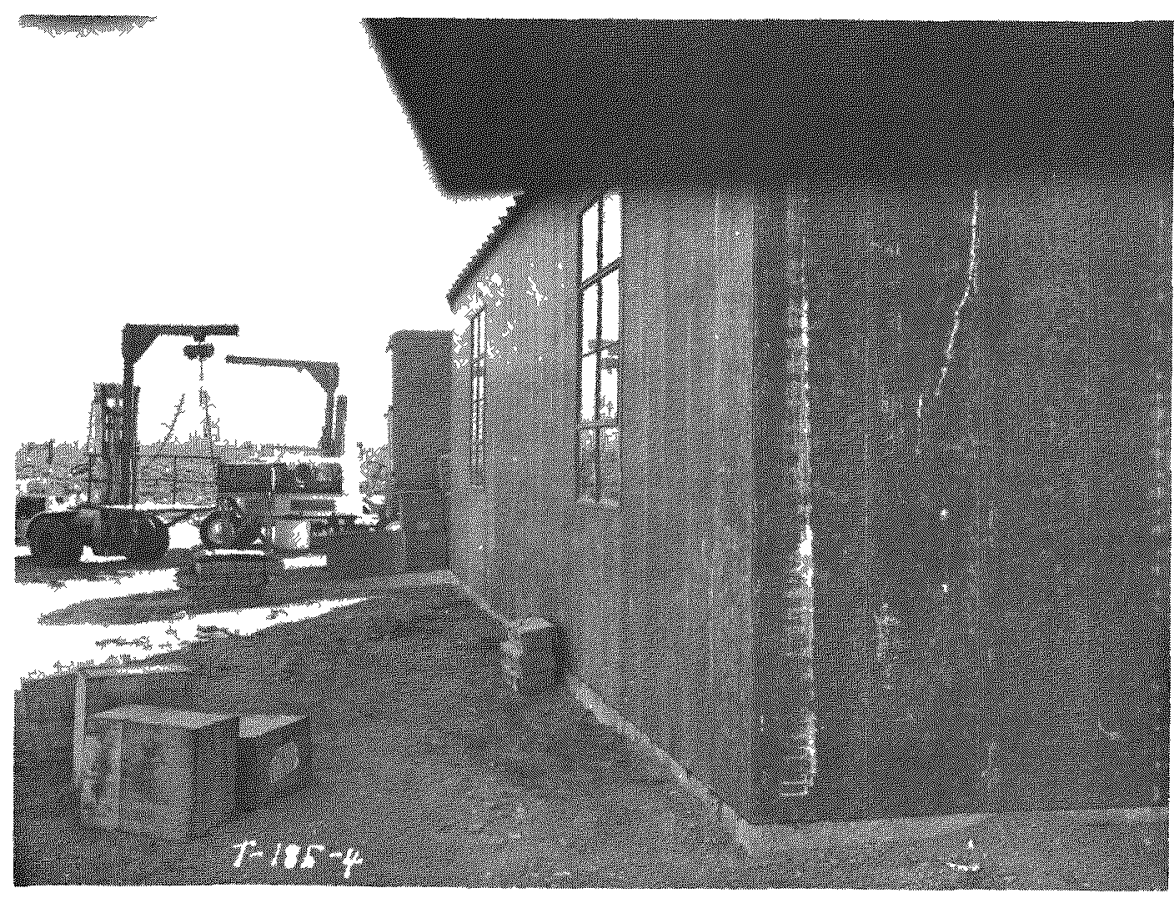

Fig. 1.23-South side of Armco bulding. 


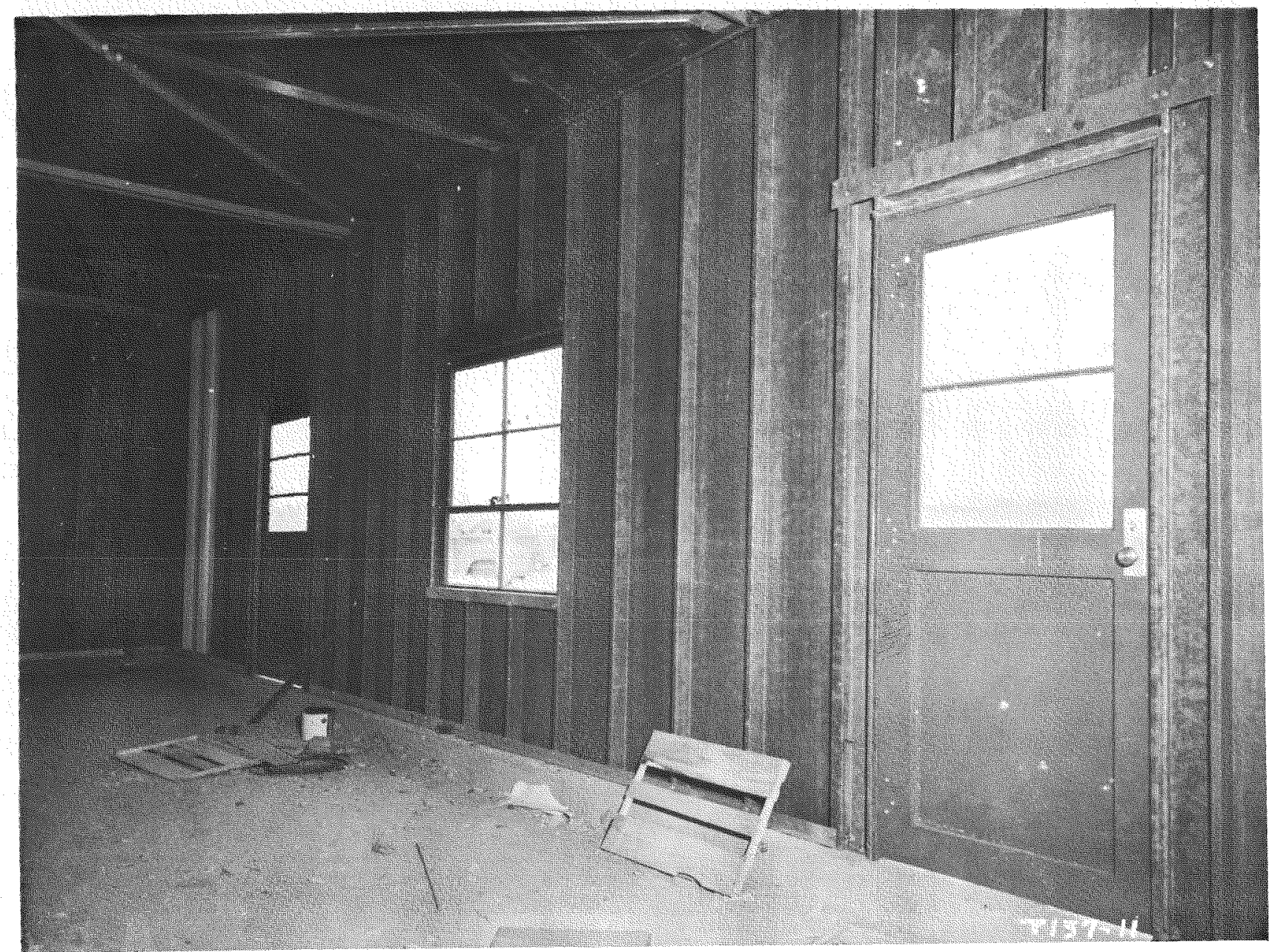

Fig. 1.24-Interior view of Armco building. 


\subsubsection{Frameless Steel Buildings with Channel Side Walls}

Buildings $31.2-\mathrm{d} 1$ at $6800 \mathrm{ft}$ and $31.2-\mathrm{d} 2$ at $15,000 \mathrm{ft}$ are a standard type developed and exposed during the test program by Armco Drainage \& Metals Products, Inc. Each wall and roof panel is a 16-in.-wide channel-shaped galvanized steel panel, interlocking along the sides. The channels can act both as a column and as a beam, no separate structural frame or girts being needed. However, the roof structure, above the eaves, is braced to form a rigid unit by horizontal struts and tension diagonals at the horizontal plane of the eaves. No roof purlins are needed. Roof sections are 18-gauge steel, and wall panels are 22-gauge steel. Doors and windows are of standard industrial type steel.

General drawings of the Armco buildings are presented in Figs. 1.20 and 1.21, and two exterior views are shown in Figs. 1.22 and 1.23. The interior view of Fig. 1.24 shows the interlocking channel flanges of the wall paneling and the bracing at the plane of the eaves.

\subsection{INSTRUMENTATION}

After the unexpected overpressure, careful offset measurements from stretched cords were made to determine the magnitude of panel deflections and sag of the top ridge line of the roof. Diagonal distances between the eaves and the opposite side base were determined to check plumbness approximately and any possible motion of the main frame.

Originally, no special instrumentation had been considered necessary for the evaluation of blast effects on the six utility buildings. However, after the unexpected test, very complete initial position measurements were made on all these buildings to locate the position of the eave level at the corners, at the longitudinal center line, and at important reference positions along the long sides. These points were positioned by measuring interior diagonal distances between scratch marks at the eave line and similar marks at the opposite base-point locations. Similar interior diagonal distances were measured between the ridge lines at the ends of the buildings and opposite building base-point locations. Local deflections along damaged panels, girts, or purlins were measured again after the test by the offset from the taut-string procedure.

In the case of the blast-resistant building for housing instrument and chemical controls, provision was made to determine the maximum deflection by means of simple scribers and scratch boards installed at four points. These provided an indication of the column and beam action during the test. Preshot measurements were made of column deviation from vertical; all horizontal and vertical deviations of girts, beams, girders; and diagonal dimensions across the walls and roof framing. Measurements were taken to saw cuts on flanges where it was impractical to check center-line to center-line dimensions. All preshot wall cracks were marked with a blue crayon. Relative elevations of the top of the column base plates were established.

A limited number of gamma radiation film badges were placed in the industrial structures, with primary emphasis on the blast-resistant building. In this structure, eight badges were placed on the outside and 25 were placed on the inside. They were in locations at five different elevations on the inside walls nearest and farthest from the origin of the blast, as well as at other central points designed to give an indication of radiation levels within the structure.

\section{RE FERENCES}

1. Los Alamos Scientific Laboratory, "The Effects of Atomic Weapons," U. S. Government Printing Office, Washington, 1950.

2. Building in the Atomic Age, conference proceedings, Massachusetts Institute of Technology, 1952.

3. N. M. Newmark, An Engineering Approach to Blast-resistant Design, Proc. Am. Soc. Civil Engrs., Separate 306 (October 1953).

4. Bruce G. Johnston and Archie Mathews, Blast-resistant Building Frames, Proc. Am. Soc. Civil Engrs., Separate 695 (May 1955). 


\section{Chapter 2}

\section{TEST RESULTS}

\subsection{DAMAGE CAUSED BY UNEXPECTED TEST}

\subsubsection{General}

At the time of detonation of the test device producing the unexpected overpressure, the three utility buildings at the 6800 -ft distance* either had been completed or were nearly completed; however, structures at the 15,000-ft distance, with the exception of the Behlen building, were in the middle stages of construction.

At the $6800-\mathrm{ft}$ line the unexpected test resulted in considerable damage to the north wall, including wall girts, and the roof of Reynolds-Butler Building 31.2-a1 and to the north and east walls of Armco Building 31.2-d1. Behlen Building 31.2-b1 experienced very minor damage.

At the 15,000-ft line Behlen Building 31.2-b2 was undamaged, and no assessment could be made as to the probable damage to Armco Building 31.2-d2 since it was in the early stages of construction.

\subsubsection{Damage from Unexpected Test at Locations 5500 and $6800 \mathrm{Ft}$ from Planned Test Shot}

The windows had not been installed in the blast-resistant structure (Union Carbide Building 31.2-e1), and there was no apparent damage of any kind to this structure.

Figure 2.1 gives a general indication of the damage from the unexpected test to the north wall of Reynolds-Butler Building 31.2-a1, which was left with permanent inward deflections up to $5 \mathrm{in}$. The offset measurements, as recorded at the site, are tabulated in Fig. 2.2 for both the unexpected and planned tests. The two wall girts were bent in along with the paneling, and the bolt heads of the panel fasteners were generally pulled through the sheeting. Washers had been omitted along these two lines of bolts, and hence no definite conclusion can be made as to the probable extent of pull through if they had been included. The roof sheeting was left with downward permanent sets, especially in the span immediately adjacent to the eaves, where the permanent deflections, as shown in Fig. 2.3 and recorded in Fig. 2.2, were measured up to 3 in. The roof purlins were not deformed appreciably. The interior view of the wall (Fig. 2.4) shows how twisting of the girts occurred with measured values up to $43^{\circ}$. It is also of interest to note the imprint of the wind-bracing ties on the wall paneling, indicative of the initial deflections that were experienced. A dynamic analysis of wall behavior in both the unexpected and planned tests is provided in Appendix A.

As shown in Fig. 2.1, the panels on the west end of the building suffered very little permanent deformation. The unexpected test involved a moderate northeast exposure, and at the east end, as indicated in Fig. 2.5, the panels were bent inward to a degree comparable with those on the north side. This picture was made during the process of repair, with damaged north and south wall panels removed but with the bent and twisted wall girts still in position.

* All references to 5500,6800 , and $15,000 \mathrm{ft}$ indicate the distance of the structures from $\mathrm{GZ}$ during the planned test. No distances from $\mathrm{GZ}$ are given for the unexpected test. 


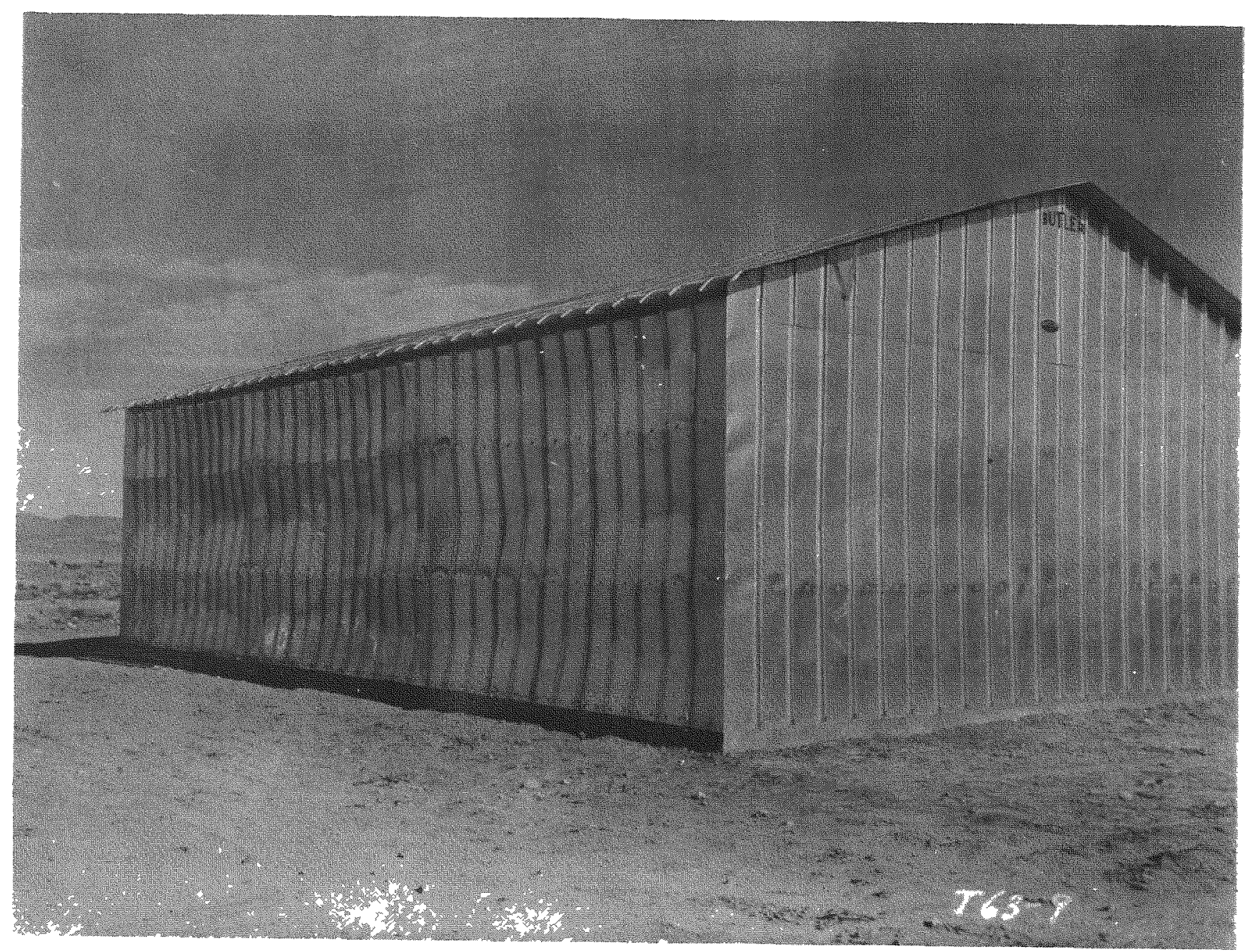

Fig. 2.1-General view of north and west end walls, showing damage from unexpected test to Reynolds-Butler Buildng 31.2-a1. 


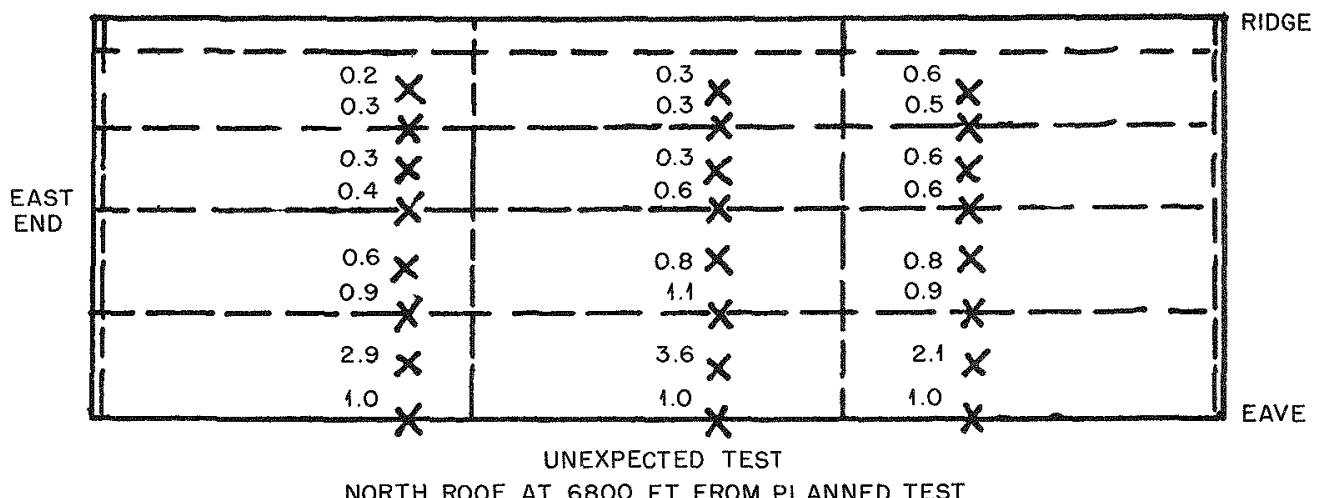

NORTH ROOF AT $6800 \mathrm{FT}$ FROM PLANNED TEST
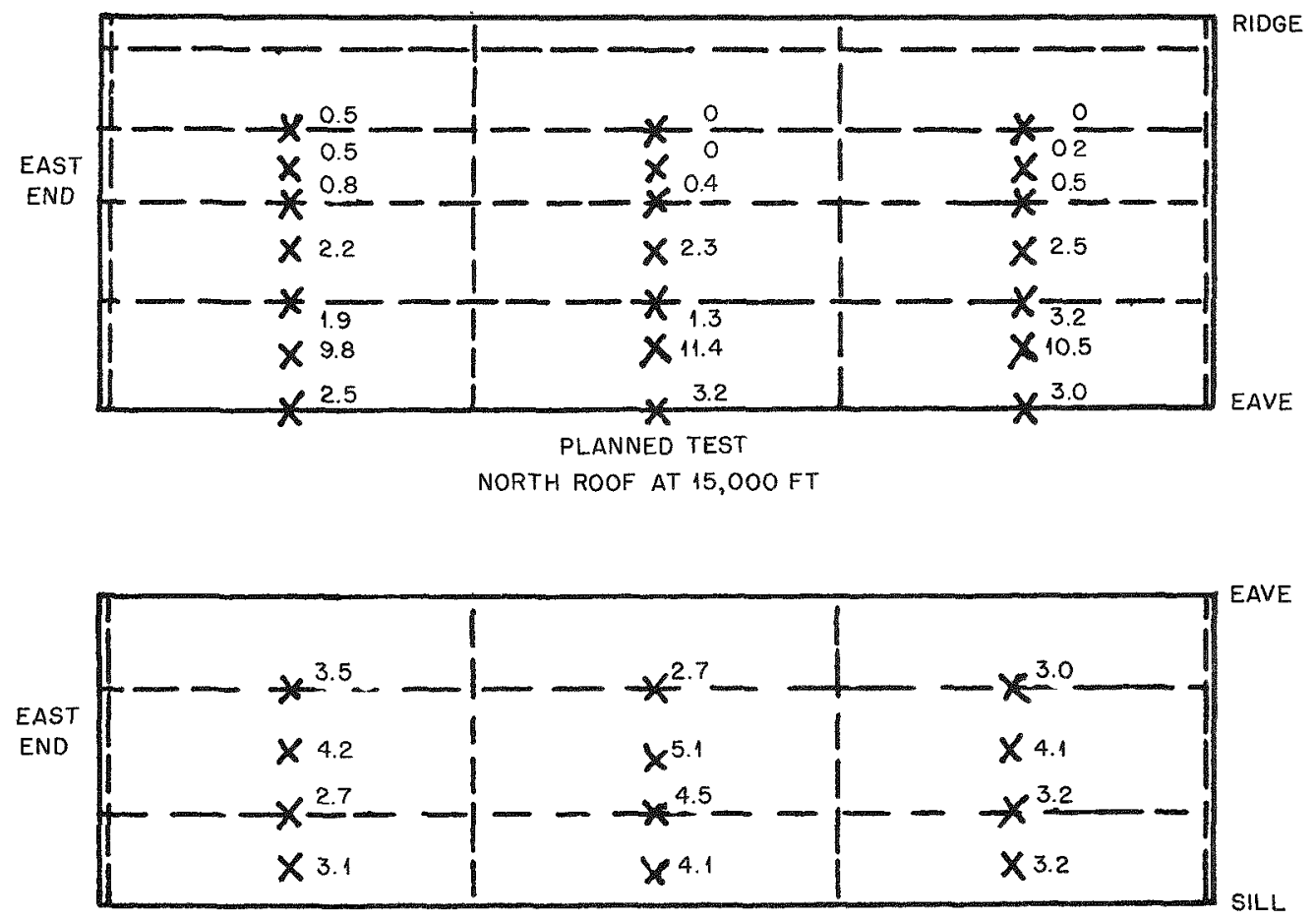

UNEXPECTED TEST

NORTH WALL AT 6800 FT FROM PLANNED TEST

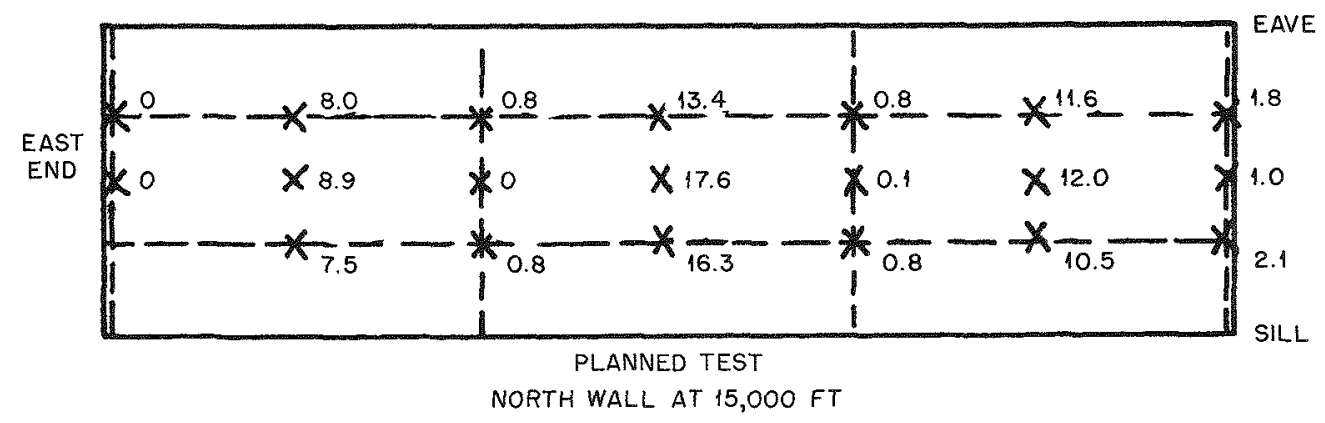

Fig. 2.2-Offet measurements of permanent wall and roof deflections in inches in Reynolds-Butler buildings in which sheeting remained in place. 


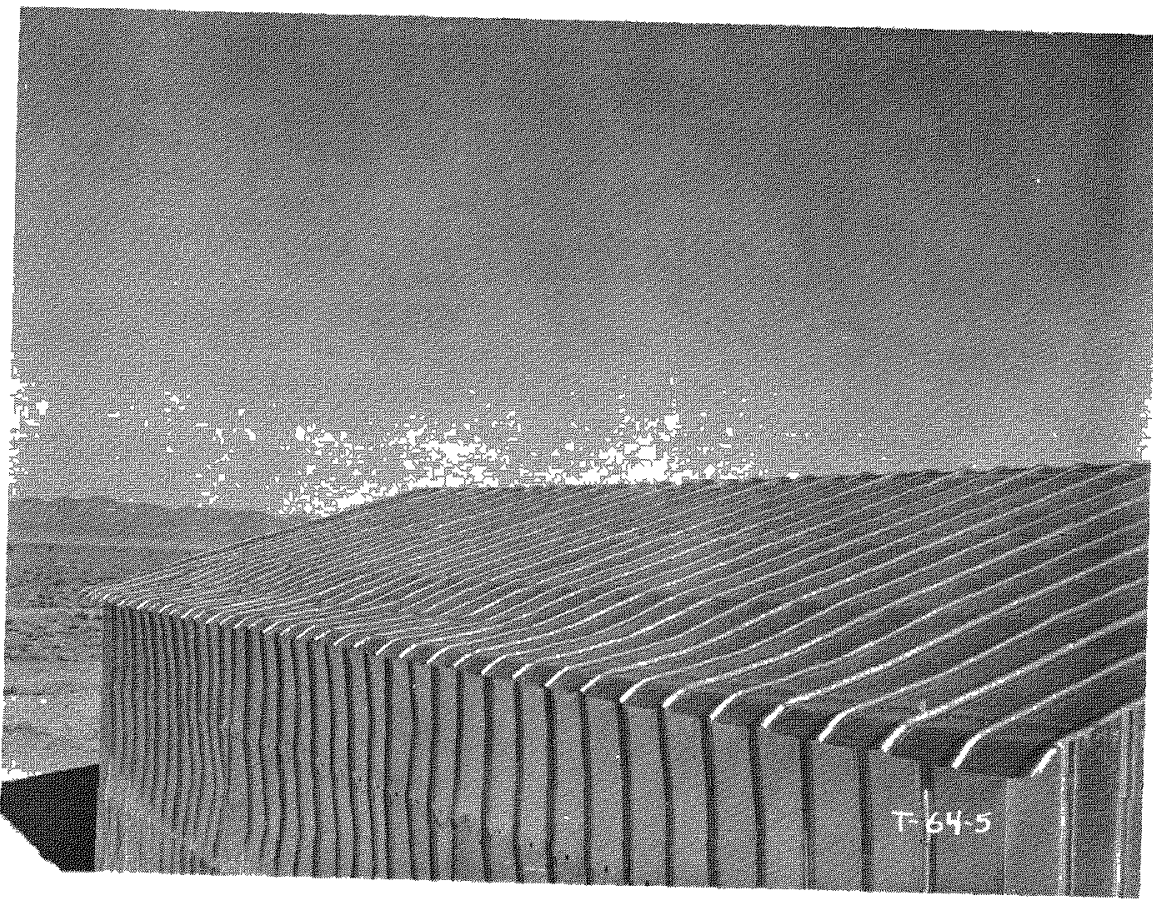

Fig. 2.3-Damage to roof of Reynolds-Butler Building 31.2-a1 from unexpected test.

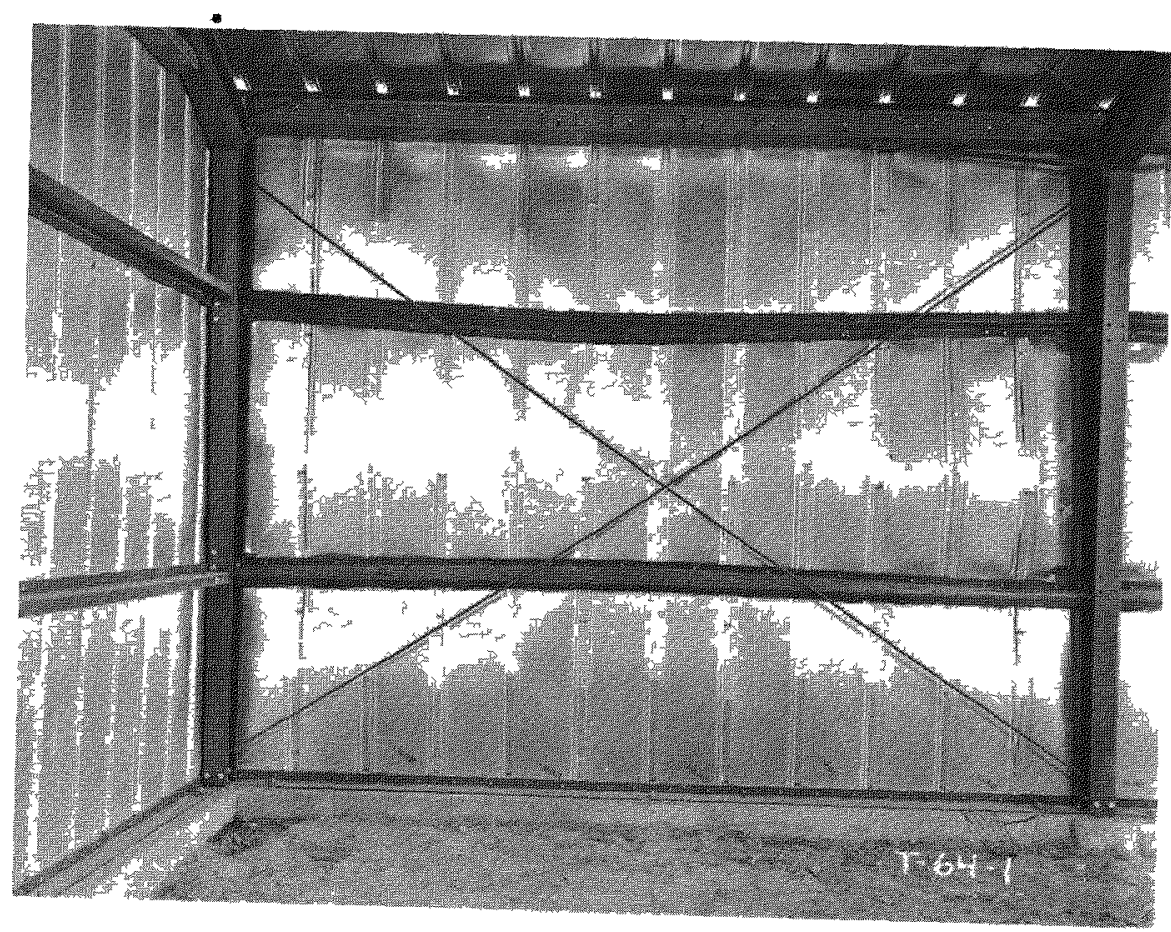
Fig. 2.4-Interior view of damage to north wall in Reynolds-Butler Building $31.2-a 1$
from unexpected test. 


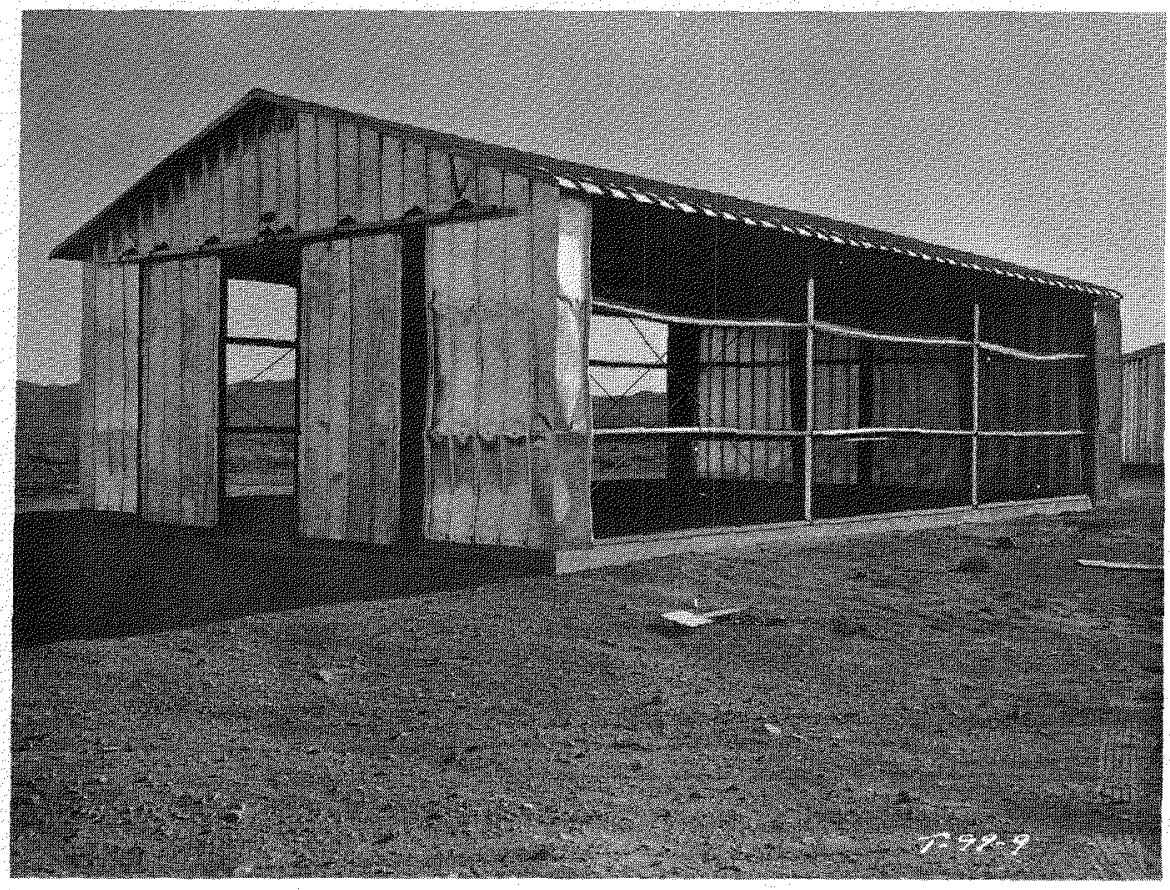

Fig. 2.5- North and south sides of Reynolds-Butler Building 31.2-a1 during repair of damage from unexpected test.

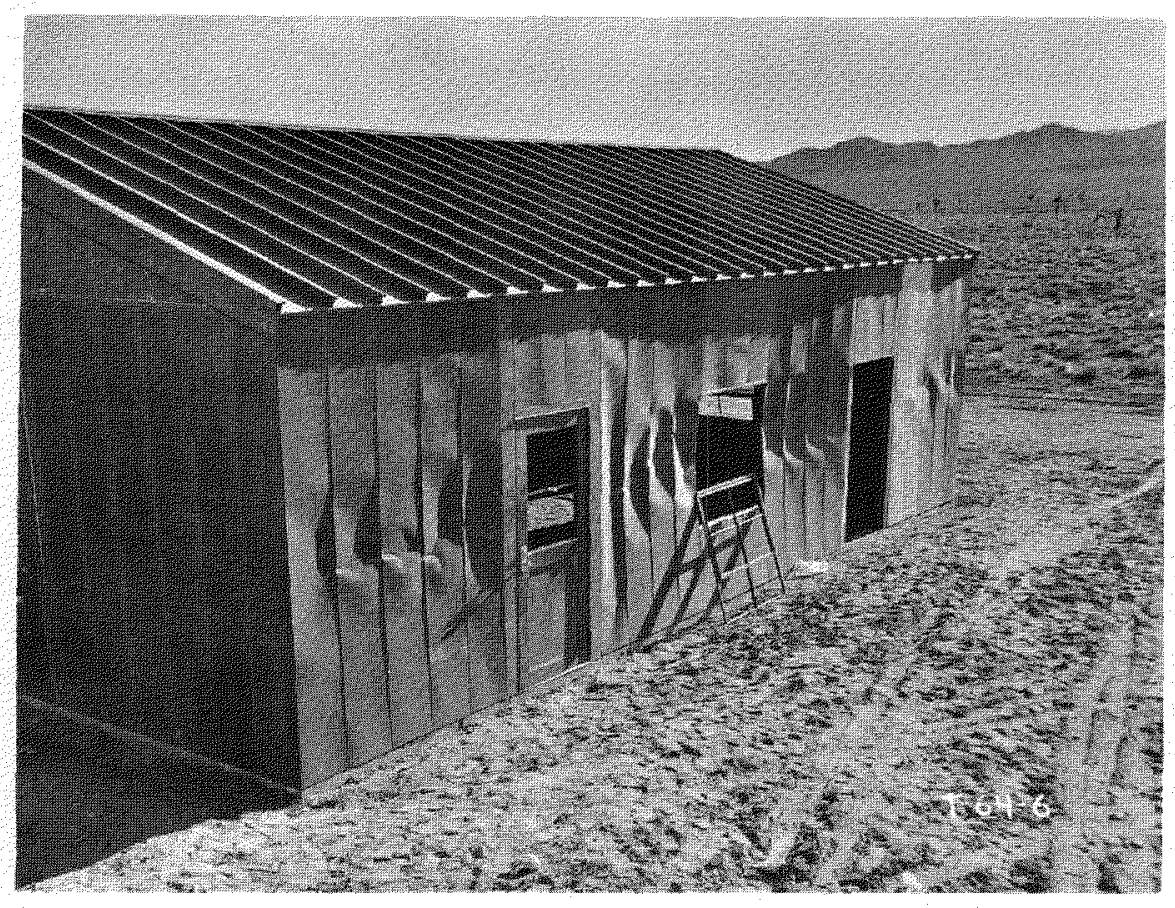

Fig. 2.6-Damage to north walls of Armco Building 31.2-d1 from unexpected test. 


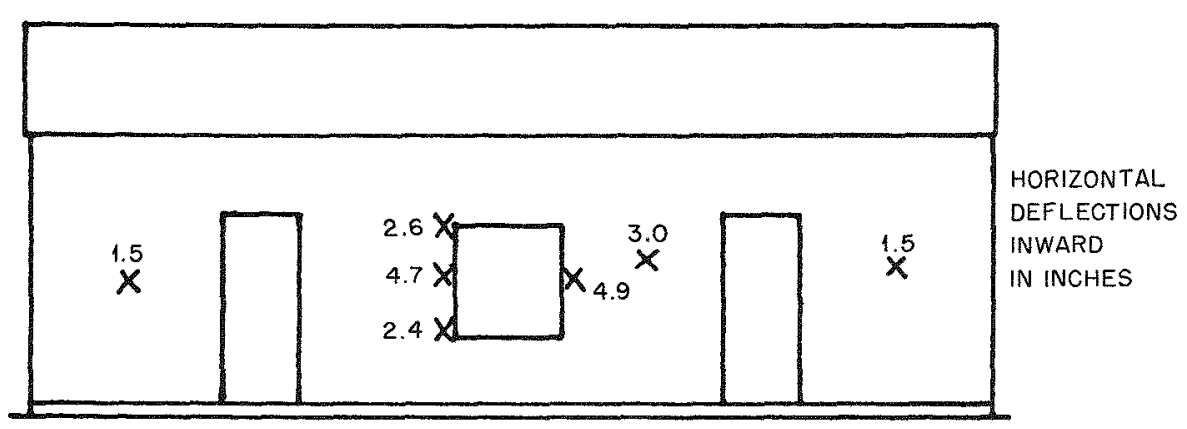

UNEXPECTED TEST

NORTH ELEVATION AT 6800 FT FROM PLANNED TEST

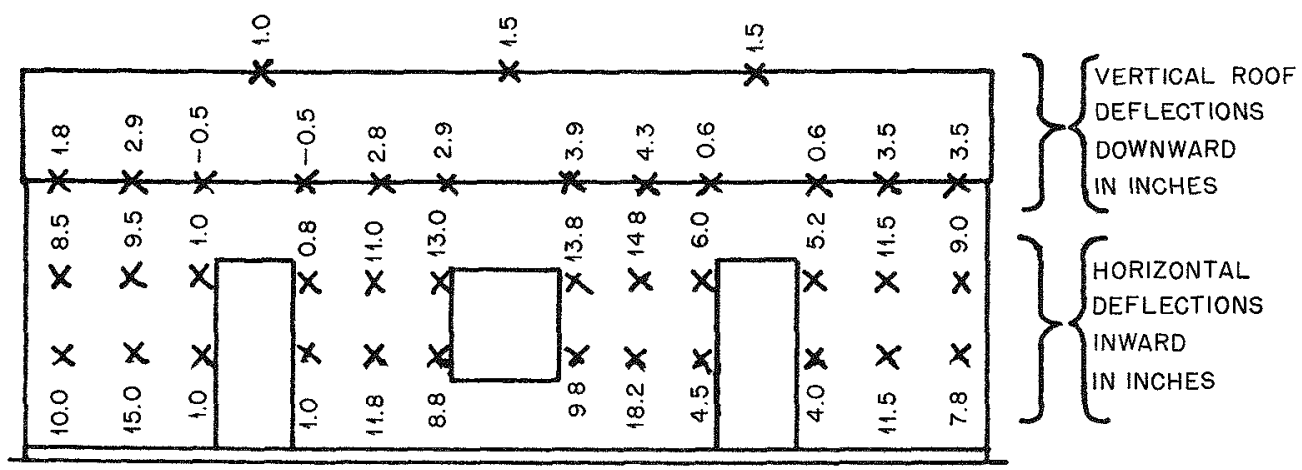

PLANNED TEST

NORTH ELEVATION AT $15,000 \mathrm{FT}$
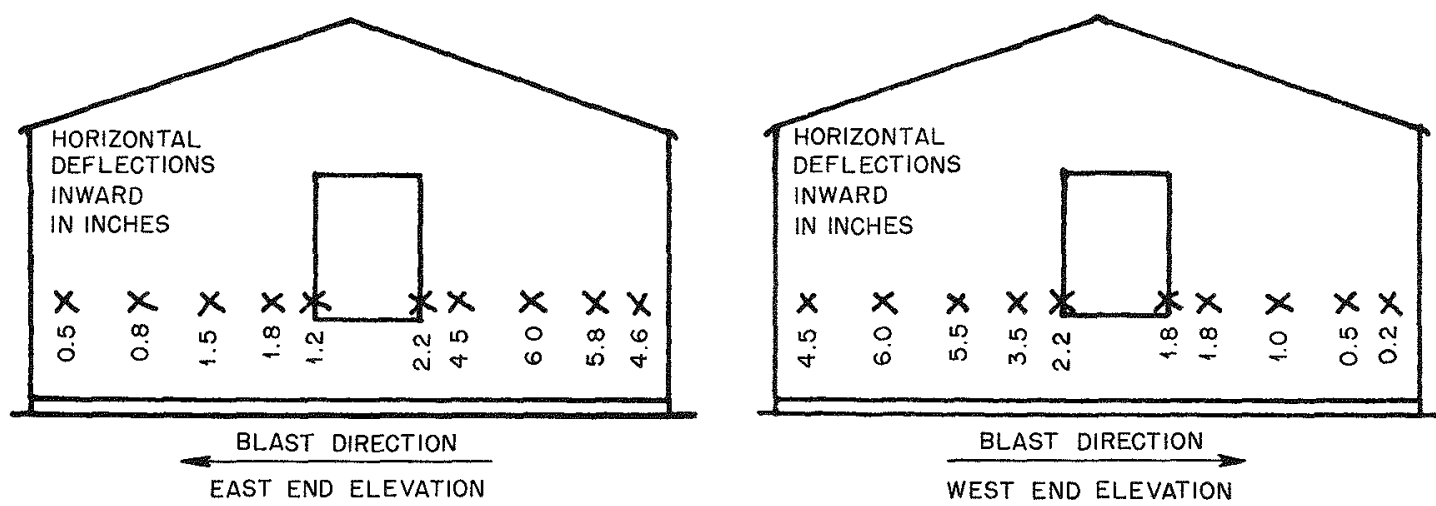

PLANNED TEST AT 45,000 FT

Fig. 2.7-Offet measurements of permanent wall and roof deflections in inches in Armco buildings that remained intact.

Aside from breakage of the lock on the front door, the only damage from the unexpected test to Behlen Building 31.2-b1 at $6800 \mathrm{ft}$ from the open shot tower was an apparent depression of the corrugation peaks, along the ridge line with respect to the ends, of a maximum amount of $1.25 \mathrm{in}$. as measured by offset at the center. This was not noticeable to the eye, but indications of displacement within the interior of the building confirmed the supposition that this was due to blast effects and not to construction.

Permanent deflections along the north side of Armco Building 31.2-d1 are shown in Fig. 2.6 and are recorded in Fig. 2.7. The first five wall panels on the east and nearest the blast origin were damaged to a lesser extent. Maximum permanent deflections of the north wall, amounting to 4.8 in., were measured adjacent to the north window. Figure 2.8 shows the local buckling on the inside of the north wall near the location of maximum deflection. This building, 


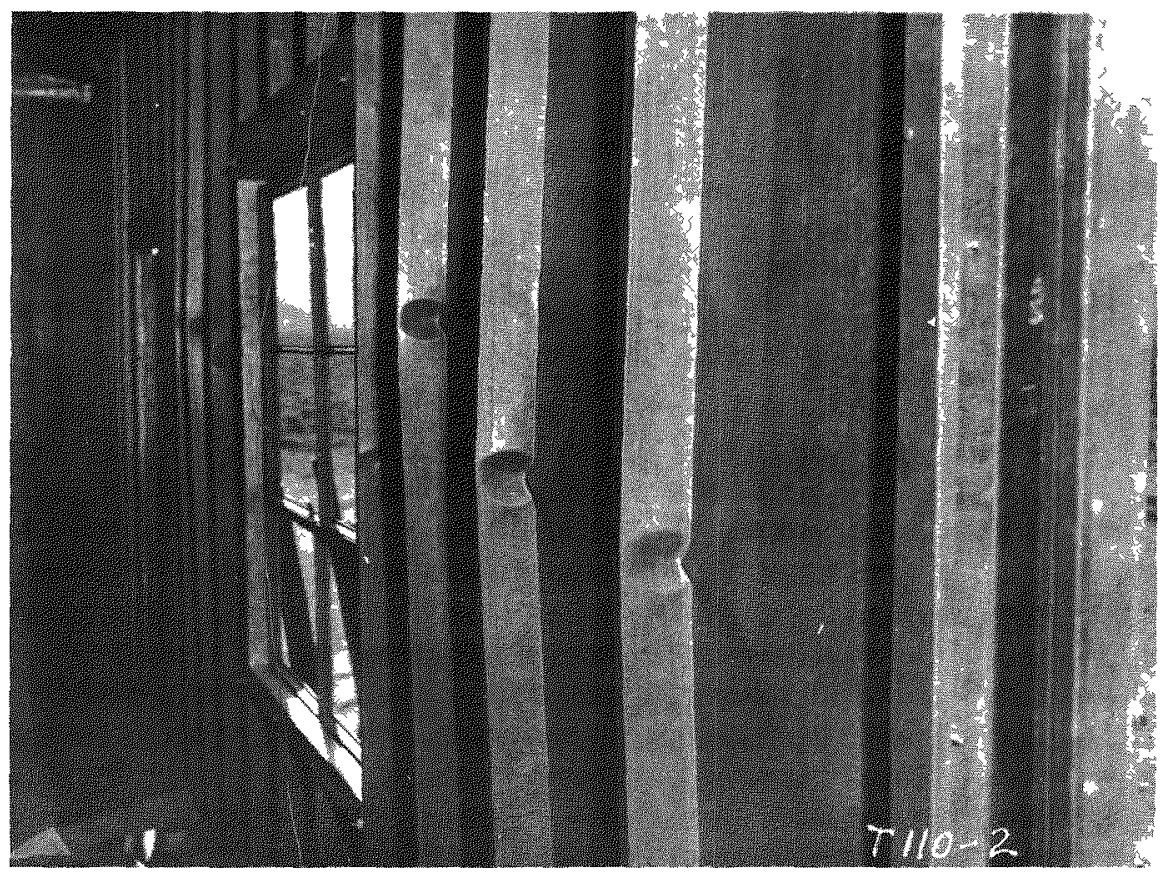

Fig. 2.8 - Interior view of damage to north wall of Armco Building 31.2-d1 from unexpected test.

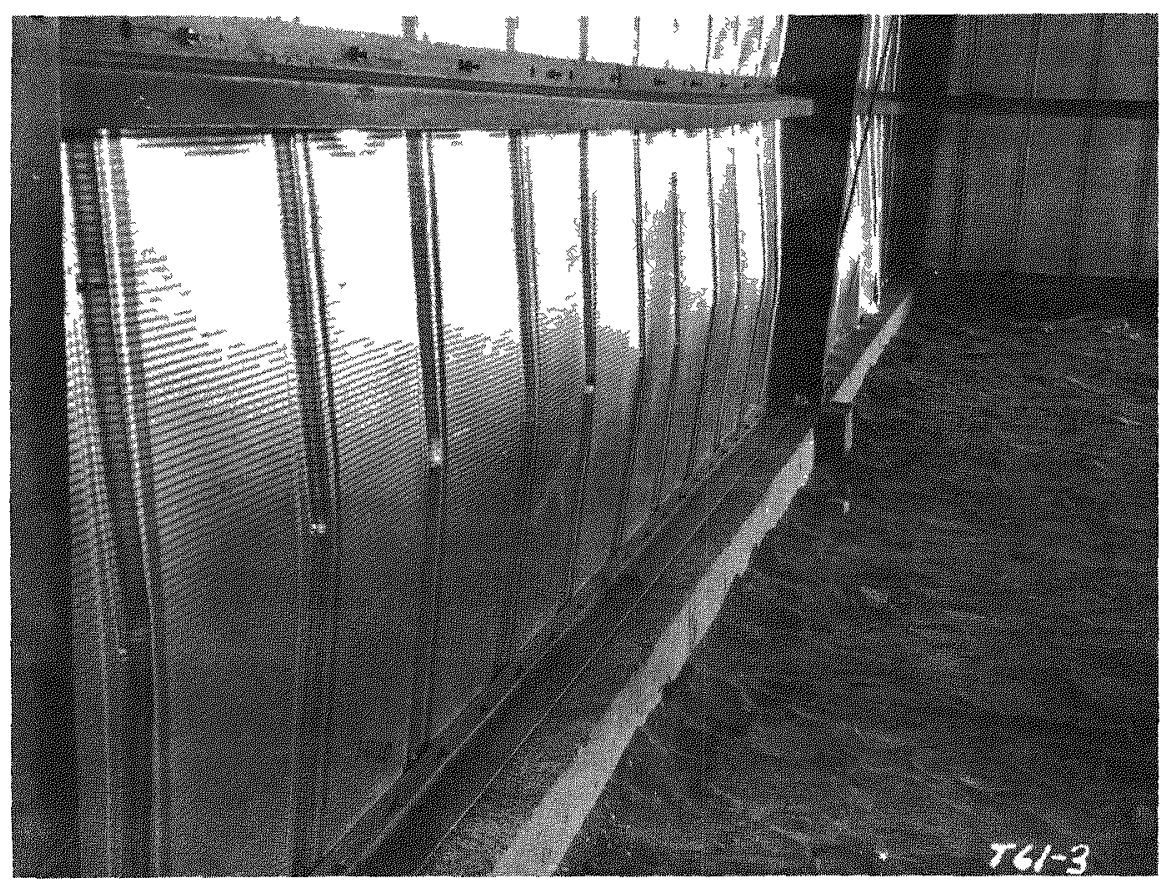

Fig. 2.9-Interior view of wall damage in Reynolds-Butler Building 31.2-a2 from unexpected test. 
after repair of the north wall damage, was previously illustrated in Fig. 1.22. Appendix B provides an analysis of the dynamic behavior of Building 31.2-d1.

\subsubsection{Damage from Unexpected Test to Buildings at 15,000 Ft from Planned Test}

The roof sheeting on Reynolds-Butler Building 31.2-a2 had not been placed, and the blast caused movement of both walls away from the blast origin, damaging both paneling and girts to a very minor extent. Deflections of the wall paneling on the north side amounted to as much as $2 \mathrm{in}$. in the lowest space, as shown in the interior view (Fig. 2.9). Washers had been installed properly with all bolts, and no bolts pulled through the sheeting on the north face, although two bolts with washers did pull through the south face sheeting due to the negative aspect of the behavior with an open roof.

There was no other damage from the unexpected test at the 15,000-ft line. Behlen Building 31.2-b2 and Armco Building 31.2-d2 had not been constructed.

\subsubsection{Repair of Damage from Unexpected Test}

All wall panels on the north and south faces of Reynolds-Butler Building 31.2-a1, together with eight damaged girts, were replaced. Several damaged panels on the east end were allowed to remain in place since they had retained fully their original strength. All the first course of roof sheeting on the north side, next to the eaves, was replaced.

All the damaged wall panels in Armco Building 31.2-d1 were replaced. Reinforcing channels were also installed adjacent to all window and door frames in both Armco Buildings 31.2$\mathrm{d} 1$ and 31.2-d2, thus rendering these buildings somewhat stronger with respect to bending of walls at these points of weakness.

Reynolds-Butler Building 31.2-a2, at 15,000 ft, was repaired by replacing damaged wall girts on both the south and north sides and by replacing all wall panels on the north side only.

\subsection{RESULTS OF PLANNED TEST}

\subsubsection{General}

The following description of the details of the damage resulting from the planned test is based on a visual inspection of each structure, dimensional measurements before and after the shot, field notes, and numerous photographs, many of the latter being included as a part of this report. Photographs of items subject to possible disturbance were made between $\mathrm{H}+3$ and $\mathrm{H}+5 \mathrm{hr}$ on $\mathrm{D}$-day; other photographs were made on $\mathrm{D}+1$ day, and some details were photographed on $D+4$ days.

Reference should be made to the appendixes for dynamic analyses relating pressure-time information to damage calculations.

\subsubsection{Damage to Union Carbide Building 31.2-e1}

In general, Building 31.2-e1 was damaged only slightly, except for the plastic windows and the standard steel industrial type door. The window facing the blast was destroyed (Fig. 2.10), and the window away from the blast suffered limited damage (Fig. 2.11). Both steel door panels were forced inward and bent considerably. One of the panels is shown on the floor in Fig. 2.12.

A mannequin standing erect in the center of the building was still erect and virtually unharmed after the blast, as shown in Fig. 2.13. The stylus points of three of the four scribers were destroyed, but general indications were obtained as to movements of structural members.

The structural-steel frames showed no damage due to the blast, except for torsional deflections in the roof girders. The bottom flanges of these girders received a permanent deformation of approximately $1 / 4$ in. toward the outside of the building. No permanent vertical deformation was observed.

Diagonal dimensions across the walls and roof, measured to saw cuts on the interior column flanges, were the same both before and after the blast, indicating no permanent horizontal deflection of the steel frame at the roof level. 
Severe vertical roof movements were indicated on scratchboards, and these movements are recorded in Fig, 2.14 at the one available location. No permanent deflections were recorded for any roof beams, except for the beam one panel from the south wall, which had a permanent upward deflection of $1 / 8 \mathrm{in}$. at the center of the beam.

None of the steel details or welded connections showed any serious indication of yielding or failure. Figure 2.15 shows the typical condition of a welded detail at the main frame connection after the test.

The reinforced-gypsum roof slab showed no sign of excessive stress or failure, except for a slight north-and-south crack in the bottom surface $5 \mathrm{ft}$ in from the west wall.

The reinforced-gypsum walls suffered only slight damage. The wall facing the blast (Fig. 1.3) showed moment cracks on the interior surface. These cracks were a maximum of $1 / 32$ in. in width, and they occurred in three of the panels formed by the vertical steel rail studs. The south wall, away from the blast center (Fig. 1.4), developed a horizontal crack approximately $1 / 16$ in. in width, starting near the southeast building column and extending across one-third of the bay. The east and west walls showed no moment cracks, but several shear cracks developed in the west wall at the top of the panels at roof level near the door opening, as shown in Figs. 1.6 and 2.16.

The general quality of construction for the gypsum walls was poor. They were not true, and there was evidence of patching. The exterior surface of the north wall was spalled excessively after the blast. A weak and patched surface structure may have been responsible, aggravated by exposure to the impact of small particles carried in the pressure wave behind the blast front. The Carbide \& Carbon Chemicals Co. had specified a minimum compressive strength of $1000 \mathrm{psi}$, and three tests of undamaged material subsequent to the blast test showed an average compressive strength of 830 psi.

The plastic window facing the blast was broken into pieces ranging from small fragments to those measuring about $3 \mathrm{ft}$ in length. The pieces were driven across the inside of the building to the far wall, where they fell to the floor. The plastic window away from the blast was left in place, except for the southeast corner, where a section approximately 18 in. square was torn out and fell outside the building. The adjacent $42-\mathrm{in}$. section was broken across the center of its span, but it remained in place.

The edges of the broken pieces of plastic exhibited a rough fibrous surface. From the appearance of the interior wall face against which they were thrown, it appeared that the plastic would not be so destructive as broken window glass.

During the blast the plastic panels were deflected to such an extent that the bolt holes were pulled through at the edges. In some few cases the corrugated filler pieces held the plastic firm, and failure occurred by shear. The foundations received no damage from the blast.

The instrumentation to scribe the motions of girts, columns, girders, and roof beams on scratchboards of plywood was deficient because all the pencil styluses were broken, except the one at the southeast corner column. Nevertheless, movement of the frame was indicated approximately by the steadying surfaces of the stylus pipe arms.

The approximate movements at the stylus points were as follows:

1. Horizontal girt in north wall: torsion and horizontal deflections, as shown in Fig. 2.14.

2. Roof girder at east wall: torsion in the girder, as shown by the impact mark on the scratchboard by the stylus pipe arm.

3. Roof beam, just north of center line: vertical displacement coupled with some torsional movement, as shown in Fig. 2.14.

4. Column in southeast corner (near girder): displacement approximately $1 / 4$ in. in north and south directions.

A child mannequin was supported in an upright position near the center of the building about $5 \mathrm{ft}$ in from the east wall. The mannequin remained upright during the blast and received only two slight abrasions on the face.

Three standard two-cell flashlights were placed inside the building, one on a wood sawhorse along the east wall, one on the floor near the south wall, and one hanging on the center scratchboard. The first two flashlights were found on the floor near their original locations, the third was still hanging on the scratchboard. They were undamaged and completely operable.

The trajectory of the window pieces from the north wall appeared to be downward. Although there were indications that small particles had struck the south wall window, most 


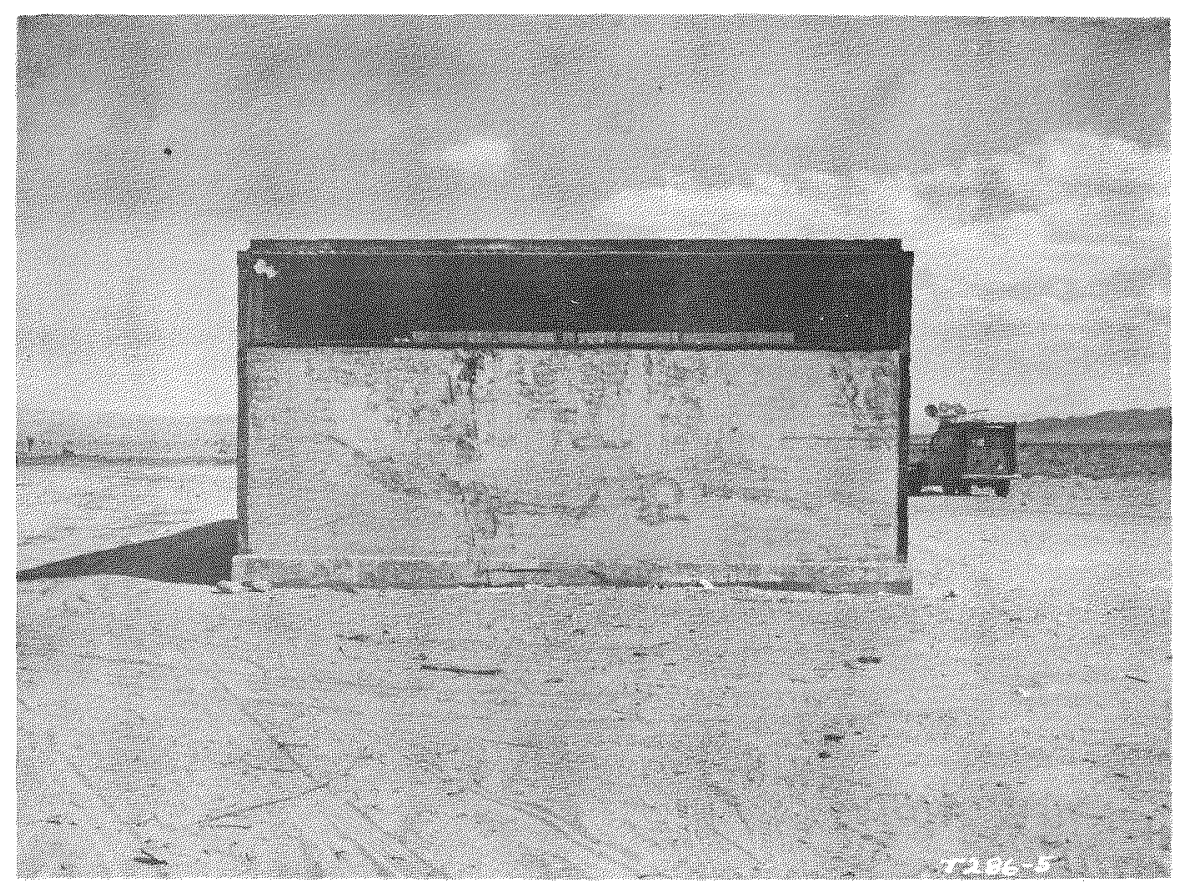

Fig. 2.10- North wall of Union Carbide building after planned test.

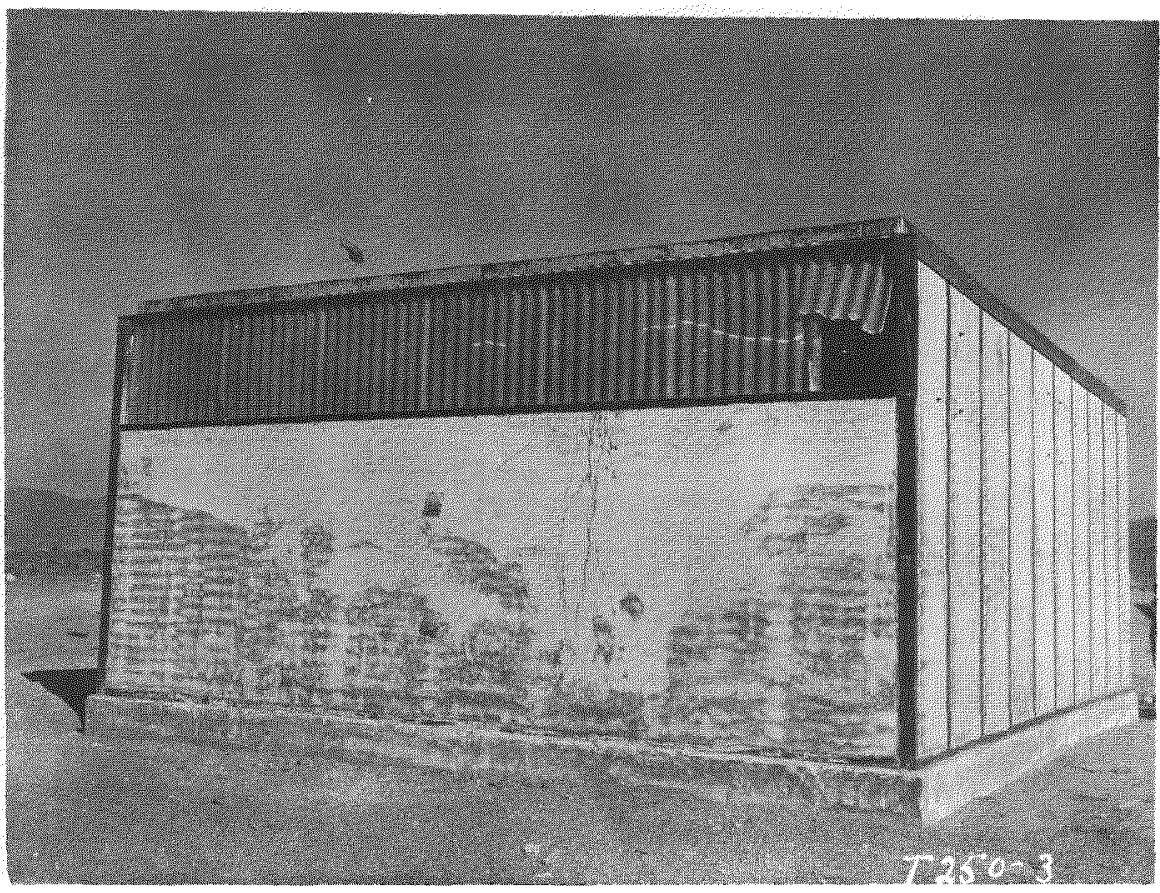

Fig. 2.11 - South wall of Union Carbide building after planned test. 


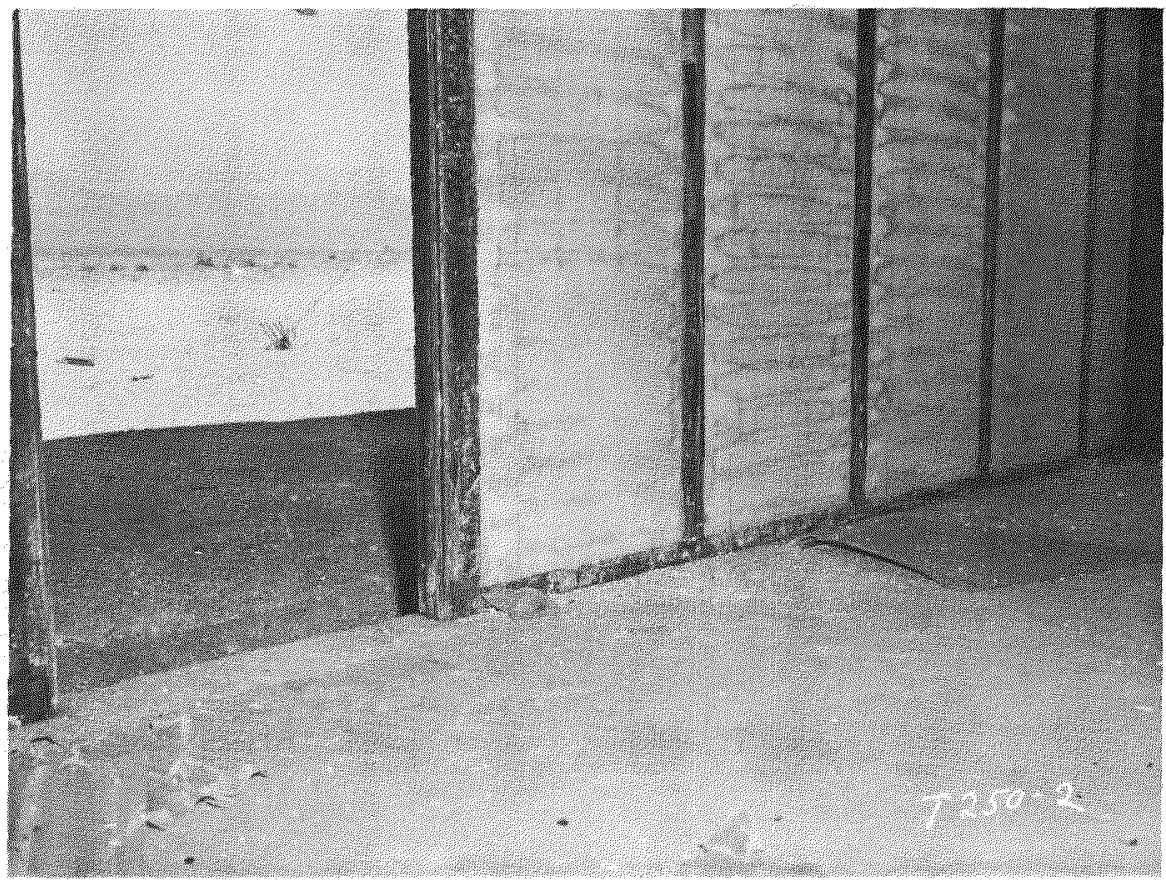

Fig. 2.12-Interior view looking out doorway of Union Carbide building after planned test.

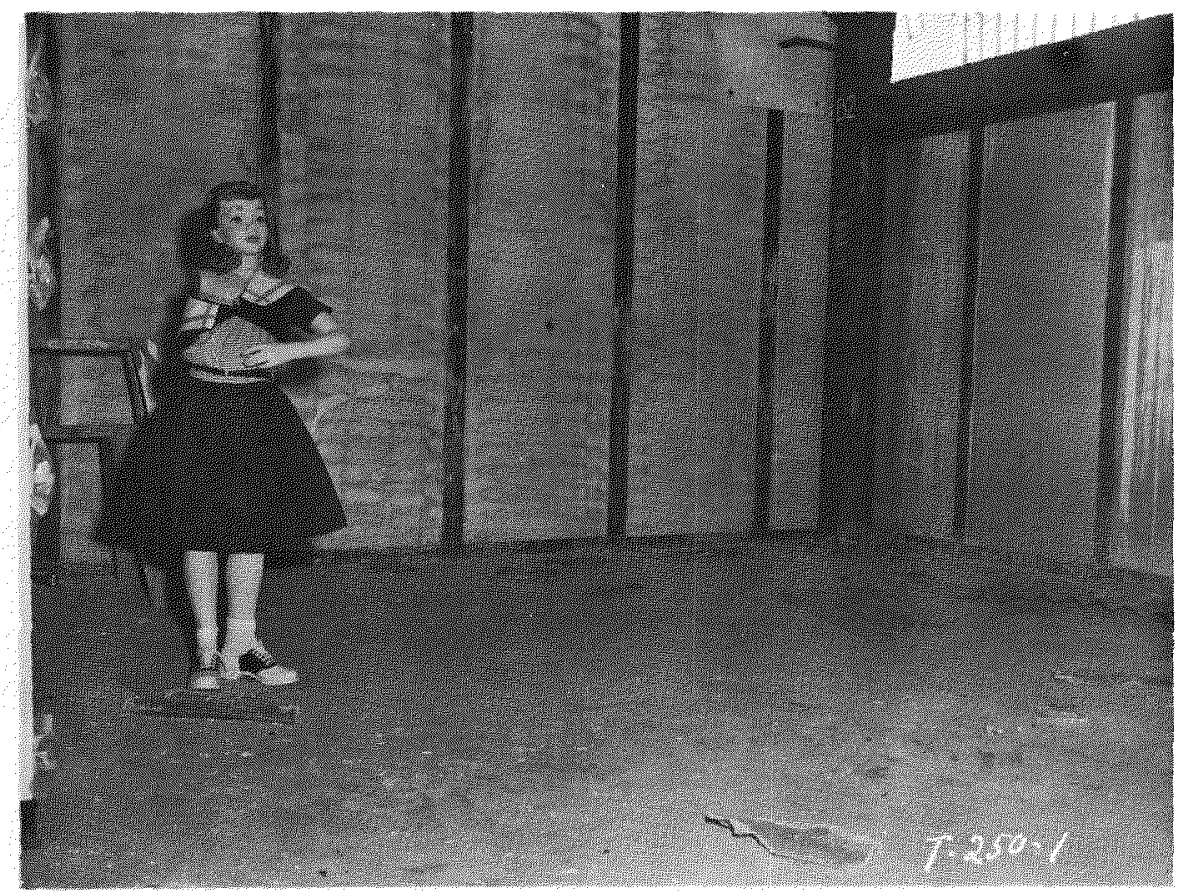

Fig. 2.13 - Interior view of southeast corner of Union Carbide building after planned test. 
Second roof purlin from north wall

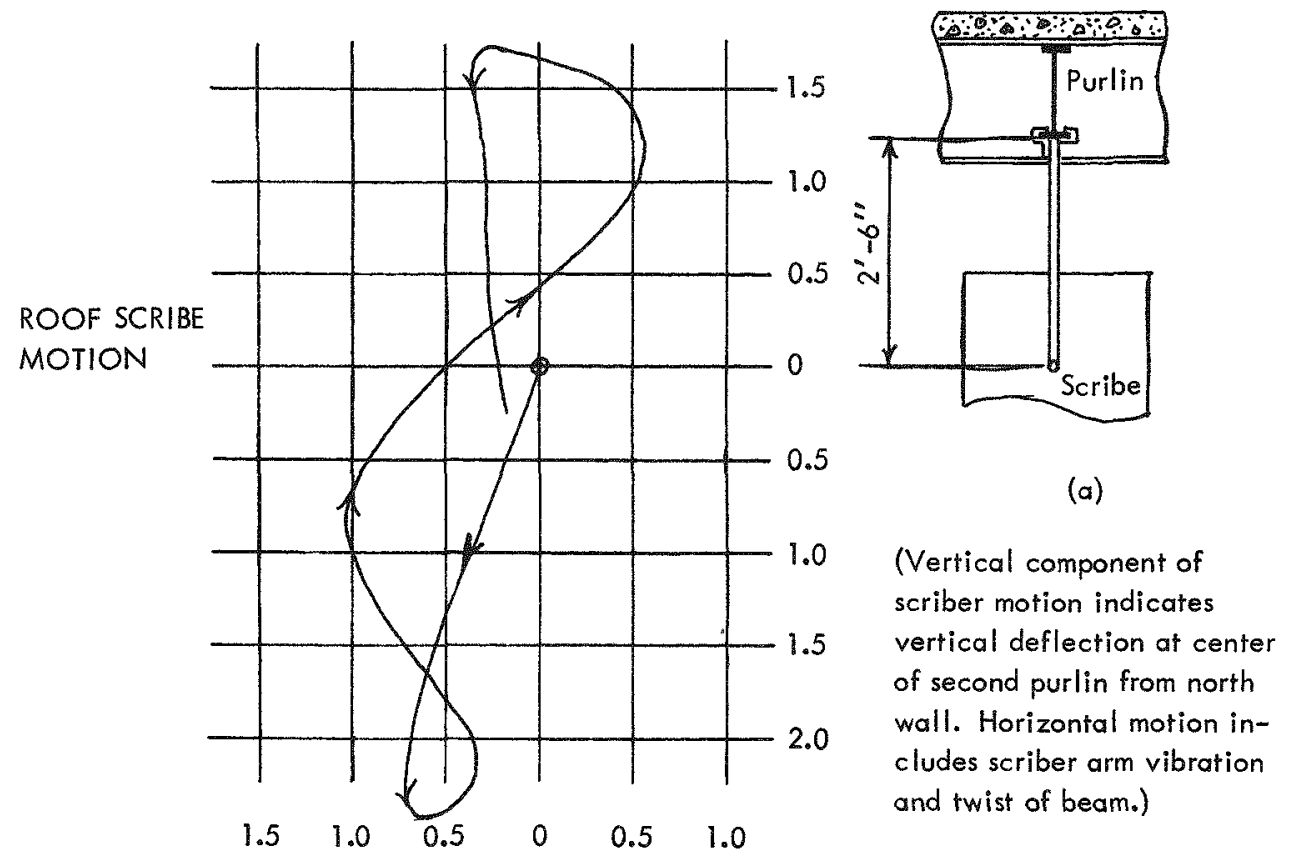

SCRIBE MOTION SHOWN FULL SCALE-

NUMBERS INDICATE INCHES FROM INITIAL LOCATION

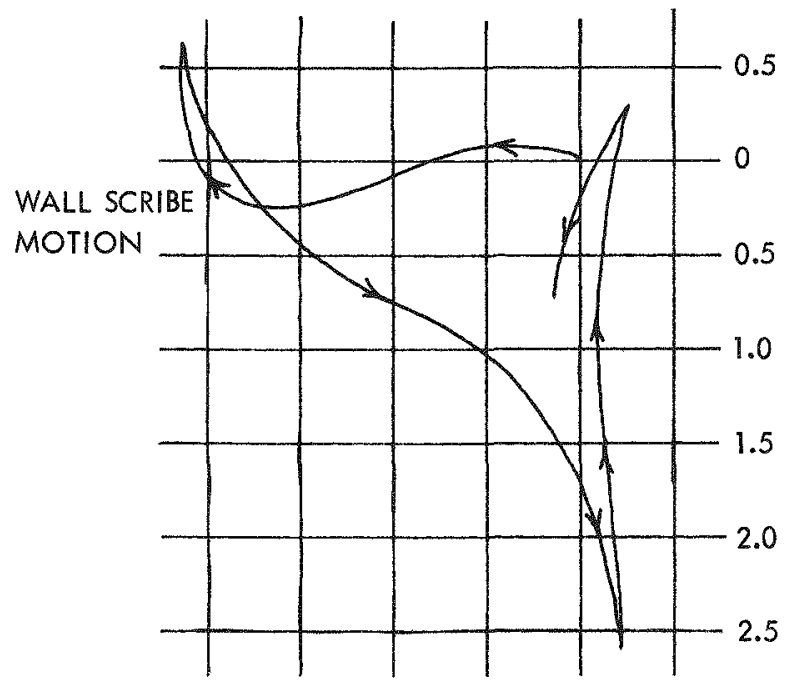

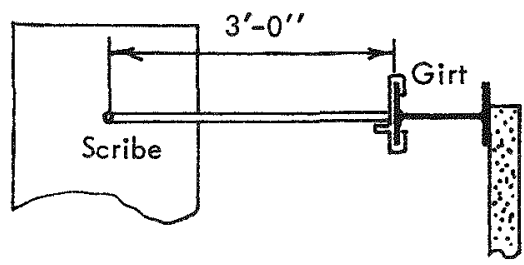

(b)

(Horizontal component of scriber motion indicates horizontal deflection of girt center just below north wall sill of window. Vertical motion of scriber includes scriber arm vibration and twist of girt.)

Fig. 2.14-Deflections of roof and north wall in Union Carbide building during planned test. 


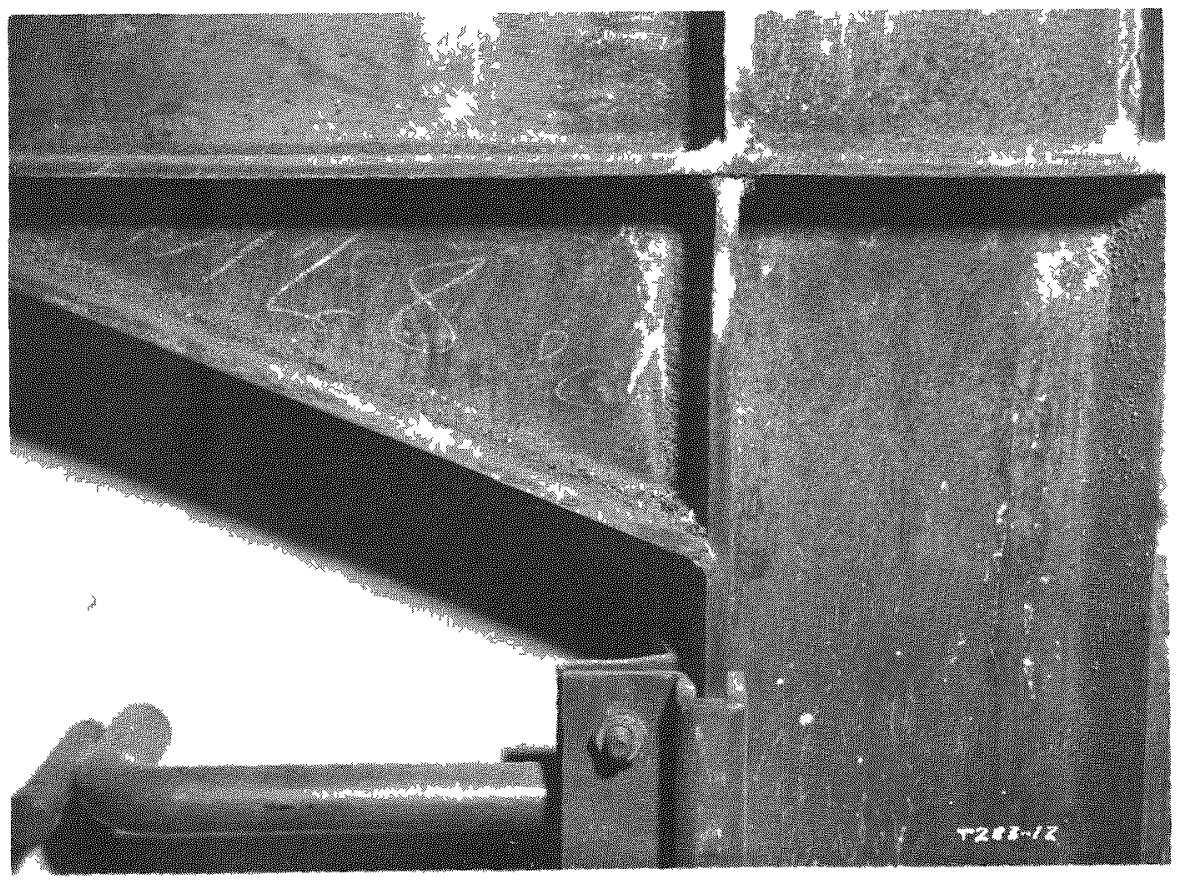

Fig. 2.15-Southeast comer frame connection of Union Carbide building.

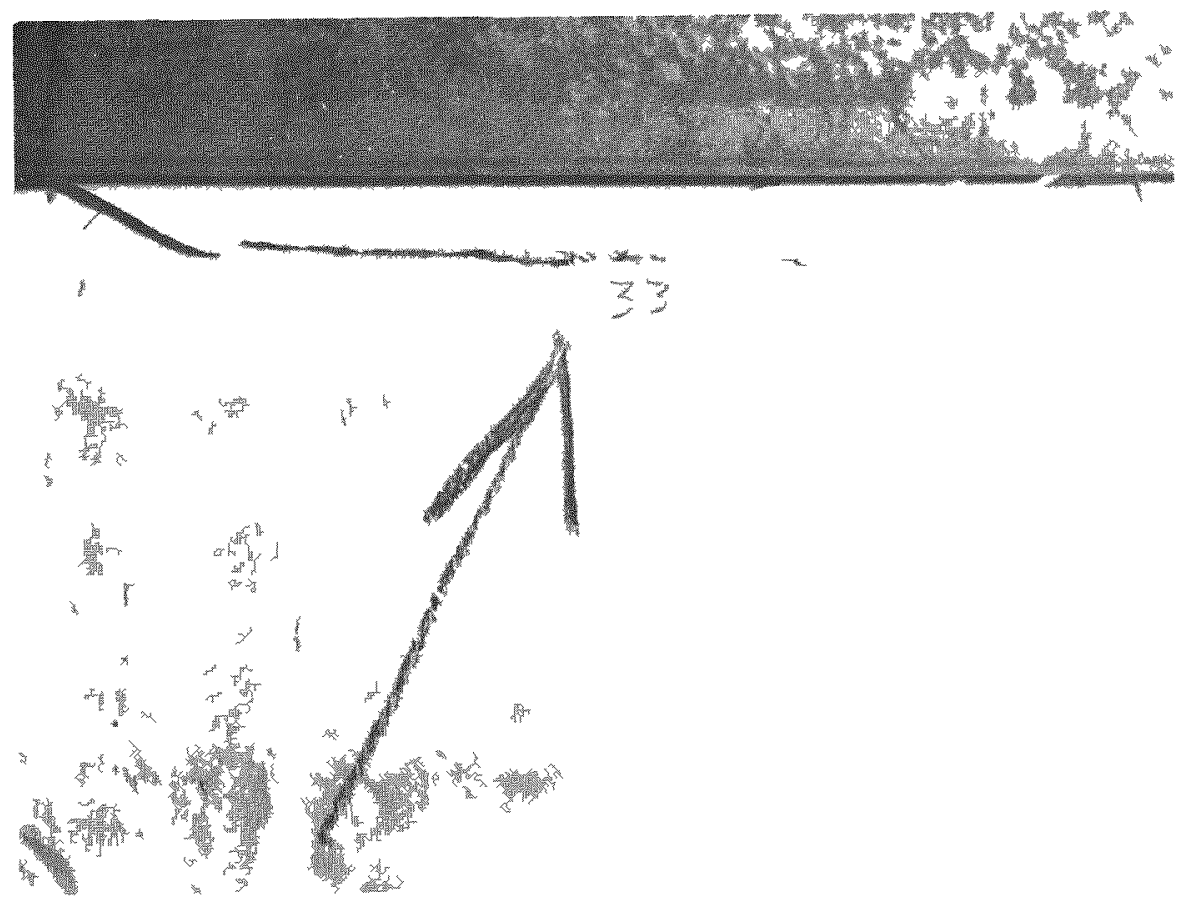

Fig. 2.16 - Shear crack at top of west wall north of Union Carbide bulding. 
marks were made on the gypsum portion of the south wall. The portion of the south window that was broken outward could have been damaged by a piece of the north window. The marks left by the plastic pieces were not sharp and penetrating.

Since there appeared to have been no movement or damage to the building foundation, it was assumed that the underground electrical conduit and cast-iron drain line were intact. This was also verified by feeling by hand through the openings in the floor slab where these services were brought up through the slab.

\subsubsection{Damage to Reynolds Metals Co.-Butler Building 31.2-a1}

This structure, at $6800 \mathrm{ft}$ from $\mathrm{GZ}$, was very severely damaged, especially with respect to the wall covering and wall support details. The wall and column footings remained intact. The four continuous-welded and bolted main frames of the structure had permanent deflections at the north eaves, away from blast origin, ranging from $5 \mathrm{in}$. at the east end to $9 \mathrm{in}$. at the west end. The same frames had somewhat less permanent deflection along the south eave lines, varying from about $4 \mathrm{in}$. at the east end to $7 \mathrm{in}$. at the west end.

In addition, the two end frames at the north corners were bowed laterally inward, a distance of about $11 \mathrm{in}$. at each end, toward the center of the building. This inward deflection is quite noticeable in the general view of the north side, as shown in Fig. 2.17. The unbalanced tension in the girts at the ends, as well as the inward pressure, was undoubtedly a factor contributing to this inward movement. In addition, the girts showed evidence of having hung on the corner columns longer than on the interior columns, thus exerting a twisting and pulling action accentuated by drag on the crumpled mass of sheeting that remained attached to these girts.

The columns, as a result of biaxial bending inward, experienced fractures at the bolt holes at the level of the lower girts. The local bent, twisted, buckled, and fractured condition at these details is shown in Figs. 2.18 and 2.19 for the northeast and northwest columns, respectively.

From the base of the wall sill to the ridge of the roof, the wall or roof paneling in each of the three spaces between bents was supported successively by a sill angle, two $\mathrm{Z}$ girts, a channel eave member, and four $\mathrm{Z}$ purlins, as shown in Fig. 1.11. Along the north wall the sill angles originally attached to the wall footing by three bolts were all torn loose from their center bolts, and at the east end the sill angle remained attached to the west bolt only. Figure 2.20 shows one of the bent and twisted sill angles and also illustrates how the paneling was torn completely loose from its bolt and washer fasteners.

Of the six girts on the north wall of the building, five were torn off at the ends in the manner shown in Fig. 2.21. The upper girt at the west end remained attached to the corner column, providing the hinge about which the two girts and the crumpled mass of sheeting swung inward toward the west end of the building, as illustrated in Fig. 2.22. Of the three north wall eave members, each was torn loose at one end and remained attached at the other end. The east eave strut was bent into a $\mathrm{V}$ shape with about a $3-\mathrm{ft}$ center deflection. The west end of the center eave strut, after tearing loose, swung down to the ground.

The purlins on the north slope of the roof will be discussed in groups of four each, in the east, center, and west bent spaces, respectively. Figure 2.23, a view looking up at the east space, shows the purlins still attached to the frames at each end, but with their ends crippled and the purlins twisted and bent, especially in the case of the two nearest the eave member. Figure 2.24 is a closer view of the end crippling of these purlins. Roof sheeting was still attached to the ridge purlin and the adjacent purlin, but the sheeting was torn loose from the two lower purlins. In the north central space the purlin nearest the eave member was torn loose at the west end, coming to rest on the ground along with the eave member, but the three upper purlins were still hanging to their bolted end connections with the roof sheeting draped loosely over them, attached only to the ridge purlins. In the west space the two central purlins were torn loose from their east connections, but they were prevented from falling by the wind-bracing rods in the plane of the roof, as shown in Fig. 2.25.

On the south wall the sheeting was all detached from girt fasteners, except for two segments that remained hanging along their top attachment to the eave members (Fig. 2.26). All the girts on the south side remained attached at their end connections to the main frames, as 


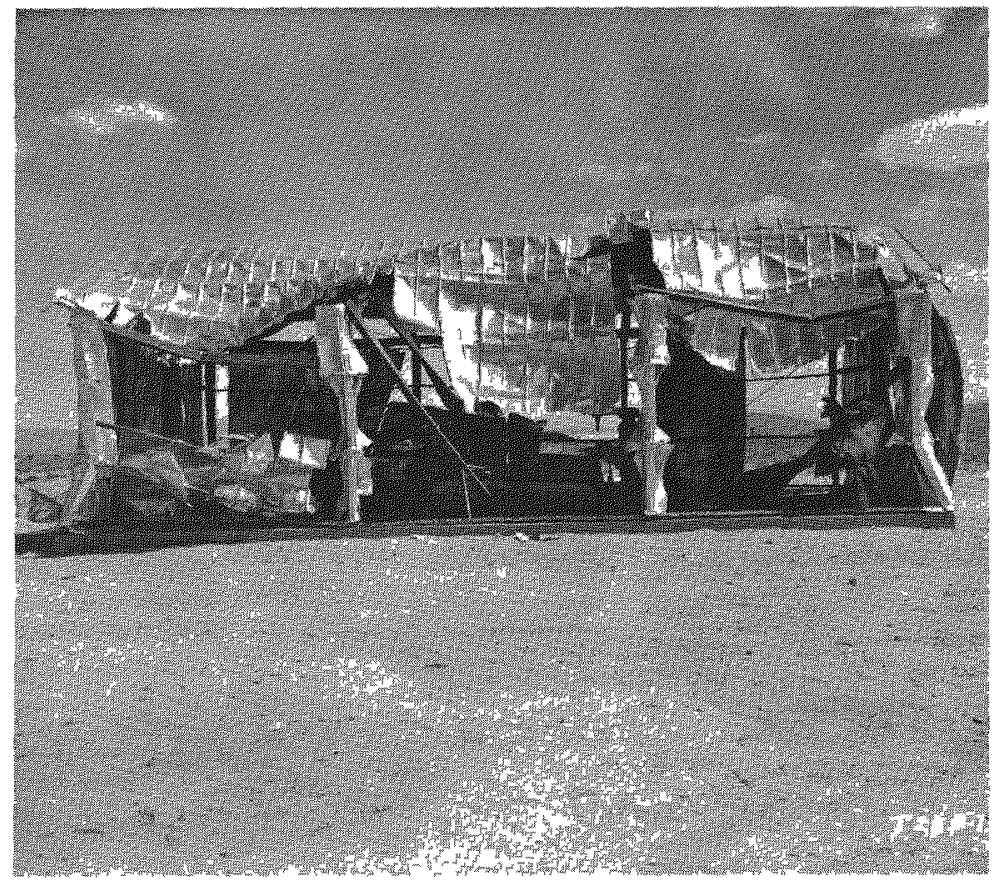

Fig. 2.17-North side of Reynolds-Butler Building 31.2-21 after planned test.

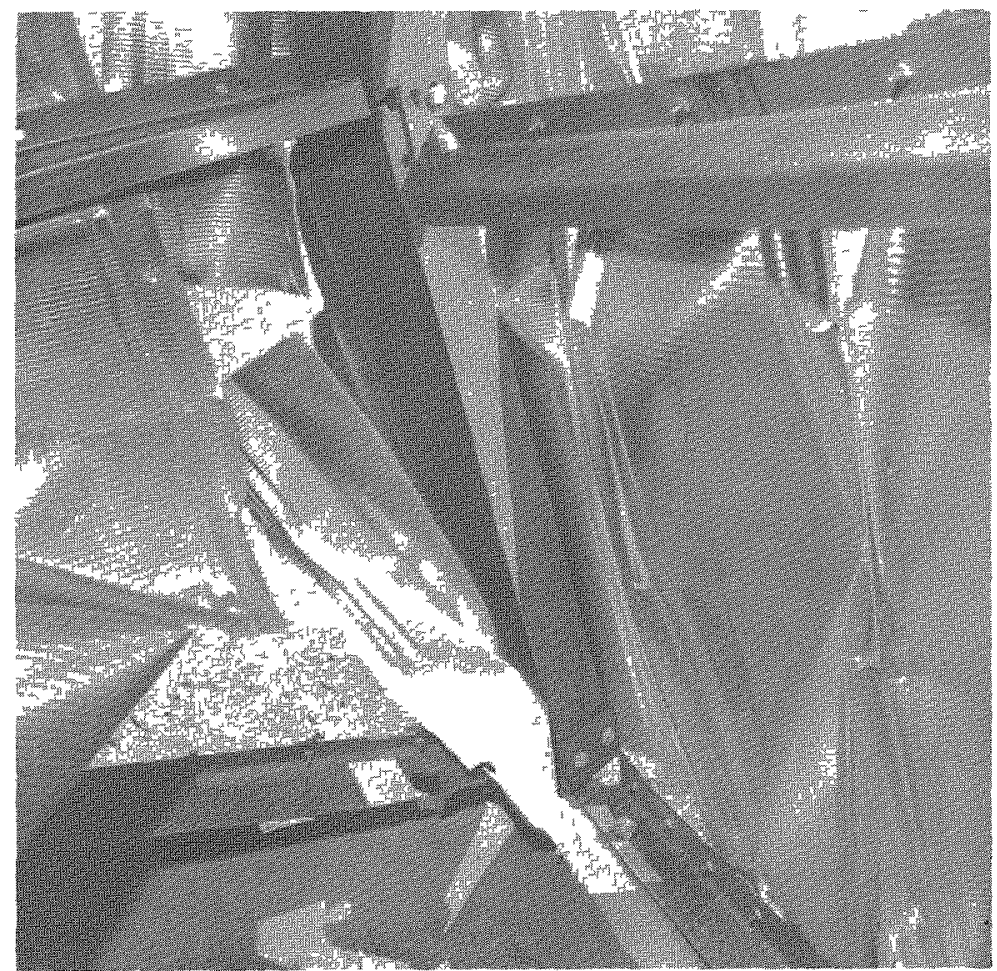

Fig. 2.18-Interior detail of northeast column in Reynolds-Butler Building 31.2-21 after planned test. 


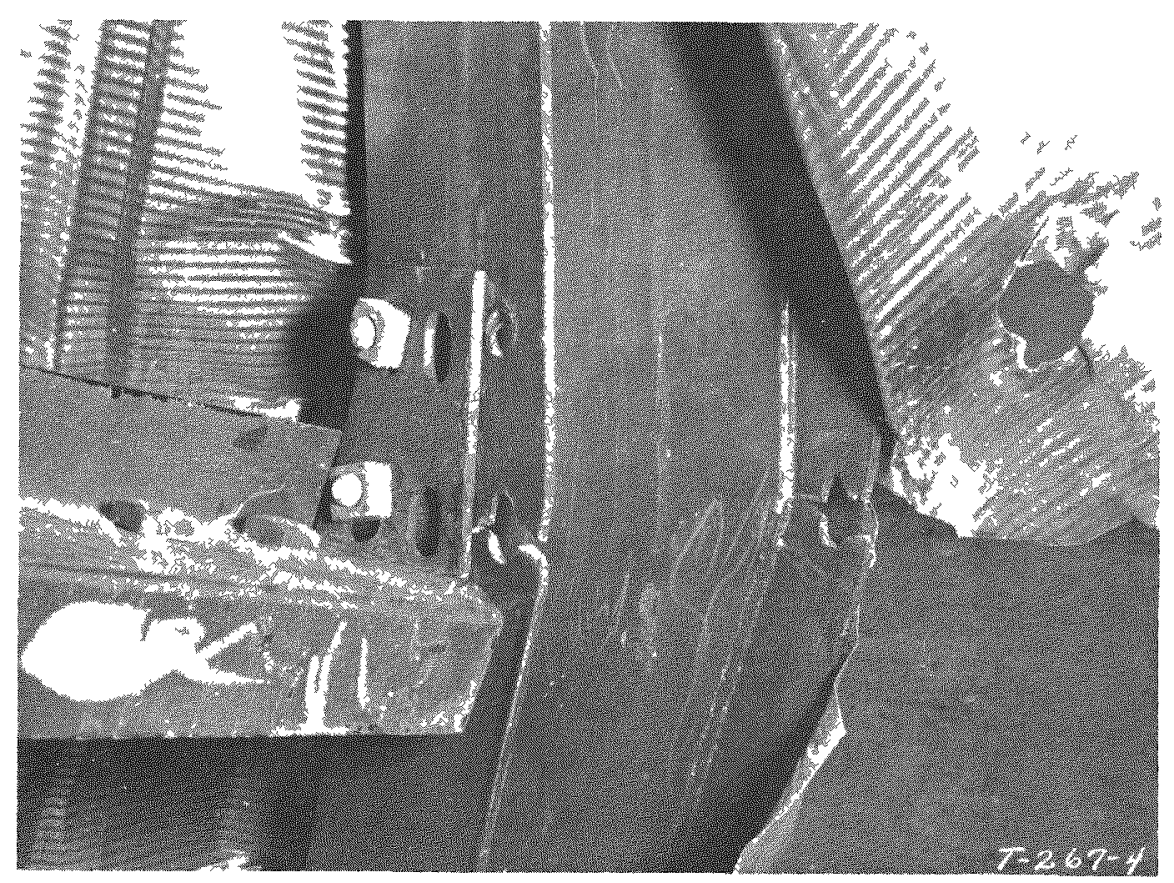

Fig. 2.19-Interior detall of northwest column un Reynolds-Butler Bunldng 31.2-a1 after planned test.

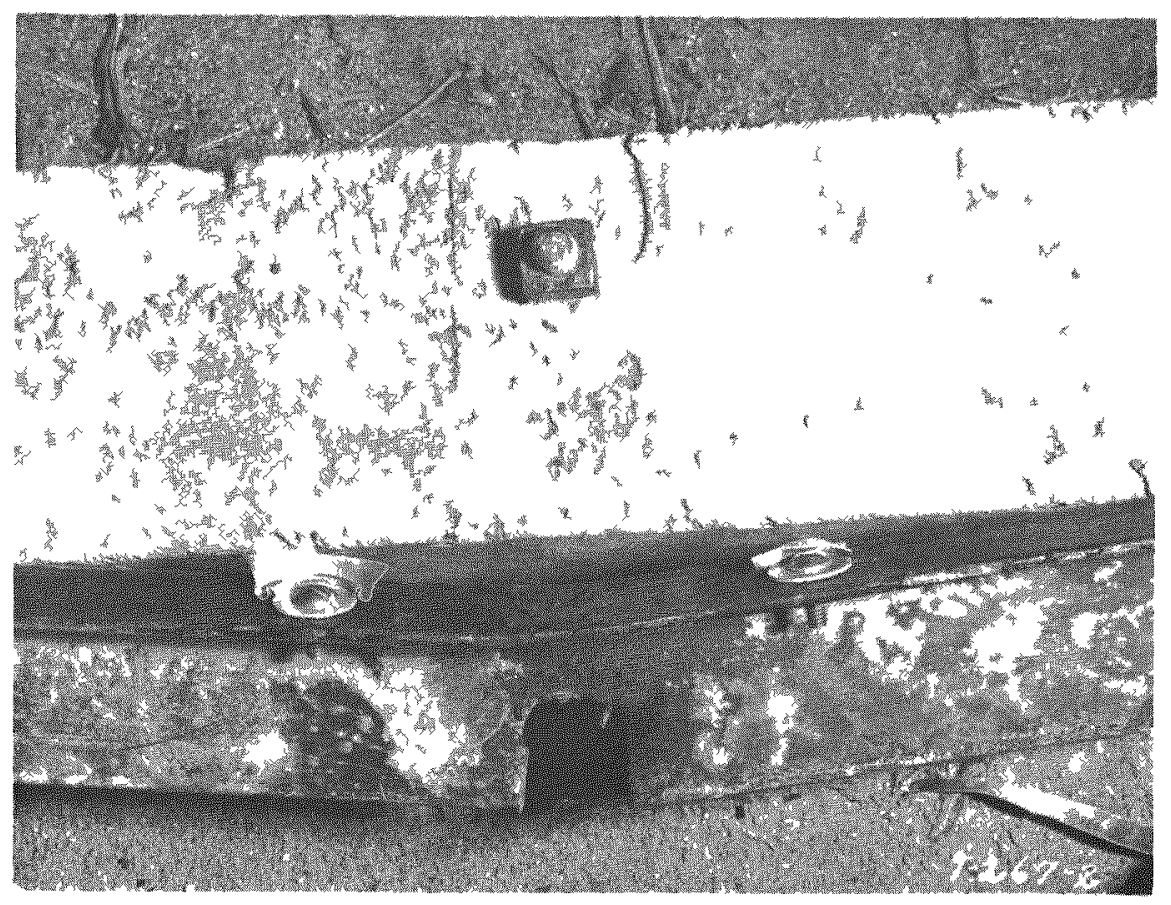

Fig. 2.20-View looking down on sill angle in Reynolds-Butler Bulding 31.2-a1 after planned test. 


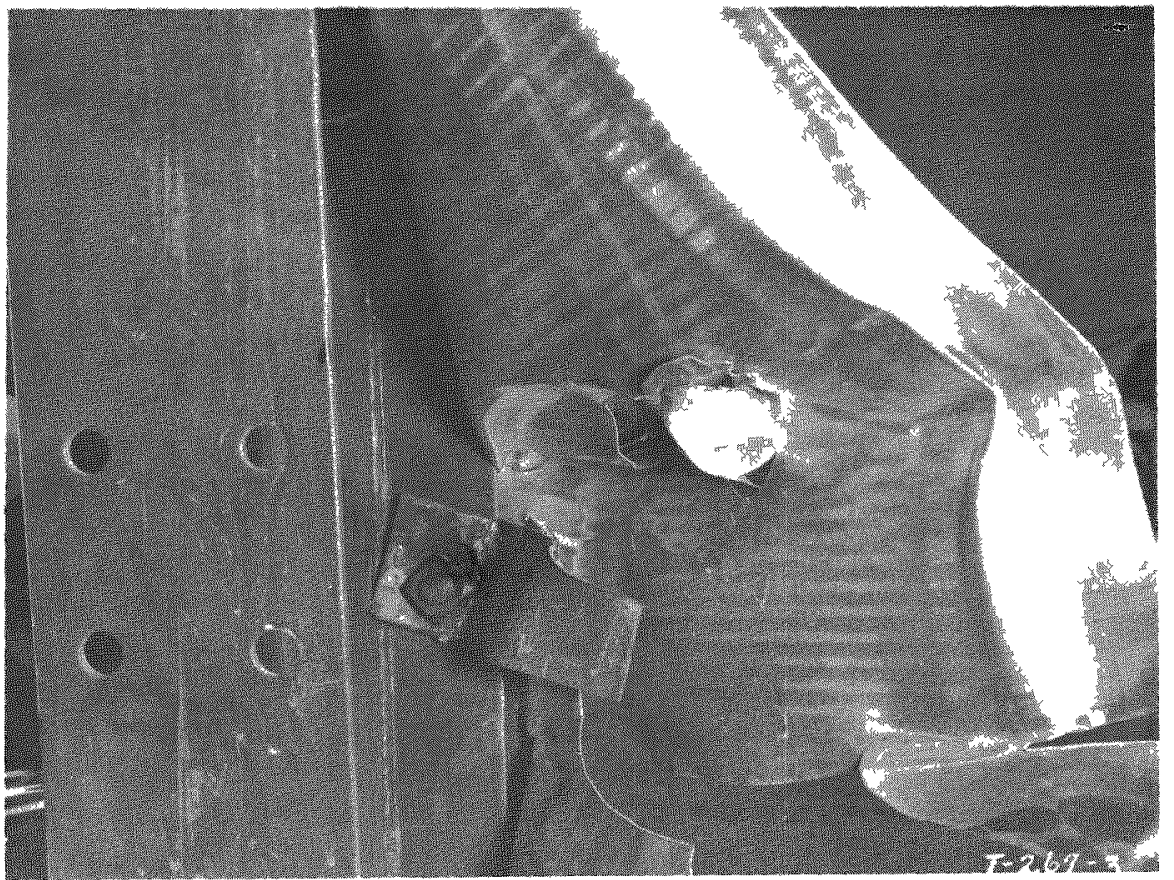

Fig. 2.21 - Interior detail of torn girt connector north of Reynolds-Butler Bullding 31.2-a1 after planned test.

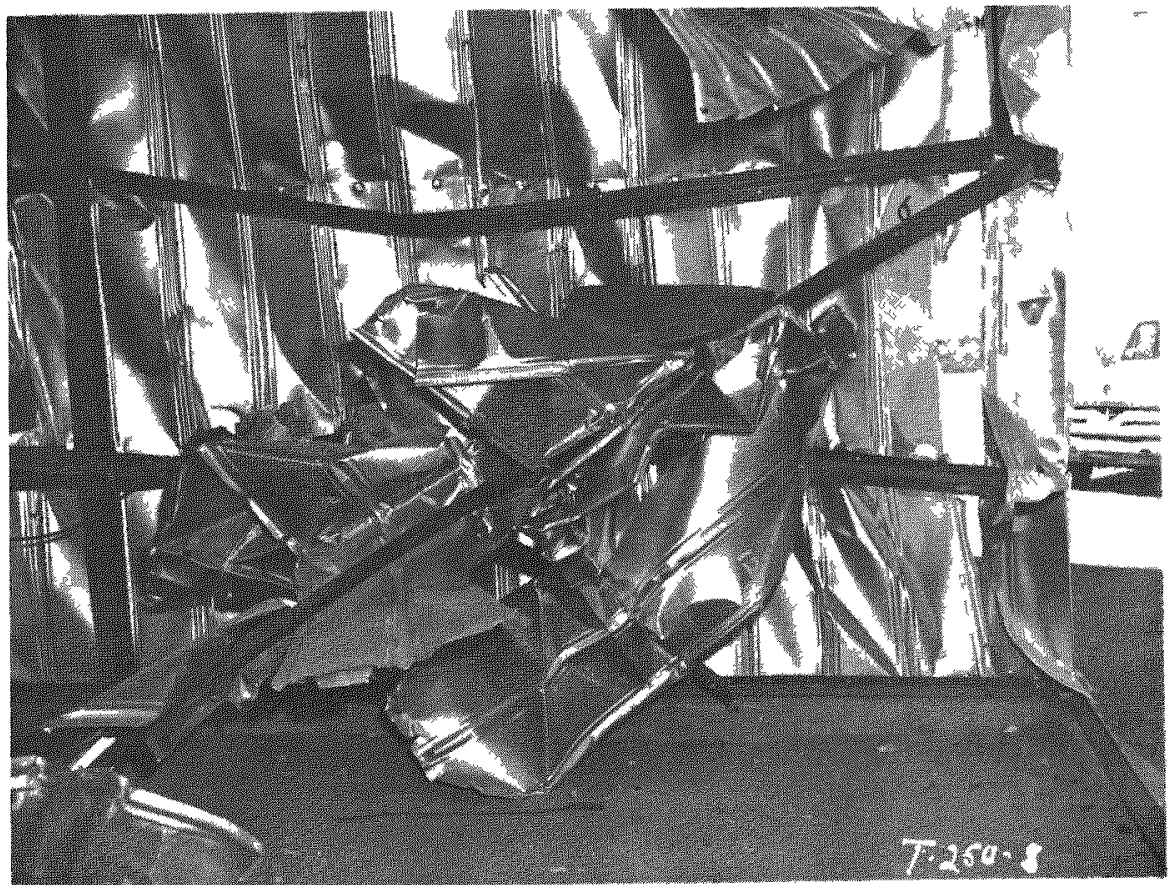

Fig. 2.22-Interior view of Reynolds-Butler Bulding 31.2-a1 after planned test. (Note that west girts and panels of north wall have been thrown against west end.) 


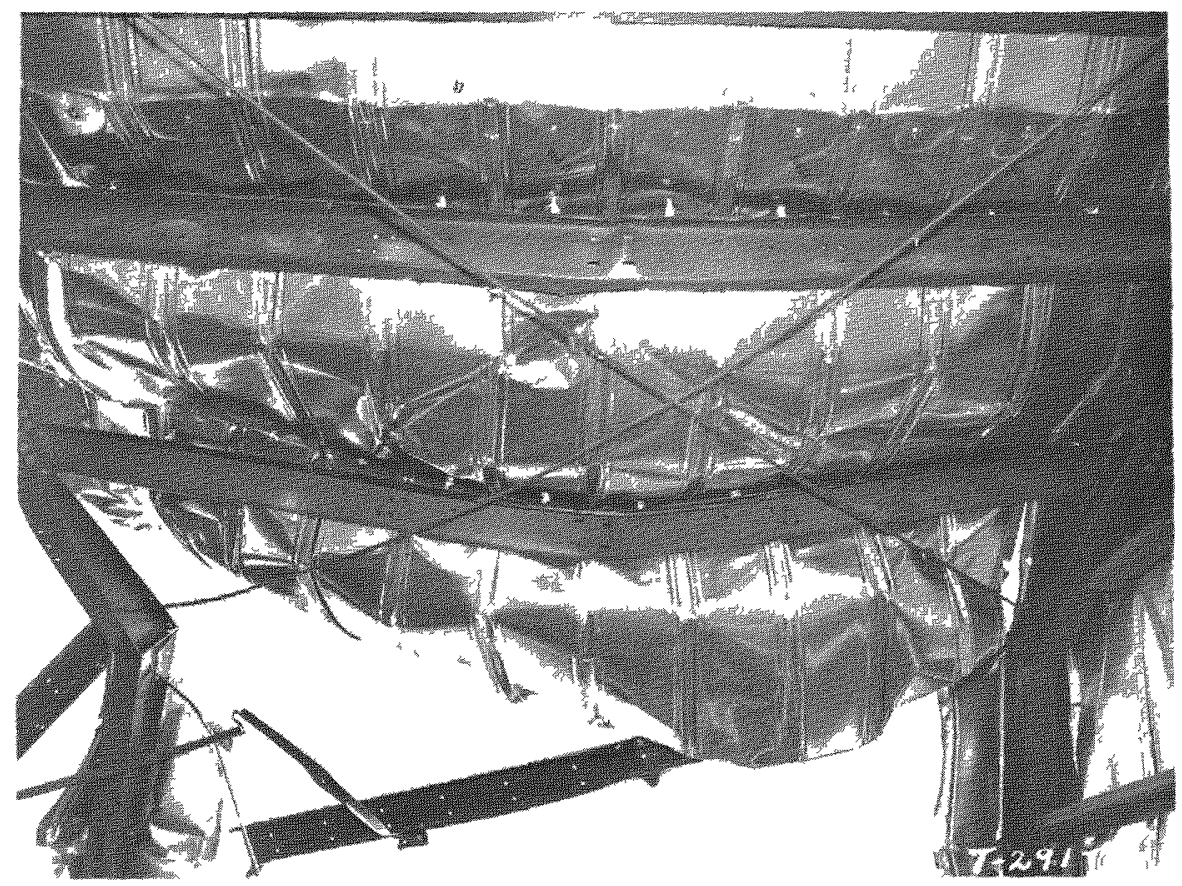

Fig. 2.23-Roof purlins at northeast comer of Reynolds-Butler Building 31.2-a1 after planned test.

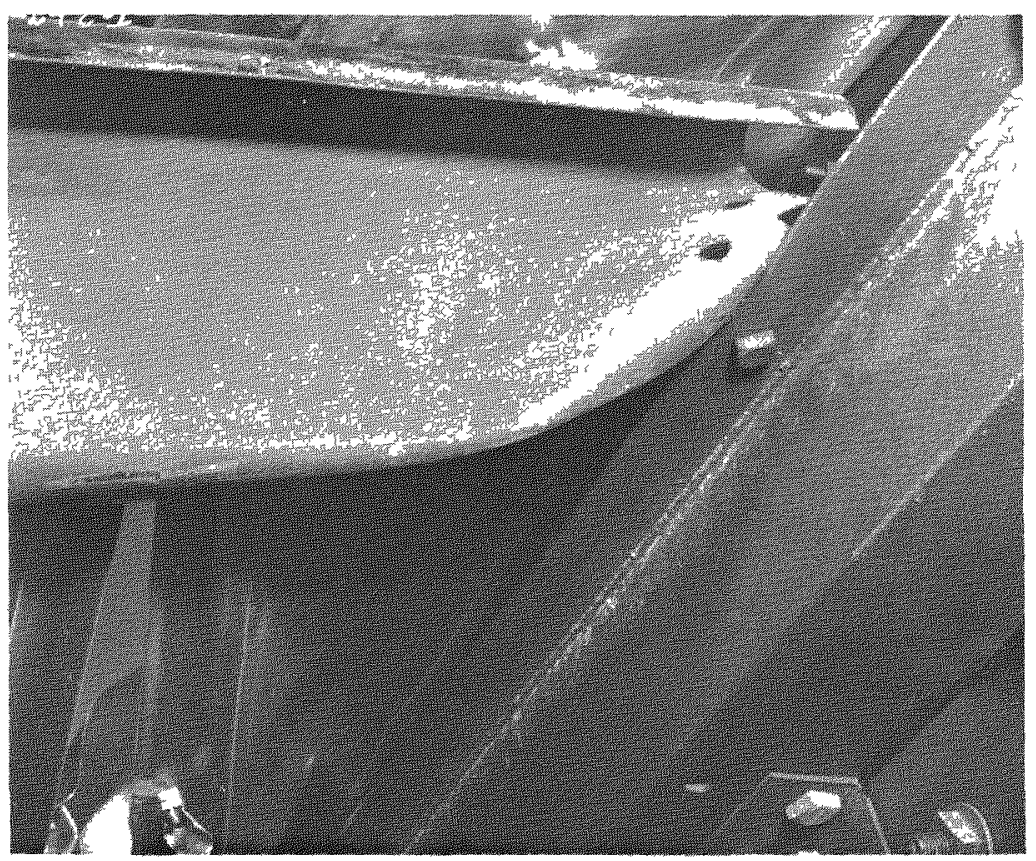

Fig. 2.24-End crippling of purlins at northeast corner of Reynolds-Butler Building $31.2-21$ after planned test. 


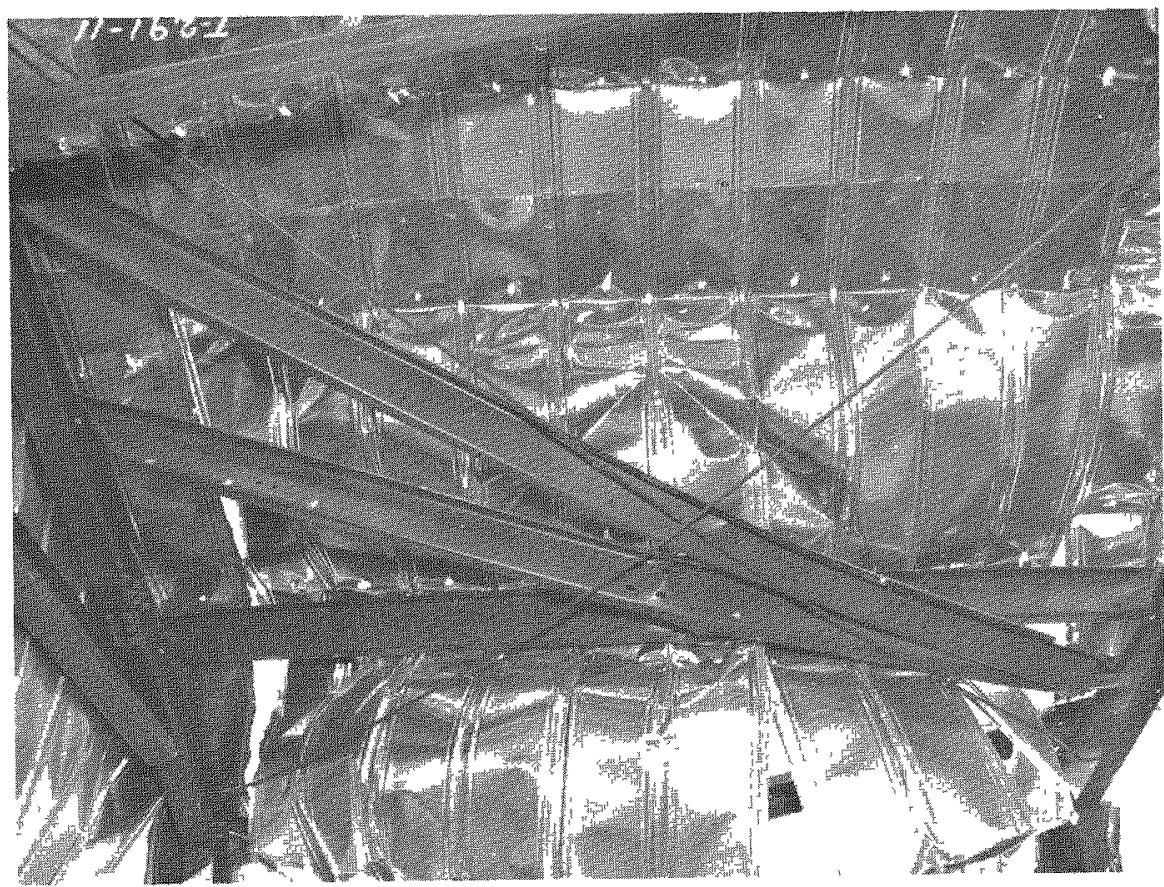

Fig. 2.25-Underside of roof at northwest conner of Reynolds-Butler Building 31.2-a1 after planned test.

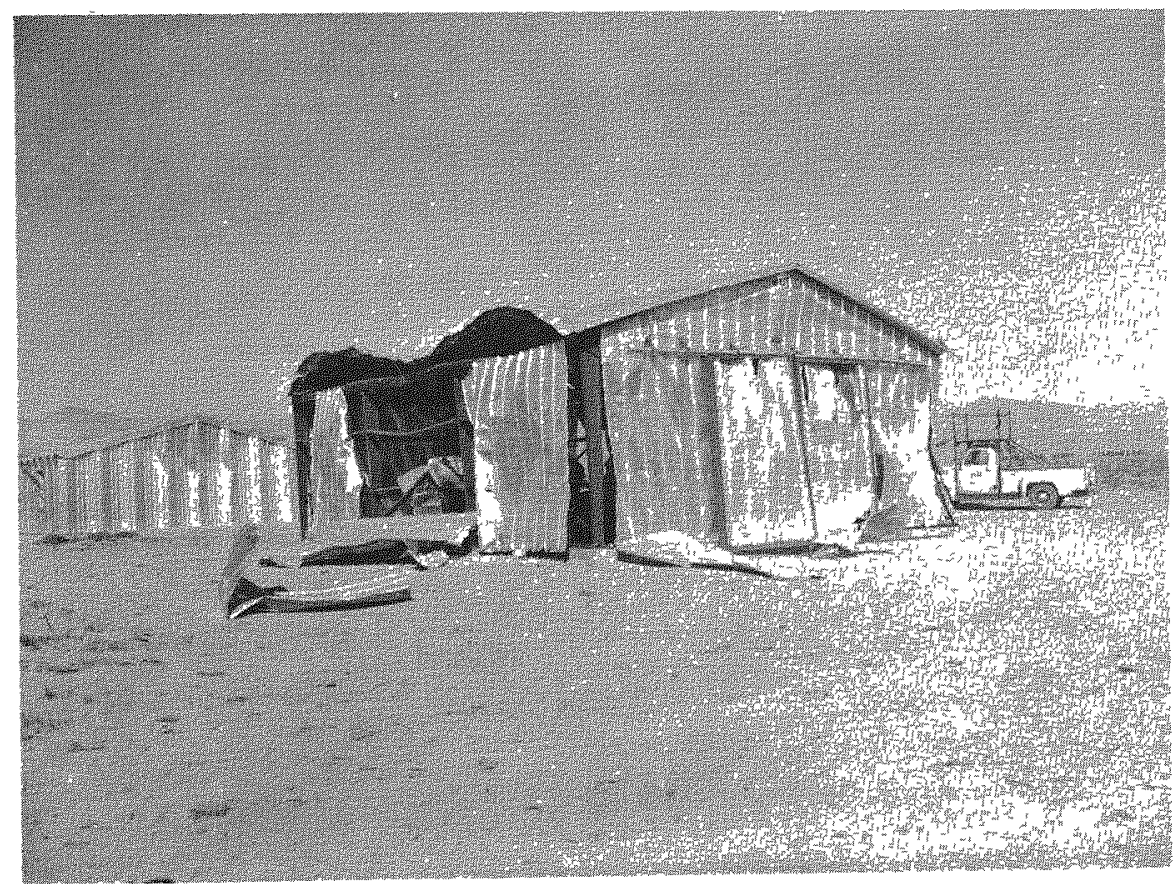

Fig. 2.26-South side and east end of Reynolds-Butler Building 31.2-a1 after planned test.

ind




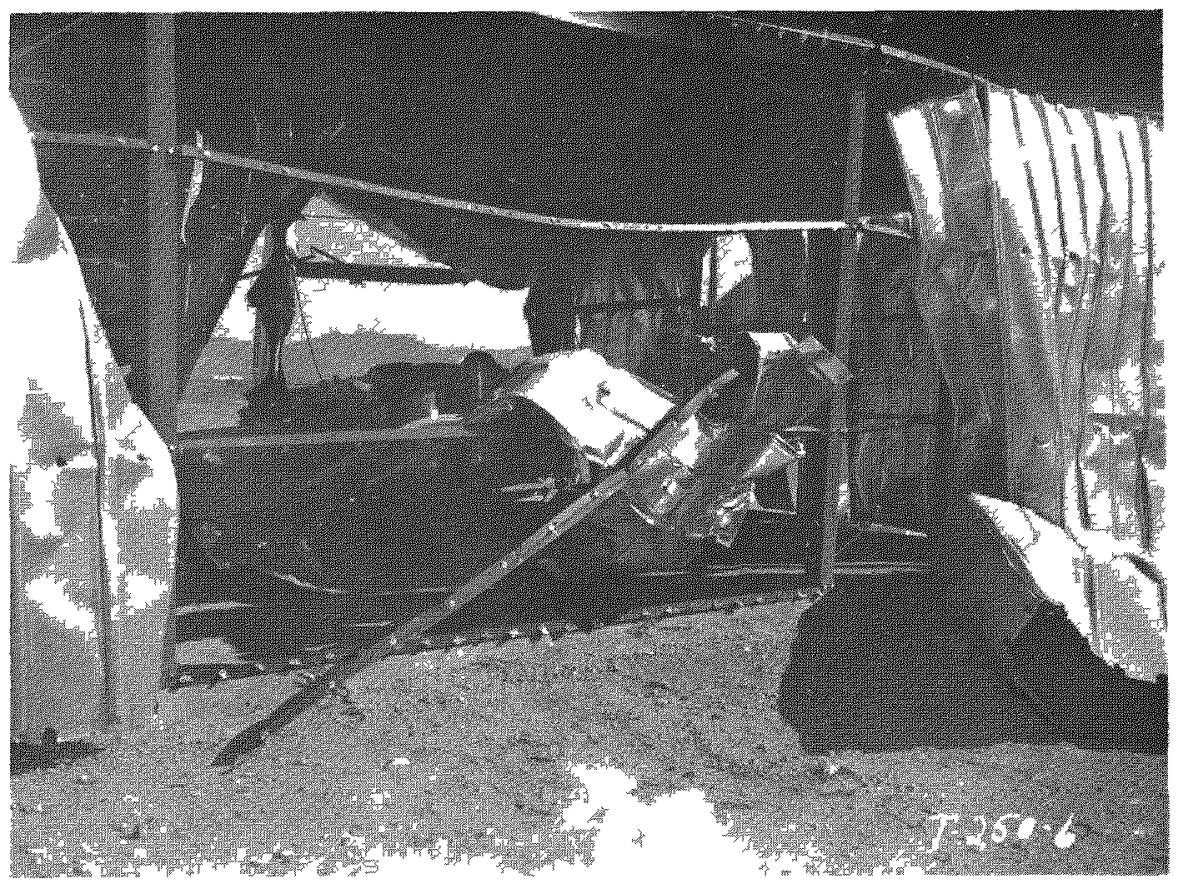

Fig. 2.27-North girts and siding blown through south wall of Reynolds-Butler Bunlding 31.2-a1 after planned test.

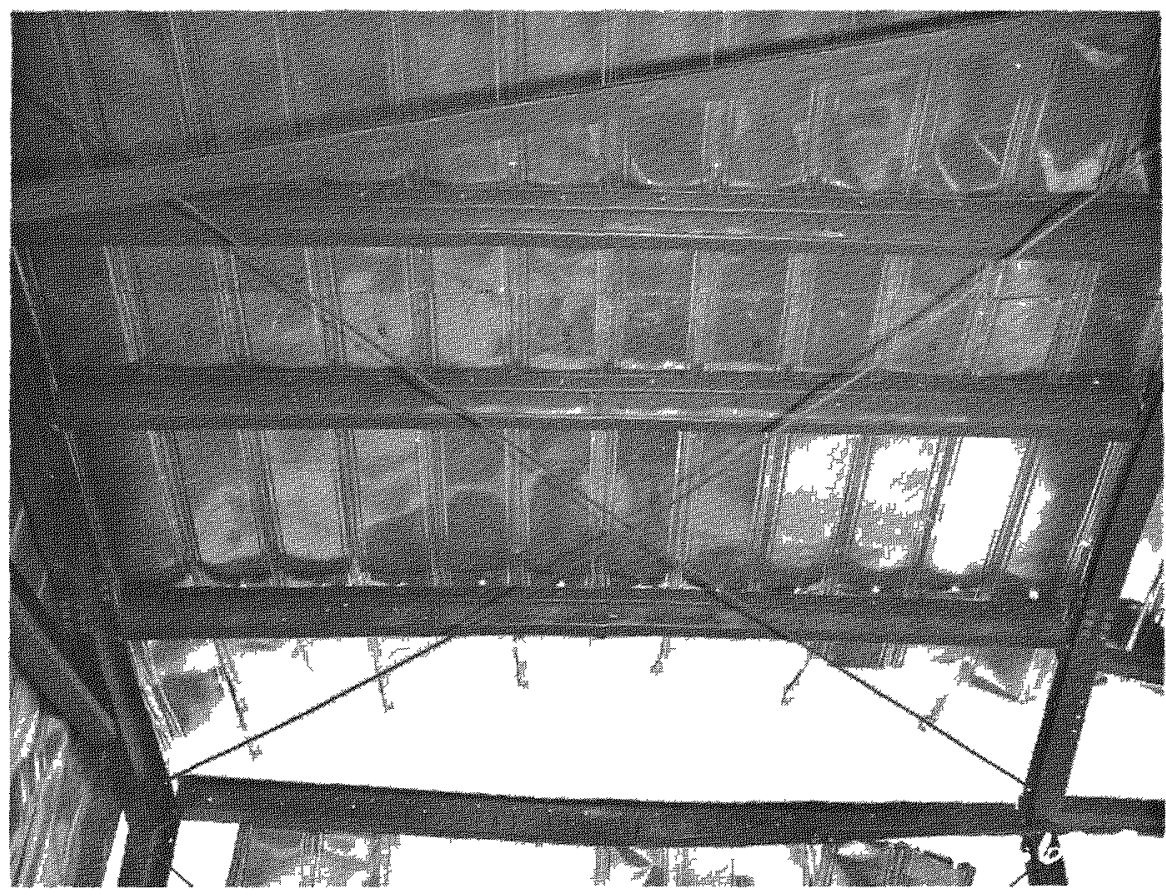

Fig. 2.28-Underside of southeast roof section of Reynolds-Butler Bullding 31.2-a1 after planned test. 


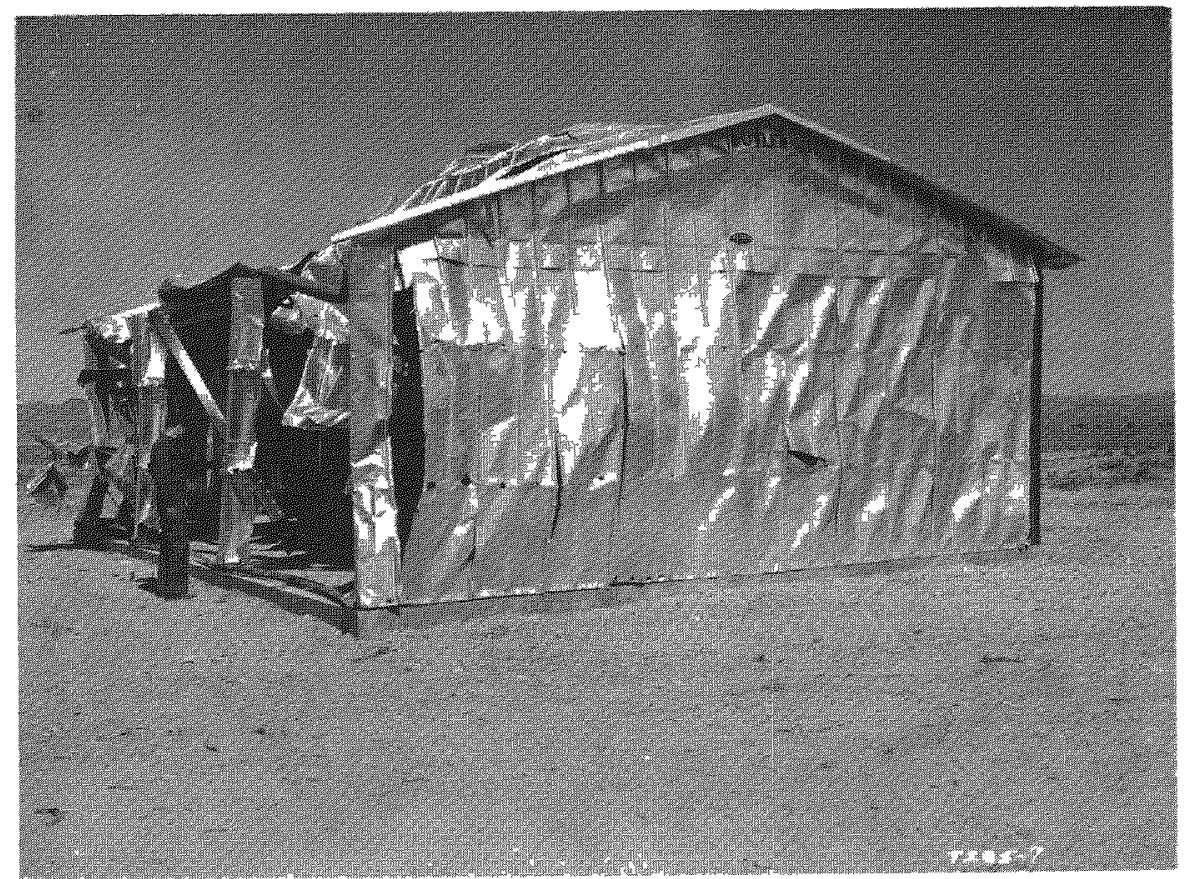

Fig. 2.29-West end of Reynolds-Butler Building 31.2-a1 after planned test.

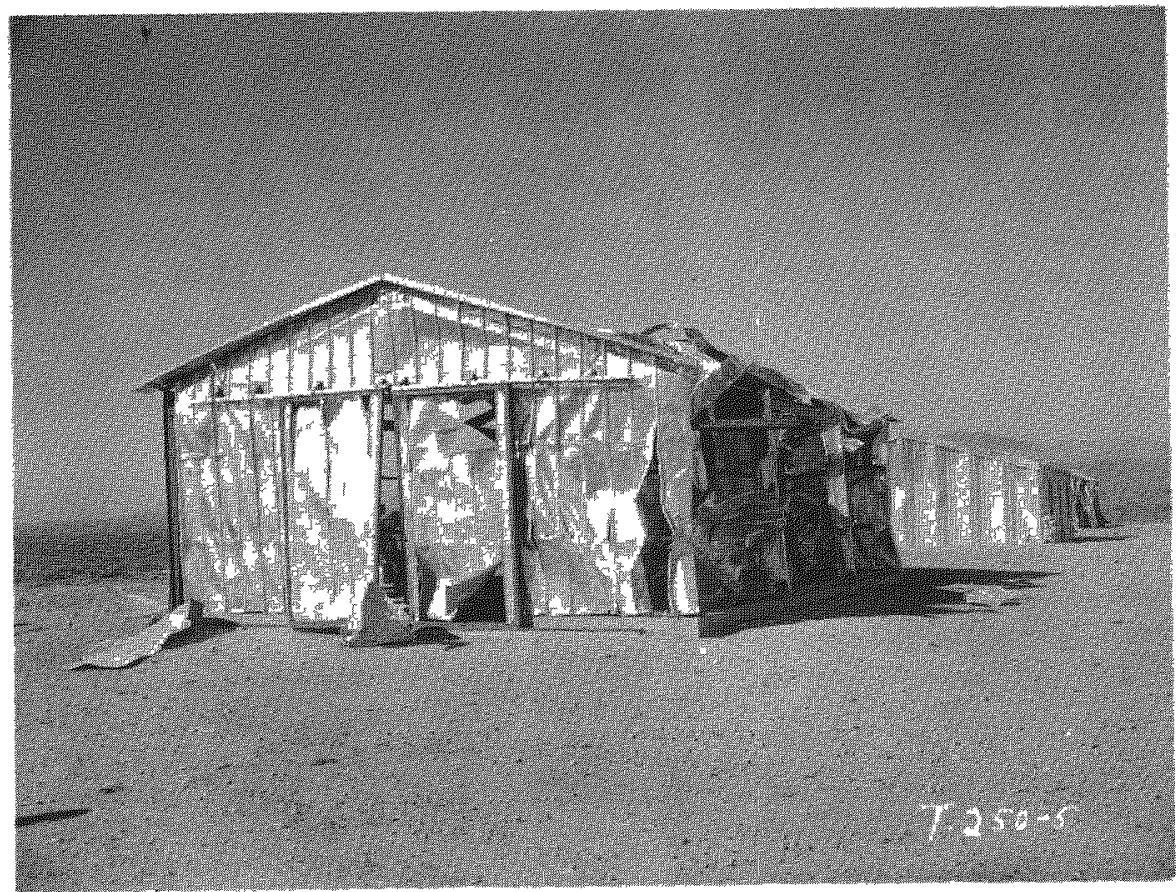

Fig. 2.30-East end of Reynolds-Butler Building 31.2-21 after planned test. 
shown in Fig. 2.27. They survived the experience of having the central wall girts and sheeting from the north wall blown against them after striking machinery within the building. Except along the ridge, the roof sheeting was largely detached from the purlins. The purlins on the south face of the roof were the least damaged of any sheet-supporting members, as shown in Fig. 2.28, a view looking upward at the east space of the south roof face.

The two ends of the building presented the least-damaged external appearance (Figs. 2.29 and 2.30) for the west and east ends, respectively. The ends undoubtedly experienced considerable pressure equalization due to the more or less complete failure of the north wall. Wall paneling on the west end remained very largely attached to the sill angle and the eave level members, although the paneling was detached from all but about one-third of the girt fasteners. At the east end a similar situation existed, and the hanging doors remained in place.

\subsubsection{Damage to Behlen Building 31.2-b1}

Although severely damaged, this was the only one of the three utility buildings on the $6800-$ ft line that remained sufficiently intact to be suitable for storage or other similar use with only minor repairs to the windows and doors.

As shown in Figs. 2.31 and 2.32, the major structural damage to this building resulted from the bending and local buckling of the roof units. The roof along the ridge line had been depressed approximately $1.25 \mathrm{in}$. as a result of the unexpected test, and there was little additional roof deflection. At the center the additional downward deflection relative to the ends amounted to a maximum of only $0.7 \mathrm{in}$. at the center of the ridge line. The deflection of the roof panel units from a straight line connecting the ridges and eaves was quite uniform (Fig. 2.31), amounting to 12 to $14 \mathrm{in}$. at points of permanent deflection. The motion pictures of this structure during the test show clearly that the maximum deflection was appreciably greater than the permanent deflection, indicating some elastic recovery from the most deflected condition. Figure 2.33 shows a typical cross section of Behlen Building 31.2-b1 after the planned test.

Diagonal measurements between wall sills and opposite eaves in the interior, confirmed by plumb-bob checks on the outside, showed that the rear wall of the building remained nearly plumb. However, the eave line of the north wall was pushed south, with permanent deflections varying from $2.5 \mathrm{in}$. at the east end to $3.2 \mathrm{in}$. at the west end. All the bolted wall and roof panel segments remained bolted to their mutual connections or to wall sill bolts. Thus the structure, except for window and door openings, retained its protective potential.

The ends of the building suffered minor damage, as shown in Figs, 2.34 and 2.35. The north half of the east end of the building was tilted toward the west, or center of the building, by varying amounts. In addition, the central panel was bent inward approximately 7 in. at midheight. Along the sloping northeast corner of the roof, the inward tilting of the end wall segments (Fig. 2.35) varied from 11 in. at the panel next to the eave corner to 2 in. at the ridge. At the west end of the ridge, the end wall remained essentially plumb, but it was bent inward locally about $2 \mathrm{in}$. near the center. Also, adjacent to the west end, there was severe local buckling near the top, which can be noted from the interior close-up view shown in Fig. 2.36. At this point, also, can be noted the failure between the longifudinal end strut and its connection to the end wall of the building, with permanent displacement in the direction of the ridge line of about 4 in.

The conventional wood panel door at the front of Behlen Building 31.2-b1 became a severe missile, tearing loose from the hinges and striking the south inner face of the building with considerable force. The undamaged hinges remained on the door frame. The front north window panes broke through, but the sash remained in place. On the south side of the building, a single pane of glass in a rear window remained unbroken. Four of the remaining 11 panes remained in place, although they were cracked.

\subsubsection{Damage to Armco Building 31.2-d1}

This building, at $6800 \mathrm{ft}$, was practically destroyed; the roof collapsed and rested at the center on machinery within the building. Front wall segments were wrapped around the machinery, and this provided a block that at least partially prevented additional movement of building wreckage in the downblast direction. 


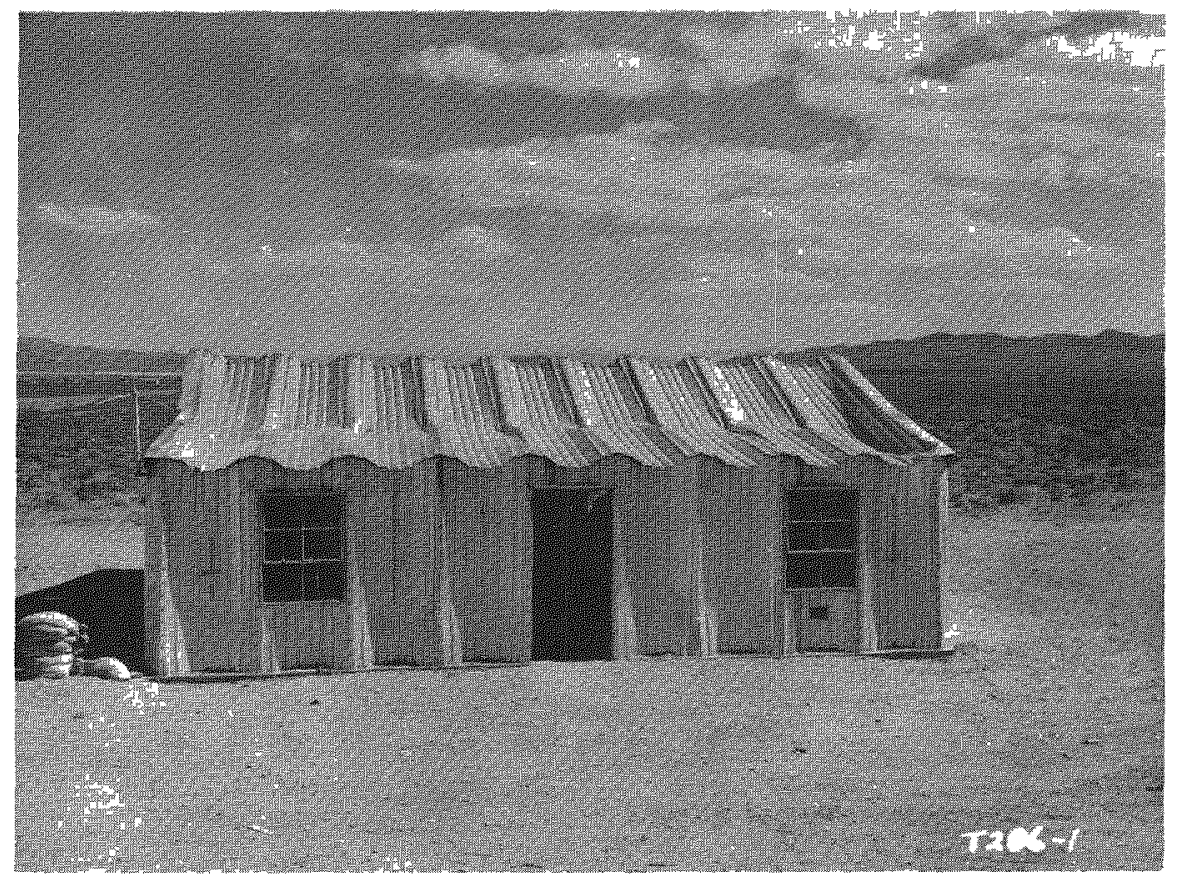

Fig. 2.31 - North side of Behlen Bunlding 31.2-b1 after planned test.

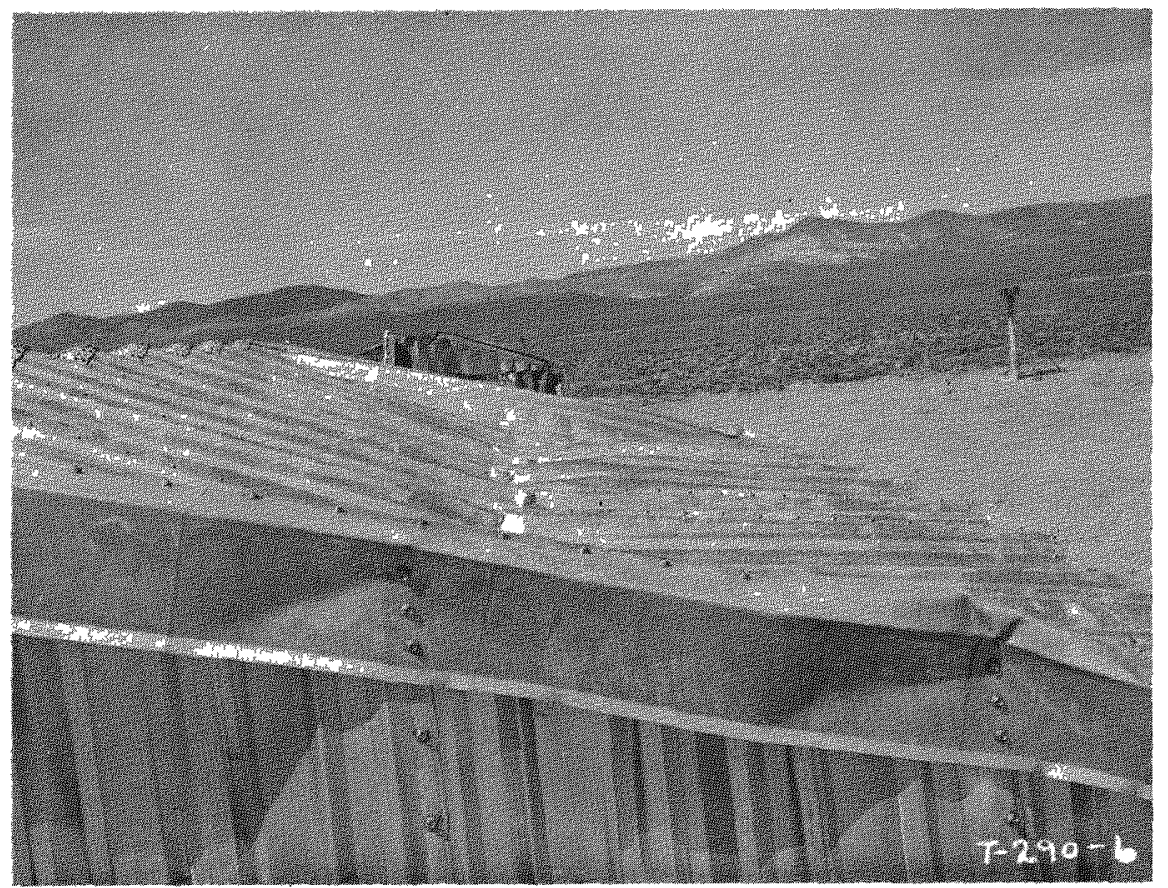

Fig. 2.32-View looking along north roof of Behlen Building 31.2-b1 after planned test. 


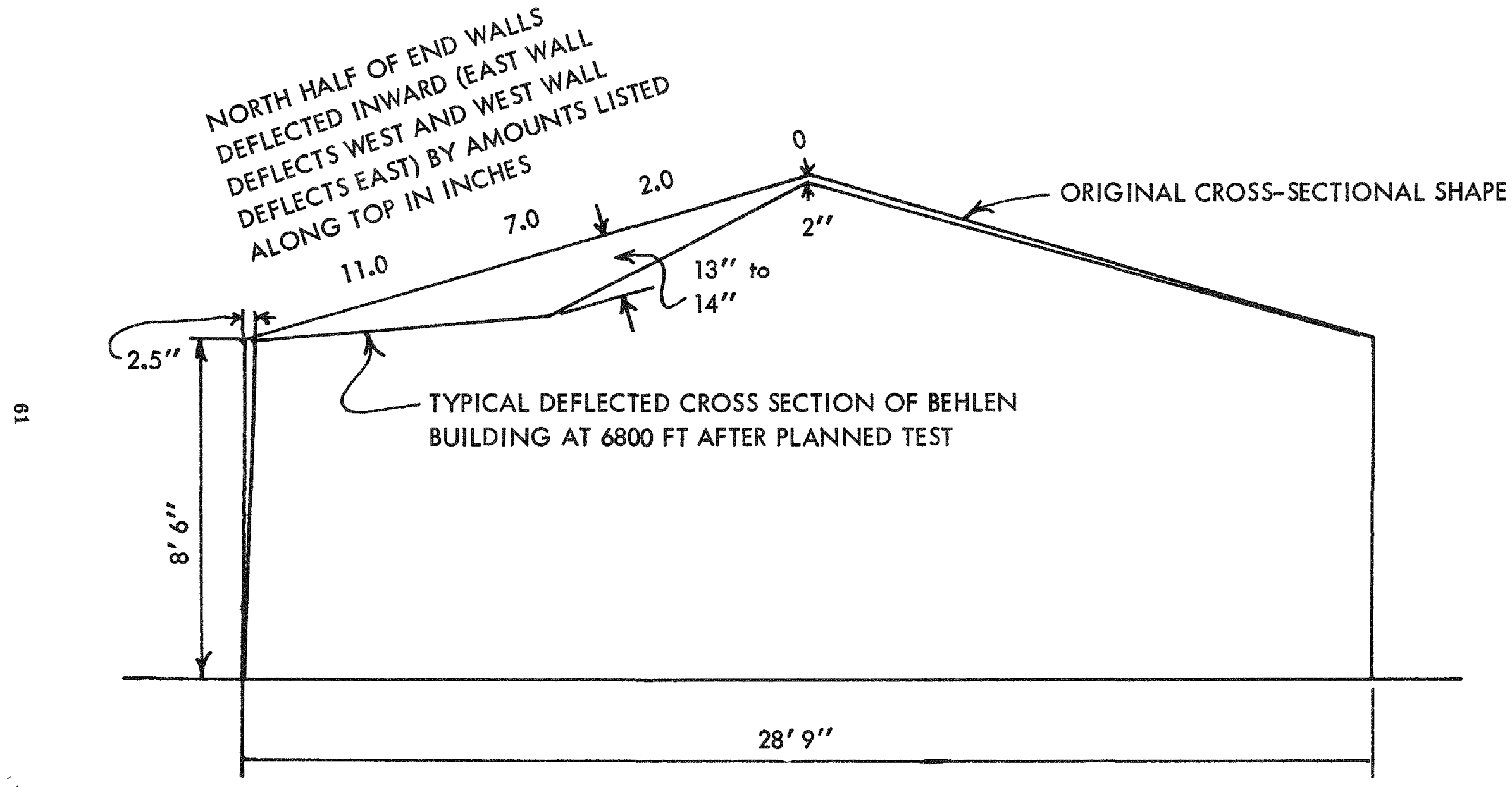

Fig. 2.33-Permanent deflection of Behlen Building 31.2-b1 at $6800 \mathrm{ft}$ after planned test. 
The north side of the building is shown in Fig. 2.37, which also indicates the sag in the roof. Figures 2.38 to 2.41 show various views of the crumpled ends and the south side of the building. Most of the wall segments remained on site, although the wall panels along the north side were largely torn loose from the wall sill connections, as shown in detail in Fig. 2.42, and one piece swept downblast about $50 \mathrm{ft}$. At the southwest corner of the building, the sill was also torn loose, as shown in Fig. 2.43. The wall paneling remained attached to the sill along 75 per cent of the east end and all the west end.

Figure 2.44 shows the inward breakage of the northeast door frame. The brittle type fracture introduced into the door frame reinforcing channel is of interest. Another interior view (Fig. 2.45) shows how the machinery blocked further downblast movement of the north panels of the building.

Although very complete structural position measurements had been made prior to the test, the failure of this particular structure was so complete as to render any postshot dimensional checks valueless.

\subsubsection{Damage to Reynolds-Butler Building 31.2-a2}

The damage in the planned test to Reynolds-Butler Building 31.2-a2 at 15,000 ft was similar in nature to, but more severe than, the damage from the unexpected test to Reynolds-Butler Building $31.2-\mathrm{a} 1$ at $6800 \mathrm{ft}$ from the planned test.

Correlation of these two tests by dynamic analyses of the wall panels and girts is given in Appendix A.

All the siding and roofing remained in place, and the structure retained its essential utility, as can be seen in Fig. 2.46, which is a general view of the north side and west end of Building 31.2-a2.. Preshot and postshot diagonal measurements show that the east-and west-end steel building frames had less than 1 in. of permanent deflection away from the blast origin. The two interior building frames had permanent deflections at the eaves of about $1.5 \mathrm{in}$. The column anchorages for the two interior frames failed at their south footings, with concrete spalling off the south face of the footing. The column base plate was displaced $0.5 \mathrm{in}$. at the east interior frame footing and $1.5 \mathrm{in}$. at the west interior frame footing. Figure 2.47 shows the spalled concrete remaining near the footing for the east interior frame column footing.

Along the north side, the west and center sill angles tore loose from their center bolts, but the east sill angle remained attached to all three sill bolts, with the center bolt considerably deformed. The wall paneling remained attached to the sill fasteners on all sides and ends of the structure. The lower west and east girts on the north side were twisted down 72 and $80^{\circ}$, respectively, on the inside, and the sheeting was pulled off five or six of the center bolts and washer fasteners. The upper east and west girts were twisted up nearly $90^{\circ}$ on the inside. Of the two center girts, the lower girt tore loose at each end, as well as from all the wall paneling, whereas the upper girt tore loose at the east end only and remained attached to all but four of the paneling bolt fasteners.

The eave members were only slightly bent, but they experienced web crippling of 1 to $4 \mathrm{in}$. at one or both ends. The first roof purlins above the eave members showed some permanent bending deflection of from 1 to 3 in., and they experienced a small amount of web crippling. The second line of purlins above the eaves showed indications of very minor web crippling and little, if any, permanent bending deflections. All remaining roof purlins on the north side (the upper two) and all purlins, eave members, girts, and sills on the south side showed little or no permanent damage.

The north wall paneling, including girts, experienced maximum inward deflections of from 7.5 to 9 in. in the east section, 13 to 17.5 in. in the central section (where the girts had detached), and 10.5 to $12 \mathrm{in}$. in the west section. The wall deformations are shown in Fig. 2.46, and field offset measurements are listed in Fig. 2.2. The wall paneling on the ends of the building (previously slightly damaged in the unexpected test) was further deflected by variable small amounts and also showed exterior evidence of main frame racking, as can be seen in Fig. 2.48. Figure 2.49 shows similar damage to the east end. The suspended sliding doors remained operable and undamaged after the blast. The roof sheeting on the north side was deflected to maximum amounts of 9.5 to 11.5 in. (Fig. 2.2) in the first span above the eaves and by a maximum of less than $2.5 \mathrm{in}$. in other spans. On the south side the roof sheeting was essentially undamaged.

(Text continues on page 74.) 


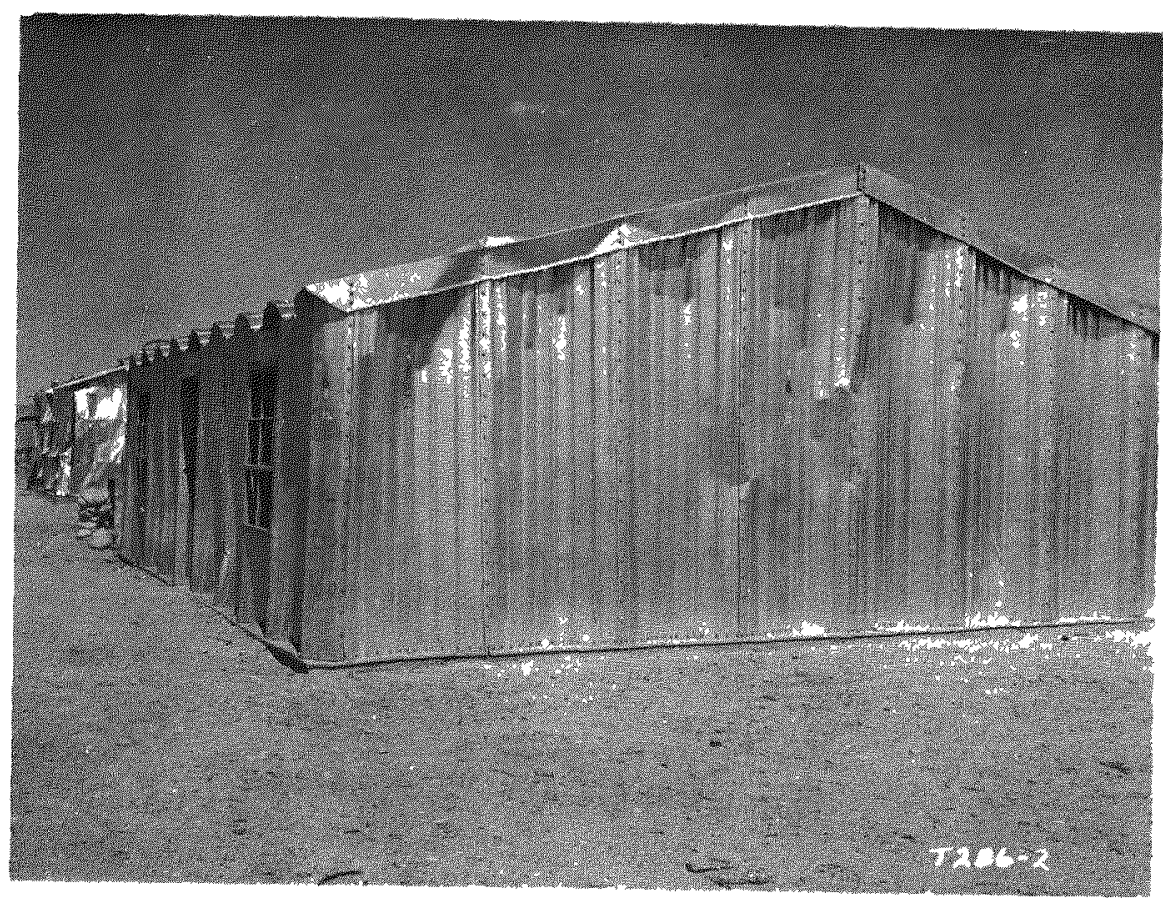

Fig. 2.34-West end of Behlen Building 31.2-b1 after planned test.

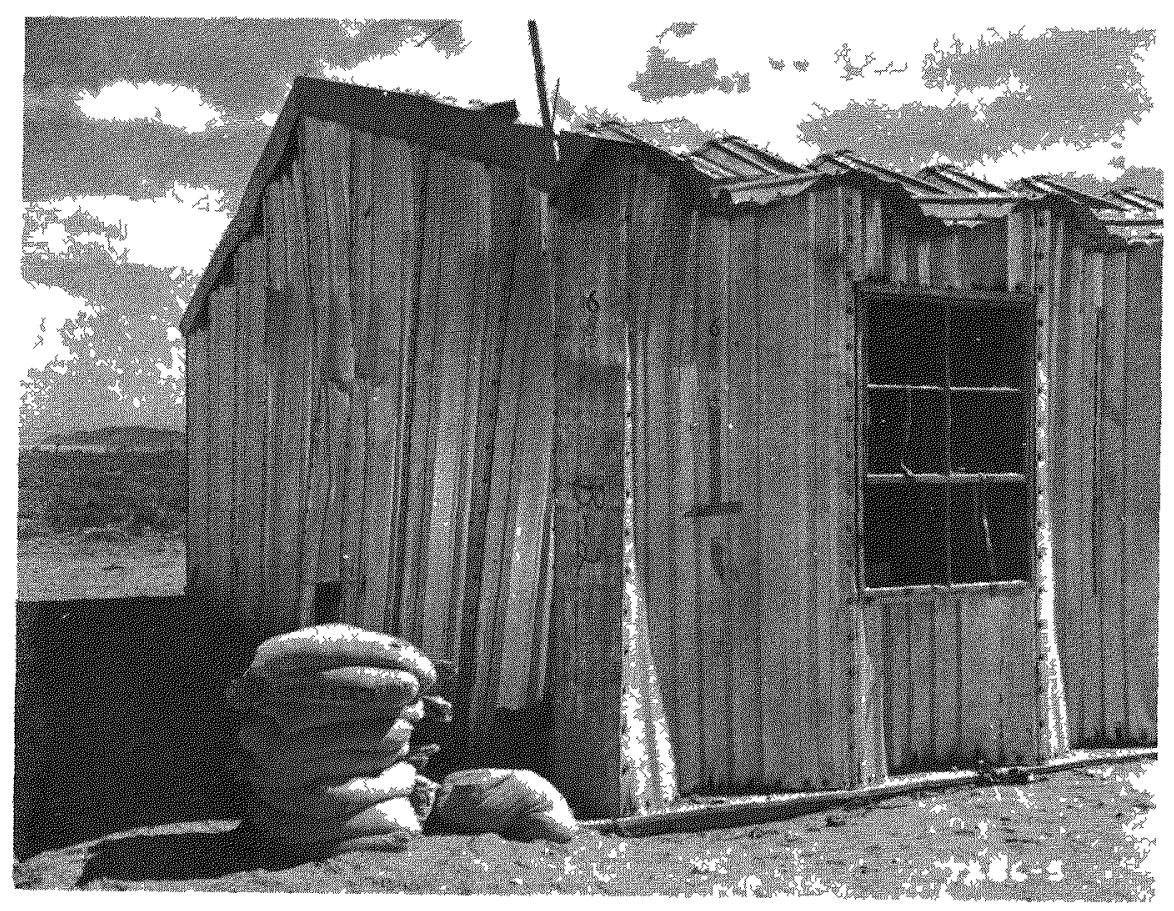

Fig. 2.35 - Northeast corner of Behlen Building 31.2-b1 after planned test. 


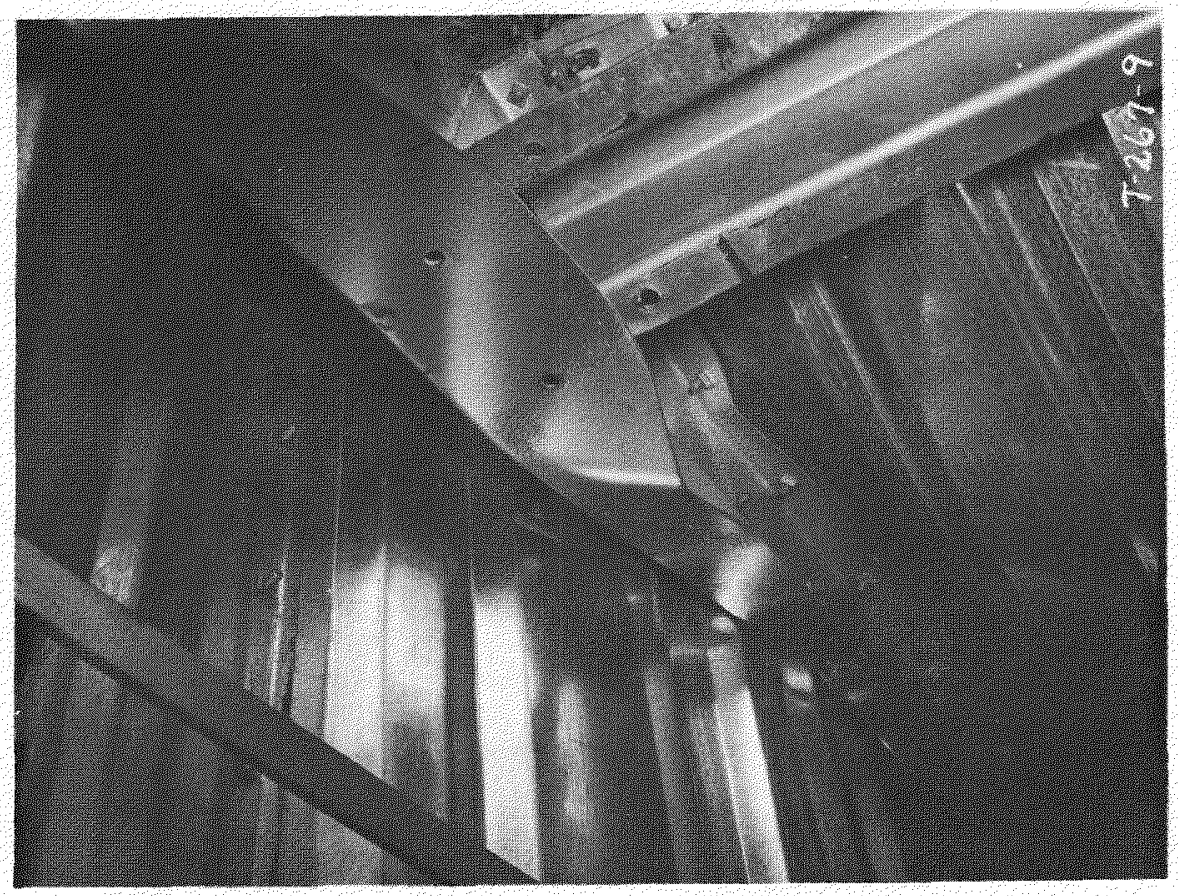

Fig. 2.36-Interior ridge detail at west end of Behlen Building 31.2-b1 after planned test.

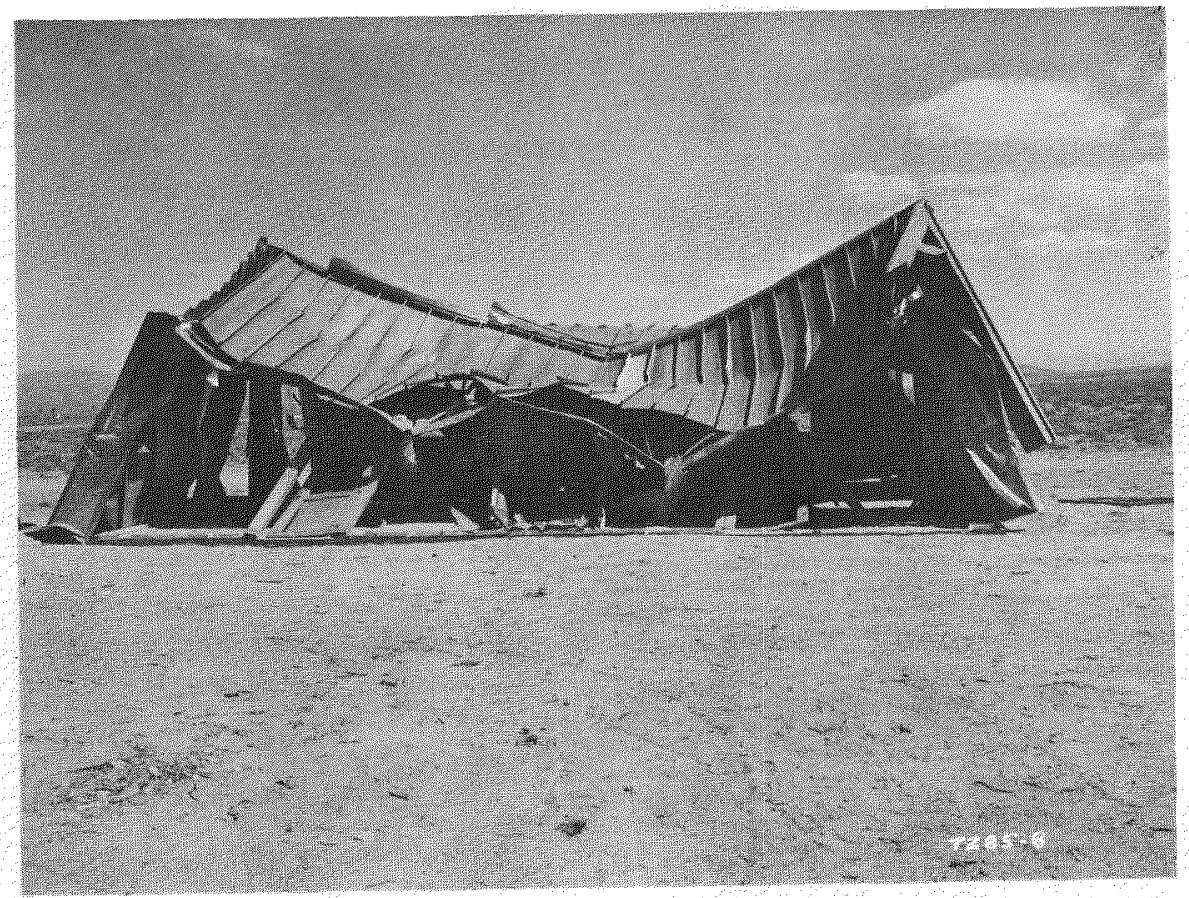

Fig. 2.37-North side of Armco Building 31.2-d1 after planned test. 


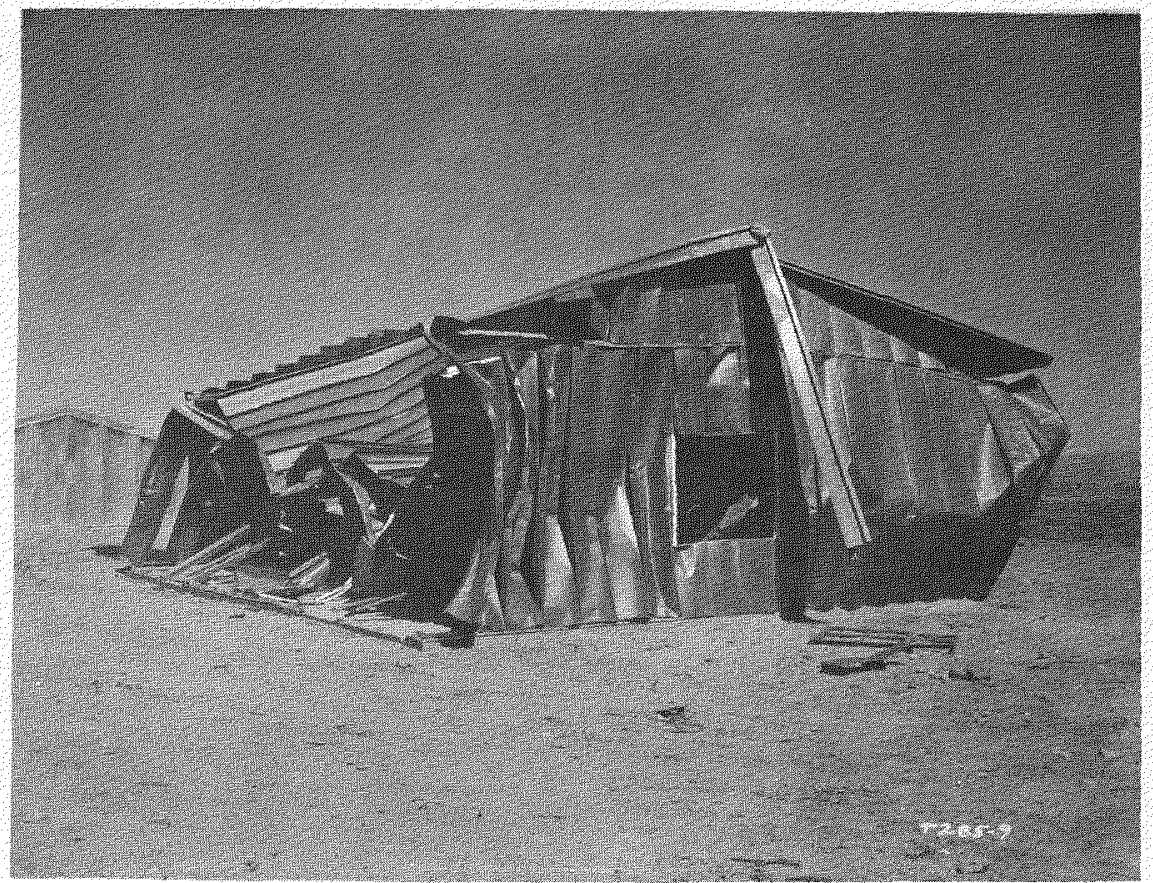

Fig. 2.38 - West end of Armco Building 31.2-d1 after planned test.

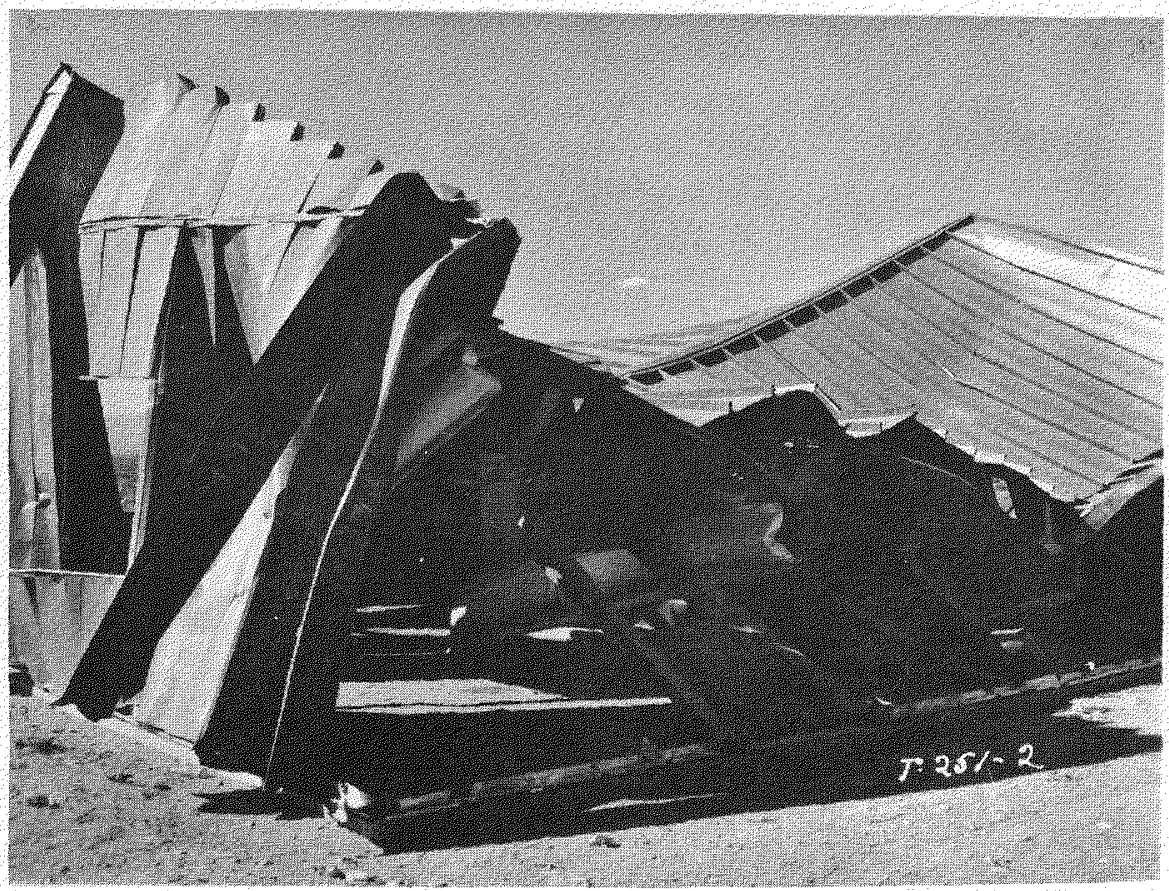

Fig. 2.39-Northeast corner of Armco Building 31.2-d1 after planned test. 


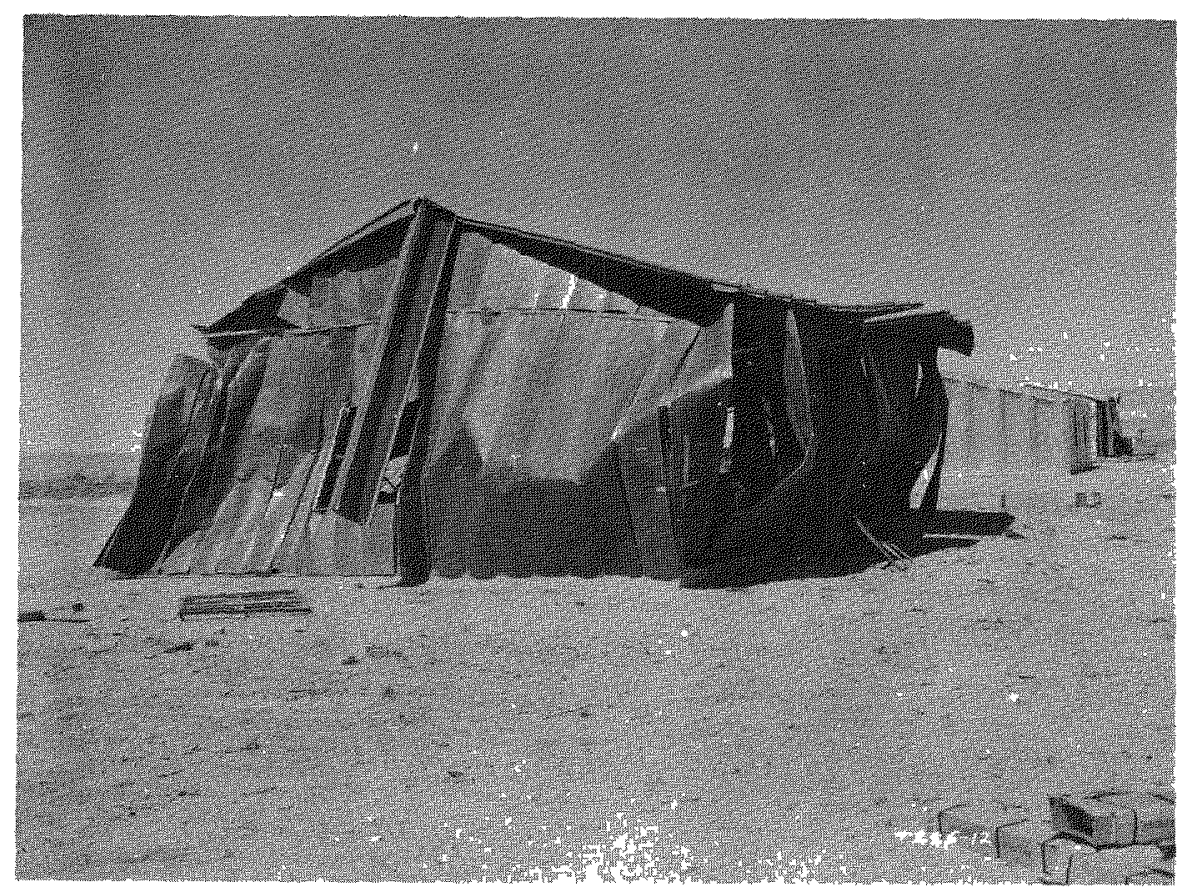

Fig. 2.40-West end and south side of Armco Building 31.2-d1 after planned test.

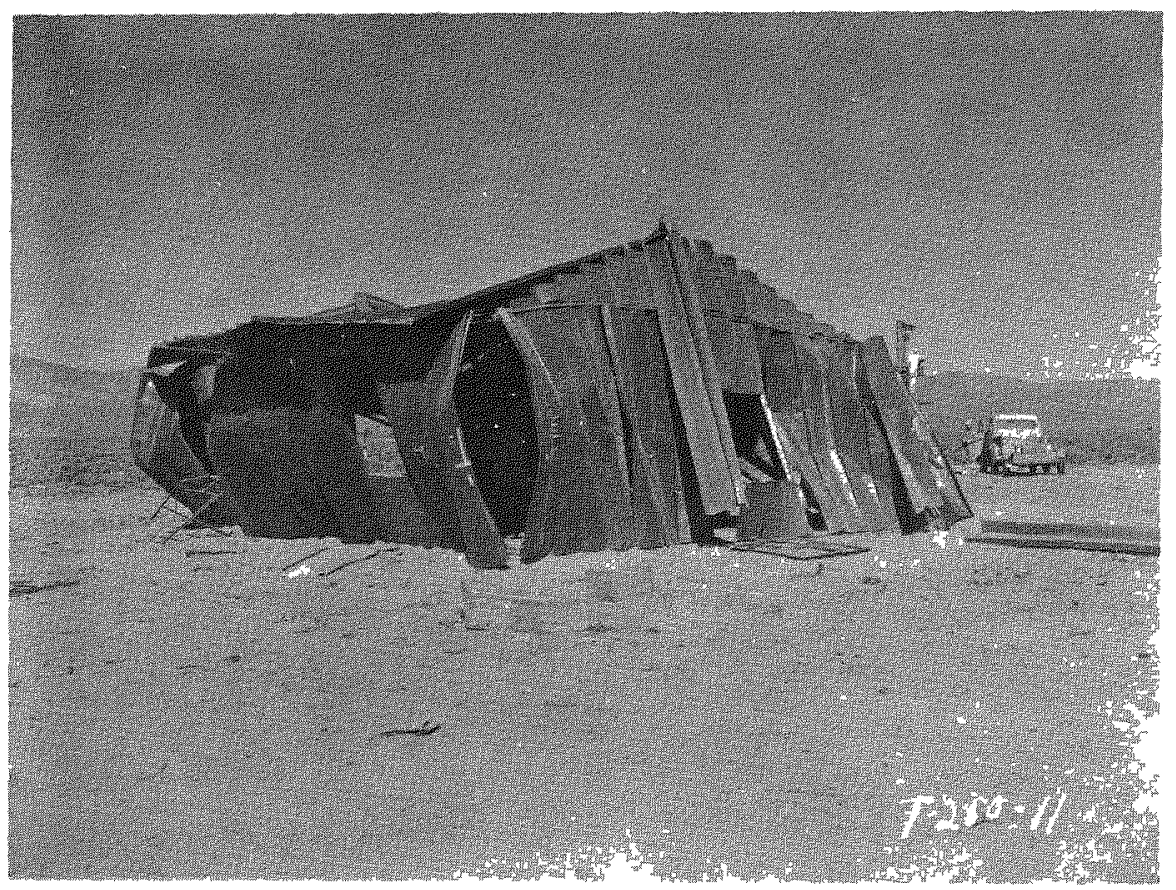

Fig. 2.41-East end and south side of Armco Bulding 31.2-d1 after planned test. 


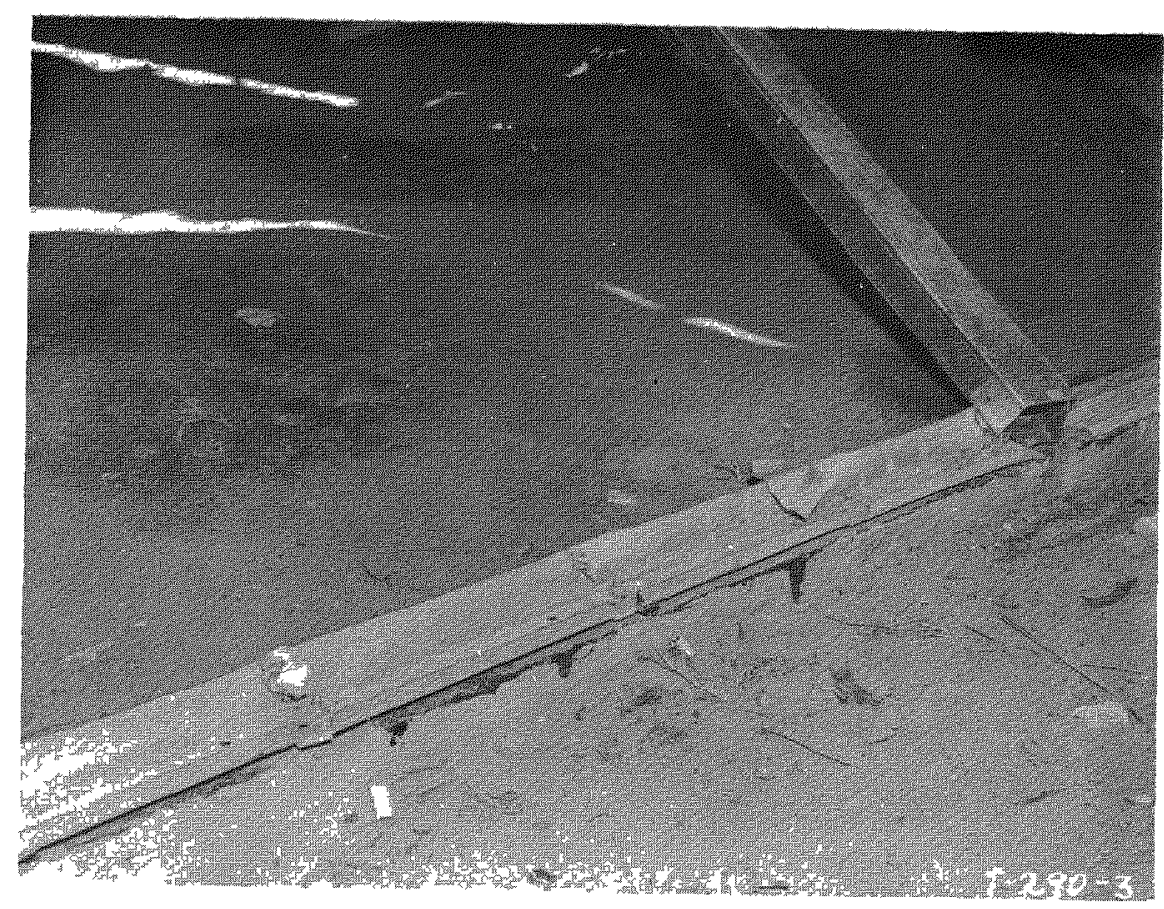

Fig. 2.42-Sill along north wall of Armco Building 31.2-d1 after planned test.

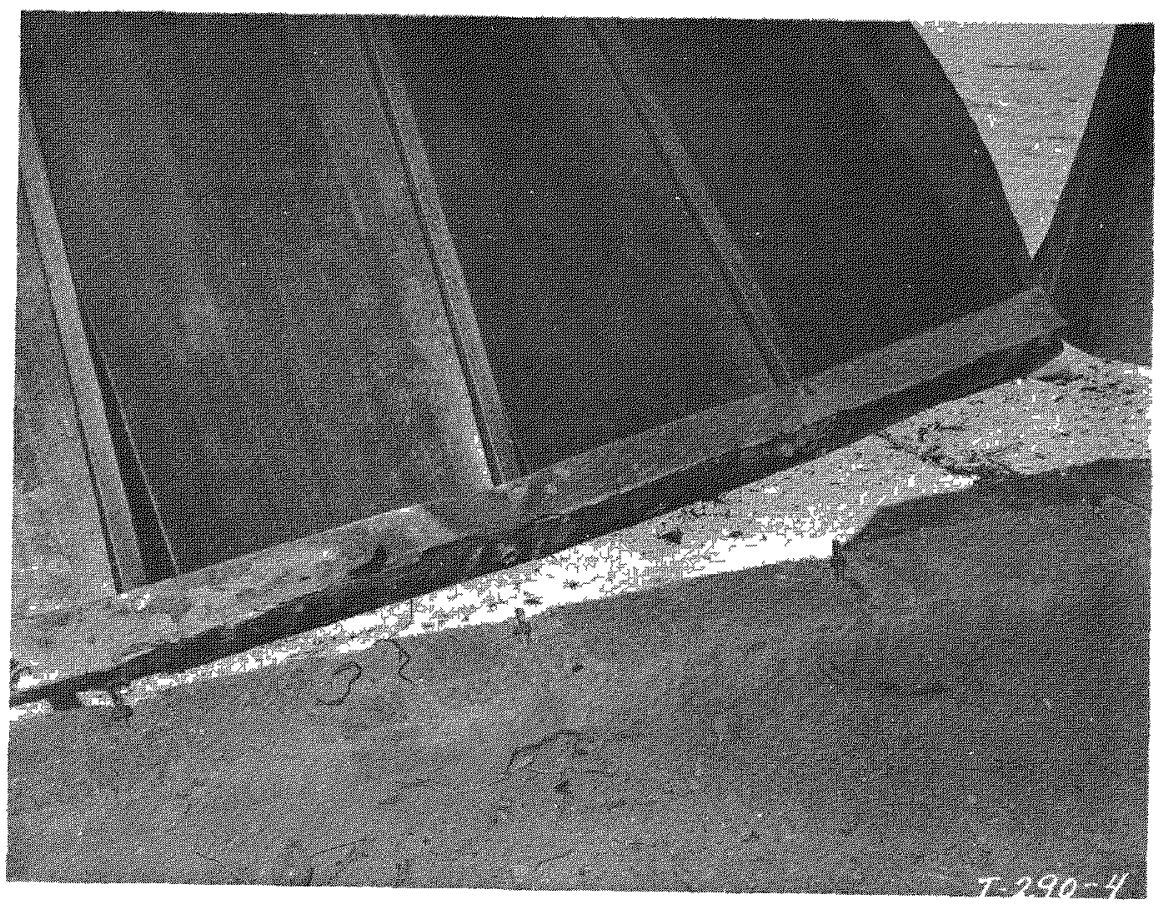

Fig. 2.43 - Interior detail of sill at southwest corner of Armco Building 31.2-d1 after planned rest. 


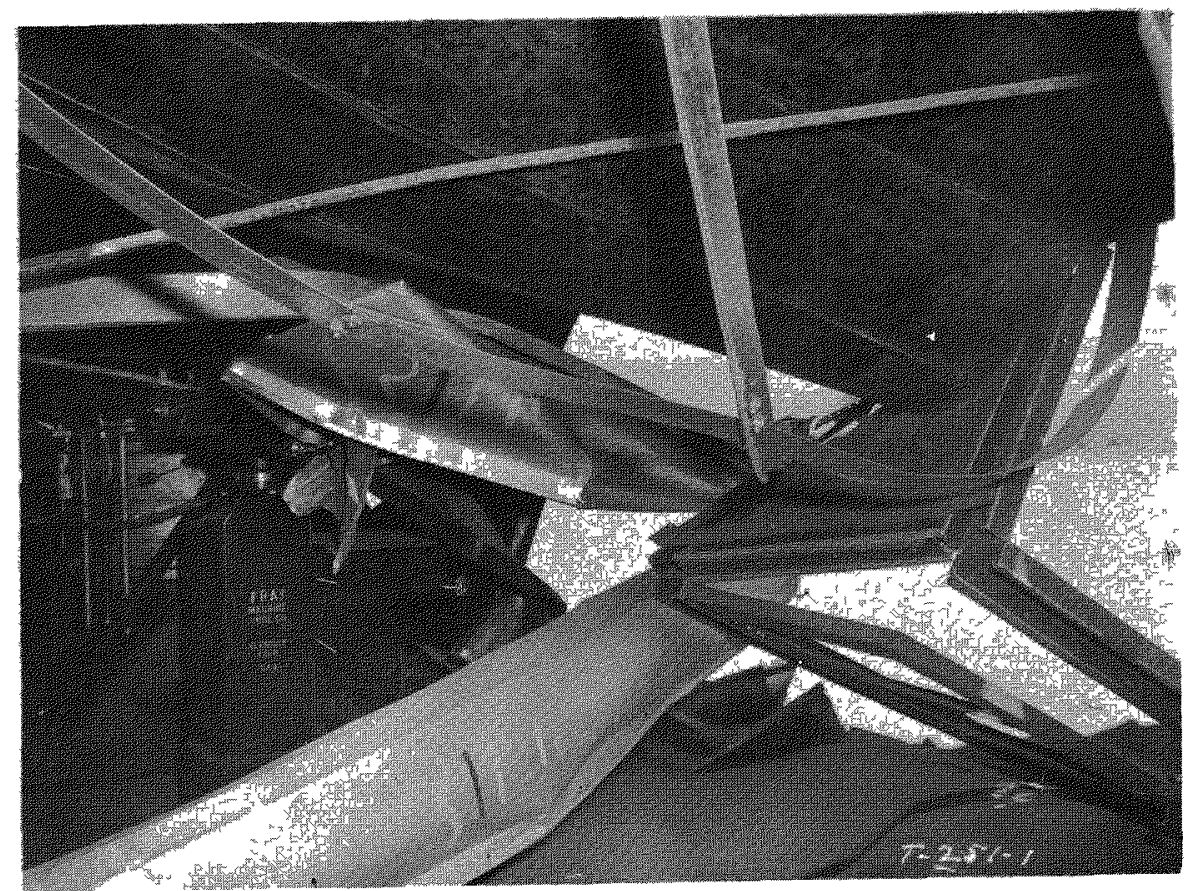

Fig. 2.44-Interior view toward northeast door frame of Armco Building 31.2-d1 after planned test.

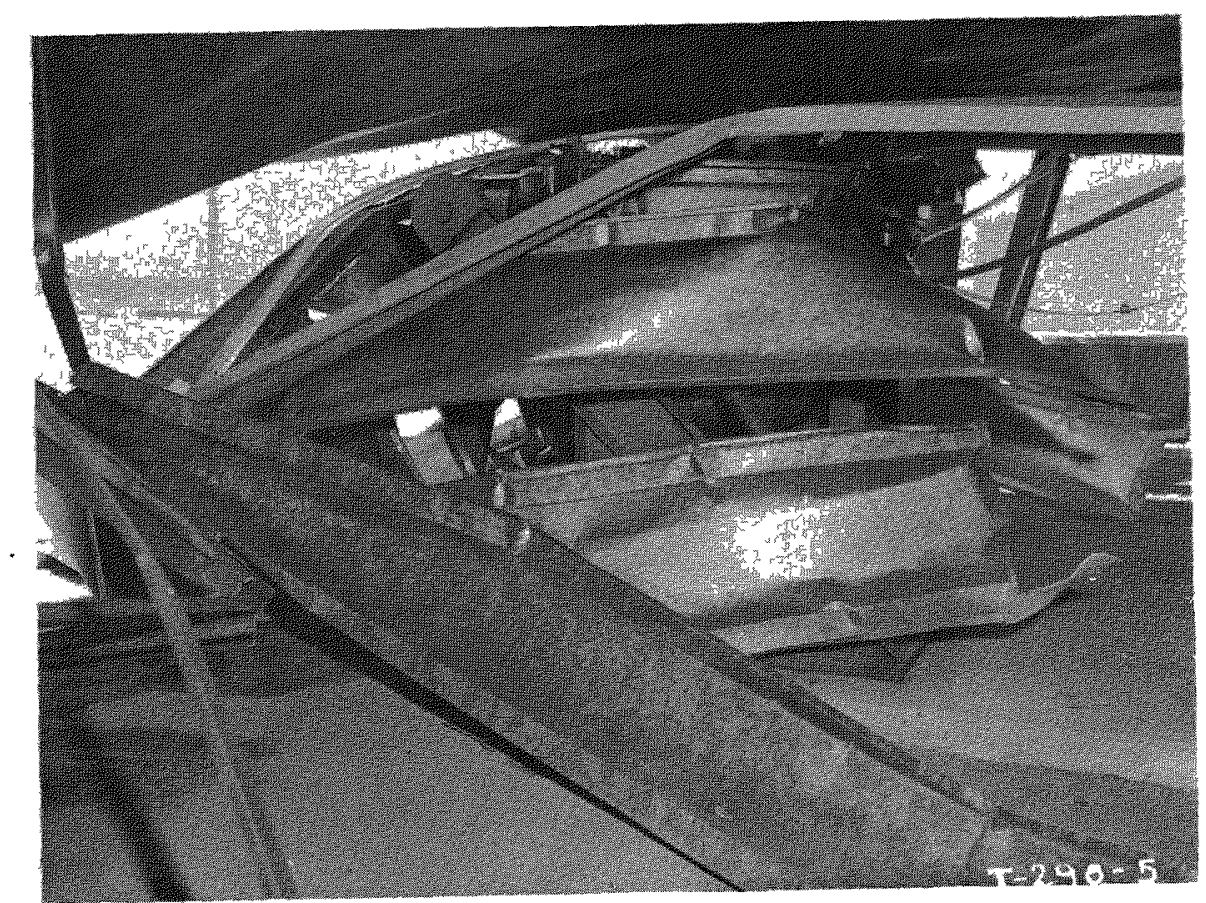

Fig. 2.45 - Interior view of Armco Building 31.2-d1, showing front paneling draped around machinery after planned test. 


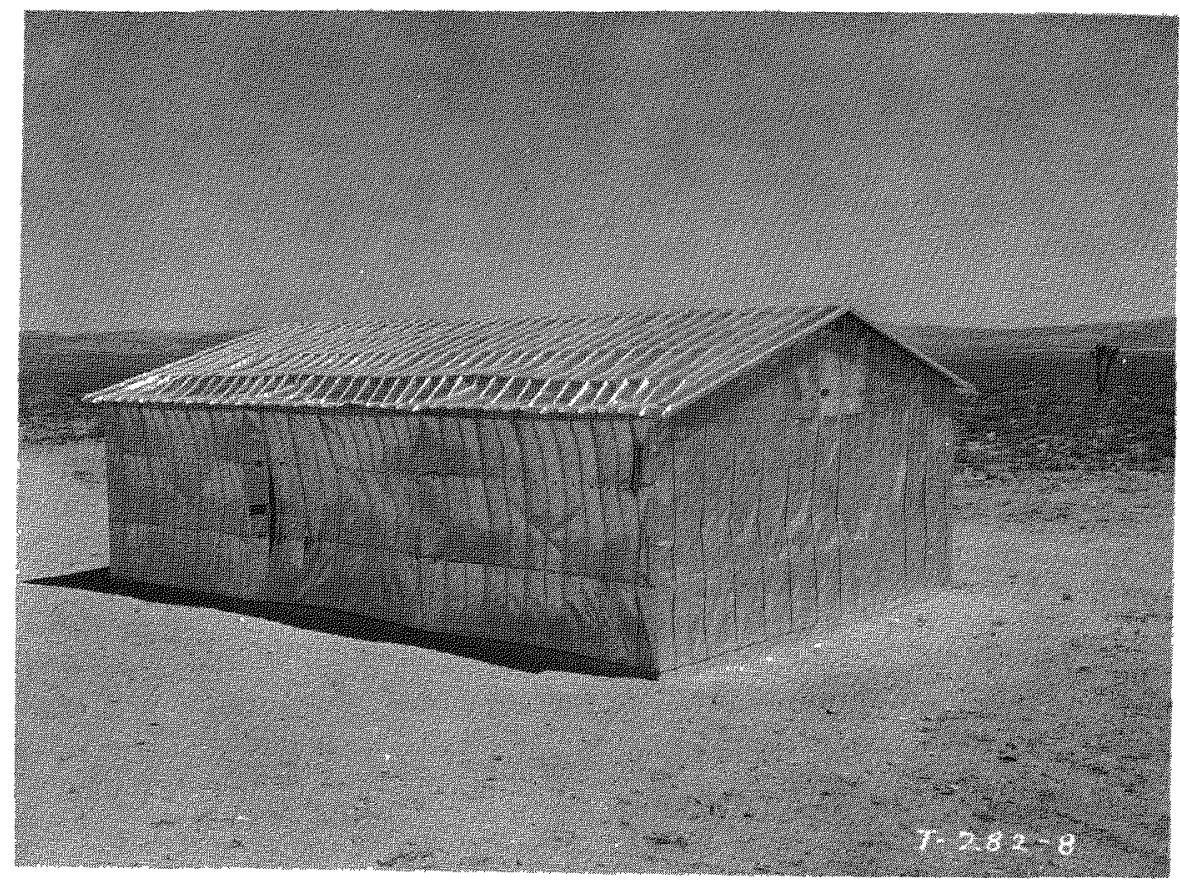

Fig. 2.46-North side and west end of Reynolds-Butler Building 31.2-a2 after planned test.

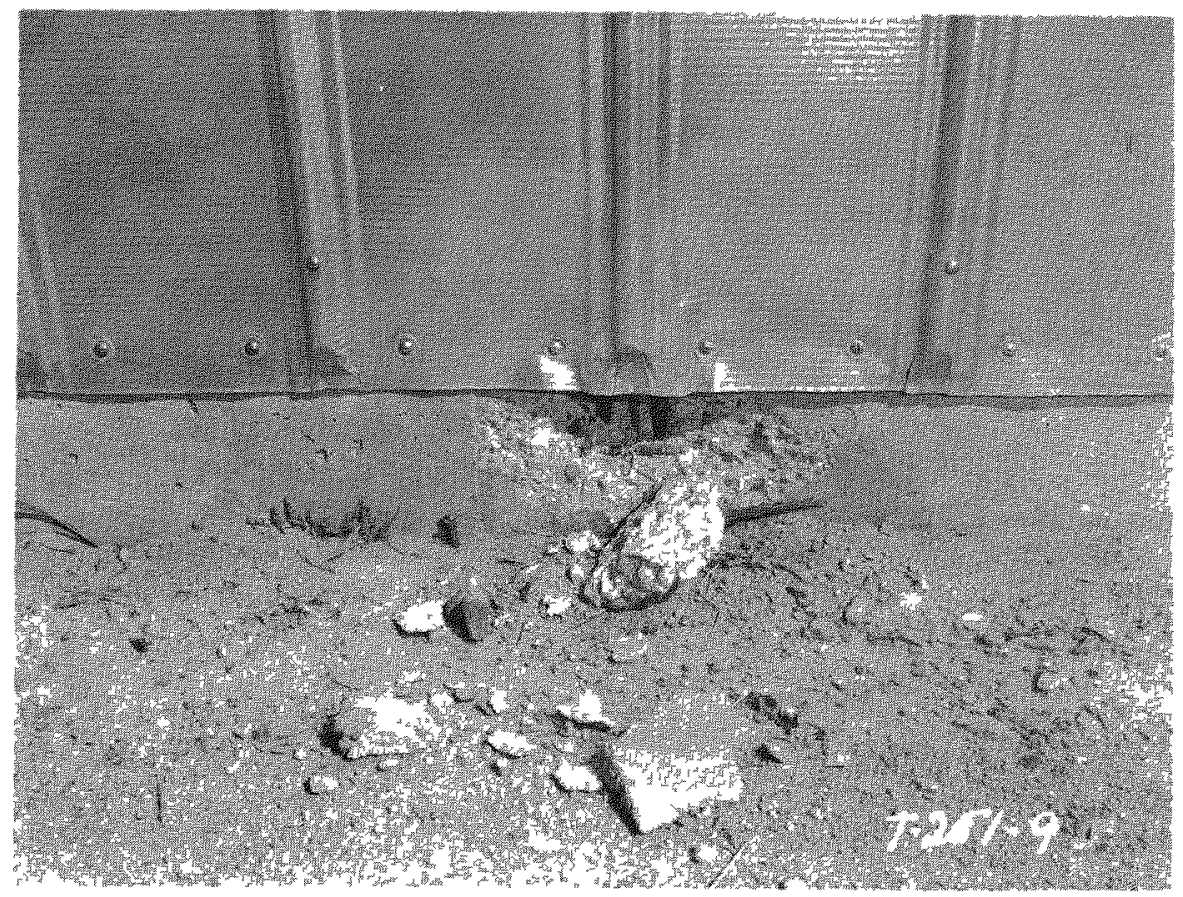

Fig. 2.47-South side of east interior column footing of Reynolds-Butler Building 31.2-a2 after planned test. 


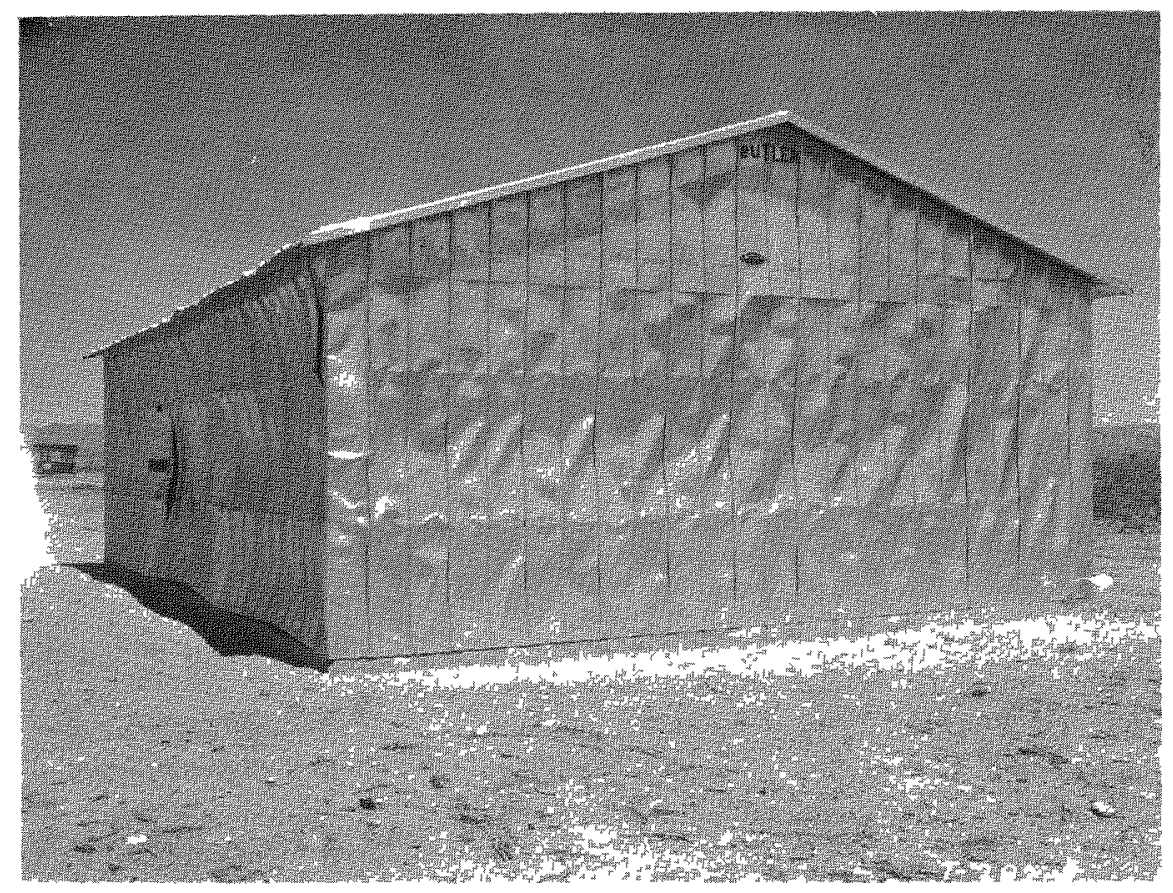

Fig. 2.48-West end of Reynolds-Butler Building 31.2-a2 after planned test.

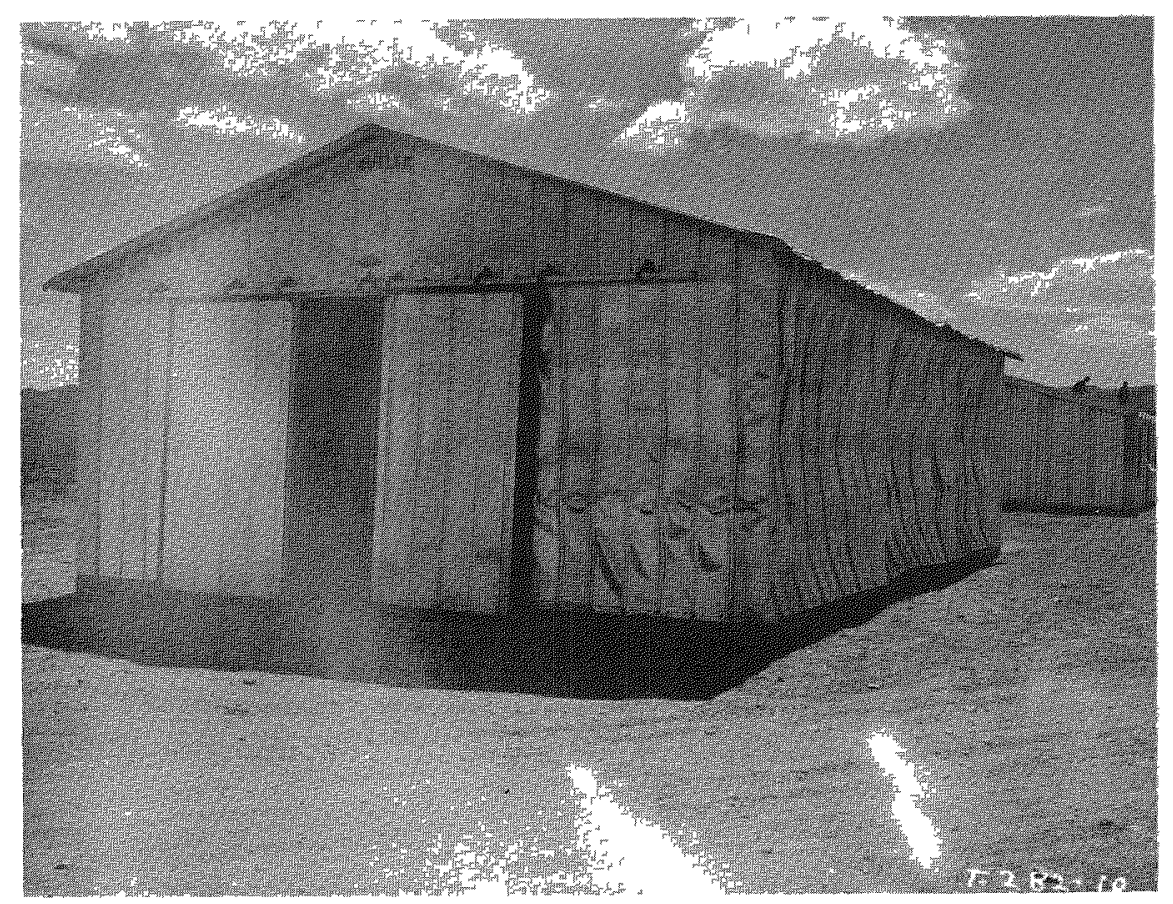

Fig. 2.49-East end of Reynolds-Butler Building 31.2-a2 after planned test. 


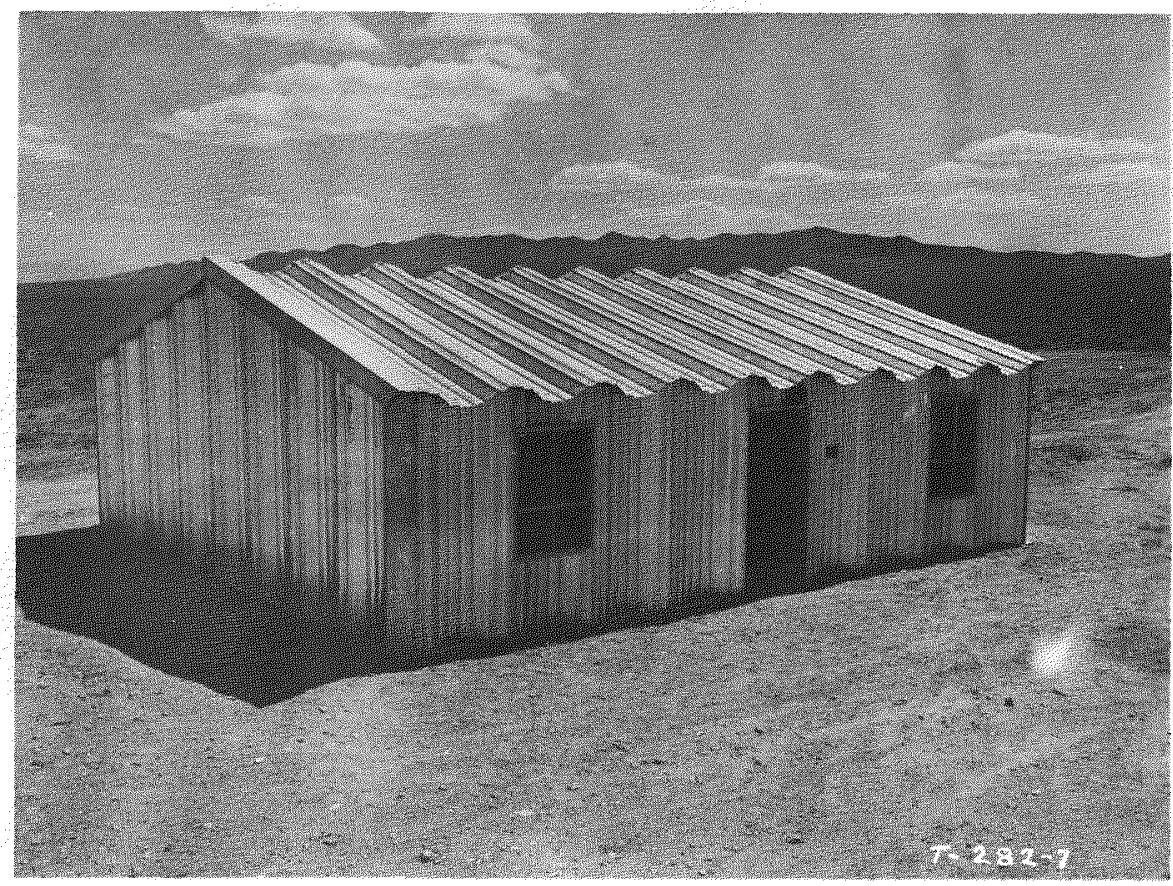

Fig. 2.50-East end and north side of Behlen Building 31.2-b2 after planned test.

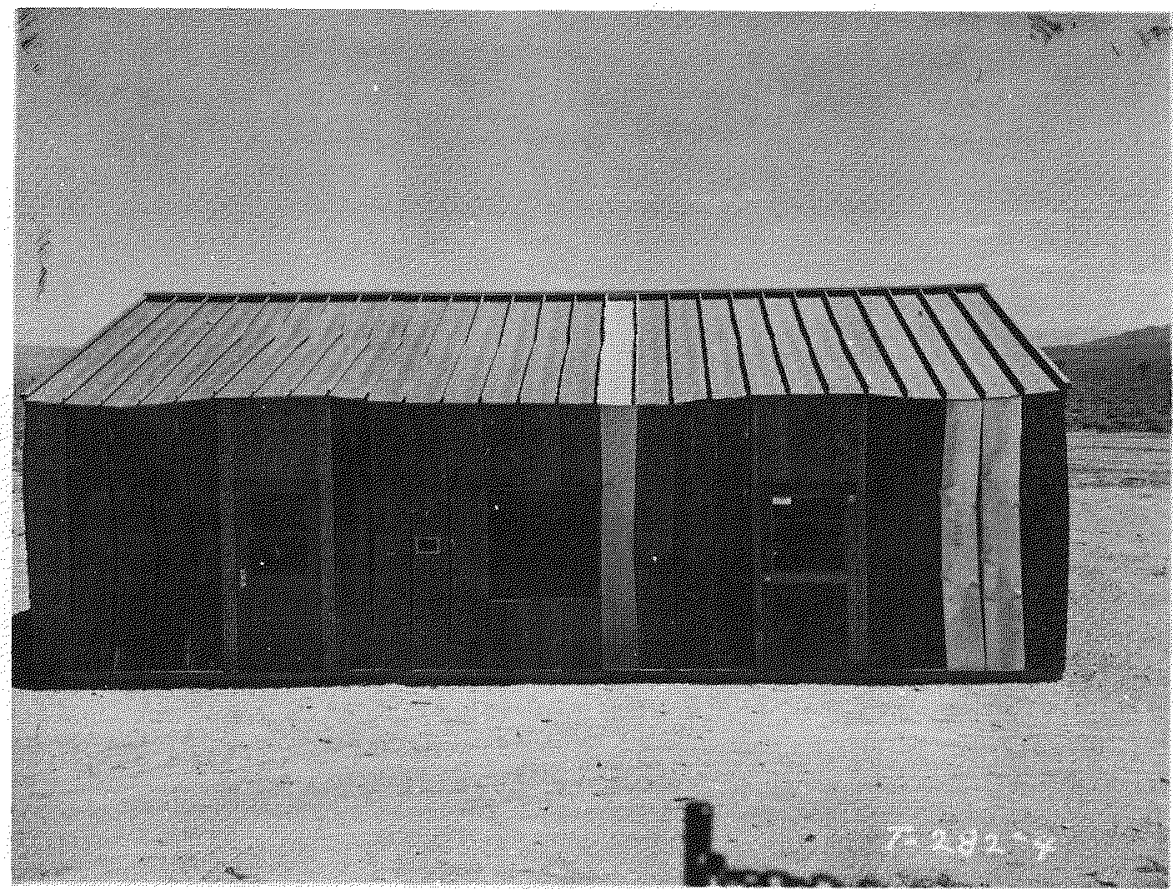

Fig. 2.51 - North side of Armco Building 31.2-d2 after planned test. 


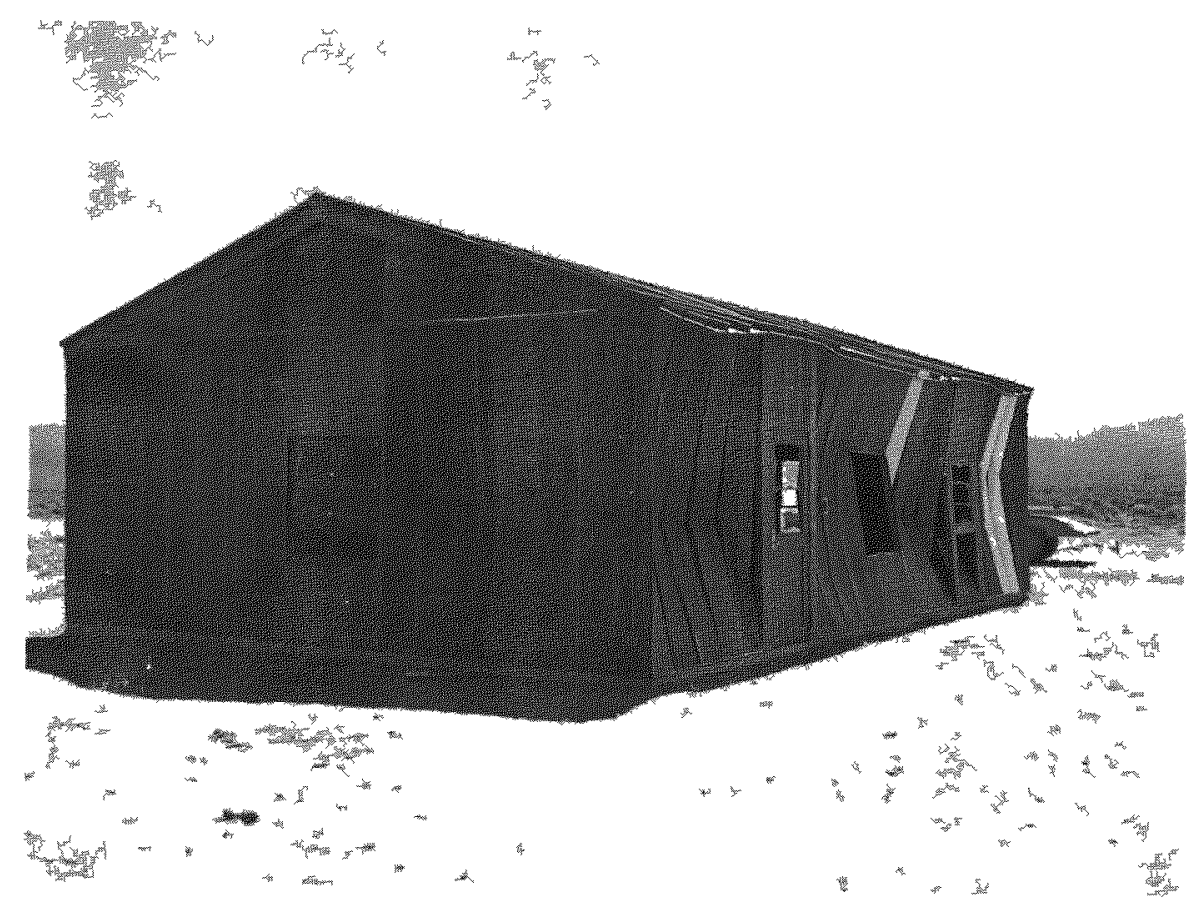

Fig. 2.52-East end and north side of Armco Building 31.2-d2 after planned test.

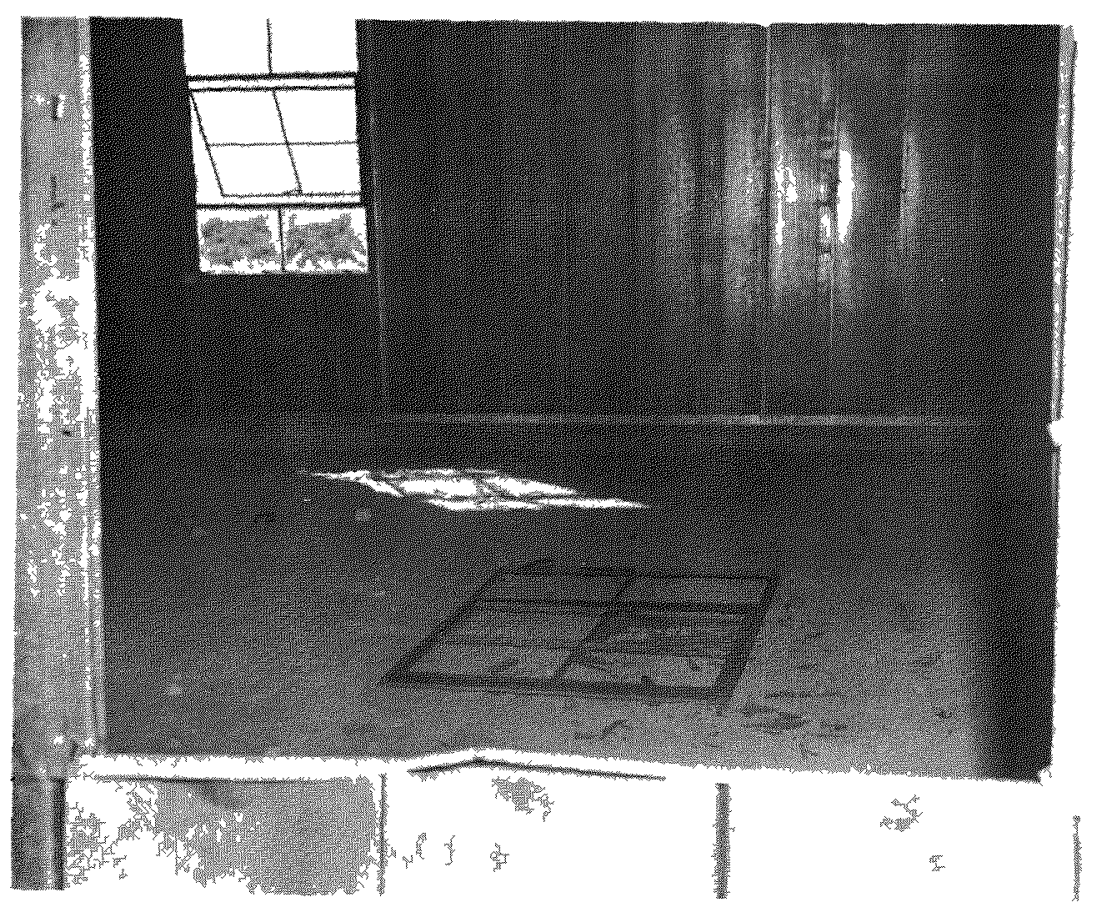

Fig. 2.53-View looking south into interior of Armco Building 31.2-d2 after planned test. 
45

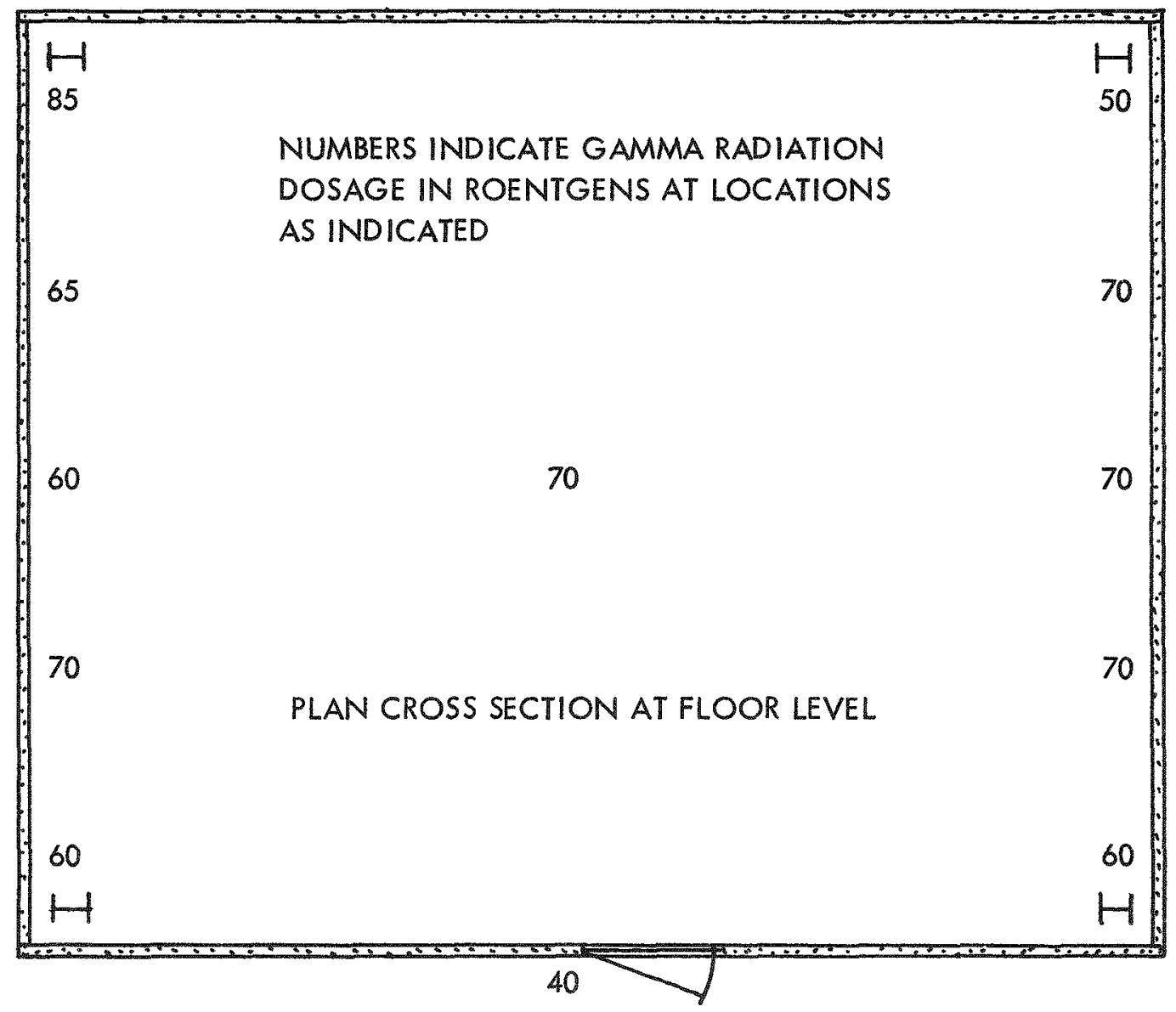

DIRECTION OF BLAST
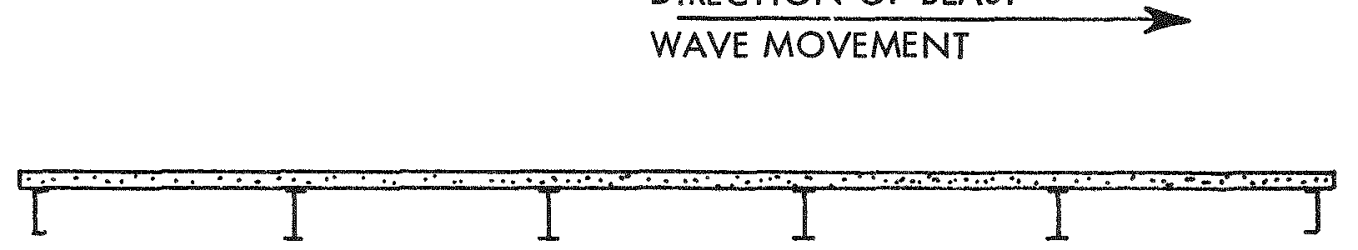

ELEVATION CROSS

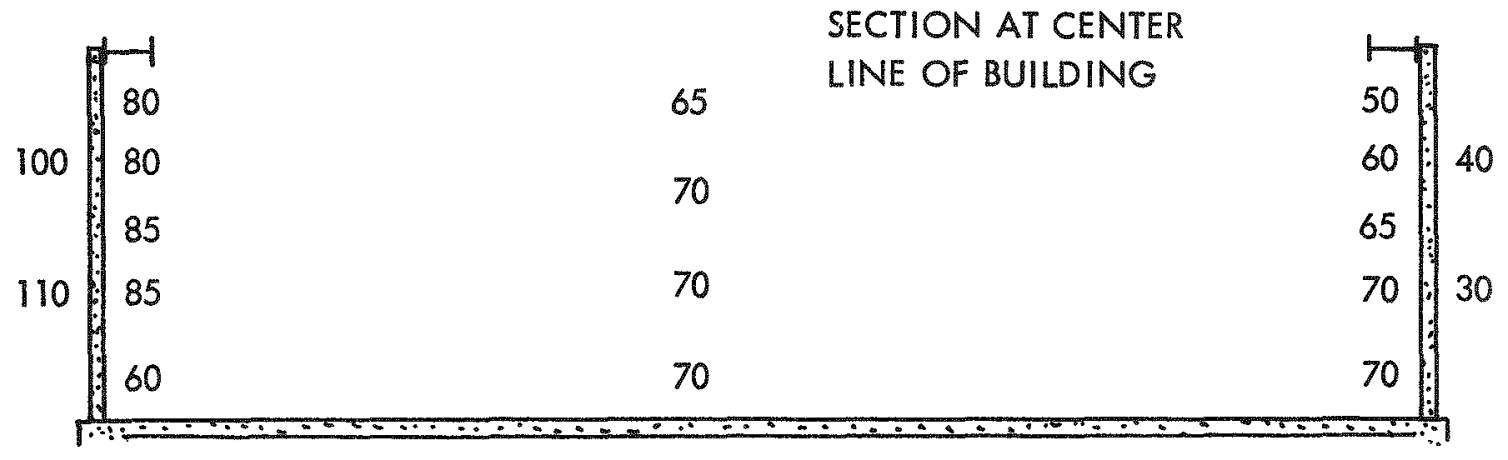

Fig. 2.54- Gamma radiation measurements in Union Carbide building. 


\subsubsection{Damage to Behlen Building 31.2-b2}

Behlen Building 31.2-b2 at 15,000 ft from GZ suffered little structural damage, as shown in Fig. 2.50. Along the ridge line a sag, caused either by the unexpected test or during construction, had been measured at about $0.5 \mathrm{in}$. After the planned test the sag had increased to 1.5 in., but this does not constitute functional damage to the building. Diagonal dimension checks in the interior showed that this building experienced no permanent sideways movement at the eaves.

There was no buckling of the roof or wall panels. With the exception of two window panes in the north wall, other panes in the windows and in the door were broken inward, but the door remained on its hinges. In the rear wall, window panes, with one exception, remained in place, although several were cracked or chipped.

\subsubsection{Damage to Armco Building 31.2 - d2}

As in the case of Reynolds-Butler Building 31.2-a2, the damage to Armco Building 31.2-d2 at $15,000 \mathrm{ft}$ from $\mathrm{GZ}$ for the planned test was similar to the damage experienced in the unexpected test to Building $31.2-\mathrm{d} 1$ at $6800 \mathrm{ft}$ from the planned test. The building had been strengthened in the interim by the addition of reinforcing channels at the doors and window frames.

The wall panels at the door frames did not buckle or bend, thus retaining their original length, whereas bending of the remainder of the north wall caused a depression of the north eave line everywhere except above the doors, as shown in Fig. 2.51. Figure 2.52, looking along the north side, accentuates the bent appearance of the north wall, where maximum wall deflections were between 10 and $18 \mathrm{in}$, except adjacent to the end walls and door frames. Field offset measurements of both wall and roof deflections are given in Fig. 2.7.

The north side of the roof was damaged. Along the ridge line, downward deflections up to $1.5 \mathrm{in}$. were measured. Along the eave line, away from the door frames, downward deflections of as much as $4.5 \mathrm{in}$. were measured. The roof panels were also deflected permanently in bending, some panels having deflections of 4 in. measured as an offset from a sloping straight line from ridge to eave.

Preshot and postshot dimensional checks showed that the north eave line had been displaced downblast approximately $3 \mathrm{in}$. at the interior panel points and $2 \mathrm{in}$. in the plane of the end walls. The south wall eave line was displaced downblast approximately 1.5 in. along its entire length.

The end walls were bent inward, as plotted in Fig. 2.7, with the north half of each wall showing by far the greater amount of deflection.

The entire window sash was blown inward, as shown in Fig. 2.53.

\subsubsection{Gamma Radiation Measurements Within Buildings}

Film badges furnished by Project 39.1 to measure radiation dosage were placed within and without the buildings on the 5500 - and 6800 -ft lines. Thirty-two film badges were placed in or on Union Carbide Building 31.2-e1 since this building appeared to be the only one offering any appreciable shielding. Twenty-one film badges were distributed to the three metal buildings on the 6800 -ft line, but the radiation levels recorded by these badges were not significantly different within and without the buildings. Readings were between 20 and $30 \mathrm{r}$ both within and without the three buildings, with the exception of three badges in Armco Building 31.2-d1. In this building, one badge, located immediately behind the foundation of a piece of heavy machinery inside the building, had a reading of $11 \mathrm{r}$; and two badges, located behind the south side corners of the building, had readings of 15 and $18 \mathrm{r}$, respectively.

In the case of the Union Carbide building at $5500 \mathrm{ft}$, with 4-in. reinforced-gypsum walls, there were significant variations in film-badge readings. A vertical cross section running north and south at the center line of this building and a horizontal cross section at floor level are shown in Fig. 2.54. The only reading not recorded in Fig. 2.54 is one on the outside center line of the east wall at about mid-height of the building which gave a reading of $80 \mathrm{r}$. The gauge near ground level at the same location had a reading of $45 \mathrm{r}$, as shown. The reduction in radiation levels behind the structure, as compared with those in front of the structure, is quite significant. 


\section{Chapter 3}

\section{DYNAMIC ANALYSES}

\subsection{GENERAL}

Since sufficient pressure-time data were available for both the unexpected and planned tests to provide an approximate estimate of load-time curves on the structures, it was planned that dynamic analyses would be made to the extent feasible within the time and budget limitations of the contract. It was not possible to make all the dynamic analyses that might be desired, and it was therefore necessary to make a selection of those problems of greatest promise. The possibilities from which selections might be made were (1) behavior of windows and doors, (2) behavior of wall panels, (3) behavior of roof, and (4) over-all behavior of the structure or main structural frames.

The firm of Ammann and Whitney had made dynamic analyses of the Union Carbide building prior to the test operation. These were for a different level of load, somewhat lower than that actually experienced by the building, and the predictions indicated very minor permanent sets. The actual behavior of the building for loads greater than those used in the dynamic analyses showed even less permanent set than predicted. Thus this building was not tested to its potential survival capacity, and, since the behavior of the structure was mostly in the elastic range, it seemed best to give first priority to dynamic analyses where damage was more severe.

The pressure-time curve for the front face of Union Carbide Building $31.2-\mathrm{e} 1$ at $5500 \mathrm{ft}$ is presented in Appendix $\mathrm{C}$ in comparison with the pressure-time curve that was used in the dynamic-analysis check by the firm of Ammann and Whitney.

In the case of the wall panels in both the Reynolds-Butler and Armco buildings during the unexpected test and at $15,000 \mathrm{ft}$ during the planned test, damage was short of complete failure, but it was nevertheless quite pronounced in all four instances. Careful offet measurements had been made before and after the planned test. Thus, here was an opportunity to correlate predicted load-time curves through strength studies and dynamic analyses with the actual test behavior. The results are presented in Appendixes A and B.

In the case of the Behlen buildings, there was no appreciable damage to either structure in the unexpected test, and in the planned test the only building to receive serious damage was the structure at $6800 \mathrm{ft}$. In this case the north slope of the roof was deflected downward 14 to 15 in.; however, the uncertainties as to the differential pressure-time curve on the roof, as well as the rather uncertain interaction between the roof and wall, made the dynamic analysis of the roof action rather complex. In addition, the differential pressure-time curve on the roof is complicated by the important effect of the build-up of internal pressure as the result of the failure of the front door and windows. The passage of an attenuated shock wave into the interior of the structure, with resultant complex reflections from the back wall and underside of the south side of the roof, is known to be of considerable importance, and it represents a calculation task beyond the scope of the present studies. 
The main continuous steel frames of the Reynolds-Butler building at $6800 \mathrm{ft}$ suffered appreciable permanent deflection in the planned test, and it would have been desirable to attempt dynamic analyses of these. However, the load-time curve would be extremely uncertain because the girts and purlins, together with shreds of broken, bent, and twisted wall paneling, remained attached to these frames after failure. Thus the calculation of the drag loading after wall failure would be impossible for practical purposes.

As a result of the foregoing considerations, the choice was narrowed to the wall panels of the Reynolds-Butler and Armco buildings. Detailed accounts of these dynamic analyses are given in Appendix A for the Reynolds-Butler wall panels and in Appendix B for the Armco wall panels.

\subsection{WALL-PANEL BEHAVIOR}

\subsubsection{General}

The dynamic analyses of the wall panels in both the Reynolds-Butler and Armco buildings involved approximately the same loading conditions since the north walls of the two structures were almost identical in size and shape. The procedure followed in making a dynamic analysis has been described in a general way in Chap. 1, Sec. 1.2. Overpressure-time curves were available at $4700,10,500$, and $15,000 \mathrm{ft}$ from $\mathrm{GZ}$. In the planned test the only dynamic analysis presented herein was for the 15,000-ft distance, and the actual available pressure-time curve was used. For the unexpected test, dynamic analyses were also made, but the pressure-time curve data were obtained by indirect means, as discussed in Appendix C.

A comparative study of all the availabie pressure-time curves was made with consideration of the altitude of the test site and other factors. For the distances at which buildings in Project 31.2 were tested, as the result of careful interpolation of available information, the following data can be used as a basis for further damage studies. The data recorded here are appropriate for the determination of equivalent standard curves, and the durations are not necessarily the same as those actually recorded.

$\begin{array}{ccc}\begin{array}{c}\text { Distance } \\ \text { from GZ, ft }\end{array} & \begin{array}{c}\text { Initial over- } \\ \text { pressure, psi }\end{array} & \begin{array}{c}\text { Duration of } \\ \text { positive phase, } \\ \text { sec }\end{array} \\ 5,500 & 4.10 & 1.15 \\ 6,800 & 2.98 & 1.20 \\ 15,000 & 1.26 & 1.48\end{array}$

Using the procedures available in declassified portions of reference 1, pressure-time curves, for the initial period during which maximum wall-panel deflections were reached, are given in Fig. 3.1 for both the unexpected and planned tests. These curves are based on the assumption that a plane shock wave strikes a rigid vertical wall and is reflected back from the wall with a reflection factor of slightly more than 2 . Since the wall panels are not rigid, these curves tend to overestimate the actual pressure in the early portions of the curves. A very crude correction has been supplied to compensate partially for the movement of the walls by introducing a hypothetical back pressure as a function of velocity, as explained in Appendix A. Appendix A gives complete details as to all steps of the dynamic analysis. The effect of virtual air mass has been introduced, allowing for the fact that the wall panels carry with them a mass of air, thus increasing their effective mass. In a heavy wall this would be a negligible factor; however, in a very lightweight aluminum wall, the effective mass is roughly doubled (Eq. A.19). It turns out that this has a relatively small effect on the final maximum deflection of the wall panel, and thus the air-mass effect in the present instance is largely of academic interest. In dynamic analyses of structures under water, the effect is customarily considered and is of greater importance. 


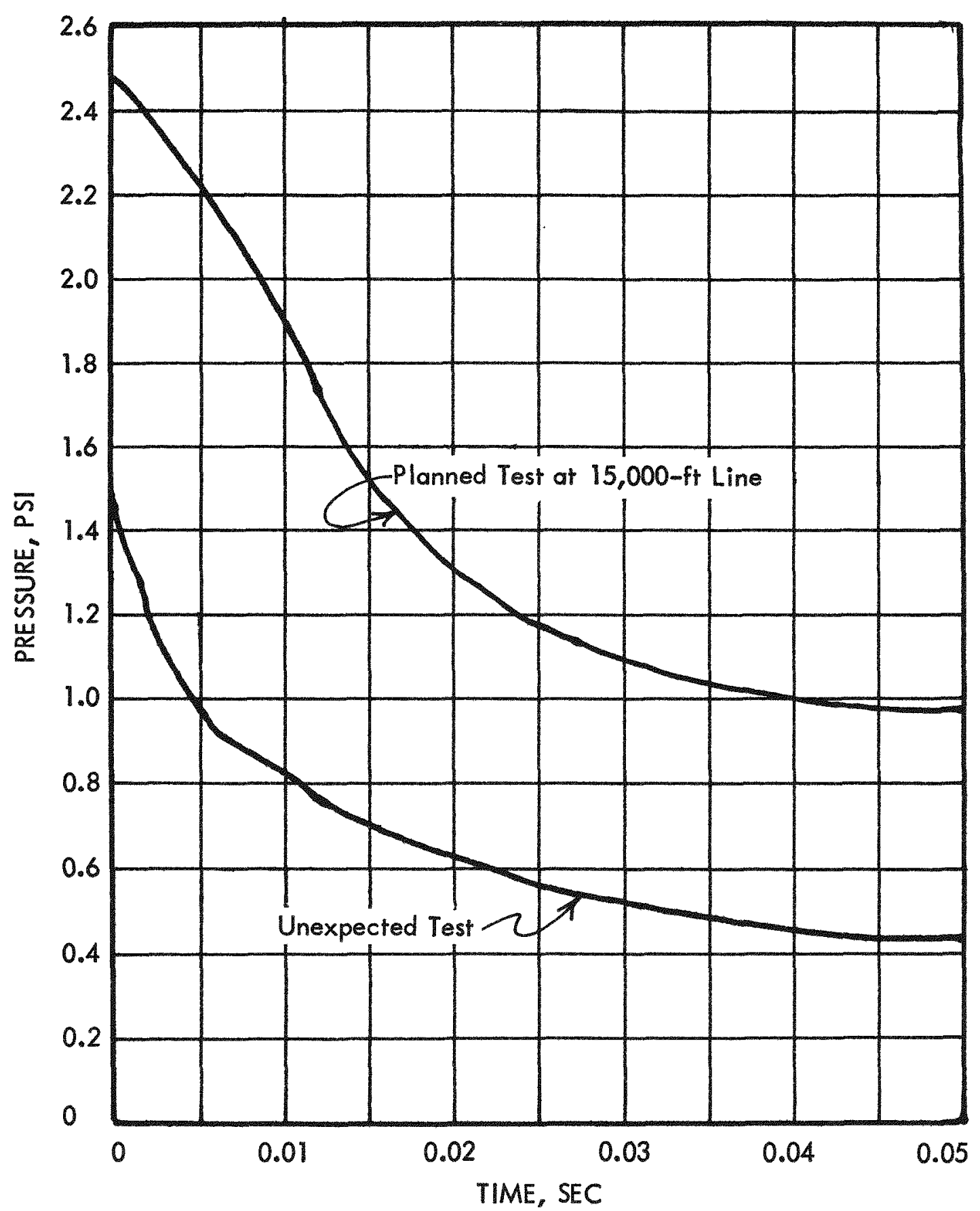

Fig. 3.1-Estimated pressure on exterior of north wall for cases analyzed in Appendixes $A$ and $B$. 


\subsubsection{Comparison of Dynamic Analyses and Test Results for Wall Panels}

A complete description of the dynamic analysis of the walls of the Reynolds-Butler buildings is given in Appendix A. This includes the establishment of the resistance function for the walls, including the bending strength of the girts, the catenary resistance of the girts, and the catenary resistance spanning vertically of the aluminum sheeting. Each of these factors must be considered in detail to obtain even an approximate agreement between the dynamic analysis and the test result. Appendix B gives the dynamic analysis of the Armco wall panels in somewhat less detail since the analysis parallels that for the Reynolds-Butler buildings. The contribution of catenary strength is relatively less pronounced in this structure. In Table 3.1 the maximum deflection refers to the maximum deflection of a girt above or below the center of the wall panel in the case of the Reynolds-Butler buildings and to the actual maximum deflection in the case of the Armco buildings.

TABLE 3.1-COMPARISON OF TEST RESULTS WITH DYNAMIC ANALYSES

\begin{tabular}{llcc}
\hline Building & Test & $\begin{array}{c}\text { Calculated maximum } \\
\text { deflection, in. }\end{array}$ & $\begin{array}{c}\text { Measured maximum } \\
\text { permanent set, in. }\end{array}$ \\
\hline Reynolds-Butler & Unexpected & 6.9 & 4.5 \\
Reynolds-Butler & Planned & 19.4 & 16.3 \\
Armco & Unexpected & 4.6 & 4.9 \\
Armco & Planned & 19.4 & 18.2 \\
\hline
\end{tabular}

In Table 3.1 it is to be noted that the unexpected test refers only to the structures on the 6800-ft line from the planned test, and the planned test refers only to the structures on the 15,000-ft line. In the planned test at the 6800-ft line, the wall panels were completely destroyed in the early milliseconds subsequent to impingement on the shock front on the front of the buildings.

\section{RE FERENCE}

1. L. J. Vortman and M. L. Merritt, Methods for Estimating Blast Loading on Simple Structures, Sandia Corporation, Report AFSWP-226, September 1953. 


\section{Chapter 4}

\section{DISCUSSION}

\subsection{GENE RAL}

With reference to the three utility type buildings, the tests fulfilled their objectives fully; overpressures were very close to those that had been anticipated, and it is possible to estimate fairly well the survival range for the structures when exposed to a bomb producing a blast wave with pressure-time characteristics similar to those experienced in the present operation. The unexpected test was a valuable supplement to the planned test in that it produced damage to two of the structures at the borderline of wall survival, thus giving two extra evaluations of the wall strength of these structures.

It should be emphasized again that none of the utility structures was designed in any way for blast resistance. The Behlen buildings, which stood up so well under blast, seemed to be considerably overdesigned for conventional loads. This is partially due to the relatively small size of the buildings under test. The relative conclusions made as a result of these tests should not be extrapolated to structures of, say, twice the roof span of those tested.

The discussion of damage in Chap. 2 has been given in considerable detail as a matter of record. It is believed that these details of damage and a study of the figures will be of considerable value in the improvement of design, even for normal type loads. The dynamic analyses of the wall-panel structures for the Reynolds-Butler buildings have been of considerable value in bringing to light certain factors that, although known, have not received sufficient emphasis. With reference to Fig. A.5, it will be seen that the major contribution by far to wall resistance in the Reynolds-Butler buildings accrues from the combined two-way catenary action of the girts horizontally and the wall panels themselves spanning vertically. This is true even though the most usual type of attachment was made at the ends of the girts and at the top and bottom of the wall panels. Catenary resistance could have been increased severalfold if fully continuous-girt end connections and better top and bottom wall-panel attachments had been used. The design for conventional load is adequate, based on bending strength alone; however, the catenary contribution to wall strength, not even considered in the design, is the major factor contributing to ultimate wall strength.

Another interesting result shown in Appendix $A$ is the fact (as indicated in Fig. A.6) that the acceleration and velocity-time patterns are markedly altered when the virtual mass of air is added to that of the very lightweight wall panels. No claim is made in this report that a highly precise analysis of this effect has been carried out. This is not possible in view of the limited state of knowledge of this phenomenon at the present time. However, it has been demonstrated that the effect is a marked one, and verification in further tests could be made by obtaining a complete acceleration-time record of a given wall panel.

In comparing the three utility type buildings in the planned test at $6800 \mathrm{ft}$, the ReynoldsButler buildings benefit because of their sturdy continuous steel frames, which have great elastic and plastic ultimate strength. These structures presented a very torn up appearance 
after the blast because of the complete and disordered failure of the very light wall and roof sheeting. In the main frame of these buildings, the corner columns on the north side were severely bent and twisted. The Behlen buildings show up in a superior way in these particular size structures. These buildings have great inherent strength because of the deep corrugations and heavy-gauge metal, and they also benefit a great deal because of the more-than-adequate bolted connections between all joining parts. This results in the over-all structure "hanging together" very well. In contrast to the Behlen buildings, the Armco buildings, although quite adequately designed for conventional wind and snow loads, show up poorly in a heavy blast zone. One of the main reasons for this is the inadequate end connections of the wall panels at the eaves, along the sill, and at other parts where the joints are made. The aim in these structures seems to be ease and speed of erection. The panels are fitted together with a minimum of connecting bolts, and metal screws are used in many instances. In general, it can be said that, if members and sheeting are interconnected by only sufficient bolts for normal loads, the full inherent strength that could be available for overloads is not anywhere near realized. The failures that were experienced in these tests were largely failures of connections. Of course, if the connections had been more adequate for blast loading, other types of failure would have ensued.

\subsubsection{Union Carbide Building 31.2-e1}

The almost complete lack of damage, except to window and door details, at the relatively close range of $5500 \mathrm{ft}$ and at a peak overpressure of about 4.1 psi, demonstrated the effective elastic resistance of well-designed continuous-welded heavy-steel-frame construction. Of course, the known ability of the same type of construction to withstand great deformation into the plastic range was not explored as it might have been if another identical structure had been exposed at a closer range. The low level of permanent sets in panels and members, ranging from none at all to measurements of $1 / 8$-in. vertical movement upward of roof girders and of $1 / 4$-in. lateral movement of the lower flange in the roof girders, validated the dynamic analyses made by Ammann and Whitney in a qualitative way. This structure could have withstood much greater overpressures without complete failure, and the results demonstrated the feasibility and value of actually designing for blast loads if protection is desired. The 4-in. -thick reinforced-gypsum wall construction also showed up very well for the relatively short spans involved. The wall suffered practically no permanent damage, except for some surface spalling and minor structural cracking. Here, also, it would have been helpful to have had exposure at a closer range since an objective of this test was to determine the behavior of reinforced gypsum at incipient failure.

The behavior of this building would doubtlessly depend, to some degree, on the orientation with respect to the origin of the blast. The large window area at the top of the building undoubtedly permitted considerable pressure relief inside the structure, reducing the differential pressure between the inside and outside.

\subsubsection{Reynolds-Butler Buildings 31.2-a1 and 31.2-a2}

Under peak overpressures of 1.26 and $0.72 \mathrm{psi}$ in the planned test at $15,000 \mathrm{ft}$ and the unplanned test, respectively, the main steel frames of these buildings stood up very well, although the wall paneling and roofing suffered very large permanent deflections along with their supporting girts and purlins in the north wall and north roof facing the blast source. Under the greater overpressure in the planned test of about $3.0 \mathrm{psi}$ at $6800 \mathrm{ft}$, the main frames were permanently damaged, and the wall paneling and girts were, in general, carried away.

The main criticism of these structures for low-level blast loading is that they are not designed as frangible wall structures optimizing survival chances of main frames, girts, and purlins and that they are not in any sense protective, even to the capacity that could be realized with moderate changes in the design. In other words, the walls as designed are not weak enough to provide good frangible construction, nor are they strong enough to provide good protective construction. If the panels had been lapped with minimum strength connections at or between each girt to reduce catenary action and provide venting, it is likely that the frame would have survived the planned test at $6800 \mathrm{ft}$ with no appreciable damage. Then new wall and roof covers could be quickly installed, and the structures could be rapidly restored to 
their original condition. Also, it would be desirable to eliminate the overhang of the roof panels at the eave. It is obvious that, from the large deflections in the roof immediately adjacent to the eave, the clearing of reflective wall pressure spilling over the front edge of the structure nearest the blast causes a severe tilting action pressing upward on the roof paneling that juts beyond the wall. When this is added to the downpressure on the roof itself, the result is an excessive deflection in the roof near the eave, as shown in Fig. 2.3. It seemed desirable to crop the roof panels off close to the eave corner, even though the appearance suffered somewhat.

A considerable improvement in the protective capacity of these structures can be achieved by the following measures:

1. Improve the design of girts and purlins. Use flanged $U$ sections instead of $Z$ sections. Improve the end reaction strength by eliminating coping cutouts and increasing the number of bolts at each end. Alternatively, the girts and purlins might be made fully continuous by welding.

2. Increase the number of bolts holding the sill angle to the wall sill footing.

3. Increase the number of bolts attaching the aluminum paneling to the sill angle at the bottom and to the eave member at the top.

4. Improve the footing and anchorage for the main frames to avoid the failure indicated in Fig. 2.47 and to improve the capacity for the greater reactive loads that would be experienced if the wall and roof construction were improved.

5. It should be emphasized that the potential catenary strength of the girts and of the aluminum sheeting, thin as it is, is not realized. Thus there is no need to increase the thickness of the thin aluminum sheeting if semiprotective construction is the goal.

6. Eliminate overhang of the roof at the eaves.

\subsubsection{Behlen Buildings 31.2-b1 and 31.2-b2}

The excellent blast resistance of Buildings $31.2-\mathrm{b} 1$ and $31.2-\mathrm{b} 2$, as described in Chap. 2, accrues from a combination of favorable circumstances:

1. The use of heavy-gauge steel sheet cold formed into shapes resistant to local buckling.

2. The considerable lateral bending strength and column strength of the same shapes that result from the very deep corrugations.

3. The use of a more-than-adequate number of reasonably large bolt fasteners to form all connections.

The unusual design characteristic of Buildings $31.2-\mathrm{b} 1$ and $31.2-\mathrm{b} 2$ is the fact that there is no internal supporting frame or bracing, other than small knee braces at the eaves and a longitudinal member just below the ridge. With all the strength concentrated in the "skin" and with more-than-adequate connections between various panels and between the wall and sill, the se structures show a great ability to hang together, although they were seriously deformed in the planned test at $6800 \mathrm{ft}$ from GZ at peak overpressures of approximately 3.0 psi.

These structures in large sizes have not been tested as yet by blast loads. Undoubtedly, large-sized structures would show the same tendency to hang together, but the survival range from $\mathrm{GZ}$ for the same yield detonation might vary considerably as the size of structure changed. This is partly due to the fact that these structures are not designed for conventional loads in the ordinary sense of the word, nor with the care that has been applied to the design of the Armco and Reynolds-Butler buildings. In these structures a great deal of painstaking design study has been given so that the buildings are just the right strength and not overdesigned for conventional loads. In the case of the Behlen buildings, a great deal of common sense and intuitive appreciation for good structures is in evidence, but it seems possible that the design analysis for conventional loads has not reduced the materials and bolt sizes to a minimum. Of course, this makes these structures show up to advantage when they are subjected to heavy blast loading.

The internal strut, running parallel and just beneath the ridge as shown in Fig. 2.36, is inadequately attached at each end, and its function has been imperfectly analyzed.

In view of the very excellent protective potential of these structures, a further study of it is recommended to make a real dynamic analysis and to permit evaluation not only of the test structure but also of larger size structures. 


\subsubsection{Armco Buildings 31.2-d1 and 31.2-d2}

The Armco buildings, like the Reynolds-Butler buildings, have been carefully designed for conventional loads, with connection material and thicknesses of all members and sheets reduced to a minimum. The Armco buildings are a very popular type, and they are put together by standard procedures in a very simple way. However, in comparison with the ReynoldsButler buildings, these structures suffer from the fact that they have no internal framing to provide a skeleton for reconstruction if damage is severe. Thus these buildings go all to pieces in the fashion of the "one-horse shay." On the other hand, at low damage level, as under an initial overpressure of $0.72 \mathrm{psi}$ in the unexpected test, these structures were easily repairable by the replacement of damaged wall panels. Repair is facilitated because of the simple interlocking construction.

When the Armco structures experience loads that cause complete wall failure, e.g., at $6800 \mathrm{ft}$ from $\mathrm{GZ}$ in the planned test, there is not much possibility of further use or repair. The skin of these structures, with their simple interlocking features and minimum number of connecting bolts, does not hold together well under destructive loading. As mentioned previously, and as is true also in the case of the Reynolds-Butler buildings, the inability of the Armco structures to survive atomic blast loads in no way reflects on their utility under the normal wind and snow loads for which they are designed.

\subsection{SUMMARY AND CONCLUSIONS}

1. The test structures, of the size and with the orientation relative to blast that were used in this program, showed an ability to survive overpressures and durations which are deduced from the unexpected and planned tests reported herein, as estimated and summarized in Table 4.1.

TABLE 4.1-BUILDING DAMAGE RELATED TO APPROXIMATE PEAK OVERPRESSURES

\begin{tabular}{|c|c|c|c|c|}
\hline \multirow[b]{2}{*}{ Type of damage } & \multicolumn{4}{|c|}{ Peak overpressure, psi } \\
\hline & Union Carbide* & $\begin{array}{l}\text { Reynolds- } \\
\text { Butler }\end{array}$ & Behlen & Armco \\
\hline $\begin{array}{l}\text { Negligible structural } \\
\text { damage; door and } \\
\text { window repair or } \\
\text { replacement needed } \\
\text { Local structural } \\
\text { damage; repairable } \\
\text { Major structural } \\
\text { damage; repair } \\
\text { difficult or im- } \\
\text { practicable }\end{array}$ & $>4$ & $\begin{array}{l}3 / 4+ \\
1 \dagger\end{array}$ & $\begin{array}{l}1 / 4 \\
3\end{array}$ & $3 / 4$ to $1 / 4$ \\
\hline
\end{tabular}

* Blast-resistant building.

$\dagger$ For a good external appearance, aluminum paneling and roofing would also need replacement over a considerable portion of the structure.

+ Repair would involve an extensive replacement of the girts and purlins, all external sheeting, and straightening of main frames by flame.

2. In connection with the utility type structures, the tests were of value in showing how each building could be improved in its ability to provide protection from low-level blast loading. In general, the greatest need is increased strength in connections.

3. In the case of the Reynolds-Butler buildings, the conventional design would lend itself to a drag type frangible wall construction if so desired. Improvements in design for such modification have been suggested.

4. The tests of the Reynolds-Butler buildings indicated that the great contribution of girts and wall panels by catenary action was not considered in the design. 
5. The effect of air cushioning on the dynamic behavior of the light wall panel has been studied, and it can be concluded that, although the change in apparent mass is pronounced, the effect on the maximum actual deflections may be of minor importance.

\subsection{RECOMMENDATIONS}

1. If further similar tests are conducted, different orientations and different building sizes should be investigated.

2. If buildings of the Union Carbide blast-resistant type are tested again, they should be built in duplicate or triplicate at variable distances from $\mathrm{GZ}$ in order to obtain enough damage to expose any weaknesses that may exist in the design.

3. If protective construction is the goal, even at much greater levels of overpressure than those experienced by the buildings in this program, the idea of utilizing the catenary or skin tension strength instead of the bending strength of wall surfaces should be fully explored. Although the importance of this fact has been demonstrated in these test structures, it has been an accidental rather than an intentional result. (Because of the importance of this item, a further study of it is planned currently at the University of Michigan.)

4. Further attention is needed to reduce the missile hazard resulting from the use of conventional windows and doors. They should be either self-venting or blast resistant to a degree comparable with the rest of the structure.

5. Although analysis of the wall panels together with their supports is a complex problem, especially in the case of the Reynolds-Butler buildings, a reasonable agreement has been obtained in these studies between deflections experienced in both the unexpected and planned tests for both the Reynolds-Butler and Armco buildings. 


\section{Appendix A}

\section{ANALYSIS OF WALL BEHAVIOR: REYNOLDS-BUTLER BUILDINGS}

A careful study of the dynamic behavior of the walls of the Reynolds-Butler buildings seemed particularly appropriate because the planned test at $15,000 \mathrm{ft}$ and the unexpected test resulted in varying degrees of partial damage which gave promise of correlation with available pressure-time data. Also, as it turned out, several novel, although complicating, factors had to be considered in order to achieve good correspondence between theory and test.

A general description of these buildings is given in Sec. 1.3.2, and general drawings, are shown in Figs. 1.10 and 1.11. Over-all behavior during the unexpected test is described in Secs. 2.1.2 and 2.1.3, and behavior during the planned test is described in Secs. 2.2.3 and 2.2.6. Figure 2.1 shows the wall after the unexpected test, and Fig. 2.2 records the measured offsets of permanent wall deflection after both the unexpected and planned tests. Figures 2.3 to 2.5 show other views of damage to the walls and roof which resulted from the unexpected tests, and Figs. 2.46, 2.48, and 2.49 show the wall condition after the planned test at the 15,000-ft line.

The walls, being of small mass, either fail or reach maximum deflection in a short time (less than $0.045 \mathrm{sec}$ ). For this reason, only the initial part of the pressure-time curves for the walls need be considered, and these curves are plotted in Fig. 3.1, as explained in Sec. 3.2.1. The curves as shown include the reflection effect, but they are based on the assumption that secondary effects due to wall motion can be neglected.

In studying the dynamic behavior, resistance to applied force is usually thought of as being comprised of two parts. First, there is the mechanical resistance, usually assumed to be equivalent to the static load resistance but increased by a "dynamic load factor" to compensate for the increase in material strength due to strain rate. Second, there is the resistance offered to the force that is required to produce acceleration of the effective wall mass, sometimes called "inertial resistance."

The resistance of the walls to pressure is initially quite simple to calculate, but the calculation is complicated by a number of factors as the deflections get large. Initially, the bending strength of the lightweight aluminum panels is sufficient to transmit the load to the girts, and they, in turn, transmit the panel reactions to the columns with adequate bending strength of their own. After the girts deflect about 2 in., they begin to develop sufficient direct tensile force so that their resistance is increased by what will be termed "catenary" action, for want of a better term. At about the same time, catenary action of the aluminum wall panels in a vertical direction begins to add appreciably to the over-all panel resistance. Thus, from maximum girt deflections of about 2 in. up to deflections of about 14 in., when the girts fail at their ends, the over-all panel resistance is comprised of three main parts, each of which will be analyzed separately:

1. Bending resistance of girts.

2. Catenary resistance of girts. 
3. Catenary resistance of aluminum wall sheeting. After failure of the girts the aluminum panels continue to deflect and offer increasing catenary resistance until they finally tear away from their bolts at the top and bottom ends with center deflections of over 20 in.

Figure A.1 shows the actual cross section through the wall with the aluminum sheeting running vertically and supported at location 1 by the sill angle, at locations 2 and 3 by girts, and at location 4 by the eave strut. Although the disposition of the girts is slightly unsymmetrical, in order to simplify the analysis the assumption of symmetry is made as shown in the force diagram of the same cross section after it undergoes large deflections. Because of symmetry, reference will be made only to the forces and deflections in one-half of the wall

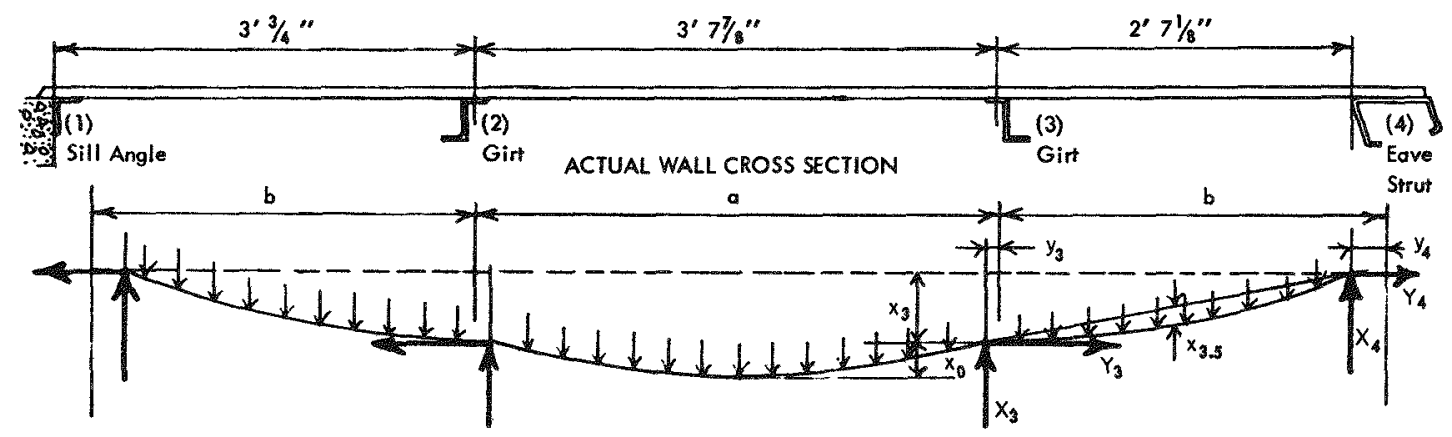

Fig. A.1-Wall cross section at center line of girt, showing forces acting at large deflections. (Dimensions slightly modified to introduce symmetry.)

cross section. After the deflections get large the catenary action predominates, and, since the sheeting tries to retain its original length, it pulls down at the top against the eave strut, developing force $Y_{4}$ with assumed center deflections $y_{4}$ in the vertical direction. It is assumed that the horizontal deflection of the eave strut can be neglected. Similarly, the sill angle at the bottom is pulled upward, with different behavior as compared with the eave strut, but this difference will be neglected in order to simplify the analysis. The top girt is also pulled down at location 3 with deflection $y_{3}$, developing its own vertical reactive force $Y_{3}$. Similarly, the lower girt at location 2 is pulled upward. Figure A.1 is intended to represent conditions at the center of the girt, hence deflection $x_{3}$ is the maximum girt deflection, and the behavior of the wall panel at all times will be referenced to this particular deflection. Forces $X_{3}, Y_{3}, X_{4}$, and $Y_{4}$ are in pounds per inch for a 1 -in.-width strip. If any value of $x_{3}$ is arbitrarily assumed, $X_{3}$ (as will be discussed in Sec. A.2) is determined since it is a function of $x_{3}$.

If all the forces in the $x$ direction are now summed, with symmetry assumed

$$
x_{3}+x_{4}=q\left(b+\frac{a}{2}\right)
$$

Now (still referring to Fig. A.1), consider a free body of the section between locations 3 and 4 and take moments about the deflected position of point 3

$$
b \mathrm{x}_{4}-\mathrm{x}_{3} \mathrm{Y}_{4}-\frac{\mathrm{qb}^{2}}{2}=0
$$

Since the girts deflect less than $x_{3}$ at points other than the center line, the contribution of panel catenary action to load resistance will not be so great at the ends of the girts as at their center. However, the desired answer is the total load capacity of all factors in combination. As a reasonable approximation the load distribution at the center will be assumed to exist at all sections along the girt.

If Eqs. A.1 and A.2 are now combined to eliminate $X_{4}$, the following equation is obtained for average unit load carried by the panel:

$$
q=\frac{2}{a+b}\left(X_{3}+\frac{x_{3}}{b} Y_{4}\right)
$$


However, in Eq. A.3, $\mathrm{Y}_{4}$ must be determined, and it can be established as a function of $\mathrm{y}_{4}$, provided the elastic stretch in the aluminum panel can be neglected. This will be a relatively good approximation if the paneling stays within the elastic limit, which will be the case if the eave strut and panel connections are relatively weak with respect to vertical load capacity. This is true in the present design.

Consideration will now be given to the determination of $y_{4}$. In the central vertical segment of wall paneling between locations 2 and 3 , the tension force per unit width of the paneling is $Y_{3}+Y_{4}$. Let the additional horizontal deflection at the center in reference to location 3 be $x_{0}$, as shown in Fig. A.1.

Considering the center segment between locations 2 and 3 and neglecting the elastic stretch in the paneling,

$$
y_{3}=\int_{0}^{a / 2} \frac{1}{2}\left(\frac{d x}{d y}\right)^{2} d y
$$

Under a uniform pressure load the paneling, in the absence of bending resistance, would deform in the shape of a circular arc. However, the assumption that the curve is a parabola will be a reasonable approximation for the deflections in the range applicable to this problem, and this assumption, introduced in Eq. A.4, leads to the following formula for $y_{3}$ :

$$
\mathrm{y}_{3}=\frac{4 \mathrm{x}_{0}^{2}}{3 \mathrm{a}}
$$

Considering now the force equilibrium of one-half of the center panel segment, which carries a tensile force of $Y_{3}+Y_{4}$, the following equation is obtained for the relative deflection $x_{0}$ at the center of the panel:

$$
\mathrm{x}_{0}=\frac{\mathrm{qa}^{2}}{8\left(\mathrm{Y}_{3}+\mathrm{Y}_{4}\right)}
$$

By combining Eqs. A.5 and A.6, the following equation for $y_{3}$ is obtained:

$$
y_{3}=\frac{q^{2} a^{3}}{48\left(Y_{3}+Y_{4}\right)^{2}}
$$

Similarly, by applying Eq. A.4 to the top panel segment between points 3 and 4 and by introducing the equilibrium of this free-body diagram, the following two equations are obtained:

$$
\begin{aligned}
& \mathrm{y}_{4}-\mathrm{y}_{3}=\frac{1}{\mathrm{~b}}\left(\frac{\mathrm{x}_{3}^{2}}{2}+\frac{8}{3} \mathrm{x}_{3.5}^{2}\right) \\
& \mathrm{x}_{3.5}=\frac{\mathrm{qb}^{2}}{8 \mathrm{Y}_{4}}
\end{aligned}
$$

By collecting the information in Eqs. A.5 to A.9, the following formula for vertical movement at the top of the panel is obtained:

$$
\mathrm{y}_{4}=\frac{\mathrm{q}^{2} \mathrm{a}^{3}}{48\left(\mathrm{Y}_{3}+\mathrm{Y}_{4}\right)^{2}}+\frac{\mathrm{q}^{2} \mathrm{~b}^{3}}{24 \mathrm{Y}_{4}^{2}}+\frac{\mathrm{x}_{3}^{2}}{2 \mathrm{~b}}
$$

As previously mentioned, $\mathrm{y}_{4}$ represents not only the vertical movement downward at the top of the panel but it is also assumed to be the center deflection vertically of the eave strut. Thus, for any arbitrarily assumed value of $\mathrm{x}_{3}$, introduced into $\mathrm{Eq}$. A.10, mutually associated values of $y_{4}$ and $Y_{4}$ which will be compatible both with the relation expressed by Eq. A.10 and the vertical load resistance of the eave strut must be determined. Also, it is noted that $Y_{3}$ enters Eq. A.10. However, this is a small effect, and a very rough approximation will serve in the present example. Before utilizing Eqs. A.3 and A.10 for the determination of the load 
capacity of the wall panel, the lateral load resistance of the girts and eave strut must be determined.

Initially, the resistance of the girt to load in either the vertical or horizontal direction results from its bending strength. After deflections of 2 in. or more at the center, the girt begins to develop a longitudinal tension force and the associated catenary resistance. If the tension force becomes appreciably high in relation to the total tensile yield strength of the member, the bending resistance in the plastic range will be reduced below the value for bending alone. The use and changing orientation of the $\mathrm{Z}$ section girts in the present design introduced a further complicating factor. As shown in Fig. A.1, the upper girt is pulled down vertically by the panel movement. This introduces a twist and changes the axis of bending so that the bending strength of the girt in a horizontal direction is weakened. Simultaneously, the bending strength in the vertical direction is strengthened. This pulling together and twisting of the girts can be clearly seen in Figs. 2.4 and 2.5 for the unexpected test, and the effect was even more pronounced, although it is not shown in the figures, in the planned test. The fact that the twist varies all along the girt with related variation in bending strength is a very complicating factor. Initially, the girt is held in position by the panel, so long as the deflections are small, and elastic behavior by bending in the $x$ direction as a simple beam can be assumed. In this range the deflection at the center will be

$$
\mathrm{x}_{3}=\frac{5}{384} \frac{\mathrm{X}_{3} \mathrm{~L}^{4}}{\mathrm{EI}}
$$

In the wall panel and girts the rates of strain will be relatively high, and it will be assumed that the steel in the girt material has a dynamic yield stress of 50,000 psi. This corresponds to a dynamic increase factor of about 50 per cent over the minimum yield strength of 33,000 psi for structural steel.

The elastic and plastic cross-sectional properties of the $\mathbf{Z}$ section girt are tabulated below:

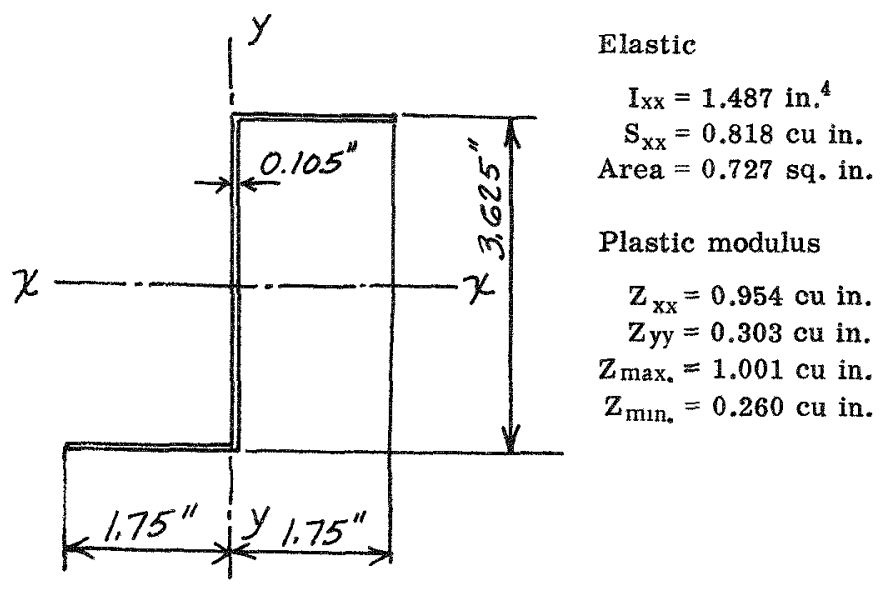

By assuming that the girt carries a uniform load and that it is simply supported at the ends, the following equation is determined as a load for an inch of length when the girt material reaches the yield point stress:

$$
\left|\mathrm{X}_{3}\right|_{\text {yield }}=\frac{8 \mathrm{~S} \sigma_{\text {yield }}}{\mathrm{L}^{2}}=\frac{(8)(0.818)(50,000)}{(142)^{2}}=16.23 \mathrm{pli}
$$

As the girt continues to bend, it presumably will increase in load capacity in the plastic range until it reaches its full plastic bending strength. However, as deflections increase and the girt twists at the center, it offers less resistance to bending, and, as a conservative assumption, it may finally orient itself in a position that offers minimum resistance to bending. At the same time, tensile force is developed due to catenary action. An investigation should now be made as to whether or not the minimum bending strength will be appreciably reduced by the tensile force in the girt. 
The cross section at the end of the girt is reduced in area by coping, and the connection consists of a single $1 / 2$-in.-diameter bolt. This is insufficient to develop the tensile yield strength of the girt, and the maximum tension force is later determined as approximately $10,000 \mathrm{lb}$. In a simple rectangular element subjected to combined bending and direct stress, the following relation holds:

$$
\frac{\mathrm{M}}{\mathrm{M}_{\mathrm{y}}}+\frac{\mathrm{T}^{2}}{\mathrm{~T}_{\mathrm{y}}^{2}}=1
$$

In the present case the tensile yield strength of the girt is $T_{y}=0.727 \times 50,000=36,400 \mathrm{lb}$. From Eq. A.13, the ratio between the resisting moment and the full yield moment of the $\mathrm{Z}$ bar, assuming the same behavior as for a simple rectangle, is

$$
\frac{\mathrm{M}}{\mathrm{M}_{\mathrm{y}}}=1-\frac{\mathrm{T}^{2}}{\mathrm{~T}_{\mathrm{y}}^{2}}=1-0.075=0.925
$$

Although the relation for the $\mathrm{Z}$ bar will be slightly different, this value will be used to determine the minimum bending strength, which, in the large deflection range, is a very small percentage of the total resistance. Thus, any error introduced by this approximation will be negligible so far as any estimate of the over-all resistance is concerned. Initially, when the girt is held vertically in position by its attachment to the panel, the maximum plastic bending strength will be

$$
\left|\mathrm{X}_{3}\right|_{\mathrm{p}}=\frac{8 \mathrm{Z} \sigma_{\mathrm{yield}}}{\mathrm{L}^{2}}=\frac{(8)(0.954)(50,000)}{(142)^{2}}=18.92 \mathrm{pli}
$$

As the girts are twisted, their plastic strength will be reduced since they tend to orient themselves so as to bend about the weakest axis, and it will be assumed that the minimum plastic bending strength is finally reached. The minimum bending strength is assumed to be reduced by the previously mentioned factor to include the rather minor effect of tensile stress in the girt. Thus

$$
\left|\mathrm{X}_{3}\right|_{\mathrm{p} \text { min. }}=\frac{(0.925)(8)(0.260)(50,000)}{(142)^{2}}=4.75 \mathrm{pli}
$$

The bending strength of the girts, thus determined, is plotted in Fig. A. 5 as the lowest of the curves shown. In Fig. A.5 the ordinate is the average load in pounds per square inch of frontal surface rather than the total load per inch of girt.

Next, the catenary resistance of the girts must be determined. First, an estimate must be made of the load-deflection properties of the girt as a tensile member. Here, an actual test would be of great value since the failure is complicated by the complex behavior at the ends. Second, the relation between girt deflection and longitudinal deformation at the ends must be established. Then, for any arbitrarily assumed value of girt deflection, a certain end deformation will be established, and this, in turn, will establish the end force on the girt. Then the equations of static equilibrium will determine the equivalent static load carried by the girt in catenary action.

Figure 2.21 shows the detail of a torn girt connector which is typical of the end failures of this member. Approximately one-half of the total girt area is cut away at this point to provide sufficient coping of the $\mathrm{Z}$ bar in order to eliminate interference between the exterior panel and the front face of the columns. The girt is then attached by a single $1 / 2$-in.-diameter bolt passing through a slotted hole. Initially, the slotted hole permits a longitudinal movement of the girt which is resisted only by the friction between the bolt and the girt material. Then at the sharp internal cut, the girt starts to tear at the end. As it does so, the torn piece of girt that remains attached to the column is twisted almost $90^{\circ}$, as shown in Fig. 2.21. There is some information available on the strength of eccentrically loaded tension members of steel which fail by tearing that starts at one side, due to a notch or stress concentration, and information $^{1}$ is also available on the strength of bolts in shear. The fact that the bolts did not fail 


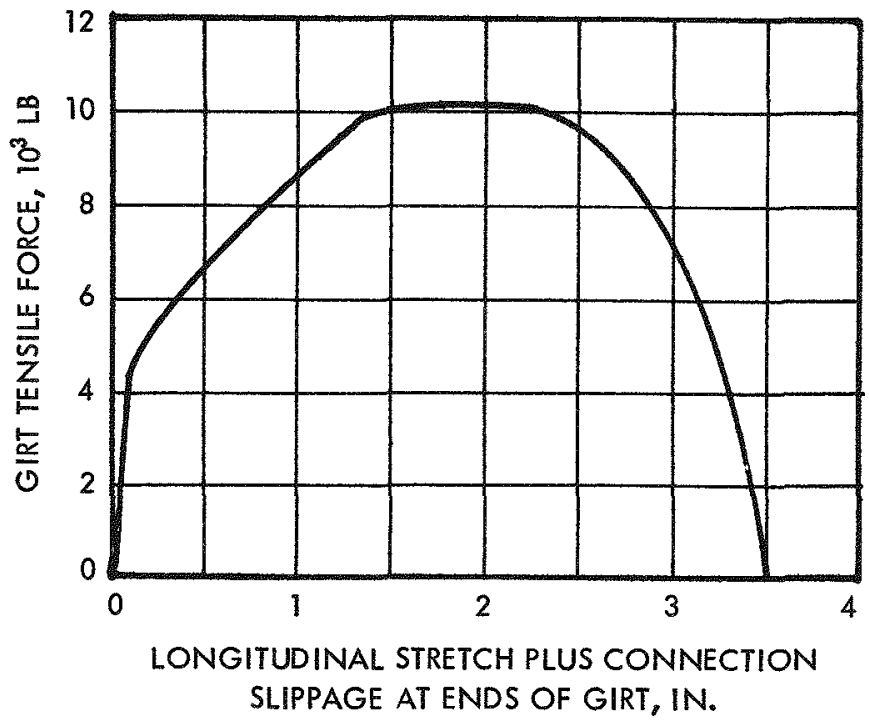

Fig. A.2-Estimated load-displacement diagram for girt in tension.

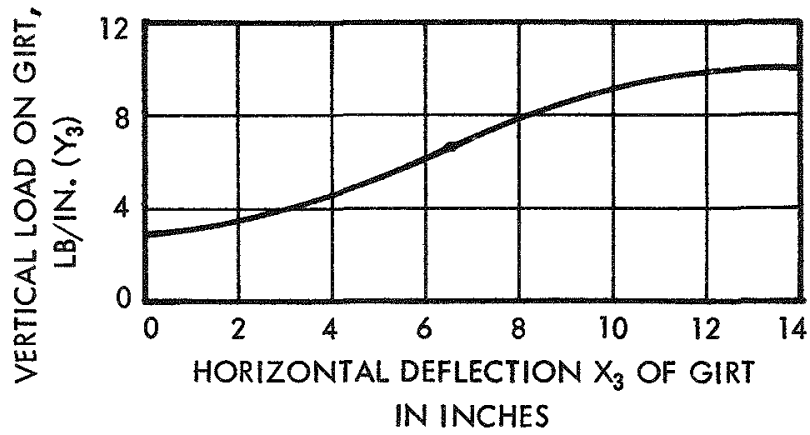

Fig. A.3-Approximate plastic resistance of girts vs vertical displacement.

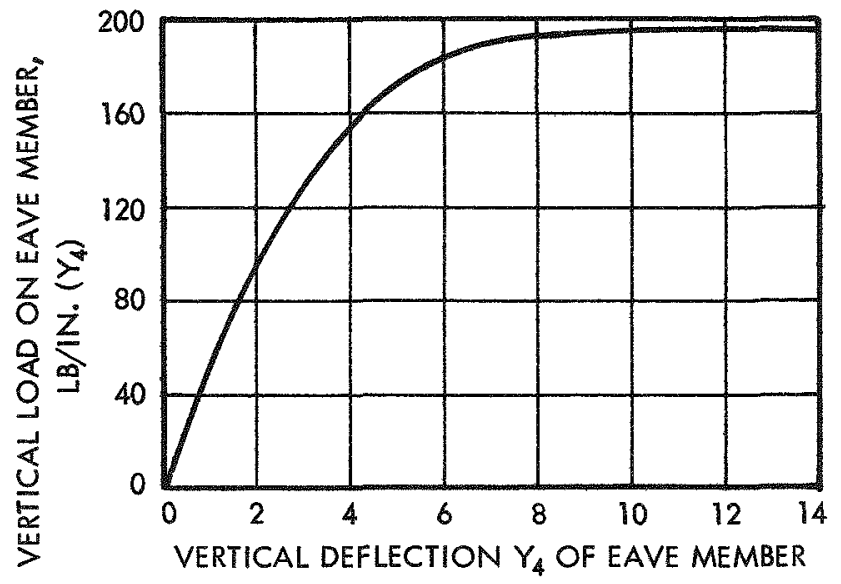

IN INCHES

Fig. A.4-Approximate plastic resistance of eave member vs vertical displacement. 
established an approximate upper limit to the girt strength. During the tearing of the girt, it can be assumed that the average stress in the untorn portion will be roughly one-half the ultimate strength of the material. This leads to an estimate of slightly over $10,000 \mathrm{lb}$ for the ultimate tensile load in one of these girts. Since it would appear that the $1 / 2$-in. bolt should be on the verge of failure at this same load, it can at least be assumed that the tensile strength was no more than this value. At a total load of $10,000 \mathrm{lb}$, the average stress in the main body of the girts where the full section exists is only 13,750 psi. The elastic deformation corresponding to this stress is less than $0.1 \mathrm{in}$. for the total length of girt; therefore the elastic stretch can be neglected, and the entire longitudinal deformation of the girt can be estimated as due to the behavior at the end connection. It is assumed that the girts start to slip at their ends at a tensile load of slightly over $4000 \mathrm{lb}$ and that total slippage (see Fig. 2.21) is slightly more than 0.5 in. at each end. Under a very slowly applied static load, the slippage would probably continue with no increase in load; however, under dynamic load it is assumed that the load increases somewhat (Fig. A.2) until, after full slip at both ends, the maximum tensile force of the girt is developed. In the absence of any test it is very difficult to estimate the amount of yielding at ultimate load that will take place locally before tearing starts, but it has been assumed that about 0.5 in. of stretch will occur at each end before tearing commences. After tearing begins (at a total stretch at both ends estimated to be about 2.25 in.), the load can be presumed to fall off rapidly, and, at a total longitudinal stretch of 3.5 in., the girts are assumed to tear loose. This estimate of total longitudinal stretch corresponding to complete failure can be confirmed by observations of the center girts in the planned test of Reynolds-Butler Building 31.2-a2 at 15,000 ft. Here the lower girt at location 2 (see Fig. A.1) was torn off at both ends in the center panel, and the upper girt at location 3 was torn off at one end only. The lower girt had a maximum center deflection of about 16 in., and the upper girt had a maximum center deflection of about 13 in. At the same time, girts in the end panel with maximum center deflections up to about 12 in. did not tear off (see Fig. 2.2). It is thus possible to bracket very closely the total longitudinal deformation of the girt at complete failure. A total longitudinal deformation of 3.5 in. corresponds to a maximum center deflection of 13.7 in.

TABLE A.1 - COMPUTATION FOR DETERMINING THE LOAD CARRIED BY CATENARY ACTION

\begin{tabular}{cccc}
$\begin{array}{c}\text { Total } \\
\text { longitudinal } \\
\text { deformation } \\
(\mathrm{e})\end{array}$ & $\begin{array}{c}\text { Catenary } \\
\text { deflection } \\
\text { of girt } \\
\left(\mathrm{X}_{3}\right)\end{array}$ & $\begin{array}{c}\text { Tensile } \\
\text { force } \\
\text { in girt } \\
(\mathrm{T})\end{array}$ & $\begin{array}{c}\text { Load } \\
\text { carried by } \\
\text { catenary } \\
\text { action } \\
\left(\mathrm{X}_{3}\right)\end{array}$ \\
\hline 0.25 & 3.65 & 5,600 & 8.1 \\
0.75 & 6.32 & 7,800 & 19.6 \\
0.825 & 6.63 & 8,100 & 21.3 \\
1.15 & 7.82 & 9,300 & 28.9 \\
1.5 & 8.94 & 10,000 & 35.5 \\
2.0 & 10.32 & 10,000 & 40.9 \\
2.5 & 11.55 & 9,500 & 43.5 \\
3.0 & 12.60 & 7,200 & 36.0 \\
3.5 & 13.70 & & 0 \\
& & &
\end{tabular}

The computations for the determination of the load carried by catenary action are given in Table A.1. The first column gives arbitrarily chosen values of total longitudinal deformation. The second column gives the center deflection of the girt corresponding to the total longitudinal deformation as determined by the relation for an assumed parabolic girt-deflection curve, or twice the value given by Eq. A.5. The third column indicates the tensile force in the girt corresponding to the total longitudinal deformation as taken from the graph in Fig. A.2. Finally, the fourth column gives the loads carried by catenary action in pounds per lineal inch of girt as determined by the following equation:

$$
\mathrm{x}_{3}=\frac{8 \mathrm{Tx}_{3}}{\mathrm{~L}^{2}}=0.0003967 \mathrm{Tx}_{3}
$$


As mentioned previously, it is recognized that the assumption of uniform load on the girt is incorrect because it underestimates the load on the girt. This is roughly compensated for by the fact that the load carried by panel catenary action is tpproximately overestimated in the same proportion. In terms of average pressure in pounds per square inch on the front face of the wall, the contribution of the girts to wall resistance in terms of their catenary behavior is plotted as the ordinate distance between the two lower graphs in Fig. A.5, as shown thereon.

The first term in Eq. A.10 involves the vertical resistance of girt $Y_{3}$. This is relatively small in comparison with $Y_{4}$, and, because of the variable twist of the girt, it is practically impossible to make a reliable estimate of the vertical strength in the absence of actual tests. It is also recognized that, in the initial stages of deformation when the panel is holding the girt in its vertical location, there is actually a negative resistance of the girt vertically since, due to the tendency toward biaxial bending, it tries to pull the panel down. However, as plastic action proceeds and the panel at girt 3 is displaced downward, it is assumed that the girt offers initially one-half of the plastic resistance that it normally would offer if this were the only load on the girt. As the girt twists, it offers greater resistance vertically, and it is estimated that the girt finally develops about one-half of the maximum plastic resistance that it would offer when twisted into its strongest position from a vertical displacement point of view. It is convenient in this analysis to thus assume that vertical girt resistance is a function of horizontal deflection rather than vertical girt deflection, and the resistance so calculated is shown in Fig. A.3. Although this is but a crude approximation, it has been mentioned before that, because of the minor role of girt 3 in vertical catenary action, large errors in this estimate will have a negligible effect on the estimate of total panel resistance.

Of great importance in establishing the vertical catenary load resistance of the aluminum sheeting is the vertical resistance to downward load of the eave strut and the vertical resistance to upward load of the sill angle. The sill angle is held to the foundation by three bolts, one at the center and one near each end. The eave strut is a cold-formed shape, as shown at location 4 in Fig. A.1. Owing to participation of wall and roof sheeting, the vertical resistance of the eave strut is much greater than would be determined from its own section properties in bending. This must be true since the eave struts were crippled downward at each end for several inches and the estimated crippling load would correspond to a uniform downward load es timated at $190 \mathrm{lb} / \mathrm{in}$. A study of the vertical plastic bending strength inherent in the eave strut alone indicates no more than $30 \mathrm{lb} / \mathrm{in}$. This value neglects the contribution of braces. Similarly, the sill angle along the bottom has a plastic bending strength of only about 10 pli. However, the sill angle very rapidly acquires considerable strength due to its own catenary action upward, and the tensile strength of the three bolts would indicate a final strength level somewhere between 160 and 200 pli of sill angle. The increase in strength of the eave strut is undoubtedly due in part to participation of the aluminum roof paneling and the aluminum sidewall sheeting adjacent, and bolted, to the eave strut. Since the bending strength of the eave strut alone is not used and since the end crippling of the eave strut proves that it carried a considerable increment of load due to wall and roof participation, it is simply estimated that, as a result of end crippling, the eave strut can carry an average uniform load of $190 \mathrm{lb}$ per inch of length, and a load-deflection diagram so estimated is shown in Fig. A.4. The initial slope of this load-deflection curve is determined by the elastic properties of the eave members. The only reliable procedure for a more accurate determination of this factor would be by actual test of a complete building unit.

It is recognized that, and this statement will be repeated from time to time, a very considerable number of approximate assumptions have been made in arriving at data leading to the estimate of wall resistance. Without careful observation and measurement of the actual wall behavior as a result of the nuclear tests, it would not have been possible to come nearly so close to a reliable estimate of wall resistance. An even better estimate could be made by a combination of nuclear tests with actual static load tests performed on site. The value of the analysis presented here lies in the fact that it indicates a procedural plan by which the behavior of similar panels under blast load can be predicted if the information that is roughly approximated here can be obtained more accurately by static load test.

After the girts tear loose at their ends, all the wall resistance must come from catenary action of the aluminum panels spanning vertically from sill to eave strut. If these panels had not been installed in single units from top to bottom, their strength after girt failure would 
have been much less, unless the panels were spliced fully at every lapped location. Figure A.5 indicates the additional load carried by the vertical paneling in catenary action after the girts tear loose. Since the behavior of the panel is being referenced to girt center deflection $x_{3}$, the deformation and resistance of the paneling will also be referenced to the same location as a matter of convenience in the final calculations. Assuming the deflected shape of the paneling to be that of a parabola, it can easily be shown that the load $q$, in pounds per square inch supported by a 1 -in.-wide strip of sheeting, is

$$
q=\frac{2 Y_{4} x_{3}}{b(h-b)}
$$

Also, from the geometry of a parabola, the relation between the maximum deflection of the center paneling and the deflection $\mathrm{x}_{3}$ at the girt is

$$
x_{0}=\frac{x_{3}}{1-\left(a^{2} / h^{2}\right)}
$$

If this relation is introduced into the geometrical relation between vertical end deflections $y_{4}$ and center deflections $\mathrm{x}_{0}$, the following is obtained:

$$
\mathrm{y}_{4}=\frac{4}{3 \mathrm{~h}}\left[\frac{\mathrm{x}_{3}}{1-\left(\mathrm{a}^{2} / \mathrm{h}^{2}\right)}\right]^{2}
$$

In the present instance, $h=112$ in., $a=44$ in., and $b=34$ in.; and the following relations are obtained:

$$
\begin{aligned}
q & =\frac{y_{4} x_{3}}{1326} \\
x_{0} & =\frac{x_{3}}{0.846} \\
y_{4} & =\frac{x_{3}^{2}}{80}
\end{aligned}
$$

These equations, along with Fig. A.4, permit an estimate of vertical catenary resistance.

Although the separate contributions of the bending strength of the girts and the catenary strength of the girts has been discussed previously, the tabulation of the total load carried by all three contributing modes of behavior (girt bending, girt catenary, and panel catenary) can conveniently be tabulated in one operation, utilizing Eq. A.10. Reference should be made to Table A.2. Column 1 is the center deflection of the girt for which values are arbitrarily selected. Column 2 is the plastic load capacity in pounds per inch of the girt in the vertical direction, as approximated in Fig. A.3. As previously discussed, no claim for great accuracy of the values in column 2 is made because of the complicating factors involved. However, the level of these values is low in comparison with the values for $Y_{4}$, which are given in column 4. In column 3, trial values of $y_{4}$ are indicated. Referring again to Eq. A.10, it will be seen that, for any trial value of $y_{4}, Y_{4}$ 's determined from Fig. A.4 as a function of $y_{4}$ can be determined, and then Eq. A.10 is used to obtain a computed value of $y_{4}$. If the computed value agrees with the trial value, no further computation for this particular $x_{3}$ is necessary. If the computed value does not agree, a new value of $y_{4}$ is tried out, and trials are repeated until agreement between trial $\mathrm{y}_{4}$ and computed $\mathrm{y}_{4}$ is reached. As explained, column 4 gives the value of $\mathrm{Y}_{4}$ corresponding to the trial $\mathrm{y}_{4}$, as read from $F$ ig. A.4. Column 5 gives the girt resistance $\left(X_{3}\right)$ in pounds per lineal inch, as read directly from the graph in Fig. A.2. If a desk computer is used in the calculations, it is convenient to introduce additional computation columns between columns 4 and 5. Continuing with Table A.2, column 7 introduces Eq. A.3, which gives the com- 


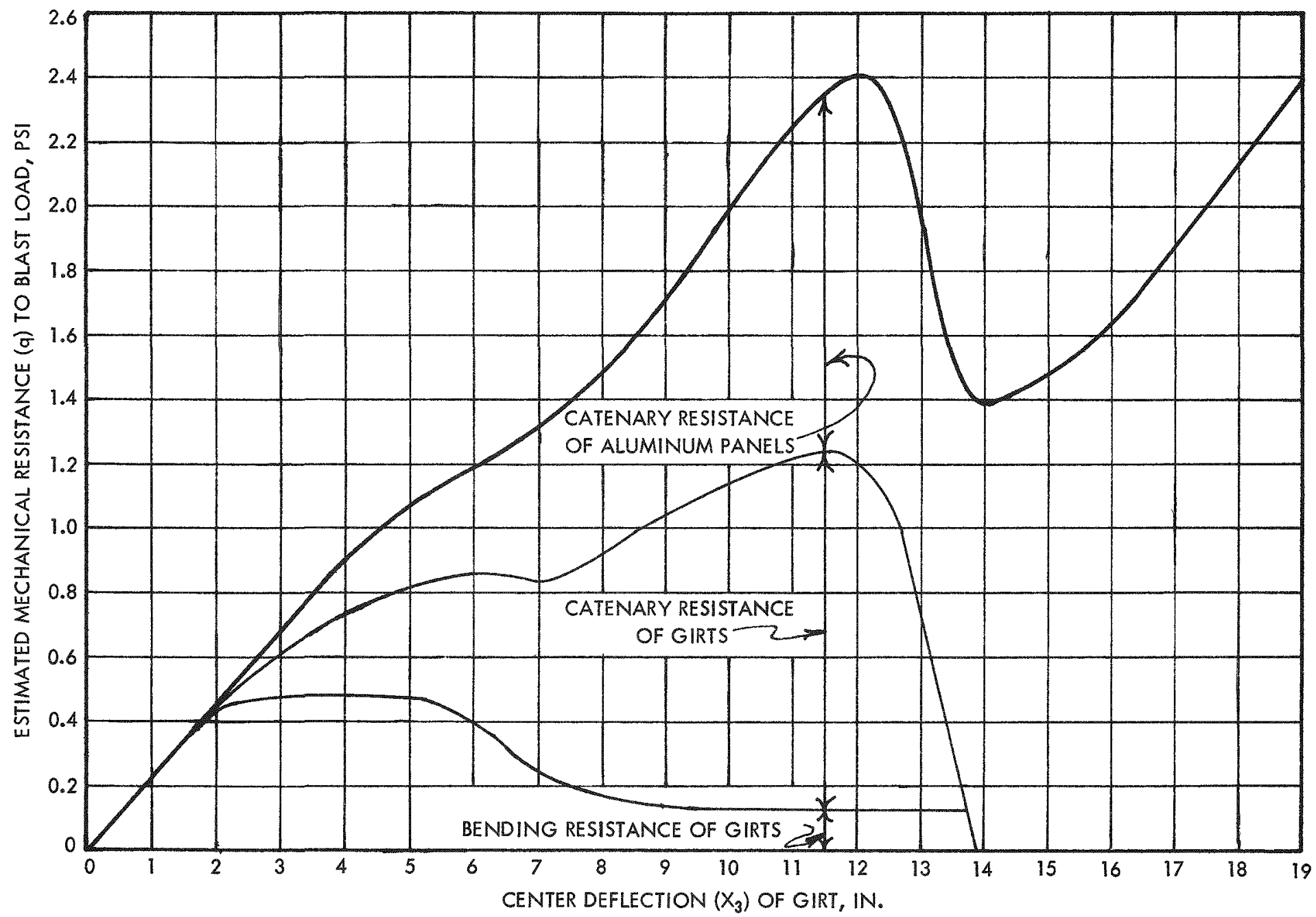

Fig. A.5-Resistance function for side walls of Reynolds-Butler buildings. 
TABLE A.2-COMPUTATION OF LOAD CARRIED BY GIRT BENDING, GIRT CATENARY, AND PANEL CATENARY

\begin{tabular}{|c|c|c|c|c|c|c|c|}
\hline (1) & (2) & (3) & $(4)$ & (5) & (6) & (7) & (8) \\
\hline $\mathrm{x}_{3}$ & $Y_{3}$ & $\mathrm{y}_{4}$ & $Y_{4}$ & $X_{3}$ & $\frac{\mathrm{x}_{3} \mathrm{Y}_{4}}{34}$ & $q$ & $y_{4}$ \\
\hline \multirow[t]{2}{*}{4.0} & 4.6 & 1.10 & 55 & 28.5 & 6.52 & 0.90 & 1.31 \\
\hline & & 1.20 & 60 & 28.5 & 7.06 & 0.91 & 0.97 \\
\hline 6.0 & 6.4 & 1.50 & 74 & 33.6 & 13.06 & 1.20 & 1.52 \\
\hline 8.0 & 8.0 & 1.80 & 87 & 37.4 & 20.47 & 1.48 & 1.84 \\
\hline \multirow[t]{2}{*}{10.0} & 9.3 & 2.30 & 106 & 45.0 & 31.18 & 1.95 & 2.53 \\
\hline & & 2.40 & 110 & 45.0 & 32.35 & 1.98 & 2.49 \\
\hline \multirow[t]{2}{*}{12.0} & 10.0 & 3.0 & 129 & 47.5 & 45.53 & 2.39 & 3.17 \\
\hline & & 3.16 & 132 & 47.5 & 46.60 & 2.41 & 3.18 \\
\hline
\end{tabular}

puted value of total load q carried by the wall panel in pounds per square inch. All the necessary information has now been tabulated for the calculation of the trial $y_{4}$ by Eq. A.10, as listed in column 8. In the original computations, four additional computation columns were included between columns 7 and 8 . Between girt deflections of 12 and $14 \mathrm{in}$., as computed and observed in the actual test structure, the girts tear entirely free at the ends, and all the load is thenceforth supported by catenary action of the vertical paneling. The calculation of load, given in Table A.3, from this point on is direct and relatively simple. Column 1 in Table A.3 is the arbitrarily assigned value of center girt deflection. Column 2 determines the vertical deflection at the end of the paneling by Eq. A.17. This is assumed to be the same at the top and the bottom since symmetry has been assumed, and, although there may be a considerable difference between the deflection at the top and bottom, the actual catenary capacity paneling is determined by the total shortening. The fact that this is different at the two ends does not

TABLE A.3-CALCULATION OF LOAD AFTER GIRT CONNECTION FAILURE

\begin{tabular}{cccc}
\hline (1) & \multicolumn{1}{c}{$(2)$} & $(3)$ & \multicolumn{1}{c}{$(4)$} \\
& $\mathrm{y}_{4}=\frac{\mathrm{x}_{3}^{2}}{80.1}$ & $\mathrm{Y}_{4}$ & $\frac{\mathrm{Y}_{4} \mathrm{x}_{3}}{1326}=q$ \\
\hline 14.0 & $3.10^{*}$ & $132^{*}$ & $1.39^{*}$ \\
16.0 & 3.19 & 135 & 1.63 \\
18.0 & 4.04 & 157 & 2.13 \\
20.0 & 4.99 & 176 & 2.65 \\
22.0 & 6.04 & 184 & 3.05 \\
24.0 & 7.19 & 190 & 3.44 \\
\hline
\end{tabular}

* Cannot spring back appreciably $-\mathrm{Y}_{4}$. already developed.

materially change the results. In column 3 , the value of $Y_{4}$ is again taken directly from that in Fig. A.4, and the load is directly computed in column 4.

Figure A.5, which has been referred to previously, now presents the information from Tables A.2 and A.3 graphically as the upper of the three curves, giving the total resistance from all effects that have been considered in this analysis.

For an irregular resistance function, such as shown in Fig. A.5, the best procedure ${ }^{2}$ for dynamic analysis is a numerical one in which it is necessary, at the end of successive time intervals, to tabulate the displacement, velocity, and acceleration of a reference point on a panel or beam under shock load. In this procedure, in order to handle the distributed pressure loads and distributed mass of the actual structure, an equivalent substitute structure, which is 
assumed to behave as a simple single-degree-of-freedom system, is introduced. The assumption of a single-degree-of-freedom system implies that the geometric shape of the deflected curve or surface is similar at all stages of deflection. The distributed pressure load in the actual system is replaced by an effective pressure applied to the substitute structure and defined as follows: The effective pressure is that pressure which, acting through a virtual displacement of the substitute structure, will do the same amount of work as the distributed pressure in going through the same virtual displacement of the reference point in the actual structure. Similarly, an effective mass is determined as that concentrated mass in the substitute structure which has the same kinetic energy at any particular time as the distributed mass in the real structure. The acceleration at any particular time is then determined by the following equation:

$$
p_{e}-q_{e}=m_{e} A
$$

where $p_{e}=K_{p} p$

$q_{e}=K_{p} p$

$\mathrm{m}_{\mathrm{e}}=\mathrm{K}_{\mathrm{m}} \mathrm{m}$

In the foregoing, $p_{e}, q_{e}$, and me are the effective pressures, resistance, and mass, respectively; $K_{p}$ is the equivalent force or resistance factor; and $\mathrm{K}_{\mathrm{m}}$ is the equivalent mass factor. Finally, by dividing both the numerator and the denominator by $\mathrm{K}_{\mathrm{p}}$, the following equation is obtained:

$$
\mathrm{p}-\mathrm{q}=\frac{\mathrm{K}_{\mathrm{m}}}{\mathrm{K}_{\mathrm{p}}} \mathrm{m}
$$

The mass modifying ratio is sometimes called the "force-mass ratio," $\mathrm{K}_{\mathrm{m}} / \mathrm{K}_{\mathrm{p}}$. This permits the use of actual load intensities in a calculation, and it introduces only one factor to produce equivalence between the real and hypothetical systems.

An interesting phenomenon, well known in dynamic studies ${ }^{3}$ of motion of solid objects in denser media, such as water, is the effect of induced air motion on the behavior of lightweight paneling under shock load. As a simplification, it can be said that, when the panel is set in motion, it carries with it (in effect) a mass of air. Although the actual phenomenon is extremely complex and indeterminate, especially while the reflected pressure front is clearing the face of the structure, it would seem that the usual type of correction should be applied and that it would be valid for the major portion of the time during which the panel is in motion. The mass of air carried with a flat rectangular plate is approximately equal to that contained by an imaginary cylinder that just encompasses the long direction of the plate, modified by a coefficient. If $B$ is the diameter of the cylinder and $L$ is the length, the total mass of air is therefore

$$
\rho\left(\mathbf{K} \frac{\pi}{4}\right) \mathrm{B}^{2} \mathrm{~L}
$$

where $\rho$ is the mass density of the air and $\mathrm{K}$ is a modifying factor dependent on the shape. In the case of the rectangle, the product of $\pi \mathrm{K} / 4$ is approximately equal to 1 . Since, in the present case, the behavior is that of the air motion around a plate projecting from one side of a semi-infinite solid, the effective width of the equivalent plate would be twice the wall height. However, the entire wall is not forced through the air as a rigid body, but it deflects as a doubly curved surface before girt failure and as a singly curved surface after girt failure. In these calculations it has been assumed that the volume of air associated with wall movement is proportional to the surface displacement. Thus, prior to girt failure, when the wall is assumed to deflect in double curvature, the ratio between displaced air and the air that would be displaced by a rigid wall movement is found to be 0.466 . After girt failure the corresponding factor is found to be 0.700 . At the altitude of the test site, there is a mass-density correction factor of 0.89 . A further modifying factor results from the fact that deflections are based on an assumed uniform load, whereas the effect of nonuniform inertial resistance is more concentrated at the center of the panel, where it has a greater effect in reducing deflection. The approximate deflection factor for this is 1.33 before girt failure, and it is 1.20 after girt fail- 
ure. Thus the lumped correction factor before girt failure is 0.552 , and after girt failure it is 0.748 .

The equivalent pressure factor for a double parabolic surface under uniform pressure load is 0.444 . In other words, an average pressure $p_{e}=0.444 p$, if applied to the whole wall area, will do the same amount of work in traveling through the reference deflection $\left(x_{3}\right)$ as an actual uniform load will do in traveling through the deflections that vary as a double parabolic surface. After the girts fail and the panel is assumed to deflect in single parabolic curvature, the equivalent pressure factor is 0.667 . The equivalent mass $m_{e}=0.284 \mathrm{~m}$ will have the same kinetic energy, on the average, at the velocities associated with the reference point as the actual average kinetic energy of the distributed mass, $m$. After girt failure the effective mass factor is 0.533 . By combining the force and mass factors, a force-mass ratio of 0.757 results before girt failure, and a ratio of 0.946 results after girt failure. In summarizing the specific problem on hand, the modified average mass of girts and paneling, in pound-inch-second units, has been determined as given below:

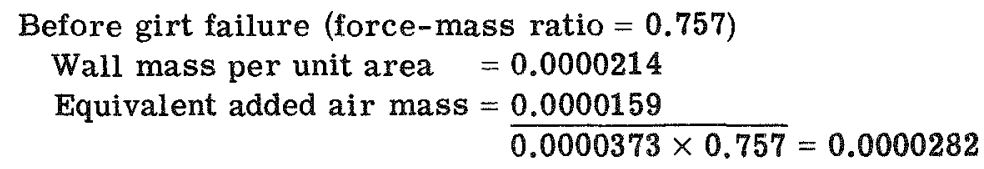

After girt failure (force-mass ratio $=\mathbf{0 . 9 4 6}$ )

Wall mass per unit area $=0.0000214$

Equivalent added air mass $=0.0000215$

$$
\overline{0.0000429 \times 0.946}=0.0000406
$$

From the preceding information it is noted that the air mass approximately doubles the average mass of the actual wall. This has a great effect on acceleration in the early stages of deformation, but it has a much lesser effect on the total permanent wall deflections.

In addition to the air-mass effect, affecting the acceleration, there is the velocity effect. This is a small item, similar to air drag on a rectangular plate. By assuming a drag coefficient of 2 and making corrections for altitude, nonuniformity of load, etc., the correction was determined as $3.47 \times 10^{-7} \times \mathrm{v}^{2}$. The effect is very minor, and detailed calculations are omitted.

Table A.4 shows a typical calculation of the dynamic behavior of the wall paneling. This particular calculation is for the planned test, including the effect of air cushioning. The procedure is adapted from that suggested by Newmark, ${ }^{2}$ and it has been called the "linear acceleration extrapolation method." The formulas that are used to extrapolate values of acceleration, velocity, and displacement for a particular time interval are given at the bottom of Table A.4, and they are based on the assumption that the acceleration varies linearly during any particular time interval. This procedure has an advantage because the time interval can be varied so that large time intervals can be used when the acceleration is approximately linear and smaller time intervals can be introduced whenever the acceleration becomes irregular, as is the present case between times 0.021 to $0.030 \mathrm{sec}$.

Column 1 in Table A.4 gives the time at any particular instant. Column 2 is the preceding time interval. Column 3 is the average pressure on the front wall as determined by procedures given in declassified sections of reference 4 and presented graphically in Fig. 2.54. Pressure in column 3, so calculated, includes the reflection effect and is based on the actual overpressure-time curves that have been made available. Column 4 is the trial resistance in pounds per square inch including both the structural resistance of the panel and the air-velocity effect. After working on a particular problem, a fairly accurate estimate can usually be made of the trial value so that few, if any, additional cycles need be made to get a check between the trial value in column 4 and the calculated value in column 10 . Column 5 gives the net difference between the average pressure and the average trial resistance, which permits the determination of the acceleration as computed and tabulated in column 6 . Column 7 gives the velocity as computed by Eq. A.20, and column 8 gives the pressure correction due to velocity. The displacement of the girt center is calculated in column 9. In column 10 the calculated resistance, taken from Fig. A.6 with the addition of the velocity correction effect, which has already been determined in column 8 , is tabulated. If the calculated resistance is about the same as the trial 
TABLE A.4 - TYPICAL CALCULATION OF THE DYNAMIC BEHAVIOR OF WALL PANELING IN POUND-INCH-SECOND UNITS

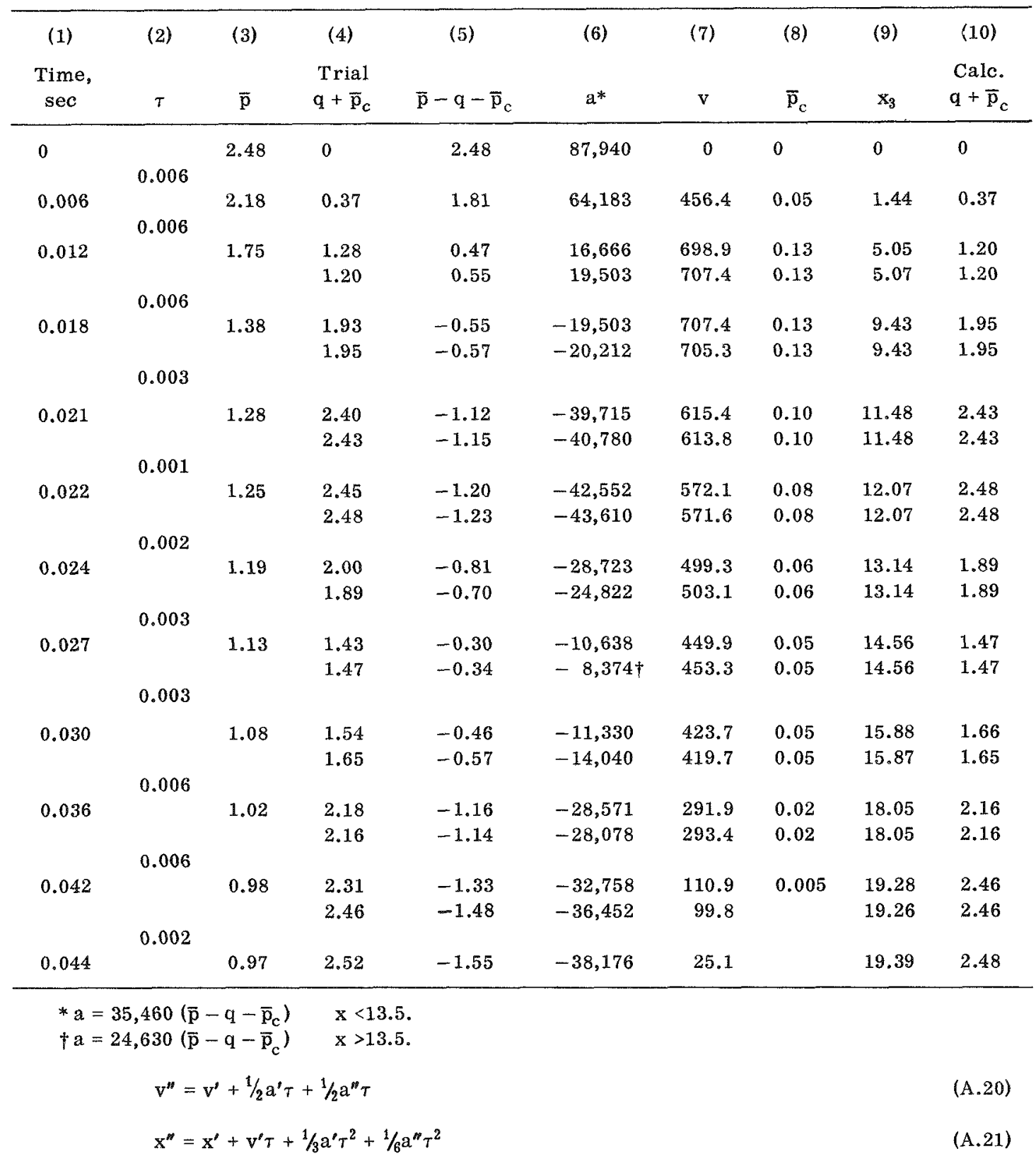

where double primed values are at the end of the time interval $(\tau)$ and single primed values are at the beginning of the time interval.

resistance in column 4 , the procedure is repeated for the next time interval. If the calculated resistance is different from the trial value, it is introduced as a new trial value in column 4 , and the operation is repeated, which will usually give a good check on the second trial. The acceleration, velocity, and deflection at the center of the girt as given in Table A.4 are also plotted in Fig. A.6 as the solid lines. Also shown in Fig. A.6, as dashed lines, are the acceleration, velocity, and displacement calculated without considering the effect of air cushioning. It is to be noted that a considerable difference is obtained in all three curves, but it is also interesting to note that the very appreciable change in mass and the corresponding acceleration introduced by the air-cushion effect results, finally, in very little difference in the calculated maximum displacement, i.e., $20.4 \mathrm{in}$. when the air cushion is neglected and $19.4 \mathrm{in}$. 

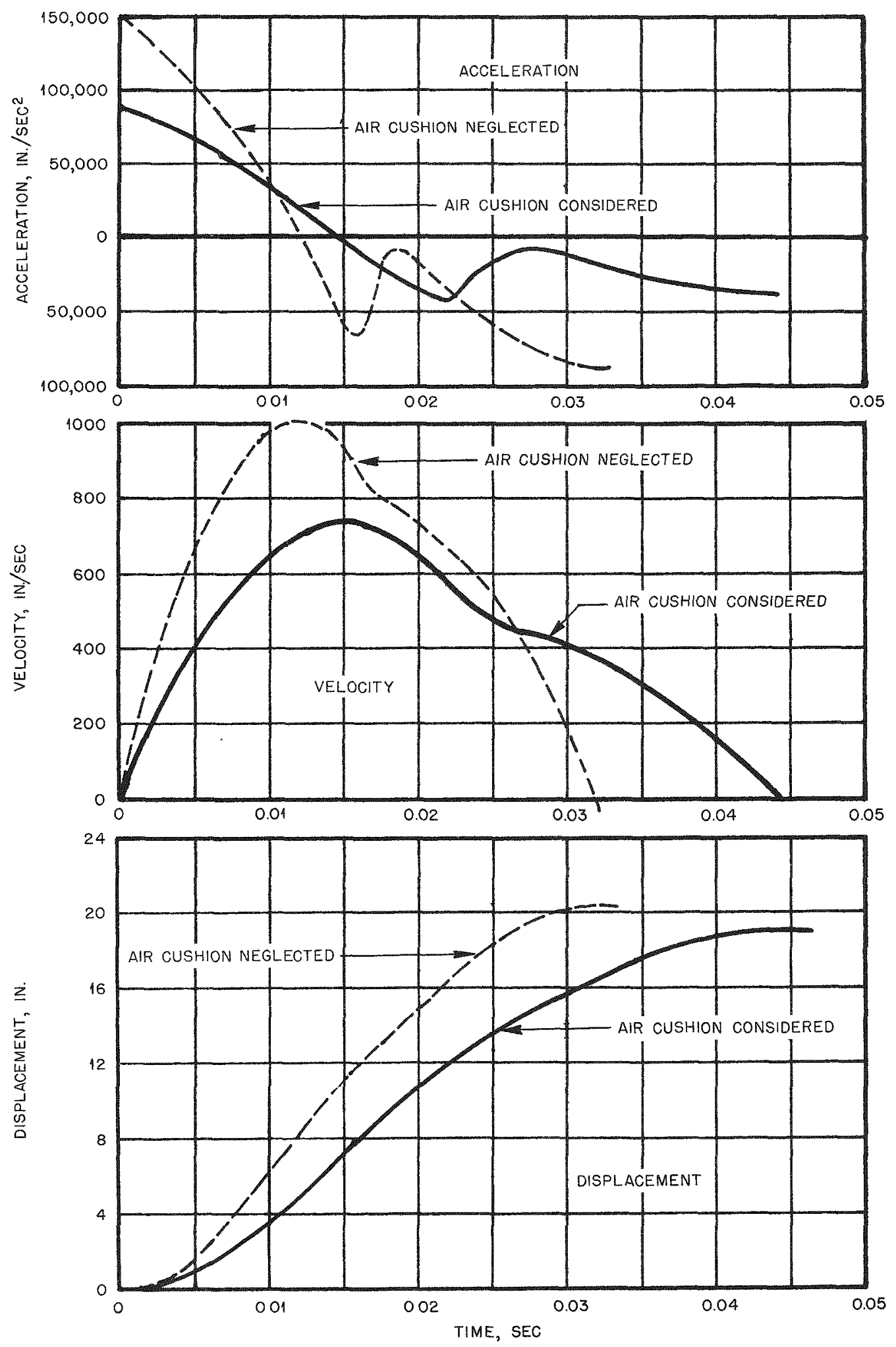

Fig. A.6 - Calculated acceleration, velocity, and displacement at center of girt in center wall panel of Reynolds-Butler Building 31.2-a2 in planned test at 15,000 ft. 
when the air cushion is considered. As shown in Fig. 2.2, the actual permanent girt deflection for these structures is $\mathbf{1 3 . 4} \mathrm{in}$. for the top girt and $16.3 \mathrm{in}$. for the bottom girt. These permanent deflections should be less than the maximum calculated deflection since there will be some elastic recovery and some reverse load effect during the negative phase.

Similar calculations were made for the unexpected test, in which the recorded permanent girt displacements at the center were 2.7 in. for the top girt and 4.5 in. for the bottom girt. The calculated maximum deflections of the girt in the unexpected test were 6.9 in., including the effect of air cushioning, and $7.5 \mathrm{in}$. when the air-cushion effect was neglected.

The similarity of the relation between maximum calculated and actual deflections in both the unexpected and planned tests indicates that the accuracy of the dynamic analysis and the required associated resistance curves are about as good as can be expected. This is also good evidence for the correctness of the average pressure-time data calculated and presented in Fig. 2.54. The only measurements on the actual structure were for the total permanent deflection, and the reduction in total deflection induced by the air-cushion effect, although real and in the right direction, is of too small a magnitude to precisely validate the assumptions that have been made herein in calculating the added mass of air associated with panel movement.

Probably the most striking and important feature of this analysis is the paramount importance of the effect of catenary action in adding to panel and girt resistance. Without a careful consideration of this effect, not even an approximate check could be made on the panel behavior by dynamic analysis.

Other analyses of the behavior of these structures might well be made, but time and funds allotted to Project 31.2 did not permit further analysis. The main frame suffered no appreciable permanent distortion during the unexpected test; however, both frames had recorded permanent deflections during the planned test. The calculation of the relatively large mainframe distortion at $6800 \mathrm{ft}$ in the planned test would be extremely conjectural because, after panel failure, the drag load is complicated by the many shreds of paneling that remain attached to the structures, as shown in Figs. 2.17, 2.21, 2.22, and 2.29.

\section{REFERENCES}

1. L. Schenker, C. Salmon, and B. G. Johnston, Structural Steel Connections, Report AFSWP352, University of Michigan, Engineering Research Institute, June 1954.

2. N. M. Newmark and S. P. Chan, A Comparison of Numerical Methods for Analyzing the Dynamic Response of Structures, Civil Engineering Studies, Structural Research Series No. 36, University of Illinois, 1952.

3. Horace Lamb, "Hydrodynamics," 6th ed., p. 77, Cambridge University Press, 1932; first American edition, Dover Press, 1945.

4. L. J. Vortman and M. L. Merritt, Methods for Estimating Blast Loading on Simple Structures, Sandia Corporation, Report AFSWP-226, September 1953. 


\section{Appendix B}

\section{ANALYSIS OF WALL BEHAVIOR: ARMCO BUILDINGS}

As can be noted by comparing Figs. 1.10 and 1.20, the Armco buildings had almost the same shape and dimensions as the Reynolds-Butler buildings. Also, as in the case of the ReynoldsButler buildings, the Armco buildings suffered measurable but not complete damage in the unexpected test and in the planned test at 15,000 ft. Thus the dynamic analysis outlined in this appendix follows a very similar pattern to that previously presented in Appendix A. Less detail will be given, and general remarks that pertain equally well to both appendixes will not always be repeated herein. Appendix $A$ should therefore be read as a preliminary to the reading of Appendix $\mathrm{B}$. One major difference in the study of the Armco buildings arises from the fact that the Armco structures had two doors and one window facing the north side exposed to the blast, whereas the Reynolds-Butler buildings had only a continuous north wall.

Unlike the Reynolds-Butler buildings, which are more or less conventional in construction (with very thin wall and roof paneling supported by girts and purlins, which are in turn supported by continuous frames), the walls of the Armco buildings are self-framing, spanning vertically from the sill to the eave, as shown in Fig. 1.20. The horizontal plane at the eaves is braced to maintain the shape of the building and to transmit reactive loads from the roof and eave member into the end walls, which act in shear to carry the load down into the end foundations. Typical details of the Armco buildings are shown in Fig. 1.21. Figures 2.6 and 2.8 show the damage to the north wall in the unexpected test, and Figs. 2.51 and 2.52 show the condition of the north wall at $15,000 \mathrm{ft}$ after the planned test. Figure 2.7 tabulates the deflection offset measurements for the north wall, roof, and both end walls. The wall panels, of standard Armco design, are of 22-gauge material $16 \mathrm{in}$. wide with interlocking rims, as shown in the cross section:

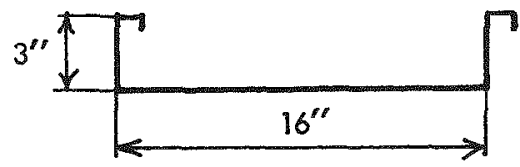

The manufacturer lists different properties for section modulus and moment of inertia when loading is in alternate directions. This is in accordance with AISI design specifications, ${ }^{1}$ which require a reduced effective width of material when very thin material is in compression. Bending of the wall panels inward causes compression in the thin outer surface; hence the lower values of such a modulus and moment inertia would appear to be the proper ones. However, trial analyses with these values led to a considerable error in estimating permanent deflections as compared to those actually experienced. Bleich ${ }^{2}$ points out that, when large normal loads are applied to plates, the buckling strength in compression is greatly increased because of the tensile membrane stresses that are caused. Although this effect is not normally taken advantage of in the design of ship hull plating, it does appear likely that the very large pressures experienced by the wall inhibit the normal buckling pattern on the compressive side of the plate. 
Therefore the full section has been assumed as effective in resisting bending, and the results so calculated agree better with the test results than when conventional effective widths are assumed.

Because of the window and door frames, the behavior pattern was nonuniform in the north wall of the Armco buildings. A wall section near the center of each building, consisting of two 16-in. panel segments running from eave to sill on each side of the central window and three panels interrupted by the window, was used as a basis for the analysis. In the planned test, channel reinforcing bars were added adjacent to the window and door frames, and this has been taken into account in the analysis.

The manufacturer gives the section modulus of one 16 -in.-wide panel as $0.401 \mathrm{cu}$ in. Multiplying this by 4 and dividing by 112 (the width of seven panels in inches), 0.0143 is obtained as the effective section modulus per inch of width. Assuming the dynamic yield stress to be 50,000 psi results in a yield moment of 715 in.-lb per inch of width. The plastic shape factor of the panel is 1.38 , which, when multiplied by 715 , gives 987 in.-lb per inch of width as the fully plastic moment, which is approached, however, only after a considerable deformation. If the ultimate plastic bending strength of the panel is developed, hinge moments at or near the center develop (in agreement with the actual behavior of the walls), and the vertical leg of the sill angles, acting as a thin continuous plate, contributes a small amount of end bending moment, which is calculated as $146 \mathrm{in}$. - $\mathrm{lb}$ per inch of width on the basis of a running plastic modulus $t^{2} / 4$ for a material having a thickness of 0.108 . The eave strut is assumed to provide a similar end restraint.

By taking the static equilibrium of a 1-in.-wide segment of the 60-in. half-length panel to one side of the span center line, the supporting load, when fully plastic, is found to be $0.63 \mathrm{psi}$. When the two vertical reinforcing channels are added adjacent to the window frame, which was the case for the planned test, the supporting load averages 0.78 psi for the same seven-panel central wall section previously described. The estimated curves of resistance due to bending strength are plotted vs center deflection in Fig. B.1 as the lower curve for each of the two cases with and without window-frame reinforcing channels.

After considerable deflection the panels derive some additional strength from catenary action, but the increase is much smaller than that occurring in the Reynolds-Butler buildings, where the edge restraints are stronger. Figure 2.51 shows clearly how the eave member is pulled down by the tensile force developed as a result of catenary action. Note in Fig. 2.51 that the door frames and doors offer enough vertical support to maintain the position of the eave member above each door. A cross section of the side-wall eave member is shown in Fig. 1.21. This eave member, together with an effective width of adjacent roof material, has a section modulus of $0.87 \mathrm{cu}$ in. This provides a bending moment at yield of $43,500 \mathrm{in}$. $-1 \mathrm{~b}$ for a dynamic yield stress of 50,000 psi. Assuming that the eave strut acts as a fixed end beam supported at each end on the side of the door frame nearest to the center of the building (an effective span of about 176 in.), the ultimate plastic load with hinge moments at the center and ends is about $30 \mathrm{lb}$ per inch of length with an assumed plastic shape factor of 1.33.

The deflected shape in catenary action of the paneling in the Reynolds-Butler buildings was assumed to be curved, as shown in Fig. A.1, with complications arising from girt behavior. In the case of the Armco buildings, the panels tend to bend locally near the center and to deflect into the shape of a shallow $\mathrm{V}$, consisting of two straight lines coming together at a point near the center. As can be seen in Fig. 2.52, this is a fairly reasonable assumption. The process of finding the additional load carried by catenary action is then similar to that followed in Appendix A for the Reynolds-Butler buildings. The downward deflection of the eave at the top, corresponding to various arbitrarily assumed deflections of the wall panel, is determined; the corresponding load carried by the eave strut is determined; and, finally, the load carried in catenary action is calculated. When this load is added to the bending resistance of the panels, the total load per square inch is shown in Fig. B.1 as the upper curves in each of the two cases, with and without window-frame reinforcing channels.

The average mass per unit area for the Armco wall paneling is 0.0000378 in pound-inchsecond units. The added mass contributed by the motion of the air, assuming the behavior to be similar to that in the Reynolds-Butler buildings, is 0.0000159 , giving a total average equivalent mass per unit area of $0.0000537 \mathrm{lb}-\mathrm{sec}^{2} / \mathrm{in} . / \mathrm{sq}$. in. 


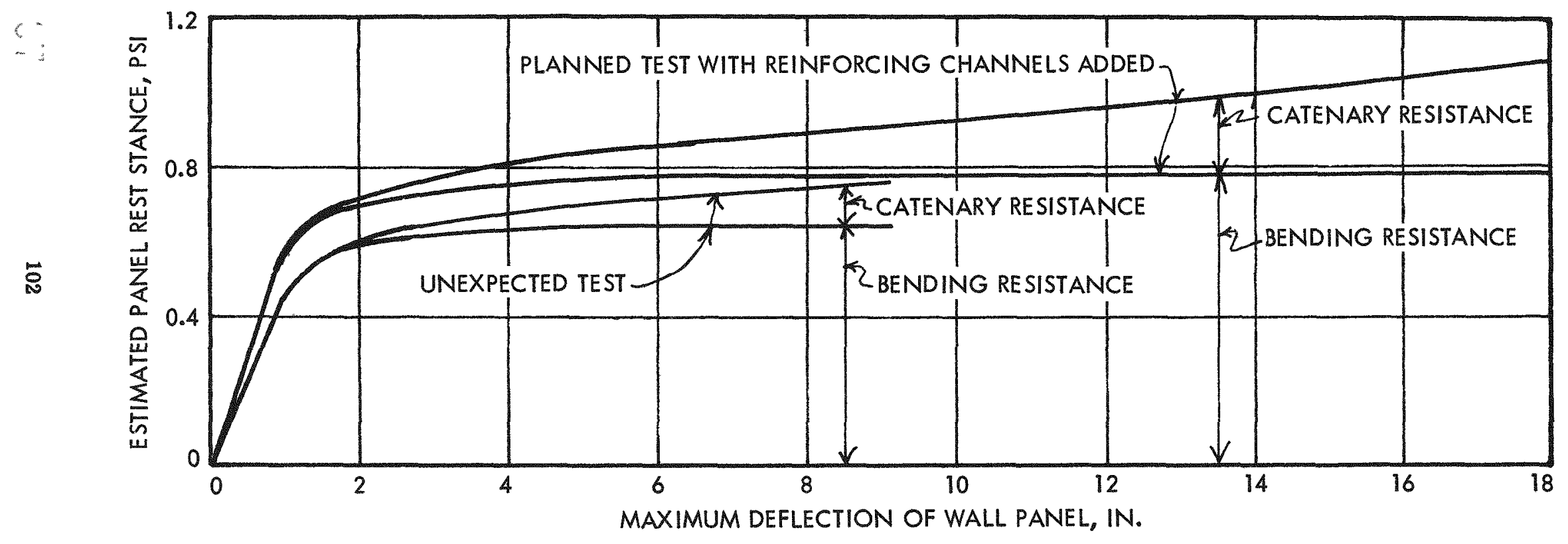

Fig. B.1-Resistance functions for side walls of Armco buildings. 
As shown in Figs. 2.6 and 2.52, three of the four door panels, together with the window in the north wall, failed in both the unexpected and planned tests. This area amounts to 9 per cent of the total frontal area on the north side. As a result of these openings, an attenuated shock wave entered the structures, relieving to some extent the pressure on the outer wall and building up back pressure on the inside of the front wall. When the attenuated wave strikes the inside of the back wall, it is approximately doubled as a result of reflection. The reflected wave from the back wall returns to strike the inside of the front wall, and it is again approximately doubled, thus providing further relief in opposition to the load on the outside of the front wall. It is of some interest that, if this effect were not introduced into the present problem, the analysis would indicate that the wall of Armco Building 31.2-d2 at 15,000 ft would fail completely in the planned test.

By utilizing procedures suggested in declassified portions of reference 3 , the overpressure outside the building is assumed to be reduced by one-half of the percentage of the openings, or by 4.5 per cent in the present case. The time for the development of the reduction is assumed to be the time required for a shock wave to travel laterally one-half of the distance between openings of the front wall. Of course, at the initial instant that the shock front strikes the building, all the window and door panels are intact, and therefore the reflected pressure on the full area is assumed at this particular time. According to reference 3 , the initial pressure build-up inside the building is equal to the average overpressure for the front of the structure without openings, multiplied by three-fourths of the ratio of the area of openings to the gross inside wall area. In the present case the inside ratio is practically the same as the outside ratio, i. e., 0.09 . The build-up of pressure inside is assumed to occur in a time interval equal to that required for a shock wave to travel between any opening and the point farthest from the opening on the inside wall. Thus, in approximately $0.006 \mathrm{sec}$, the multiplying factor for pressure on the inside of the front wall is assumed to be $(0.75)(0.09)=0.675$. Thus, in a very short time, the differential pressure on the front wall is $0.955-0.0675=0.888$ times the pressure that would exist on the outside of the front wall if there were no openings. To get the average pressure on the seven-panel section of the front wall, the fact that there is no load on the window area after the window is broken must be further taken into account. In the wall section under consideration, the window sash covers 13 per cent of the area. Thus the multiplying factor to determine the average pressure on the seven-panel segment under dynamic analysis is $(0.888)(0.87)=0.77$. This was used for the first $0.42 \mathrm{sec}$, until the time that the back wall reflection of the internal shock front returns to the inside of the front wall. As noted previously, the ratio 0.0675 is used to determine the initial overpressure in the internal shock wave. After this wave is reflected from the inside of the back wall, the pressure factor is assumed to be doubled to 0.135 , and, after this wave is in turn reflected from the inside of the front wall, the pressure factor is assumed to be again doubled to 0.27 . Thus, after reflection off the inside of the front wall, differential pressure on the front wall is assumed to be $(0.955-0.27) 0.87=0.60$.

The reduced effective pressures are incorporated into a dynamic analysis that follows a similar pattern to that given in Appendix A as tabulated in Table A.4, with the further exception that different load-mass factors pertain to a panel assumed to bend in only one direction with a sharp bend at the center. The load-mass factor in the elastic range was taken to be 0.79 , and in the plastic range it was taken to be 0.67 . The results of the dynamic analysis indicate a maximum deflection of 4.6 in. for Armco Building 31.2-d1 in the unexpected test, which is very close to the average maximum measured deflection of $4.8 \mathrm{in}$. at the mid-height of the building adjacent to the center window frames. The dynamic analysis for Armco Building $31.2-\mathrm{d} 2$ at $15,000 \mathrm{ft}$ in the planned test gives a maximum deflection of $19.4 \mathrm{in}$., whereas the maximum measured deflection was 18.2 in.

\section{RE FE RENCES}

1. American Iron and Steel Institute, "Specification for the Design of Light Gage Steel Structural Members," 350 Fifth Ave., New York, 1946.

2. F. Bleich, "Buckling Strength of Metal Structures," p. 497, McGraw-Hill Book Company, Inc., New York, 1952.

3. L. J. Vortman and M. L. Merritt, Methods for Estimating Blast Loading on Simple Structures, Sandia Corporation, Report AFSWP-226, September 1953. 


\section{Appendix C}

\section{PRESSURE ON TEST STRUCTURES}

\section{C.1 GENERAL}

Three of the test structures for Project 31.2 at the 6800-ft line from the open shot were nearing completion when they were exposed to unexpected overpressure that caused minor damage. The overpressure in the area of the buildings resulted from atmospheric conditions existing during the detonation of a nuclear device. Fortunately, pressure-time information for this shot was determined in an area near the buildings, thus permitting a preliminary damage evaluation comparable to that of similar structures exposed to Apple II shot at $15,000 \mathrm{ft}$ from GZ but at a different level.

In addition to describing how the pressure data for the unexpected test was evaluated, this appendix discusses the procedure for converting overpressure data to load data on the test structures.

\section{C.2 OVERPRESSURE DATA NEAR TEST SITE 1}

One of the pressure gauges activated during this earlier shot was in an area close enough to the buildings to permit information on overpressures at the buildings to be derived. Figure C.1 gives the measured pressure-time curve for this gauge. The initial peak was 0.6 psi. Also shown is the pressure-time curve expected at the gauge location under normal atmospheric conditions. There was an obvious magnification effect because of existing atmospheric conditions. The discrepancy between actual and "normal" peak pressures is indicative of the unexpected nature of the damage that resulted.

On the assumption that the pressure curve at the gauge had the same shape at the industrial buildings located 6800 and $15,000 \mathrm{ft}$ from the open shot and that its variation with respect to distance from the earlier shot followed a normal pattern, hypothetical curves of pressure vs time have been constructed as shown in Fig. C.1. These curves were the basis for the dynamic analyses of wall behavior reported in Appendixes A and B for the ReynoldsButler and Armco buildings, respectively. Since the buildings on the 15,000-ft line from the open shot were not completed, no analysis has been made for them. The damage to the unfinished structures was very slight. At the 6800 -ft line from the open shot (Fig. C.1), the initial pressure from the unexpected test was estimated at $0.72 \mathrm{psi}$, dropping rapidly to 0.24 psi, with an estimated positive-phase duration of $1.44 \mathrm{sec}$.

\section{C.3 PRESSURE DATA AT 5500 FT FROM GZ, APPLE II SHOT}

Measured overpressure-time curves for Apple II shot were available at 4700, 10,500, and $15,000 \mathrm{ft}$ from GZ. The curve for $15,000 \mathrm{ft}$ was used directly for the dynamic analyses presented in Appendixes A and B. Conversion from overpressure to reflected pressure was in accordance with procedures outlined in reference 1. 


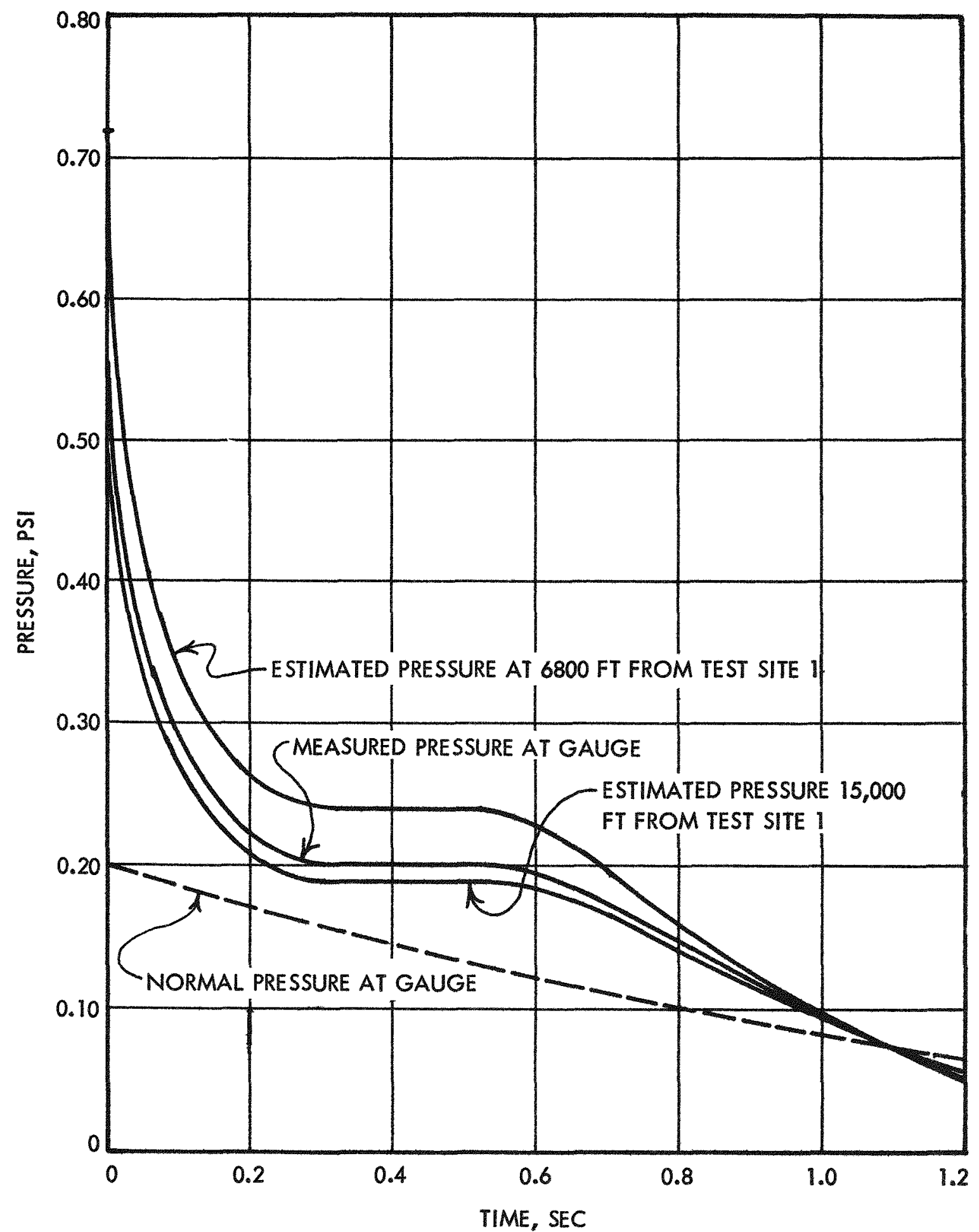

Fig. C.1-Overpressure-time curves for the unexpected test. 


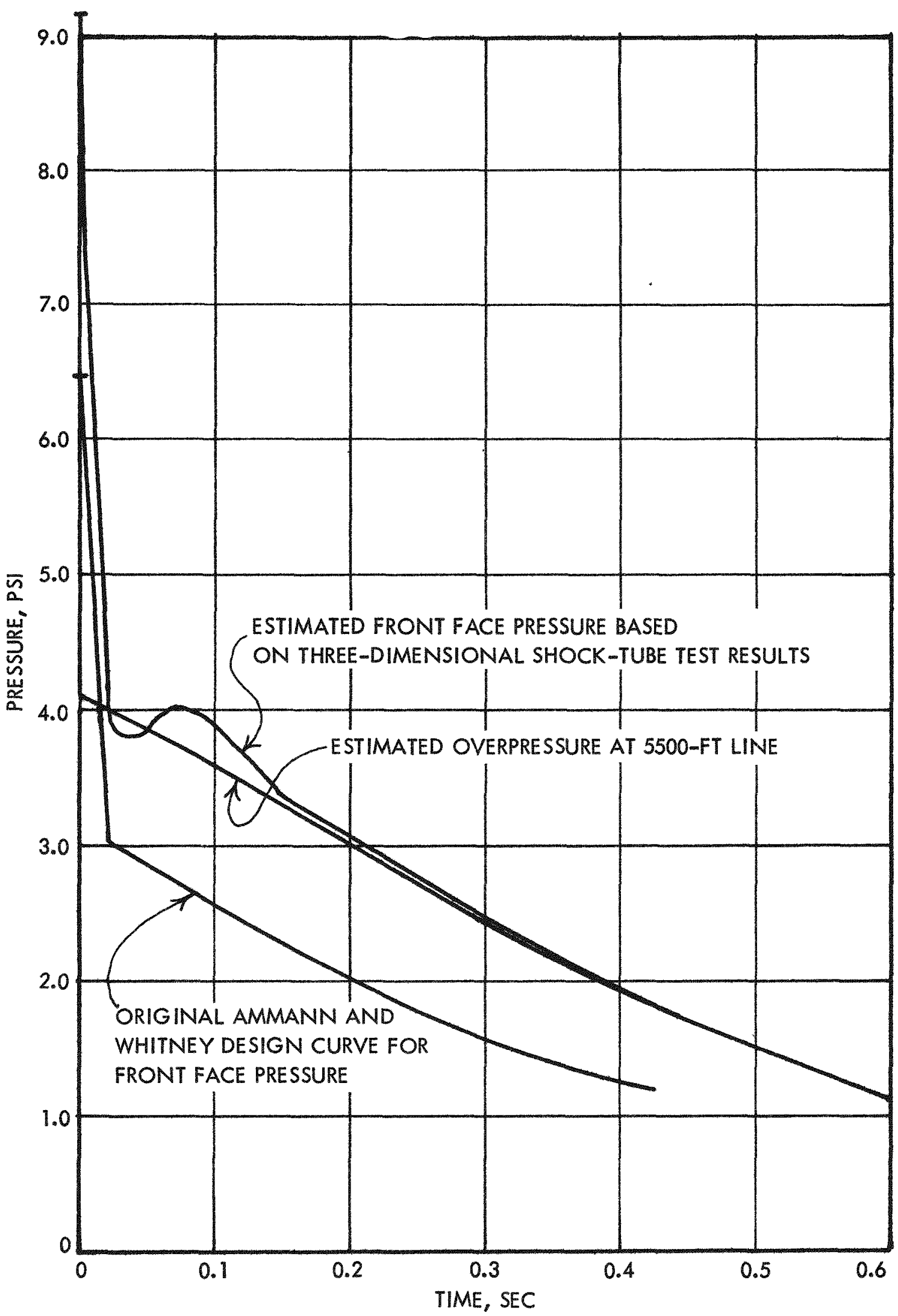

Fig. C.2-Comparison of design and estimated front face average pressures on Union Carbide building for Apple II shot.

$154-101$ 
No dynamic analyses were made at $6800 \mathrm{ft}$ from $\mathrm{GZ}$ for Apple II pressure-time effects. The firm of Ammann and Whitney had checked the design of the Union Carbide building at $5500 \mathrm{ft}$ by the use of dynamic analyses that were based on hypothetically forecast pressuretime curves. The reflected pressure on the front wall, as calculated for design purposes by Ammann and Whitney, is shown in Fig. C.2, which also gives the estimated actual pressuretime curve based on an interpolation of measured pressures at 4700 and $10,500 \mathrm{ft}$ from GZ. In making the interpolation, the measured curves were reduced to nondimensional ratios with respect to peak overpressure and positive-phase duration. Then a reduced curve at $5500 \mathrm{ft}$ was determined by interpolation weighted according to distance from measuring points. Actual predicted pressures at $5500 \mathrm{ft}$ could then be determined on the basis of a peak initial pressure of $4.10 \mathrm{psi}$, as given in Report ITR-1192 (reference 2). Finally, average pressures on the front face were determined by the use of recent three-dimensional shock-tube test data ${ }^{3}$ for a similar structure subjected to shocks of similar strength.

\section{RE FERENCES}

1. L. J. Vortman and M. L. Merritt, Methods for Estimating Blast Loading on Simple Structures, Sandia Corporation, Report AFSWP-226, September 1953.

2. G. W. Rollosson, Static and Dynamic Overpressure Measurements, Operation Teapot Preliminary Report, ITR-1192, May 1955 (to be superseded by Report WT-1192).

3. C. N. Kingery and J. H. Keefer, Air-blast Loading on a Scaled Three-dimensional Structure, Report 952 (Report AFSWP-813) Aberdeen Proving Ground, Maryland, July 1955. 